Editores

\author{
Miguel Francisco \\ Túñez-ló pez Campos-Freire
}

Innovación en

Comunicación

Retos en la TV pública europea

y en el periodismo móvil

Prólogo:

Miguel Túñez-López/Francisco Campos-Freire

Cuadernos Artesanos de Comunicación / 141 


\section{Cuadernos Artesanos de Comunicación}

Coordinador editorial: José Manuel de Pablos - jpablos@ull.edu.es

Comité Científico

Presidencia: José Luis Piñuel Raigada (UCM)

Secretaría: Milena Trenta

- Núria Almiron (Universidad Pompeu Fabra, UPF)

- Victoria Tur (Universidad de Alicante, UA)

- José Cisneros (Benemérita Universidad Autónoma de Puebla, BUAP)

- Bernardo Díaz Nosty (Universidad de Málaga, UMA)

- Carlos Elías (Universidad Carlos III de Madrid, UC3M)

- Paulina B. Emanuelli (Universidad Nacional de Córdoba, UNC)

- José Luis González Esteban (Universitas Miguel Hernández de Elche, UMH)

- Marisa Humanes (Universidad Rey Juan Carlos, URJC)

- Juan José Igartua (Universidad de Salamanca, USAL)

- Xosé López (Universidad de Santiago de Compostela)

- Maricela López-Ornelas (Universidad Autónoma de Baja California, AUBC)

- Javier Marzal (Universidad Jaume I, UJI)

- José Antonio Meyer (Benemérita Universidad Autónoma de Puebla, BUAP)

- Ramón Reig (Universidad de Sevilla, US)

- Miquel Rodrigo Alsina (Universidad Pompeu Fabra, UPF)

- Xosé Soengas (Universidad de Santiago de Compostela)

- José Luis Terrón (Universidad Autónoma de Barcelona, UAB)

- Miguel Vicente (Universidad de Valladolid, UVA)

- Ramón Zallo (Universidad del País Vasco, UPV-EHU)

* Queda expresamente autorizada la reproducción total o parcial de los textos publicados en este libro, en cualquier formato o soporte imaginables, salvo por explícita voluntad en contra del autor o autora o en caso de ediciones con ánimo de lucro. Las publicaciones donde se incluyan textos de esta publicación serán ediciones no comerciales y han de estar igualmente acogidas a Creative Commons. Harán constar esta licencia y el carácter no venal de la publicación.

\section{(c) (7) $\odot$ Este libro y cada uno de los capítulos que contiene (en su} EY NO No caso), así como las imágenes incluidas, si no se indica lo contrario, se encuentran bajo una Licencia Creative Commons Atribución-No Comercial-Sin Derivadas 3.0 Unported. Puede ver una copia de esta licencia en http://creativecommons.org/licenses/by-nc-nd/3.0/ Esto significa que Ud. es libre de reproducir y distribuir esta obra, siempre que cite la autoría, que no se use con fines comerciales o lucrativos y que no haga ninguna obra derivada. Si quiere hacer alguna de las cosas que aparecen como no permitidas, contacte con los coordinadores del libro o con el autor del capítulo correspondiente.

* La responsabilidad de cada texto es de su autor o autora. 
Miguel Túñez-López/Francisco Campos-Freire/Editores Prólogo: Miguel Túñez-López/Francisco Campos-Freire

\section{Innovación en Comunicación}

Retos en la TV pública europea y en el periodismo móvil

Cuadernos Artesanos de Comunicación / 141 
CAC $141^{\circ}$ - Innovación en Comunicación. Retos en la TV pública europea y en el periodismo móvil

Editores del CAC $141^{\circ}$ : Miguel Túñez-López y Francisco Campos-Freire

Coordinación y revisión editorial: Sara Pérez-Seijo y Marta Rodríguez-Castro

| Precio social: $11,15 €$ | Precio en librería. 14,50€ |

Editores: Javier Herrero y Milena Trenta

Diseño: F. Drago

Ilustración de portada: Fragmento del cuadro " Mujer de

Fuenteventura, de Vale (Bolonia)."

Imprime y distribuye: F. Drago. Andocopias S. L.

c/ La Hornera, 41. La Laguna. Tenerife.

Teléfono: 922250554 | fotocopiasdrago@,telefonica.net

Edita: Sociedad Latina de Comunicación Social - edición no venal - La Laguna (Tenerife), 2017 - Creative Commons

http://www.revistalatinacs.org/14SLCS/portada2014.html

Descargar en pdf:

http://www.cuadernosartesanos.org/\#141

Protocolo de envío de manuscritos con destino a CAC: (la colección que corresponda)

http://www.cuadernosartesanos.org/protocolo.html

ISBN - 13: 978-84-17314-00-2

DL: TF-669-2018

DOI: $10.4185 / \operatorname{cac} 141$ 


\section{Índice}

Prólogo. Los retos de innovación en gestión: el panorama de la TV pública europea

Miguel Túñez-López y Francisco Campos Freire.

1. Los archivos audiovisuales de televisión: estrategias para su revalorización en un entorno transmedia

Mercedes Caridad Sebastián, Ana María Morales García, Sara Martínez

Cardama y Fátima García López

2. Gestión de marca corporativa online de los canales públicos de televisión en Europa. Propuesta de indicadores para su medición Carmen Costa-Sánchez y Virginia Guarinos....

3. Las radiotelevisiones públicas europeas en el entorno web

María-Magdalena Rodríguez-Fernández, Eva Sánchez-Amboage y Carlos

Toural-Bran

4. Reconectar con la audiencia joven. Narrativa transmedia para la transformación de la televisión de servicio público en España, Francia, Alemania y Reino Unido

Ana Azurmendi.

5. El discurso reproducido como indicador del pluralismo interno de los medios de comunicación: el caso de los telediarios de TVE y TV3

María Ángeles García Asensio, Carlos Aguilar Paredes, Lucía Jiménez Iglesias, Cristina Ruiz Moreno y Lydia Sánchez Gómez

6. La Europa de dos velocidades reflejada en la financiación del servicio audiovisual público: un análisis basado en los presupuestos

Óscar Juanatey-Boga, Valentín-Alejandro Martínez-Fernández y Marta Rodríguez-Castro. 157

7. El tratamiento de la información política e institucional en TVE Xosé Soengas-Pérez, Carlos Elías-Pérez y Ana María López-Cepeda

8. La innovación en la rendición de cuentas de los medios de comunicación de servicio público (PSM). E1 caso de la CCMA

Joaquín Marqués-Pascual, Joan-Francesc Fondevila-Gascón y Juan Morillo Bentué

9. Innovación en radiotelevisiones públicas europeas: narrativas inmersivas y organización de los contenidos $\mathbf{3 6 0}$ grados en plataformas digitales

Sara Pérez-Seijo, María Melle Goyanes y Francisco Javier Paniagua Rojano.249

Los autores y las autoras. 


\section{Innovación en Comunicación. Retos en la TV pública europea y en el periodismo móvil}

Editores: Miguel Túñez-López y Francisco Campos-Freire

\section{Resumen:}

La innovación es una de las principales preocupaciones estratégicas de la gestión de las empresas públicas y privadas de medios de comunicación como consecuencia del carácter disruptivo provocado por la introducción de nuevas tecnologías, modelos de negocio alternativos, sistemas de distribución abiertos, cambios en los consumos culturales y diferentes formas de acceso de los usuarios.

Esa preocupación se traslada también a la Academia y a la investigación para hallar transferencia de aplicaciones y estudiar el impacto de sus repercusiones sociales en la esfera de la televisión pública en Europa. Una inquietud que se materializa en el presente libro gracias a un trabajo, esfuerzo e interés colectivo.

Este documento ofrece al lector una aproximación a diferentes temáticas tanto a nivel teórico como práctico. A lo largo de estas páginas se encuentran una serie de reflexiones sobre retos presentes y futuros. Los diferentes estudios se centran en casos prácticos actuales con el fin de presentar una revisión actualizada acerca de la innovación en el sector de las televisiones públicas europeas.

Palabras clave: innovación, televisiones públicas europeas, periodismo móvil, indicadores de calidad.

\section{Forma de citar este libro}

Túñez-López, M. y Campos-Freire, F. (Eds.) (2018). Innovación en Comunicación. Retos en la TV pública europea y en el periodismo móvil.

Cuadernos Artesanos de Comunicación, cac141. La Laguna (Tenerife): Latina. DOI: 


\section{1 \\ Prólogo}

\section{Los retos de innovación en gestión: el panorama de la TV pública europea}

$\mathrm{E}$

L SERVICIO audiovisual público europeo está en proceso de cambio para ajustarse al nuevo ecosistema digital en un momento en el que la innovación y la creatividad se configuran como elementos básicos en las apuestas de futuro del periodismo y, en general, de los medios de comunicación.

Este nuevo Cuaderno Artesano de Comunicación (CAC) recoge nueve artículos de veintisiete profesores de once Universidades de España (Carlos III, A Coruña, Sevilla, Navarra, Barcelona, Ramón LlullBlanquerna, Castilla-La Mancha, Santiago, Pompeu Fabra, Málaga y EAE Bussines School) que han sido publicados en la Revista Latina de Comunicación Social para conocer los mejores trabajos sobre innovación en Comunicación y sobre los retos en la TV pública europea y en el periodismo móvil. Son resultados de importantes investigaciones que, como se resalaba en el call for papers, se orientan a revisar la gestión de la innovación en los servicios audiovisuales de las radiotelevisiones públicas europeas, el estudio de la innovación aplicada a los sistemas de gobernanza, financiación y/o rendición de cuentas; y la creatividad e innovación en las programaciones, emisiones, redes sociales, realidad aumentada, narrativas transmedia y difusión de contenidos informativos, de entretenimiento y otros servicios aplicados en los medios audiovisuales públicos europeos. También se orientaba a conocer estudios sobre indicadores de calidad y sistemas de evaluación del impacto social del servicio audiovisual público, sobre análisis de las tipologías de los cibermedios periodísticos 
o sobre interactividad, hipertextualidad y multimedialidad en los cibermedios periodísticos; e investigaciones en torno a comunicación móvil y periodismo móvil, narrativas para dispositivos móviles y usos y consumos informativos desde dispositivos móviles

Los nueve artículos de este CAC son un anticipo del III Simposio Internacional de Latina que está previsto que se celebre en la Facultad de Ciencias de la Comunicación de la Universidade de Santiago de Compostela, en septiembre de 2018, con el mismo título: Innovación en Comunicación. Retos en la TV pública europea y en el periodismo móvil. De este modo este Cuaderno Artesano es el primero de una trilogía de publicaciones que dibujan un completo mapa del estado actual de la radiotelevisión pública y de los avances innovadores en periodismo. El segundo, (Debates sobre Valores e Indicadores del Servicio Audiovisual Público en Europa), reflejará las aportaciones de un representativo grupo de investigadores sobre la televisión pública europea y el tercero (La TV Pública en Europa: Innovación, Retos y Tendencias) contendrá las comunicaciones que sean aceptadas y defendidas en el III Simposio.

La innovación es una de las principales preocupaciones estratégicas de la gestión de las empresas públicas y privadas de medios de comunicación como consecuencia del carácter disruptivo provocado por la introducción de nuevas tecnologías, modelos de negocio alternativos, sistemas de distribución abiertos, cambios en los consumos culturales y diferentes formas de acceso de los usuarios. Esa preocupación se traslada también a la Academia y a la investigación para poder realizar transferencia de aplicaciones y estudiar el impacto de sus repercusiones sociales, como ocurre en los nueve capítulos de este libro.

Mercedes Caridad Sebastián, Ana María Morales García, Sara Martínez Cardama y Fátima García López, profesoras de la Universidad Carlos III de Madrid, analizan la presencia de distintas estrategias transmedia que los archivos audiovisuales de televisión europeos pueden utilizar potencialmente para dar a conocer y revalorizar sus fondos. Su capítulo, Los archivos audiovisuales de televisión: estrategias para su revalorización en un entorno transmedia, recoge los resultados de un interesante estudio de caso de British Broadcasting Corporation Archives 
(BBC, Reino Unido), Institut National de l'audiovisuel (Francia), Netherlands Institute for Sound Fraand Vision (Holanda) y Archivo de RTVE (España), que ilustran diferentes modelos de conservación y difusión. $\mathrm{Su}$ análisis compara el Acceso Expandido (Expanded Access), la Adaptación de Contenido (Repackaged Content) y el Contenido Expandido o Auxiliar (Ancillary Content). Las autoras concluyen que la estrategia más frecuente se relaciona con el Acceso Expandido, constatan que muchas estrategias transmedia no se están implementando y que los archivos audiovisuales se mantienen en una etapa prematura en relación con este tipo de usos de reutilización del contenido.

El capítulo 2 aborda la Gestión de marca corporativa online de los canales públicos de televisión en Europa. Propuesta de indicadores para su medición, de las profesoras Carmen Costa-Sánchez, de la Universidade da Coruña, y Victoria Guarinos, de la Universidad de Sevilla, que estudian como los canales de televisión públicos afrontan una crisis derivada de los cambios en los mercados televisivos y del cuestionamiento de su gestión y de su necesidad. En su propuesta, Costa y Guarinos avanzan a presentar tres indicadores sintéticos para medir y evaluar la solidez de la comunidad de seguidores online, para analizar el grado de transparencia en la información corporativa y de balance y para conocer el nivel de lo que conceptúan como orgullo de representación generado.

El entorno web de las radiotelevisiones públicas también centra la propuesta de María-Magdalena Rodríguez-Fernández, Eva SánchezAmboage, profesoras de la Universidade de A Coruña, y Carlos TouralBran, profesor de la Universidade de Santiago de Compostela, en su análisis sobre el proceso de adaptación de las emisoras públicas de radiotelevisión a los nuevos escenarios que internet ha posicionado como soportes para informar, comunicar y difundir contenidos a sus audiencias. Esta investigación, recogida en el capítulo 3, revisa los websites de las radiotelevisiones públicas de los países de la Unión Europea para diseccionar sus estrategias de posicionamiento, engagement, procedencia de la audiencia y dispositivos de acceso. Los resultados evidencian una duración de las visitas limitada y una tasa de rebote elevada que apuntan a que los sitios web de las radiotelevisiones 
públicas europeas no están cumpliendo con las expectativas de sus usuarios.

El capítulo 4, Reconectar con la audiencia joven. Narrativa transmedia para la transformación de la televisión de servicio público en España, Francia, Alemania y Reino Unido, es obra de Ana Azurmendi, profesora de la Universidad de Navarra, que explica en su texto el esfuerzo que están realizando las televisiones de servicio público de los países europeos para reconectar con las audiencias jóvenes movidas por los datos que reflejan una "pérdida dramática" de espectadores jóvenes que obliga a los operadores televisivos a adaptar el medio al entorno cultural convergente. Azurmendi presenta un detallado e interesante examen de los contenidos transmedia más exitosos de las televisiones públicas europeas, de informativos webdocs y de contenidos de entretenimiento.

$\mathrm{M}^{\mathrm{a}}$ Ángeles García Asensio, Carlos Aguilar Paredes, Lucía Jiménez Iglesias y Lydia Sánchez Gómez, profesoras de la Universitat de Barcelona, y Cristina Ruiz Moreno, de la Universitat Ramon Llull Blanquerna, analizan en el capítulo 5 El discurso reproducido como indicador del pluralismo interno de los medios de comunicación: el caso de los telediarios de TVE y TV3. Las cinco autoras ejecutan un pormenorizado análisis lingüístico y discursivo de las noticias políticas emitidas por dos televisiones públicas (TVE1 y TV3) en periodo preelectoral y comparan el acceso a la narración periodística de las voces representativas de la actividad política y concluyen que es necesario incorporar el discurso reproducido como indicador de la calidad democrática del medio.

La Europa de dos velocidades reflejada en la financiación del servicio audiovisual público a través de un análisis basado en los presupuestos vertebra el capítulo 6, con la investigación desarrollada por Óscar Juanatey-Boga, ValentínAlejandro y Martínez-Fernández, profesores de la Universidade da Coruña, y Marta Rodríguez-Castro, de la Universidade de Santiago de Compostela. El capítulo condensa el análisis de la evolución de la financiación de las radiotelevisiones públicas (RTVP) europeas entre 2010 y 2016, además de abordar la necesidad de legitimización y actualización de los distintos modelos de financiación vigentes en la UE. Los resultados constatan el impacto de la crisis económica ya que se advierten dos trienios con tendencias diferentes: la constricción 
presupuestaria que caracteriza al periodo 2010-2013 y una cierta recuperación en los años 2013-2016.

Xosé Soengas-Pérez, de la Universidade de Santiago de Compostela, Carlos Elías-Pérez, de la Universidad Carlos III, y Ana María LópezCepeda, de la Universidad de Castilla-La Mancha, abordan en el capítulo 7 cuál es el tratamiento que se hace en Televisión Española de los temas de información política e institucional. Los datos que aportan indican que casi todas las noticias $(97 \%)$ tienen un tratamiento formal correcto, pero, también, que tres de cada cuatro informaciones $(74 \%)$ son temas de información institucional con un enfoque que "favorece, refuerza o avala la imagen del Gobierno y de los organismos afines".

En el capítulo 8, Joaquín Marqués-Pascual y Juan Morillo Bentué, profesores de EAE Business School, y Joan-Francesc FondevilaGascón, profesor de la Universidad Pompeu Fabra, analizna la transparencia de los servicios públicos de radiotelevisión a través del estudio de los sistemas de gobernanza y Responsabilidad Corporativa de los medios audiovisuales públicos catalanes de la Corporació Catalana de Mitjans Audiovisuals (CCMA). Su investigación, La innovación en la rendición de cuentas de los medios de comunicación de servicio público (PSM). El caso de la CCMA, incluye propuestas de innovación para actualizar los instrumentos de rendición de cuentas analizados, que los autores consideran que son válidos pero están estancados desde hace una década.

La incorporación de las narrativas inmersivas como ejemplo de innovación centra la investigación de Sara Pérez-Seijo y María Melle Goyanes, de la Universidade de Santiago de Compostela, y Francisco Javier Paniagua Rojano, profesor de la Universidad de Málaga, sobre las estrategias de organización de vídeos $360^{\circ}$ seguidas por las radiotelevisiones públicas europeas en sus plataformas. En el capítulo 9, Innovación en radiotelevisiones públicas europeas: narrativas inmersivas y organización de los contenidos 360 grados en plataformas digitales, los autores explican su análisis de las páginas webs y los canales de YouTube de las radiodifusoras que implementan narrativas inmersivas en contenidos con vídeos $360^{\circ}$.

La publicación de la trilogía de tres Cuadernos que se abre con este libro está impulsada por la Red de Investigación de Gestión de la 
Comunicación (REDES 2016 GI-1641 XESCOM ED341D R2016/019, apoyada por la Consellería de Cultura, Educación e Ordenación Universitaria de Galicia) y coordinada por el Grupo de Investigación de Novos Medios de la Universidad de Santiago de Compostela. Los tres CAC se enmarcan en las actividades de los proyectos de I+D del Programa estatal de Fomento de la Investigación Científica y Técnica de Excelencia, subprograma estatal de Generación de Conocimiento del Ministerio de Economía y Competitividad de España sobre "Indicadores de gobernanza, financiación, rendición de cuentas, innovación, calidad y servicio público de las RTV europeas aplicables a España en el contexto digital" (referencia CSO2015-66543-P) y "Usos y preferencias informativas en el nuevo mapa de medios en España: Modelos de periodismo para dispositivos móviles" (referencia CSO2015-64662-C4-4-R).

\section{Miguel Túñez-López Francisco Campos-Freire \\ Universidade de Santiago de Compostela}

PARA CITAR: Túñez-López, M. y Campos-Freire, F. Los retos de innovación en gestión: el panorama de la TV pública europea. En Túñez-López, M. y Campos-Freire, F. (Eds.) (2018). Innovación en Comunicación. Retos en la TV pública europea y en el periodismo móvil. Cuadernos Artesanos de Comunicación, cacX, pp. 7-12. La Laguna (Tenerife): Latina. DOI: 


\title{
Los archivos audiovisuales de televisión: estrategias para su revalorización en un entorno transmedia
}

\author{
Mercedes Caridad Sebastián \\ Universidad Carlos III de Madrid \\ Ana María Morales García \\ Universidad Carlos III de Madrid \\ Sara Martínez Cardama \\ Universidad Carlos III de Madrid \\ Fátima García López \\ Universidad Carlos III de Madrid
}

PARA CITAR: Caridad Sebastián, M., Morales García, A.M., Martínez

Cardama, S. y García López, F. (2018). Los archivos audiovisuales de televisión: estrategias para su revalorización en un entorno transmedia. Revista Latina de Comunicación Social, 73, pp. 870 a 894. La Laguna (Tenerife): Latina. http:/ www.revistalatinacs.org/073paper/1286/45es.html DOI: http:/10.4185/RLCS-2018-1286

\section{Resumen}

Se analiza la presencia de distintas estrategias transmedia que los archivos audiovisuales de televisión europeos pueden utilizar potencialmente para dar a conocer y revalorizar sus fondos. Se realiza un estudio de caso de cuatro archivos audiovisuales de televisiones europeas que ilustran diferentes modelos de conservación y difusión: British Broadcasting Corporation Archives (BBC) (Reino Unido), Institut National de l'audiovisuel (Francia), Netherlands Institute for Sound Fraand Vision (Holanda) y Archivo de RTVE (España). Para ello, se analizaron sus sitios web y los perfiles de Twitter y se establecieron tres categorías 
de evaluación basadas en: Acceso Expandido (Expanded Access), Adaptación de Contenido (Repackaged Content) y Contenido Expandido o Auxiliar (Ancillary Content). Se ha podido determinar que las estrategias más frecuentes son las relacionadas con el Acceso Expandido, particularmente con su uso para una finalidad contextual (conmemoraciones, efemérides o ilustrar realidades actuales con imágenes del pasado). Se constata que muchas estrategias trasmedia no se están implementando por parte de los archivos audiovisuales analizados. A diferencia de otras instituciones patrimoniales que emplean estrategias transmedia aprovechando, por ejemplo, series de ficción para dar a conocer sus fondos, los archivos audiovisuales se mantienen en una etapa prematura en relación con este tipo de usos de reutilización del contenido.

Palabras clave: Estrategias trasmedia, Archivos Audiovisuales de Televisión, British Broadcasting Corporation Archives (BBC), Institut National de l'audiovisuel (INA), Netherlands Institute for Sound Fraand Vision, Archivo de RTVE.

\section{Introducción y estado de la cuestión}

$\mathrm{E}$ L PRESENTE artículo nace de la necesaria puesta en valor de los archivos audiovisuales de televisiones públicas en la sociedad actual. Se establecen los medios digitales, y particularmente, los sociales, como principal activo para esta revalorización. En concreto, se escoge las estrategias transmedia visibles a través de sus portales y de sus cuentas de Twitter. Para desarrollar este proyecto, se seleccionaron los archivos representativos de diferentes modelos de conservación y difusión de cuatro países: British Broadcasting Corporation Archives (BBC) (Reino Unido), Institut National de l'audiovisuel (Francia), Netherlands Institute for Sound Fraand Vision (Holanda) y Archivo de RTVE (España).

Este artículo permite realizar un estado de la cuestión y una conveniente prospectiva de la situación de los archivos audiovisuales ante el reto digital multiplataforma. Estos activos audiovisuales ya no basan solo su actividad en dar soporte a los usuarios internos, o de 
investigación; por ello, su valor patrimonial debe reconvertirse hacia fines de explotación y revalorización de sus contenidos.

Es, pues, importante esta reutilización a través de la ventana de las narrativas transmedia como mecanismo de proliferación de nuevos universos de contenido. Este universo es definido por Scolari como "un tipo de relato en el que la historia se despliega a través de múltiples medios y plataformas de comunicación, y en el cual el cual una parte de los consumidores asume un rol activo en ese proceso de expansión (2013, p.46). Por su parte, Jenkis, et.al. (2006:46) definen estas historias como aquellas "contadas a través de diferentes plataformas de medios de comunicación". Costa y Piñeiro (2015) establecen en el desarrollo de Internet y de la web participativa el marco idóneo para la aplicación de las narrativas transmedia.

Los archivos, al igual que el resto de instituciones patrimoniales, no pueden ser ajenos a este fenómeno que se produce en medios sociales. Esta multiplicidad de medios y el carácter participativo ofrecen una gran posibilidad a estas instituciones ya que, una vez digitalizados, pueden agregar valor a sus fondos mediante su reutilización en otros contextos. Se considera, pues, que esta perspectiva es apta para la realización de este estudio, debido al reto de los medios de comunicación televisivos de dar visibilidad a sus archivos. A través de este tipo de estrategias, podrán constituirse como un elemento de innovación en la generación de contenido, con varios fines: desde nutrir programas propios, servir de nexo al ilustrar el material con acontecimientos históricos pasados o actuales y, por último, servir de apoyo para expandir universos transmedia generados, comúnmente, desde programas de ficción.

Para defender esta función, es importante recordar la doble dimensión de los archivos audiovisuales para relacionarlos con la cultura transmedia. A tenor de Arranz-Escacha y Caldera Serrano (2013), estos son:

-Valor patrimonial: como documentos de archivos que son. Tiene un doble espectro de usuarios: los internos o empleados del medio y los investigadores externos. Este valor no solo se encuentra en los productos terminados o ya emitidos sino también en los brutos, y todo aquel material grabado que pueda tener valor futuro. En este entorno, 
la preservación digital se vuelve imprescindible. El valor patrimonial en el entorno web cambia, y adquiere su razón de ser en las políticas de difusión y puesta a disposición del público.

-Valor de explotación: asociado a su utilidad. El material de archivo es el medio natural para la elaboración y obtención de información por parte de los periodistas. Sin embargo, este material puede ser reutilizado. Esta reutilización puede ser de tipo interno, para nutrir contenidos, pero también a nivel comercial obteniendo un rendimiento económico gracias a su rentabilización.

Además, en este artículo se le añade un valor social, ligado a su digitalización y puesta en valor a través de medios digitales, sobre todo en aquellos que prima la participación colectiva. Ese valor le dota al material de archivo audiovisual de la capacidad para nutrir contenido social susceptible de ser viralizado como soporte de noticias y otro tipo de contenido. Se puede manifestar también como núcleo de estrategias de políticas de Social Media, en las que el vídeo adquiera un papel relevante. Asimismo, este valor social tiene una función pública ya que revierte en la ciudadanía. Los contenidos audiovisuales televisivos públicos merecen ser conocidos y difundidos al gran público, y, por ende, las televisiones tienen que pensar en nuevas estrategias para su revalorización.

A esta estrategia social también se suma el nuevo consumo de televisión y contenidos, que favorece esta reutilización. Los modelos de consumo de televisión y contenido han cambiado, por lo que la distribución de archivos audiovisuales también ha de hacerlo. En este sentido, León-Moreno, Zapico-Alonso y Caldera-Serrano (2016) apuntan a las inversiones de empresas en la difusión web y su recepción a través de dispositivos móviles de manera rápida. Rodríguez Mateos y Hernández Pérez (2015) añaden dos fenómenos clave en esta nueva tendencia de los contenidos: la audiencia social y la convergencia de la televisión con otras plataformas como los medios sociales.

Estas afirmaciones se pueden completar con el Digital News Report de The Reuters Institute for the Study of Journalism (2017) que señala como elementos clave el incremento de las redes sociales como medio para obtener noticias, y un consumo de contenido en móviles y tabletas $(47 \%)$ por encima del ordenador (46\%). Asimismo, a tenor de este 
estudio, desciende el consumo de medios tradicionales offline, situándose en el 59\% de los internautas.

Esta encuesta también recalcaba el peso de las redes sociales como fuente de información (el 28\% de los encuestados entre 18 y 24 las reconocen como principal fuente de noticias) y el papel del video en esta transmisión (29\% de los menores de 45 años se informa online a través de este formato).

Como puede verse, el video y los medios sociales adquieren un peso esencial en la transmisión de contenidos a las nuevas generaciones. Esta idea entronca con la desarrollada en el presente trabajo para su amortización.

Para la formulación teórica de las estrategias planteadas en este trabajo para las colecciones audiovisuales es preciso conocer qué políticas rigen el medio audiovisual europeo en el caso de los archivos, y si estas están orientadas, al menos parcialmente, a la difusión del patrimonio audiovisual en un entorno multiplataforma y orientado a la participación.

\subsection{Transversalidad de programas comunitarios enfocados al fortalecimiento de la industria de contenidos multimedia}

Desde principios de este milenio se comienza a vislumbrar un fortalecimiento de acciones comunitarias para el desarrollo de la Sociedad de la Información que materializan las directrices trazadas por los Planes de Acción eEurope (2002 y 2005), i2010, Europe 2020 y su Digital Agenda for Europe (2010-2020), como uno de los pilares clave. Estas acciones se han propuesto desde sus inicios traducir las recomendaciones, incluidas en los planes de acción, en programas e iniciativas comunitarias para el desarrollo del patrimonio cultural, los contenidos digitales, la industria multimedia, el $\mathrm{I}+\mathrm{D}+\mathrm{I}$, la educación, la seguridad en Internet y la administración electrónica (CaridadSebastián, Morales-García y García-López, 2011: 440).

Haciendo una retrospectiva histórica, uno de los aspectos más importantes de la estrategia de la Unión Europea sobre la Sociedad de la Información empezó a desarrollarse a mediados de los ochenta, con programas destinados a implementar ya la industria de los contenidos 
multimedia: IMPACT 1 y 2. Al finalizar IMPACT 2, surge INFO2000 (1996-1999), que complementó y reforzó otras actividades comunitarias encaminadas a fomentar la naciente industria de los contenidos multimedia en Europa.

Los programas para el desarrollo de la cultura, los contenidos digitales y la industria multimedia tomaron en consideración los rápidos cambios tecnológicos. Se esperaba que el uso de la tecnología digital fuese más accesible, gracias a las nuevas formas de "transporte" de contenidos. En el marco de las políticas de información de la Unión Europea, se pusieron en marcha diferentes programas para el desarrollo de servicios y aplicaciones electrónicas (Morales García, 2008):

a) eTen (2000-2006), fue un instrumento esencial del plan de acción eEurope 2005, encaminado a fomentar el desarrollo de servicios, aplicaciones y contenidos electrónicos, y a acelerar el despliegue del acceso seguro de banda ancha a Internet. Según se recoge en CORDIS (2006), uno de los proyectos que ha resultado ser un éxito ha sido el proyecto MICHAEL, que ha desarrollado un sistema electrónico para acceder, gestionar y actualizar los registros digitales de 13 colecciones nacionales, incluyendo objetos de museo, sitios arqueológicos y turísticos, archivos de música y audiovisuales, material biográfico, documentos y manuscritos.

b) eContent (2001-2005), tuvo como predecesores el Programa INFO 2000 y el programa MLIS. Pretendió, esencialmente, el desarrollo de contenidos digitales y la promoción de la diversidad lingǘstica en la Sociedad de la Información, a través de múltiples canales, incluyendo el rápido crecimiento de los nuevos servicios y plataformas, como Internet móvil. Por su parte, eContent Plus (2005-2008), sucesor de eContent, constituyó el programa plurianual comunitario que incrementó las posibilidades de acceso, utilización y explotación de los contenidos digitales en Europa. Uno de los proyectos de mayor interés en este ámbito, resultó ser European Digital Library Network (EDLnet), que, lanzado en 2008, dio comienzo al emblemático proyecto Europeana, punto de acceso a las colecciones de patrimonio cultural y audiovisual. 
c) Cultura (2007-2013), se derivó del Programa Cultura (2000-2006) y estuvo destinado a financiar proyectos e iniciativas para proteger la diversidad cultural de Europa y aumentar su patrimonio cultural, promoviendo y fomentando la creación de redes culturales europeas.

d) MEDIA, constituyó el segundo modo de acción de la política audiovisual europea, después de la Directiva «Televisión sin fronteras» cuyos principios básicos fue la libre circulación de programas televisivos europeos en el mercado interior y la obligación de las cadenas de televisión de dedicar, siempre que sea posible, más de la mitad de su tiempo de emisión a obras europeas (EUR-LEX, 2008). El programa MEDIA previó medidas de apoyo a la industria europea del cine y la televisión para que esta industria fuese más competitiva y capaz de satisfacer las necesidades de las cadenas de televisión. Con su programa MEDIA (2007-2013), la Comisión tuvo la intención de continuar las medidas adoptadas en los programas anteriores: MEDIA I, MEDIA II, MEDIA Plus, MEDIA Formación y MEDIA MUNDUS, que han favorecido el desarrollo de la industria audiovisual europea desde 1991.

e) Europa Creativa (2014-2020), destinado a impulsar los sectores cultural y creativo, con un presupuesto global de 1.460 millones de euros (9\% más que sus predecesores), aúna los programas previstos para el período 2007-2013: Cultura, MEDIA y MEDIA Mundus y se subdivide en tres apartados:

- Subprograma Cultura: con un 31\% del presupuesto, propone que, al menos 8.000 organizaciones culturales y 300.000 artistas y profesionales de la cultura recibirán apoyo con el fin adquirir nuevas competencias.

- Capítulo intersectorial: con un 13\% del presupuesto total, establecerá un instrumento de garantía de los Sectores Cultural y Creativo.

- Subprograma MEDIA: con un $56 \%$ del presupuesto total, fomentará el desarrollo y la distribución de más de 1.000 películas europeas, por medio de plataformas tradicionales y digitales; aportará financiación para ayudar a los profesionales audiovisuales a tener acceso a los mercados internacionales y promoverá la realización de películas y otros contenidos audiovisuales. 
Según un Comunicado de prensa de la propia Comisión Europea (2016), desde el lanzamiento del programa MEDIA, en 1991, se ha invertido más de 2.400 millones de euros en la creatividad y la diversidad cultural europeas. Este programa ha apoyado a unas 2.000 producciones europeas (películas, series de televisión y otros proyectos), cuya distribución se realiza por medios digitales en salas de cine, a través de la televisión y mediante servicios de vídeo a la carta. MEDIA ha contribuido a la formación de más de 20.000 productores, directores y guionistas, que han podido así adaptarse a las nuevas tecnologías. Como dato curioso, este comunicado apunta a que 40 películas financiadas por MEDIA han obtenido la Palma de Oro, el Gran Premio o el Premio al mejor director y han recibido un total de 20 millones de euros en ayudas. Por otra parte, en el año 2016, 10 de las 21 películas de la selección oficial de Cannes recibieron el apoyo económico del programa MEDIA.

En el portal del Programa Creative Europe MEDIA, y dentro de la sección "Datos y cifras", se alude a que sólo para el período 20142020, se destinarán más de 800 millones de euros al apoyo de la competitividad y diversidad de la industria, a través de una serie de acciones: Formación para profesionales audiovisuales; Apoyo a la distribución de películas no nacionales; Apoyo al acceso a mercados; Apoyo para festivales cinematográficos que muestren contenido europeo; Fondos de apoyo a la coproducción internacional; Apoyo a la distribución online; Apoyo al desarrollo de series de televisión y drama, Apoyo al desarrollo de videojuegos; Apoyo al desarrollo de películas; Apoyo a redes de salas de cine y Apoyo a proyectos de desarrollo de audiencias.

Paralelamente, y desde la década de 1980, se dio el avance más significativo en la política científica comunitaria, con la puesta en marcha de los Programas Marco de Investigación y Desarrollo Tecnológico.

Bajo la financiación del $4^{\circ}$ programa Marco, se puso en marcha el proyecto AVIR, basado en algoritmos inéditos, donde se desarrollan descriptores innovadores para programas de televisión, a partir de la información básica extraíble, ya sea del canal de audio o de vídeo, o de ambos. Estos descriptores permiten el análisis y la indización del contenido audiovisual. Por otra parte, ya están disponibles funciones 
de navegación entre fotogramas, búsqueda de noticias, recuperación por similitud y otras muchas funciones (Cordis, 2005).

Para el $7^{\circ}$ Programa Marco (2007-2013), la Comisión Europea puso en marcha diferentes proyectos donde algunos continúan vigentes o son sustituidos por proyectos similares. El $7^{\circ}$ Programa Marco (FP7) estimula la reciprocidad entre las industrias del sector multimedia, las instituciones culturales y las universidades en un marco de asociación. Ejemplo de ello, lo encontramos en proyectos como EUROTRANSMEDIA, Notube y EUscreen.

EUROTRANSMEDIA, comprendido desde 2013 al 2016, aporta un cambio de paradigma que implica la convergencia de todos los medios de comunicación, tradicionales y digitales. Según se recoge en las páginas de Cordis (2017), el equipo impulsor de este proyecto puso de relieve la necesidad de desarrollar contenidos interactivos y la aceptación indiscutible por parte de los usuarios. Además, el proyecto recomendó a la Unión Europea que dejase atrás el antiguo modelo de protección de contenidos locales para fomentar la creación de universos artísticos libres de barreras culturales. Forman parte de EUROTRANSMEDIA el consorcio formado por TWIST-Cinema \& Digital Media Cluster in Wallonia (principal organización empresarial en el campo de las tecnologías digitales para la manipulación de imágenes, sonido y texto en Bélgica), Media Evolution de Suecia (con más de 400 miembros), EureCat-Centre Tecnologic Catalunya (una organización privada, sin ánimo de lucro que integra en su Junta a representantes de instituciones de investigación, universidades, administración pública y empresas), Cap Digital (con 800 miembros de los cuales el $80 \%$ son pymes y startups que incluyen a los más activos de la industria digital francesa), Le Pôle Média Grand Paris (organización sin ánimo de lucro, con más de 100 miembros que reúne a empresas, autoridades públicas, académicos y actores de investigación que cubren todas las actividades de la industria de medios digitales: cine, televisión, transmedia, animación CGI, archivo digital, entre otras), Plaine Commune de Francia (alberga quince centros de datos, sesenta y cinco estudios de cine, televisión y la industria audiovisual), Servicio Público de Valonia-SPW (administración regional a cargo de la gestión general en la Región de Valonia), INTERFACEUROPE y Estonian Digital Centre. 
Por su parte, el Proyecto NoTube (2009-2012), reunió a entidades dedicadas a la creación y difusión de contenidos digitales (como la British Broadcasting Corporation, objeto de estudio) y a expertos en integración de plataformas. Su propósito fue vincular los distintos medios: web y televisión (Web+TV), para que los consumidores puedan visionar programas e interactuar con sus contactos, con independencia del dispositivo que utilicen. Dan Brickley, uno de los coordinadores del proyecto, afirmó que los prototipos "Web+TV", que más beneficiarán a los espectadores serán aquellos que utilicen estándares abiertos. En un reportaje financiado con arreglo al FP7ICT, se afirmó que gracias al proyecto dirigido por BBC R\&D (departamento de investigación de dicha cadena), se desarrollaron métodos para generar recomendaciones relativas a programas, en función de la actividad social, y se crearon tecnologías que facilitan al televidente que comente $\mathrm{y} / \mathrm{o}$ difunda información televisiva en sus redes, sin vulnerar su privacidad (Cordis, 2012).

Fruto del proyecto EUscreen (2009 y 2012), surgió el portal EUscreen, basado en la experiencia de una red de archivos audiovisuales, académicos y socios técnicos y se estableció un consorcio, con 31 organizaciones (donde están presentes dos de los archivos de televisión analizados: INA de Francia y Netherlands Institute for Sound and Vision). Los organismos de radiodifusión y los archivos de toda Europa han aportado un importante volumen de videos y programas propios, con contenido audiovisual profesional.

El portal EUscreen ofrece acceso gratuito en línea a miles de contenidos que representan el patrimonio audiovisual. Este sitio web proporciona una visión de los eventos sociales, culturales, políticos y económicos acaecidos en los siglos XX y XXI, narra eventos históricos importantes y permite explorar programas de televisión que se enfocan en la experiencia cotidiana. Por otra parte, en el proyecto EUscreen, se crearon exposiciones virtuales para contextualizar los elementos de la colección.

Su sucesor, EUscreenXL, comenzó en 2013 y se extendió hasta el año 2016, bajo el programa $7^{\circ}$ Programa Marco. A través del propio portal se anuncian las expectativas de este último proyecto: "Core Collection (plataforma de EUscreen) constará de 60,000 elementos de contenido y metadatos de alta calidad, enriquecidos y curados, disponibles a través de EUscreen y 
Europeana. Se agregarán 20,000 elementos de contenido basados en contenido de series de televisión de toda Europa o de distintas colecciones de películas y videos al contenido existente de 40,000 articulos (seleccionados por tema histórico o para exposiciones especificas)".

Asimismo, si bien Europeana fue un proyecto que nació del mencionado programa eContentplus (2005-2008), bajo el nombre de European Digital Library Network (EDLnet), actualmente recibe también financiación de los programas de $\mathrm{I}+\mathrm{D}$, en concreto del $7^{\circ}$ Programa Marco. Este proyecto se ha convertido es un punto de acceso único a más de 51132068 recursos digitales de archivos (diciembre de 2017) que van desde la prehistoria hasta la actualidad, especializados en arte, moda, música, fotografía y la Primera Guerra Mundial. Contienen gallerías, blogs y exposiciones aportadas por 2.200 instituciones europeas, donde están presentes también tres de los archivos de televisión analizados: BBC (United Kingdom); Netherlands Institute for Sound and Vision (Holanada) y Institut National de l'Audiovisuel (Francia) (Tabla 1).

Tabla 1: Europeana Collections: agregadores de contenidos

\begin{tabular}{|l|l|l|l|}
\hline \multicolumn{1}{|c|}{$\begin{array}{c}\text { Cifras totales en } \\
\text { Europeana }\end{array}$} & $\begin{array}{c}\text { Colección } \\
\text { BBC }\end{array}$ & $\begin{array}{c}\text { Colección } \\
\text { Netherlands } \\
\text { Institute for Sound } \\
\text { and Vision }\end{array}$ & Colección INA \\
\hline $\begin{array}{l}\text { EUscreen } \\
(1,064,062)\end{array}$ & $\underline{\text { BBC (852) }}$ & $\begin{array}{l}\frac{\text { Netherlands }}{\text { Institute for Sound }} \\
\underline{\text { and Vision (21,218) }}\end{array}$ & \\
\hline $\begin{array}{l}\text { Europeana } \\
\text { Fashion (867,177) }\end{array}$ & $\begin{array}{l}\frac{\text { Netherlands }}{\text { Institute for Sound }} \\
\underline{\text { and Vision (671) }}\end{array}$ & \\
\hline $\begin{array}{l}\text { Europeana Sounds } \\
\text { (530,633) }\end{array}$ & $\begin{array}{l}\frac{\text { Netherlands }}{\text { Institute for Sound }} \\
\text { and Vision (3,837) }\end{array}$ & $\begin{array}{l}\text { Institut National de } \\
\text { l'Audiovisuel } \\
\text { (101,356) }\end{array}$ \\
\hline $\begin{array}{l}\text { Institut National de } \\
\text { l'Audiovisuel } \\
(101,356)\end{array}$ & & & \\
\hline
\end{tabular}

Fuente: Europeana - Proveedores de datos (diciembre 2017) (https://www.europeana.eu/portal/es/explore/sources.html)

Finalmente, el objetivo de la estrategia Europa 2020 incluye, en el presente periodo, una inversión del $3 \%$ del PIB en I+D. Entre las 
medidas propuestas para alcanzar este objetivo, la Comisión Europea presentó el último programa de I+D+i, Horizonte 2020 (2014-2020), dotado con 80 billones de euros. Según datos recogidos por CORDIS (2017), uno de los proyectos puestos en marcha ha sido SENTAB, financiado por Horizon, que conecta a las personas mayores con otros ciudadanos, combinando teléfonos inteligentes, tabletas y PC con televisores para realizar llamadas de video fáciles de usar, juegos cognitivos, interacción con la comunidad, contenido gratuito, noticias y redes sociales.

Una vez vistas las principales estrategias europeas y con el fin de contextualizar el estudio, se esbozan a continuación los diferentes modelos de conservación y difusión de los archivos audiovisuales de los organismos analizados.

\subsection{Archivos audiovisuales de televisiones europeas: modelos de conservación y difusión}

Los archivos audiovisuales de televisión forman parte del patrimonio audiovisual y cultural de una nación. Su consideración de acervo cultural viene avalada por organismos internacionales con competencias en la materia como la UNESCO, que ya desde 1980 en la 21 Reunión de la Conferencia General, propone una recomendación orientada a "la salvaguarda y conservación de las imágenes en movimiento" (UNESCO, 1980), entre las que se incluyen las "producciones televisivas realizadas por o para los organismos de radiodifusión".

La recomendación señala algunas directrices jurídicas y administrativas para que las instituciones de archivo oficialmente reconocidas puedan disponer para su salvaguardia y conservación de una parte o la totalidad de la producción nacional del país como "la creación de sistemas de depósito legal". No obstante, se insiste en que las medidas deben respetar la legislación nacional e internacional vigente en temas sensibles como "la protección de los derechos de autor".

Coincidiendo con la conmemoración del $25^{\circ}$ aniversario de la aprobación de esta recomendación, y como medida de sensibilizar sobre la necesidad de preservar este patrimonio, la UNESCO proclama 
el 27 de octubre Día Mundial del Patrimonio Audiovisual (UNESCO, 2005).

Así mismo, organismos de carácter profesional como la FIAT, Federación Internacional de Archivos de Televisión (FIAT/IFTA), vienen, desde su creación en el año 1977, realizando recomendaciones en este sentido. En el año 2004, en el marco de su Conferencia anual, redactó el denominado "Llamamiento de París" para que los gobernantes tomen medidas para la salvaguardia de los archivos de radio y televisión (Hidalgo, 2014:11).

Sin embargo, a pesar de este reconocimiento, la mayoría de los países carecen de una legislación ad hoc. En sus numerosos estudios sobre los archivos de televisión, Hidalgo $(2013,2014,2017)$ subraya que la falta de políticas de conservación, preservación y acceso a los documentos que albergan suele ser la práctica habitual.

Respecto a las estructuras de conservación y/o difusión no existe un modelo único. Para los archivos de las televisiones públicas europeas, la autora señala diferentes realidades derivadas de la presencia o ausencia de un marco jurídico que regule su gestión y de su mayor o menor protección.

Entre las diferentes situaciones encontramos países en los que los documentos audiovisuales de televisión están sujetos a una Ley de Depósito Legal y cuya responsabilidad jurídica depende de organismos públicos, a veces creados ex profeso, como Francia que encomienda la gestión de los archivos de todas las televisiones tanto públicas como privadas al INA o Noruega cuya gestión depende de propia Biblioteca Nacional del país.

En la mayoría de los países, sin embargo, no existe un organismo de carácter oficial para tal uso, ni cuentan con una Ley obligatoria de Depósito Legal para los documentos audiovisuales siendo los propios las propias empresas y organismos de televisión los responsables de la gestión y conservación de los mismos que dependerá, por tanto, de los criterios de carácter comercial y empresarial de las propias cadenas (Hidalgo, 2013: 149).

Por lo que respecta a nuestro estudio, los archivos audiovisuales de los organismos analizados (BBC, INA, Netherlands Institute for Sound and Vision y RTVE) responden a diferentes estructuras de 
conservación por lo que ejemplifican de manera paradigmática los diferentes modelos de gestión del patrimonio audiovisual televisivo.

\section{BBC}

Los programas de televisión en el Reino Unido no están sujetos a una norma legal de depósito. La gestión de los archivos de televisión es compartida por la propia BBC y el NFA (National Film Archive) (Pérez, 2011: 170). Esta institución, creada en 1935, que forma parte del British Film Institute (BFI) es la responsable de las funciones de preservación y acceso tanto de películas cinematográficas como de programas de televisión. Su archivo conserva el material de la BBC para su preservación desde 1950. Por su parte, la BBC conserva en archivo parte de su producción correspondiente a las primeras emisiones y al periodo después de la segunda guerra mundial (Hanford, 1986).

Desde la página web del propio archivo de la BBC se puede acceder en abierto a algunas colecciones temáticas de programas de radio y televisión, documentos y fotografías desde la década de 1930. Si bien, la propia página informa de que ha dejado de actualizarse.

\section{INA}

Francia es uno de los países que ha ido adoptando paulatinamente una autentica política de conservación y donde se reconoce el valor patrimonial de los archivos audiovisuales desde época más temprana. Desde su creación en 1975, el INA es el organismo público encargado garantizar la conservación y preservación de los archivos de radio y televisión.

En 1992 se encomienda además al INA el control del depósito legal de los documentos de radio y televisión de todas las cadenas públicas y privadas. Para su gestión, en 1995 se crea la Inathèque de France, estableciéndose el primer centro de consulta en la Biblioteca Nacional de Francia en 1998. Asimismo, desde 2006 es responsable también junto con la $\mathrm{BnF}$, del depósito legal de los sitios web de medios de comunicación franceses.

El INA se configura desde su creación como institución pública de carácter patrimonial siendo, además, una entidad de carácter industrial y comercial encargada también de la explotación de los archivos de 
televisión de todas las cadenas públicas y de aquellas privadas que han suscritos convenios con el INA.

Entre las acciones previstas para el periodo 2015-2019 del INA se contempla la necesidad de repensar la función de los archivos audiovisuales en la era digital, así como en el contexto de las redes sociales.

\section{Netherlands Institute for Sound and Vision}

Holanda es otro de los países que cuenta con una institución pública como el Netherlands Institute for Sound and Vision para la preservación y conservación del patrimonio audiovisual nacional. La configuración de un organismo nacional con responsabilidad en esta área comienza a gestarse a mediados de la década de 1990. Así, en 1997 se crea el Dutch Audiovisual Archive que fusiona los archivos audiovisuales de la radio y televisión públicas holandesas, el RVD (Servicio de Información de Holanda), el Dutch Film and Science Foundation y el Broadcasting Museum in the Netherlands.

Desde 2006, bajo la denominación ya de Netherlands Institute for Sound and Vision, añade a su misión patrimonial la función museística, convirtiéndose actualmente en una institución para la cultura de los medios que se centra en recopilar y preservar la mayor parte del patrimonio audiovisual de los Países Bajos y ponerlo a disposición del mayor número de usuarios posible. Actualmente, cuenta con colección multimedia con fondos audiovisuales, fondos de prensa escrita, sitios web y objetos relacionados con los distintos medios de comunicación.

Su página web permite el acceso de manera gratuita a una selección del material para su uso con fines educativos. No obstante, la propia institución informa de que pondrá en abierto toda la colección audiovisual en 2019.

\section{RTVE}

El valor del patrimonio audiovisual español es reconocido en diferentes leyes y normativas, sin embargo, la responsabilidad y procedimientos para su salvaguarda sigue siendo difusa. Precisamente, los "programas audiovisuales emitidos por servicios de comunicación audiovisual" figuran entre los "excluidos de depósito legal" en la última Ley de Depósito Legal de 29 de julio de 2011(Hidalgo, 2014:22). 
España sería, por tanto, uno de los países en el que la preservación y conservación del patrimonio audiovisual de las televisiones es responsabilidad de las propias cadenas. En el caso concreto de la televisión pública estatal, es la propia Corporación de RTVE la responsable de la conservación de sus archivos históricos audiovisuales (Hidalgo, 2013:148).

En 2008, RTVE da a conocer, a través de su sede web, el Archivo RTVE que permite el acceso abierto y de forma gratuita a su patrimonio audiovisual (Bazán, 2014: 12). En este sentido, la política de la televisión pública española sería una buena práctica de cómo se pueden revalorizar y dar a conocer estos archivos (Hidalgo, 2013:162).

\subsection{La cultura transmedia en el contexto de archivos audiovisuales}

Como se ha apuntado en la introducción, la experiencia y el consumo de contenidos, bien sean ficción o no, ha cambiado radicalmente debido a nuevos elementos como la interacción con la audiencia, su distinta medición y el consumo a través de diversas plataformas. Para entender esta propuesta de estrategias transmedia para la difusión de material audiovisual de archivo, es necesario previamente conocer cómo se abordan estas nuevas perspectivas en la literatura científica.

El concepto de "Televisión social" surge, como reconocen Quintás y González (2014), de la combinación de redes sociales, segundas pantallas y televisión. Scolari la denomina "hipertelevisión" (2008), mientras que algunos autores la denominan, debido a su capacidad de adaptación, como "TV morfosis" (Orozco, 2012).

A pesar de estos cambios, para Hagedoorn y Agterberg (2016), la televisión está jugando un papel esencial en la recuperación de documentos de archivo que se pueden distribuir a través de las nuevas plataformas online. Esta reutilización de material fílmico de archivos audiovisuales en nuevas plataformas conecta a los usuarios con el pasado a la vez que sirve como contexto para obtener productos storytelling transmedia y crossmedia (Hagedoorn, 2016:168).

En este contexto, los archivos audiovisuales pueden configurarse como los nuevos canales de comunicación, reformulándose en un escenario donde el poder de interacción entre el emisor y receptor es impredecible, tal y como apunta Jenkins (2006). En estos contextos 
innovadores, los contenidos son pensados para ser transmedia: para reutilizarse en múltiples plataformas.

Esas nuevas narrativas digitales basadas en el storytelling son una oportunidad para la reutilización de imágenes de archivo. Desde los últimos años de la década de los 90, la tecnología digital ha fomentado la creación de historias de manera más rápida. En especial mediante las nuevas formas de software social que han abierto las historias a sujetos emisores no-expertos o amateurs (Hancox, 2017). En este sentido, el storytelling digital emerge como parte de un cambio de paradigma en Comunicación más amplio, donde la tradicional jerarquía evoluciona hacia un entorno comunicativo peer-to peer (Hartley, 2009).

En la narrativa transmedia en concreto, además de desarrollarse en varios medios, cada aportación nueva hace una contribución específica y valiosa a la totalidad (Jenkins, 2008). En este entorno, se espera del espectador un papel activo en el consumo, similar al de recolector o cazador, en busca de esos fragmentos de contenido, por lo que se fomenta la participación y un entretenimiento más activo (Jenkins, 2008). Por ello, además de la estrategia comunicativa se fortalece una implicación con el contenido. La dimensión emocional en estas estrategias se vuelve decisiva para que sean más efectivos (Sánchez Castillo y Galán, 2016). El archivo puede ser un partner más que colabore en la expansión de estos universos fomentando el vínculo emocional con los espectadores. Para ello, hay que romper la visión tradicional de las imágenes de archivo en la televisión. En este sentido, Hagedoorn y Agterberg (2016) reivindican el papel de los archivos de las televisiones nacionales como agentes esenciales en el conocimiento histórico contemporáneo. Para este fin, valoran el potencial impacto tanto de la capacidad de su distribución online, como de su contextualización y, por supuesto, de su preservación digital. Sin duda, en los términos de este artículo la contextualización es un elemento clave. Dekker (2014) valora en estas estrategias su unicidad y originalidad, sin que se repliquen meramente contenidos de archivo duplicados. Este autor, considera que la distribución, a pesar de ser mutiplataforma, sigue siendo convencional, viendo una oportunidad en los nuevos conceptos transmedia para su difusión. Un paso más allá en este tipo de estrategias la establece Caldera Serrano y León Moreno (2016) cuando reconocen la posibilidad de jugar con tecnologías de 
realidad aumentada para explotar las colecciones de archivo. Estos autores defienden la utilización de dispositivos móviles para acceder a imágenes utilizadas en la creación de un programa, mezclada con elementos adicionales que susciten interés en los usuarios. Con la ayuda de este tipo de nuevas tecnologías, puede desarrollarse un nuevo producto multimedia que actúe como un mapa conceptual de contenidos audiovisuales de un evento o programa, basándose en documentos de archivo.

Hagedoorn y Agterberg (2016) reconocen el papel que las televisiones $\mathrm{y}$ archivos pueden ejercer en el desarrollo de nuevos tipos de compromiso en los usuarios, incluyendo de manera explícita, contenido a demanda, más abierto y favoreciendo nuevas experiencias con el contenido televisivo. Señalan que, en el caso holandés, esta tendencia ha coincidido con el incremento de producciones sobre historia y documentales, en el que han hecho gala de nuevas formas de crossmedia y storytelling que reutilizaban el material de archivo de diferentes maneras. Hagedoorn en 2015, establecía el ejemplo de la serie In Europe, proyecto televisivo basado en una estrategia storytelling multiplataforma. La autora recalcaba, además, la labor de estos mecanismos para la creación de memorias colectivas más efectivas.

En este sentido, en España, sucede lo mismo con los programas de ficción, en concreto, con la intersección de la propia ficción con los documentos de archivo que actúan como elemento contextualizador. El ejemplo más paradigmático de colaboración y del desarrollo de un universo expandido no ha sido llevado a cabo por un archivo audiovisual, sino por instituciones patrimoniales, como la Biblioteca Nacional o el Archivo Nacional en ficciones como El Ministerio del Tiempo, donde estas instituciones actúan no solo de universo expandido de la serie, sino que realizan un auténtico proceso de Curación de Contenidos con su propia colección para difundir y valorizar a través de medios sociales su propio acervo (Martínez Cardama, 2017).

Tanto las televisiones, como sus archivos, están adaptándose a nuevos tipos de participación con las audiencias, basándose en la recontextualización de los contenidos y sus oportunidades. A nivel profesional, es necesario destacar el ejemplo holandés del desarrollo de la herramienta $A V$ ResearchXL, donde se puede apreciar una 
metodología de trabajo en la que el contenido va más allá de solo lo emitido (Figura 1).

\section{Figura 1: $\boldsymbol{A}$ VResearch $X L$}

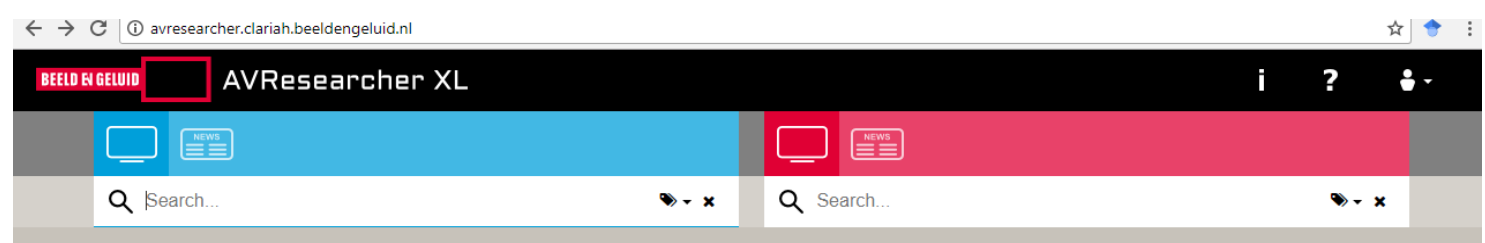

Fuente: https://www.beeldengeluid.nl/

Se trata de un metabuscador destinado a investigadores a través del que pueden localizar metadatos tanto de contenido tradicional de catálogos, como de los programas y contenidos emitidos, así como de aquello asociado a los mismos en la red social Twitter. Este ejemplo, muestra cómo a nivel profesional ya se entienden las perspectivas multiplataforma y transmedia para relacionar y estudiar contenidos. Comprende políticas de preservación digital distintas, incluyendo, desde el archivado de la web a toda la documentación digital asociada a los procesos productivos audiovisuales (Hagedoorn y Agterberg, 2016).

Tanto desde la visión de la creación de memoria colectiva como desde la visión social, los archivos audiovisuales pueden ser un elemento fundamental para las políticas de social media y hacer uso de estas opciones dinámicas de storytelling.

El reto de los archivos audiovisuales ha sido bien analizado y tratado por Rodríguez y Hernández (2015), enfocándolo a tres conceptos clave en la Televisión 2.0 que ya encontramos en el trabajo de Askwith (2007): acceso expandido, contenido expandido y contenido adaptado. En cuanto al primero, el acceso expandido, constituye el acceso a los contenidos donde no hay una reelaboración original. Rodríguez y Hernández (2015) establecen en los documentalistas audiovisuales la labor de revitalización, relacionándolo con la actualidad u otras series y programas. En cuando al contenido adaptado, constituye la elaboración de nuevos contenidos basados en los preexistentes. Por último, el contenido expandido o auxiliar, es aquel expandido a raíz de la emisión: esa creación de universos (biografías, resúmenes históricos sobre la época de la ficción, etc.). 
En cualquiera de estas tres categorías, el rol del documentalista audiovisual puede resultar crucial para el análisis del contenido textual generado, antes durante y después de cada consumo televisivo (Rodríguez y Hernández, 2015). Estos autores plantean el seguimiento de etiquetas o hashtags para seguir los contenidos y con metadatos, proceder a su segmentación. Esto entronca con los nuevos retos futuros de la profesión: la medición de las audiencias sociales en diferido y de la participación de los documentos de archivo en este proceso.

\section{Método y materiales empleados}

El objetivo fundamental de este estudio es conocer el actual papel de los materiales de archivos audiovisuales en la creación de estrategias transmedia. En este caso, teniendo en cuenta el gran papel de las audiencias sociales, nos hemos centrado principalmente en la plataforma Twitter. Paralelamente, se pretende conocer los diferentes modos que las televisiones públicas emplean para dar a conocer y poner en valor su acervo audiovisual a las nuevas generaciones utilizando para ello los nuevos medios digitales. Se analizan, por tanto, los perfiles de Twitter de cuatro televisiones públicas que podemos considerar paradigmáticas: RTVE de España, BBC de Reino Unido, el INA de Francia y Netherlands Institute for Sound and Vision holandés. Se ha pretendido, mediante esta elección, ofrecer una panorámica de diferentes modelos de conservación y difusión del patrimonio audiovisual. Desde una perspectiva muy proteccionista, donde las imágenes están sujetas al Depósito Legal del país o se han se han creado organismos públicos para su gestión como el INA francés o el Netherlands Institute for Sound and Vision holandés hasta modelos menos protectores donde son los propios organismos de producción y radiodifusión los encargados de conservar y difundir este patrimonio como sería el caso de RTVE en España y un tercer mecanismo como el inglés, donde la gestión está compartida entre los propios archivos audiovisuales de las televisiones y el British Film Institute (BFI) que se encarga del acceso.

Los sitios web y perfiles twitter de los que se obtuvo información son los siguientes (Tabla 2): 


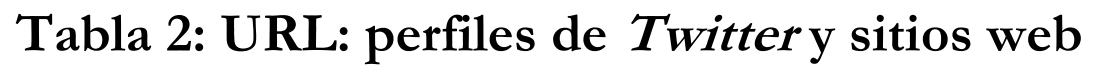

\begin{tabular}{|c|c|c|}
\hline Archivos & Perfiles en Twitter & Sitio web \\
\hline BBC (Reino Unido) & $\begin{array}{l}\text { https://twitter.com/ } \\
\text { beeldengeluid }\end{array}$ & $\begin{array}{l}\text { http://www.bbc.co.uk/archi } \\
\text { ve/ } \\
\text { http://www.gettyimages.co.u } \\
\underline{\mathrm{k} / \text { footage/bbcmotiongallery }} \\
\underline{\#} *\end{array}$ \\
\hline INA (Francia) & $\begin{array}{l}\underline{\text { https: / / twitter.com } /} \\
\text { inafr officiel?lang }=\mathrm{e} \\
\underline{\mathrm{s}}\end{array}$ & http://www.ina.fr/ \\
\hline $\begin{array}{l}\text { Netherlands } \\
\text { Institute for Sound } \\
\text { and Vision } \\
\text { (Holanda) }\end{array}$ & $\begin{array}{l}\text { https://twitter.com/ } \\
\text { beeldengeluid }\end{array}$ & $\begin{array}{l}\underline{\text { https://www.beeldengeluid.n }} \\
\underline{\perp}\end{array}$ \\
\hline RTVE (España) & $\begin{array}{l}\underline{\text { https://twitter.com/ }} \\
\text { archivortve?lang=es }\end{array}$ & $\begin{array}{l}\text { http://www.rtve.es/televisio } \\
\text { n/archivo/ }\end{array}$ \\
\hline
\end{tabular}

*El segundo enlace corresponde al servicio profesional que gestiona la venta de imágenes online. Fuente: elaboración propia

Puesto que en la literatura profesional no se abordan indicadores de evaluación tan específicos para analizar estrategias transmedia de los archivos audiovisuales, se ha procedido a identificar ámbitos de evaluación propios. Para la elaboración de estas categorías se han tenido en cuenta tendencias apuntadas en algunos estudios recientes sobre el sector, como los elaborados por Hagedoom (2015) donde recurre al storytelling multiplataforma para la revalorización de documentos audiovisuales de archivo para crear una memoria participativa colectiva. Esta misma tendencia, la apuntan en 2016 Hagedoorn y Agterber en la que señalan el fin del archivo televisivo convencional prediciendo un futuro marcado por la difusión de contenidos bajo estrategias crossmedia. Se han descartado otros estudios de carácter más generalista que evalúan las páginas web de los archivos audiovisuales de televisiones (Antón y Guallar, 2014) y el de Codina, Aubia y Sánchez (2008) que proporciona indicadores para analizar únicamente los sitios web de las corporaciones.

El trabajo de Rodríguez y Hernández (2015), a pesar de estar centrado únicamente en un estudio de caso concreto sobre una serie de ficción como es El Ministerio del Tiempo de RTVE, se ha tenido también en cuenta, para agrupar los ámbitos de evaluación ya que es un trabajo 
relevante sobre posibles aplicaciones de la transmedialidad a documentos de archivos audiovisuales. En él, los autores, como ya se ha mencionado, se basan en tres tareas de dinamización de archivos audiovisuales establecidas ya en Askwith (2007): acceso expandido (Expanded Access), adaptación de contenidos (Repacked Content), contenido expandido o auxiliar (Ancillary Content).

Partiendo de estas propuestas, se han establecido los siguientes ámbitos de evaluación (Tabla 3).

\section{Tabla 3: Estrategias trasmedia para la dinamización de archivos audiovisuales}

\begin{tabular}{|c|c|}
\hline Áreas de interés & Ámbitos de evaluación \\
\hline $\begin{array}{l}\text { 1. Acceso expandido } \\
\text { (Expanded Access): se } \\
\text { revaloriza el contenido } \\
\text { respetando tal y como } \\
\text { fue producido } \\
\text { originalmente. }\end{array}$ & $\begin{array}{l}\text { 1.1. Difusión de programas completos ya emitidos } \\
\text { a los que se puede acceder a través de la página del } \\
\text { archivo. } \\
\text { 1.2. Finalidad contextual: conexión de imágenes de } \\
\text { archivo para ilustrar una realidad actual. Tiene tres } \\
\text { usos: conmemoraciones, efemérides y utilización } \\
\text { de sucesos pasados para contextualizar noticias } \\
\text { actuales con las que guardan algún tipo de } \\
\text { relación. } \\
\text { 1.3. Estrategias de fidelización a través de Twitter. } \\
\text { Empleo de hasbtags para fidelizar a nuevos usuarios } \\
\text { (i.e. \#felizlunes, \#happymonday...). }\end{array}$ \\
\hline $\begin{array}{l}\text { 2. Adaptación de } \\
\text { Contenido (Repackaged } \\
\text { Content): elaboración de } \\
\text { nuevos contenidos } \\
\text { reutilizando las } \\
\text { producciones originales. }\end{array}$ & $\begin{array}{l}\text { 2.1. Apoyo a programas nuevos basados en } \\
\text { documentos de archivo. }\end{array}$ \\
\hline $\begin{array}{l}\text { 3. Contenido expandido } \\
\text { o auxiliar (Ancillary } \\
\text { Content): el punto de } \\
\text { partida es una } \\
\text { producción a partir de la } \\
\text { cual se genera y se } \\
\text { difunde nuevo } \\
\text { contenido. }\end{array}$ & $\begin{array}{l}\text { 3.1. Creación de narrativas transmedia a través de: } \\
\text { páginas propias de personajes o tramas, making of, } \\
\text { realidad virtual, contenido histórico ad hoc para } \\
\text { expandir la trama. }\end{array}$ \\
\hline
\end{tabular}

Fuente: elaboración propia a partir de Askwith (2007) 


\section{Resultados}

El análisis de resultados se ha acometido desde una perspectiva cualitativa teniendo en cuenta los ámbitos de evaluación establecidos (Tabla 3). Partiendo de estas categorías, se ofrecen los resultados agrupados para las cuatro instituciones objeto de estudio: BBC, INA, Netherlands Institute for Sound and Vision y RTVE.

\subsection{Acceso expandido (Expanded Access)}

Se trata de la estrategia más común entre los diferentes organismos analizados para dinamizar sus archivos a través de medios digitales. Como se ha precisado, consiste en dar a conocer los fondos del archivo respetando su producción original, a través de tres ámbitos de evaluación:

a) Difusión de programas completos ya emitidos a los que se puede acceder a través de la página del archivo

Las respuestas en el análisis de este ítem vienen marcadas por la propia idiosincrasia de cada uno de los archivos y de sus políticas de acceso a los fondos:

\section{- BBC}

Aunque la página del archivo digitalizado de la BBC ofrece colecciones y selecciones de programas digitalizados, esta nos informa que sus contenidos han dejado de actualizarse, estando accesibles en otras plataformas online: como su propio sitio web de TV (BBC Player), su servicio profesional de venta de imágenes, la actual BBC Motion Gallery, alojada en Getty imágenes, y sus fondos offline, previo contacto con el centro, en BBC Broadcast Archive. Es importante destacar que esta gestión es compartida con la institución BFI, que alberga fondos de esta compañía desde 1950.

En cuanto a su perfil de Twitter, @BBCArchive, creado en 2009, cuenta con 8.916 publicaciones (diciembre 2017). De este histórico, se puede constatar que en ninguno de los casos nos remite a programas completos ya emitidos a través de la página web del archivo. De hecho, por estar embebido, no proporciona enlace alguno a la página de origen. 


\section{- INA}

El Instituto Nacional Audiovisual francés es la entidad pública que gestiona el acceso a los archivos audiovisuales de las televisiones francesas, públicas y privadas. Sus contenidos se disponen en la página web agrupadas no solo por emisiones, sino por categorías temáticas y personalidades. Dispone, además, de un potente buscador, que permite filtrar los contenidos por categorías y fechas. Sus 13,3 K publicaciones en Twitter, tampoco nos ofrecen acceso a programas completos. Al igual que la $\mathrm{BBC}$, en muchos casos también se suele embeber el video sin ofrecer enlaces externos. No obstante, en varias ocasiones nos da la posibilidad de acceder a contenido elaborado como dosieres sobre diferentes temas de actualidad, como la inmigración, accesibles bien a través de la página del archivo o bien a través de canales de youtube.

\section{- Netherlands Institute for Sound and Vision}

Este importante Instituto, que alberga el $70 \%$ de la producción audiovisual de los Países Bajos, es uno de los archivos audiovisuales más importantes de Europeana. Como hemos señalado, tiene una triple dimensión: es el archivo central de las televisiones holandesas, un instituto cultural y patrimonial y un museo. A pesar de ello, su perfil de Twitter@BeeldenGeluid, creado en 2009, y con 9.733 publicaciones, no se utiliza para poner en valor su gran patrimonio, siendo excepcionales los casos en los que ofrece acceso a algún documento audiovisual contextualizado. En la mayoría de los casos los tweets hacen referencia a la actividad y agenda del Instituto.

\section{- RTVE}

El sitio web del archivo de RTVE se presenta en 2008 dando acceso paulatinamente a todo tipo de contenido ya digitalizado. De los archivos analizados, es el que muestra un mayor compromiso a la hora de ofrecer material completo sin previo pago.

Su perfil de Twitter@ArchivoRTVE, con 10,1 k publicaciones, fue creado en 2014. Sin embargo, es un ejemplo de la difusión de acceso expandido de contenidos originales. Cada tweet remite a través de un enlace a la página web del archivo desde donde podemos visualizar programas completos ya emitidos.

b) Finalidad contextual: conexión de imágenes de archivo para ilustrar una realidad actual. Tiene diferentes usos: 
conmemoraciones, efemérides o se recurre a sucesos pasados para contextualizar noticias actuales con las que guardan algún tipo de relación

Tras analizar cada uno de los archivos, se detecta que es la estrategia de dinamización más utilizada en sus perfiles sociales. En la mayoría de los casos se aprovechan imágenes de archivo para ilustrar sucesos de la realidad actual.

\section{- BBC}

En cuanto a las publicaciones en @BBCArchive, se aprecia que esta estrategia prima sobre otros usos. Siguiendo la práctica habitual de varias instituciones patrimoniales conectan contenidos propios con efemérides a través de hashtags comunes en este medio como \#OTD (On this day), dirigido fundamentalmente a efemérides propias relacionadas con la historia de su programación (Figura 2):

\section{Figura 2: Uso del hashtag \#OTD en @BBCarchive}

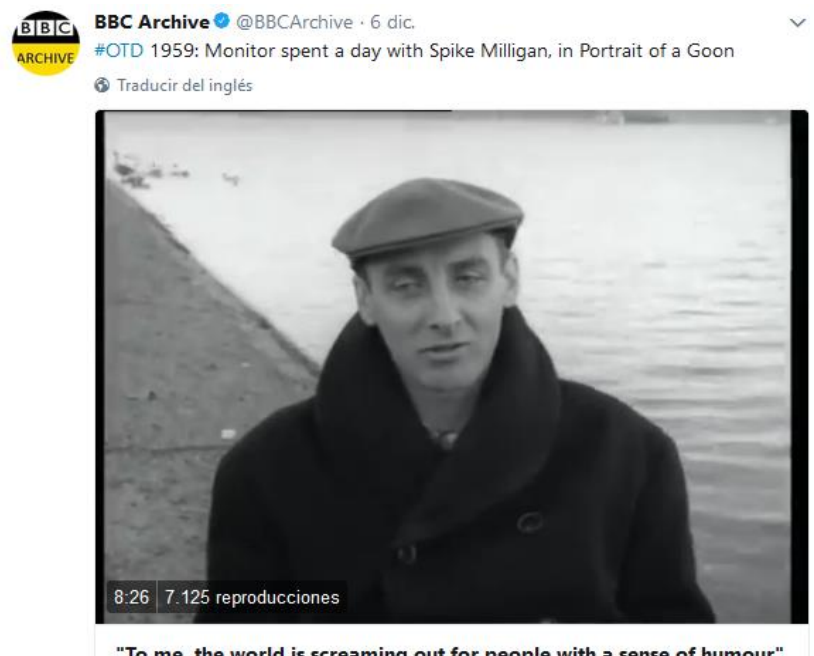

Fuente: $\underline{\text { https: } / / \text { twitter.com/bbcarchive?lang }=\text { es\&lang }=\text { es }}$

$\mathrm{Al}$ igual que en otros casos que veremos a continuación, también se utiliza este hashtag para conmemorar nacimientos, fallecimientos o acontecimientos de personas relevantes (escritores, actores...).

\section{- INA}

A diferencia de la BBC, en la institución francesa se observan otras estrategias de tipo contextual. Por ejemplo, en el caso de las efemérides, el INA no utiliza ningún hashtag del tipo \#cejour (tal día como hoy), sino que lo expresa directamente en el texto del tweet (Figura 3). 
Figura 3: Recordatorio del fallecimiento de la escritora Marguerite Yourcenar en @Inafr_officiel

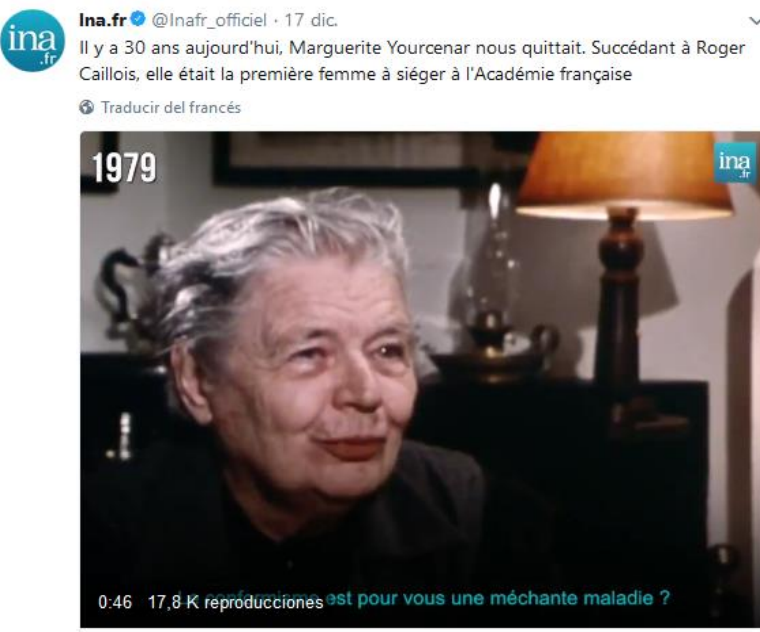

1979 - Marguerite Yourcenar sur le conformisme

L'académicienne s'entretient avec Bernard Pivot en 1979.

Fuente: https://twitter.com/inafr_officiel?lang=es

Asimismo, se difunden contenidos ya emitidos a través de su archivo para contextualizar eventos actuales. Como se puede ver en el ejemplo (Figura 4), el INA aprovecha el lanzamiento de la nueva película de Star Wars (empleando el hashtag \#Starwars8) para mostrarnos la entrevista realizada en su momento a Carrie Fisher.

\section{Figura 4: Entrevista a Carrie Fisher en@Inafr_officiel}

ina Ina.fr@@Inafr_officiel.13 dic.

1 \#StarWars8 : Princesse Leĩa est-elle l'une des premières icônes féministes ?

(2) Traducir del francés

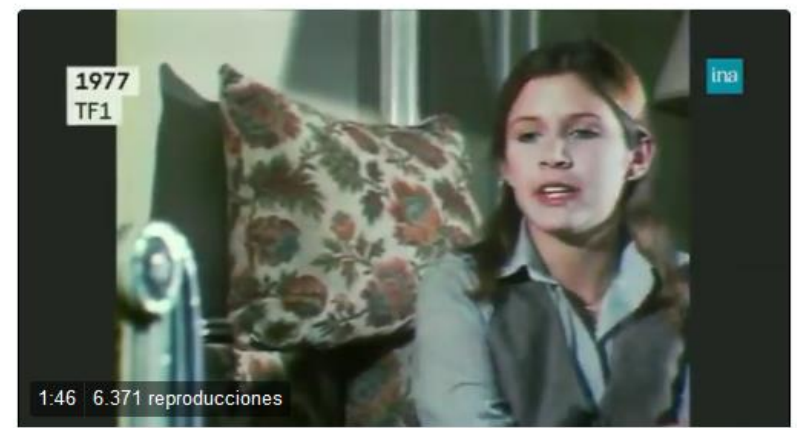

Princesse Leïa, première icône féministe ?

Le nouveau Star Wars sort ce mercredi. L'occasion de voir Carrie Fisher dans son rôle de Princesse Leīa. Un personnage à rebours des clichés, qui anticipe d'autres rôles féministes..

Fuente: $\underline{\text { https://twitter.com/inafr officiel?lang=es\&lang=es }}$

- Netherlands Institute for Sound and Vision

Como se ha mencionado, la política de difusión de contenidos del instituto holandés es radicalmente distinta a la de los otros organismos. 
La mayoría de los contenidos publicados en su perfil hacen referencia a las actividades llevadas a cabo por el propio instituto y su museo. Tras hacer una búsqueda exhaustiva, se ha comprobado que la estrategia de tipo contextual es muy limitada. Asimismo, tampoco hacen uso de hashtags \#Opdezedag (tal día como hoy) para conmemorar efemérides u otros eventos.

\section{- RTVE}

Televisión española, a través de su archivo, es la institución que, a nuestro juicio, realiza una mejor estrategia de dinamización de contenidos para dar a conocer sus fondos con una finalidad contextual. Cumpliría los tres casos establecidos en esta área de evaluación (Figura $5)$.

Figura 5. Estrategias de efemérides, conmemoración y utilización de sucesos pasados para contextualizar noticias actuales.

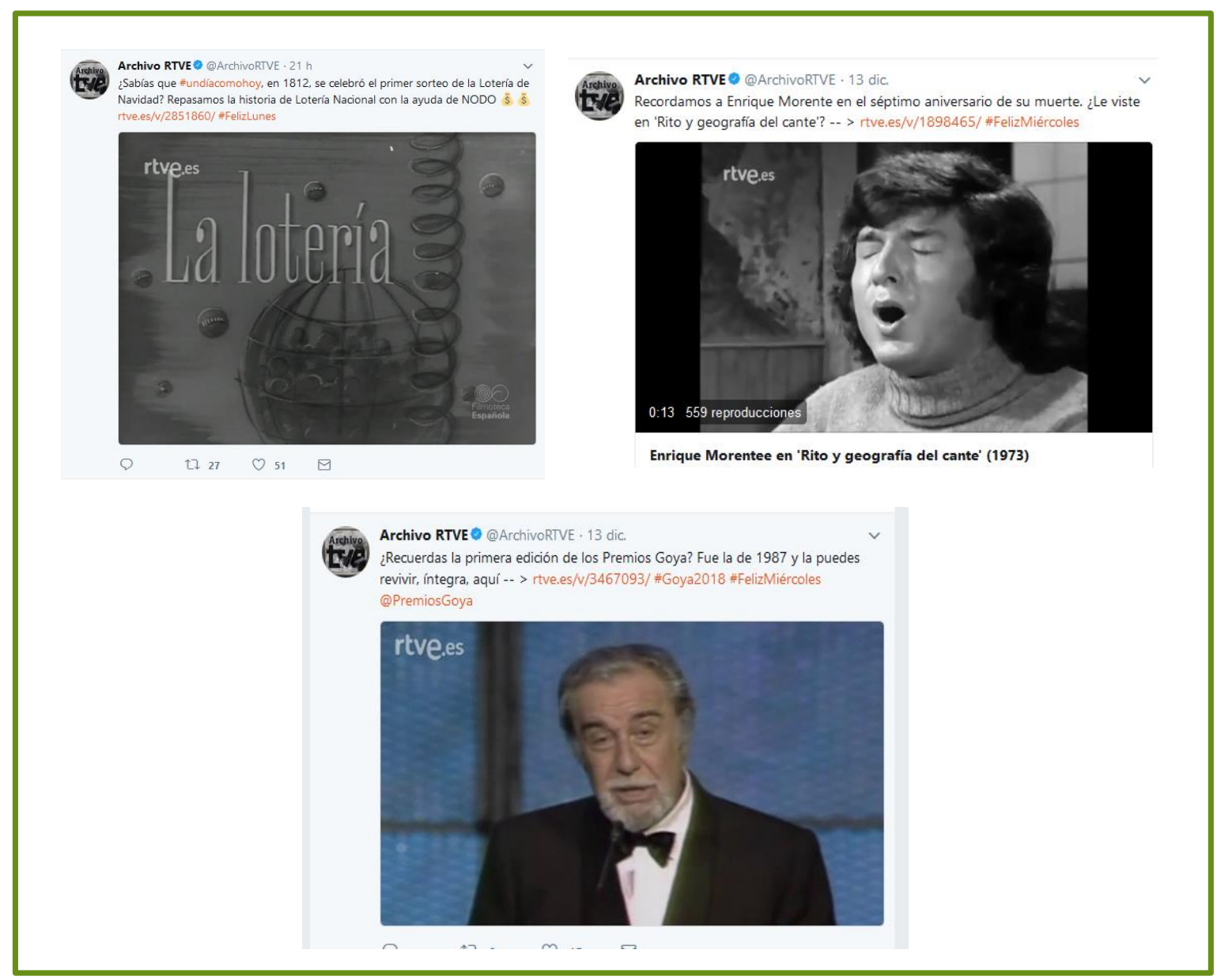

Fuente: https://twitter.com/archivortve 
Para las efemérides, se observa que RTVE emplea, al igual la BBC, el hashtag \#undiacomohoy, muy común en las estrategias de Social Media de las instituciones patrimoniales, siempre acompañado de un enlace al propio archivo de televisión, dando la posibilidad de visualizar el contenido completo. Esta misma filosofía de difusión se utiliza para las conmemoraciones y para rescatar sucesos pasados que puedan ilustrar realidades y noticias actuales (Figura 5).

c) Estrategias de fidelización a través de Twitter. Empleo de hashtags de uso habitual para fidelizar a nuevos usuarios (i.e.\#felizlunes, \#happymonday...)

En algunas instituciones utilizan también hashtags que suelen ser tendencia en Twitter, aunque carecen de sentido semántico, como medio para llegar a un tipo de público que de otro modo no llegaría a acceder al archivo. Esta práctica es habitual en los contenidos difundidos por el Twitter del archivo de RTVE (Figura 6).

\section{Figura 6: Estrategia de fidelización con el hashtag \#felizfinde}

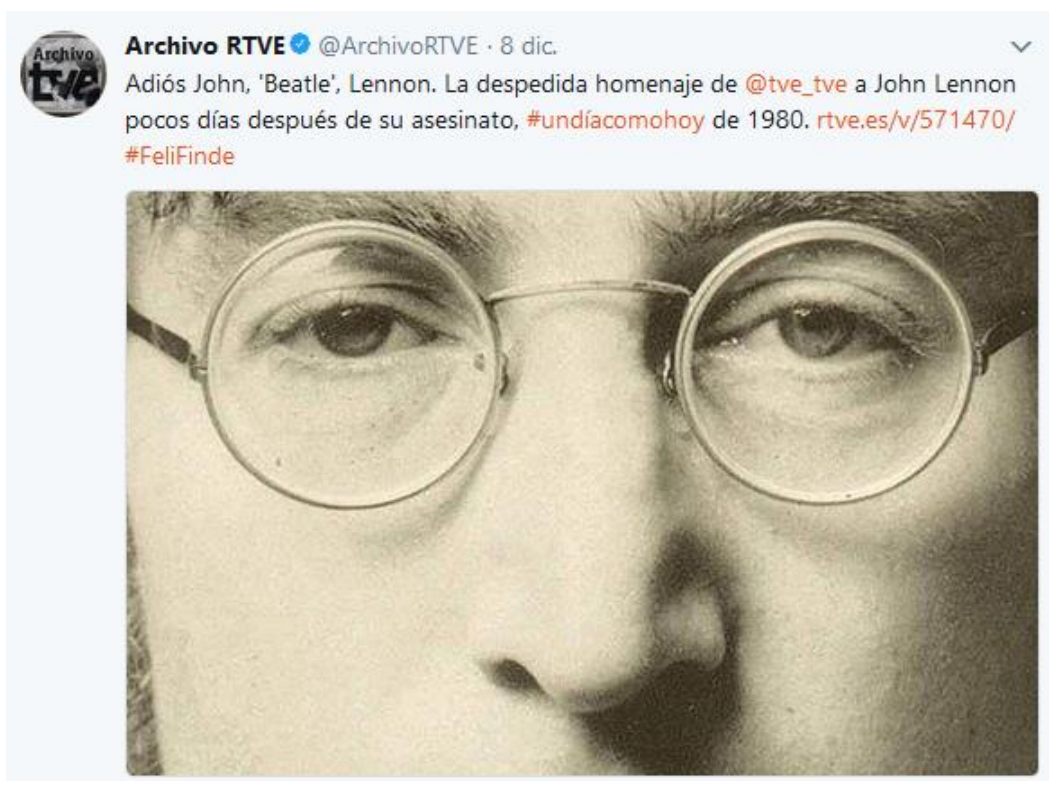

Fuente: https://twitter.com/archivortve

Una tendencia similar para aprovechar hashtags que son tendencia, se observa también en el INA francés. Un ejemplo es el hashtag colaborativo de fomento a la lectura \#vendredilecture, orientado a difundir imágenes de archivo de libros y escritores (Figura 7). 


\section{Figura 7: Estrategia de fidelización con el hashtag \#vendredilecture}

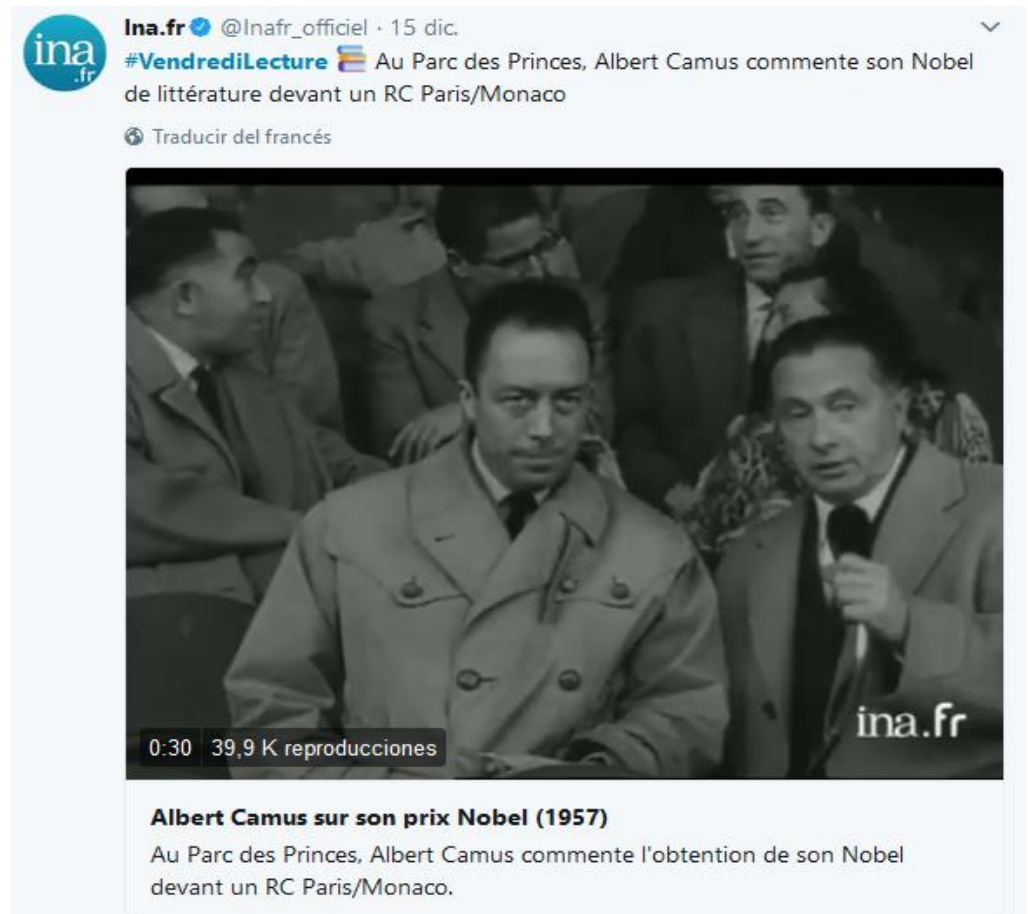

Fuente: https://twitter.com/Inafr_officiel?lang=es

\subsection{Adaptación de Contenido (Repackaged Content)}

En este punto se trata de dar a conocer si los diferentes perfiles de las instituciones ofrecen información sobre producciones actuales realizadas mediante la reutilización de imágenes de archivo. Si se compara esta estrategia con la anterior, se observa que no suele ser una práctica tan habitual.

a) Apoyo a programas nuevos basados en documentos de archivo Un análisis detallado de las cuatro instituciones nos ha permitido encontrar esta tendencia en el INA y en RTVE.

Por lo que respecta al INA, a través de su perfil de Twitter se puede acceder a productos nuevos elaborados a partir de su archivo. Cabe reseñar, que nunca ofrece el contenido completo en abierto por razones de su política comercial. Un ejemplo de este caso, es el producto sobre la crisis actual de los Rohinyás en Birmania donde se entremezclan imágenes de distintas televisiones francesas desde 1978 a las más recientes de 2017 (Figura 8). 


\section{Figura 8: Apoyo a nuevas producciones}

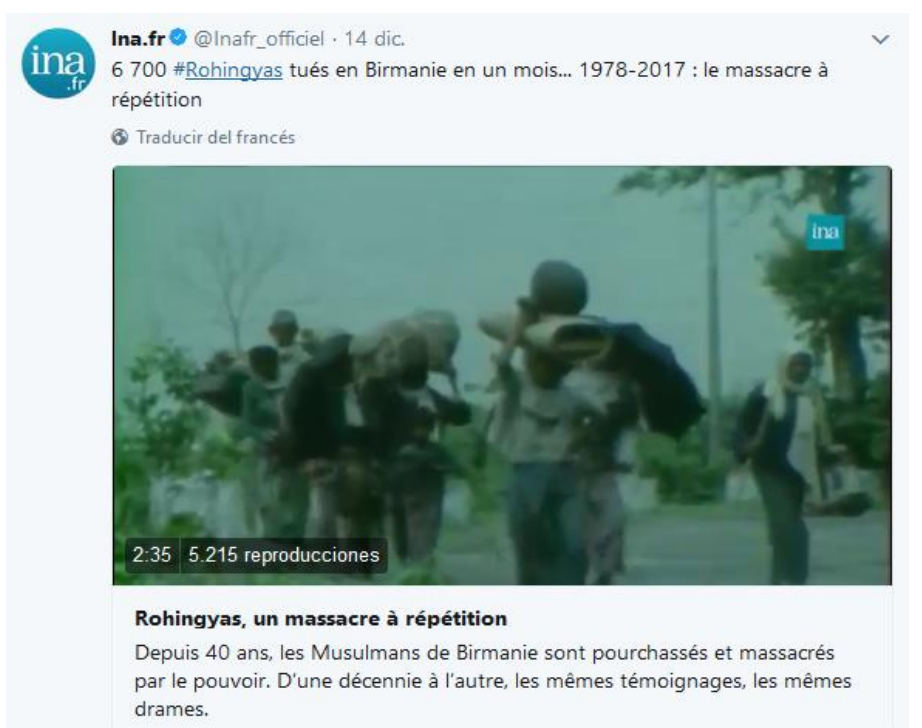

Fuente: https://twitter.com/Inafr officiel

El caso español, nuevamente es el más destacado. En los últimos años, la crisis económica ha propiciado la proliferación de programas que se elaboran principalmente utilizando las imágenes del archivo de RTVE. El caso más paradigmático sería el programa Cachitos de Hierro y Cromo. El Twitter del archivo RTVE aprovecha su emisión para, durante la semana y mediante los hashtags oportunos, recordar momentos claves de su emisión (Figura 9).

\section{Figura 9: Difusión del programa Cachitos con el hashtag \#cachitoszoo}

Archivo RTVE@@ArchivoRTVE·17 dic.

Ooooohhhh.... jEl "pavo real" de "El puma"! Uno de los exitazos del año 1981 que

puedes repasar (y bailarrrrr) aquí rtve.es/v/3665777/ \#CachitosZoo

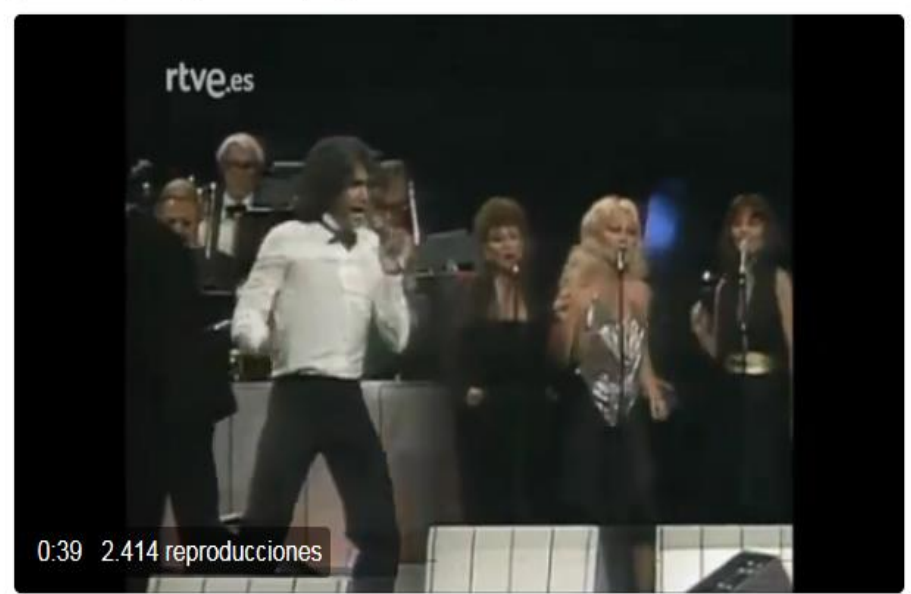

Fuente: $\underline{\text { https: / } / \text { twitter.com/archivortve?lang }=\mathrm{es}}$ 


\subsection{Contenido expandido o auxiliar (Ancillary Content)}

a) Creación de narrativas transmedia a través de: páginas propias de personajes o tramas, making of, realidad virtual, contenido histórico ad hoc para expandir la trama...

Por lo que respecta a narración transmedia entendida como contenido expandido, llama poderosamente la atención la ausencia de estrategias en este sentido, cuando podría ser un mecanismo de gran potencial para que los organismos televisivos dieran a conocer sus fondos de una manera más efectiva, sobre todo entre el público más joven. Su uso en series de ficción, por ejemplo, podría ser un escenario muy atractivo para difundir sus archivos como vienen haciendo otras instituciones patrimoniales como Biblioteca Nacional de España y Archivo Histórico Nacional con series como El Ministerio del Tiempo, Isabel o Carlos, Emperador.

En el Twitter del archivo de RTVE no se encuentran menciones ni expansiones a estas tramas que, sin embargo, sí se están llevando a cabo en las propias plataformas de difusión de este tipo series. Asimismo, como se ha mencionado, otras instituciones patrimoniales lo realizan.

Sí podemos considerar, en cierto modo, el uso de narrativas de este tipo en la selección de materiales que el INA y el Sound and Vision holandés elaboran y ponen a disposición a través de sus catálogos, y de manera gratuita, para fines educativos. En la mayoría de los casos, son productos audiovisuales, elaborados con material de sus propios archivos a los que, mediante contenido expandido, se les aporta valor añadido. Así los documentos van acompañados de guías temáticas, guías didácticas, lecciones, presentaciones y otros materiales didácticos.

El Sound and Vision cuenta además con proyectos de realidad virtual expandida como BigArtRide y de Media Art que permite a artistas jóvenes reutilizar imágenes del propio archivo para sus creaciones artísticas. 


\section{Conclusiones}

Tras el análisis realizado, puede detectarse un uso muy limitado de las estrategias transmedia por parte de los archivos analizados. Teniendo en cuenta el valor patrimonial de estos archivos como garante de la memoria colectiva, los profesionales del medio audiovisual deberían tomar conciencia de la importancia del desarrollo de estrategias de este tipo orientadas a la explotación y revalorización de sus contenidos.

Las cuatro instituciones analizadas representan diferentes estructuras en cuanto a modelos de conservación y difusión. Salvo el instituto holandés, todos ellos reutilizan su material en la categoría de acceso expandido. Si el material de archivo siempre ha sido fuente para la creación de contenidos nuevos, utilizarla bajo estrategias transmedia aumentará la visibilidad de sus fondos y un mayor engagement con los usuarios.

Se considera que los archivos audiovisuales están perdiendo una oportunidad de oro para poner en valor todos sus fondos. Como instituciones culturales que son, ofrecen contenido cultural, pero si este puede ser combinado con la creación de experiencias en una estrategia que abarque varias plataformas en una propuesta transmedia, reforzará la visión social de los archivos audiovisuales y concienciará a la población sobre la importancia de la salvaguarda de nuestro Patrimonio Audiovisual.

\section{Referencias bibliográficas}

Antón, L y Guallar, J. (2014). Análisis de los archivos audiovisuales en internet de las televisiones autonómicas españolas. Revista española de Documentación Científica, 37, 1. doi:http://dx.doi.org/10.3989/redc.2014.1.1044

Askwith, I. D. (2007). Television 2.0: reconceptualizing TV as an engagement medium. (Tesis doctoral, Massachusetts Institute of Technology). Recuperado de: http://dspace.mit.edu/handle/1721.1/41243

Bazán Gil, V. (2014). "La memoria colectiva: contenidos para el recuerdo, del archivo a la Web de RTVE. Métodos de 
información (MEI), 5, 8, p. 5-16. DOI: 10.5557//IIMEI5-N8005016

Codina, L, Aubia, L y Sánchez, N. (2008). Propuesta nuclear de análisis de sitios web de televisión. Barcelona: UPF

Caldera-Serrano, J. y Arranz-Escacha, P. (2013). Documentación audiovisual en televisión. Barcelona: Editorial UOC.

Caldera-Serrano, J y León-Moreno, J. (2016). Implicaciones de la realidad aumentada en la gestión de la información audiovisual televisiva. Journal of Information Science, vol. 42, no 5, p. 675680.

Caridad Sebastián, M.; Morales García, A.M. y García López, F. (2011). "Las políticas de información europeas como acción clave para el desarrollo de la ciencia de la información". Ciencia Da Informacao. Brasília, DF: IBICT. 40(3), p.439-459

Cordis (2005). Retrieval of television archived material using intelligent descriptors. Recuperado de:

http://cordis.europa.eu/result/rcn/80331_en.html

Cordis (2006). Commission selects 30 new eten projects.

Recuperado de:

http://cordis.europa.eu/news/rcn/26680_en.html

Cordis (2012). Networks and ontologies for the transformation and unification of broadcasting and the internet. Recuperado de: http://cordis.europa.eu/project/rcn/89494_en.html

Cordis (2017). EUROTRANSMEDIA (Gathering media clusters to bridge digital content with emerging technologies). Recuperado de: http://cordis.europa.eu/result/rcn/194555_en.html

Cordis (2017). The EU-funded SENTAB project is integrating digital technology with traditional televisions in order to prevent loneliness among senior citizens. Recuperado de: http://cordis.europa.eu/result/rcn/210723 en.html

Costa Sánchez, C. y Piñeiro Otero, T. (2012). "Nuevas narrativas audiovisuales: multiplataforma, crossmedia y transmedia. El caso de Águila Roja (RTVE)." Icono14. 10(2), p.6-28.

Dekker, S. (2014). Kamerbrief over toekomst van het publieke mediabestel. Brief van staatssecretaris Dekker (OCW) aan de Tweede Kamer over de toekomst van het publieke mediabestel. Recuperado de https://www.rijksoverheid.nl/documenten/kamerstukken/201 
4/10/13/kamerbrief-over-toekomst-vanhet-publiekemediabestel.

Eur-Lex (2008). Actividades de radiodifusión televisiva: Directiva «Televisión sin fronteras» (TSF). Recuperado de: http://eurlex.europa.eu/legalcontent/ES/TXT/?uri=LEGISSUM:124101

European Commission. Creative Europe. Recuperado de: https://eacea.ec.europa.eu/creative-europe_en

European Commission. Euscreen. Recuperado de: http://euscreen.eu/about.html

European Commission. Horizon 2020. Recuperado de:

http:/ /ec.europa.eu/research/horizon2020/index_en.cfm?pg= h2020

European Commission. Invertir en creatividad: el programa MEDIA celebra sus 25 años en el Festival de Cine de Cannes (Comunicado de prensa. Bruselas, 13 de mayo de 2016).

Recuperado de: https:/ /ec.europa.eu/digital-singlemarket/en/news/23-films-supported-creative-europe-mediascreened-cannes

Europeana. Recuperado de: https://www.europeana.eu/

Hagedoorn, B. (2015). "Towards a Participatory Memory: Multiplatform Storytelling in Historical Television Documentary". Continuum, 29(4), p.579-592

Hagedoorn, B., y Agterberg, B. (2016). "The End of the Television Archive as We Know It? The National Archive as an Agent of Historical Knowledge in the Convergence Era". Media and Communication, 4(3).

Hancox, D. (2017). "From subject to collaborator: Transmedia storytelling and social research". Convergence, 23(1), p.49-60. Hanford, A. (1986). Panorama de los archivos audiovisuales. Madrid: RTVE.

Hartley, J. (2009). TV Stories. From representation to productivity. Story Circle, en HARTLEY.J \& MCWILLIAM, K. (Coords.) Digital Storytelling Around the World. Chichester, UK: Blackwell Publishing. p.16-36

Hidalgo, P. (2013). "Prevenir la amnesia colectiva: El acceso público a los archivos de televisión”, Documentación de las Ciencias de 
Información, 36, p. 143-166.DOI: 10.5209/rev_DCIN. 2013.v36.42946.

Hidalgo, P. (2014). "El archivo de RTVV Patrimonio Audiovisual de la Humanidad”, Métodos de información: MEI, 5, 8, p.17-30. DOI:10.5557//IIMEI5-N8-017030.

Hidalgo, P. (2017). Preservación del patrimonio audiovisual de televisión. El archivo de Televisión Española (TVE): de los orígenes a la digitalización. Director: Félix del Valle Gastaminza. Tesis doctoral. Universidad Complutense de Madrid. 2015.

Jenkins, H. (2006). Convergence culture: Where old and new media collide. Nueva York: New York University Press. ISBN: 08147-4281-5

Jenkins, H. (2008). La cultura de la convergencia de los medios de comunicación. Barcelona: Paidós

Jenkins, H.; Purushotma, R.; Clinton, K.; Weigel, M. y Robison, A. (2006). Confronting the challenges of participatory culture: Media education for the 21st century. Chicago: The John D. and Catherine McArthur Foundation, Recuperado de http:/ /www.digitallearning.macfound.org/

León-Moreno, J.; Zapico-Alonso, F., y Caldera-Serrano, J. (2016). "¿Archivos audiovisuales aún sin digitalizar? seguridad, preservación y amortización”. Cuadernos de Documentació Multimedia, 27(2), p.178-190. DOI:10.5209/CDMU.54488

Martínez Cardama, S. (2017). El papel de las narrativas digitales en la difusión de instituciones culturales. En: Lo 2.0 y 3.0 como herramientas multidisciplinares. Madrid: Tecnos. Recuperado de http://www.seeci.net/cuiciid/

Morales García, A.M. (2008). La sociedad de la información: políticas y acciones en Europa. Bogotá: Rojas Eberhard Editores. p.397. ISBN: 978-958-9121-90

Orozco, G. (Coord.) (2012). Tvmorfosis: la televisión abierta hacia la sociedad de redes. México, D.F: Tintable.

Pérez, B. (2011). Fuentes para la producción audiovisual. En: Documentación Audiovisual. Madrid: Síntesis. ISBN 978-84975674-6-6, p.167-197.

Quintás, N. y González, A. (2014). “Active Audiences: Social Audience. Participation in television. Audiencias activas: 
participación de la audiencia social en la televisión". Comunicar. XXII (43), p.83-90. DOI: 10.3916/C43-2014-08

Reuters Institute. (2017) Digital News Report. Recuperado de http:/ /www.digitalnewsreport.org/

Rodríguez-Mateos, D. y Hernández-Pérez, T. (2015). "Televisión social en series de ficción y nuevos roles del documentalista audiovisual: el caso de "El Ministerio del Tiempo".

Index.Comunicación Revista Científica de Comunicación Aplicada. 5(3). p.95-120.

Sánchez Castillo, S. y Galán, E (2016). "Narrativa transmedia y percepción cognitiva en El Ministerio del Tiempo (TVE)". Revista Latina de Comunicación Social, 71, p. 508 a 526 http://www.revistalatinacs.org/071/paper/1107/27es.html DOI: 10.4185/RLCS-2016-1107

Scolari, C. (2008). "Hacia la hipertelevisión. Los primeros síntomas de una nueva configuración del dispositivo televisivo". Diálogos de la Comunicación, 77, p.1-9. Recuperado de http://goo.gl/SOlbxz

Scolari, C. (2013) Narrativas transmedia: cuando todos los medios cuentan. Barcelona: Deusto

UNESCO. Actas de la Conferencia General, 33a reunión París, 3-21 de octubre de 2005. Recuperado de: http://unesdoc.unesco.org/images/0014/001428/142825s.pdf.

UNESCO. Recomendación sobre la Salvaguardia y la Conservación de las Imágenes en Movimiento, 27 de octubre de 1980. Recuperado de: http://portal.unesco.org/es/ev.phpURL_ID=13139\&URL_DO=DO_TOPIC\&URL_SECTION $=201 . \mathrm{html}$ 


\title{
Gestión de marca corporativa online de los canales públicos de televisión en Europa. Propuesta de indicadores para su medición
}

\author{
Carmen Costa-Sánchez \\ Universidade da Coruña \\ Virginia Guarinos \\ Universidad de Sevilla
}

PARA CITAR: Costa-Sánchez, C. y Guarinos, V. (2018). Gestión de marca corporativa online de los canales públicos de televisión en Europa. Propuesta de indicadores para su medición. Revista Latina de Comunicación Social, 73, pp. 895 a 910 .

http: /www.revistalatinacs.org/073paper/1287/46es.html

DOI: http:/10.4185/RLCS-2018-1287

\section{Resumen}

Los canales de televisión públicos afrontan una triple crisis derivada de los cambios en los mercados televisivos y del cuestionamiento de su gestión y de su necesidad. Se realiza el desarrollo de la literatura científica y la propuesta de indicadores para sistematizar el análisis comparativo de gestión de la marca corporativa en el entorno online para los principales canales de televisión europeos. Se desarrollan tres indicadores sintéticos. Uno para medir y evaluar la solidez de su comunidad de seguidores online; otro para analizar el grado de transparencia en su información identitaria y de balance y un tercero para analizar el nivel de orgullo de representación generado. La arena digital 
supone un nuevo ámbito al que aplicar su estrategia de comunicación y en el que proyectar imagen. Los sistemas de medición tradicionales ya no resultan el único modo posible de analizar el cumplimiento de su misión de servicio público.

Palabras clave: Televisión pública, comunicación corporativa, comunicación online, Europa, indicadores sintéticos.

\section{Introducción. La triple crisis de la televisión pública}

T OS CAMBIOS para las industrias culturales se suceden sin tregua, 1 especialmente, desde su entrada en el contexto de la digitalización. La industria televisiva, industria clásica de flujo (Lacroix \& Tremblay, 1997), se vuelve permanente y estocable, de consumo privativo, en soportes inmateriales y con un sistema de financiación mixto (Fernández Quijada, 2007).

En el caso de las televisiones públicas, los cambios generales del sector repercuten asimismo sobre su actividad. Múltiples pantallas, televisión a la carta, aplicaciones móviles e incremento de la competencia a través del crecimiento del número de actores del sector audiovisual supone uno de los vectores de cambio al que la televisión pública no puede resistirse.

"Nuevos productores, gigantes tecnológicos y otras compañías totalmente ajenas al negocio tradicional de la televisión -Facebook, Amazon, Google, Apple o Snapchat, entre otras - han desembarcado o anunciado su llegada al mercado audiovisual para disputar el liderazgo del mercado a los radiodifusores clásicos" (Cerezo y Cerezo, 2017). Por ello, la industria orienta su futuro hacia la personalización y el consumo móvil en un mercado cada vez más fragmentado. Ésta es la primera crisis que afronta el medio televisivo, que se había convertido en el rey de las industrias culturales desde su aparición y que ve cómo Internet y los nuevos modos de consumo audiovisual le obligan a revalidar el título de hijo predilecto de los hogares europeos. La segunda oleada de OTTs refrenda el contexto de cambio que vive la televisión tradicional como medio. 
La consecuencia ha sido evidente para unos canales públicos que partieron de una posición ventajosa en términos de competencia: la fragmentación de las audiencias, así como el surgimiento de nuevos perfiles de consumo televisivo, usuarios jóvenes, que practican patrones de consumo personalizados. "La digitalización de los procesos, la atomización de las audiencias, la multiplicación de la oferta de libre acceso mediante la TDT y la consolidación de Internet y los nuevos medios como dispositivos de consumo conducen hacia una nueva etapa en la dinámica y el alcance de la televisión pública" (Manfredi, 2011:51).

En segundo lugar, la crisis económica ha afectado gravemente a las economías europeas desde el año 2008, en mayor o menor medida. La limitación de los presupuestos públicos crea la sombra de duda sobre la necesidad de una televisión pública que pasa a requerir justificarse ante la sociedad. Las entidades de titularidad pública procuran explicarse a la sociedad asumiendo que el foco de atención también está puesto sobre ellas (López \& Manfredi, 2013).

La apuesta por la transparencia ha sido, en este sentido, un denominador común en términos comunicativos, en aras de recuperar la confianza de una ciudadanía marcada por los recortes y las dificultades económicas (López López et al., 2017). El cuestionamiento privado y político de su sistema de financiación pública ha obligado a las respectivas corporaciones a incrementar sus niveles de transparencia sobre el destino de los fondos y a la necesidad de mejorar su reputación (Fernández y Campos, 2013).

En tercer lugar, y ligado a lo anterior, encontramos la revalidación de su legitimidad, tras la puesta en cuestionamiento intermitente acerca de su credibilidad. Se necesitan argumentos en pro de su actividad y de la continuidad del modelo (con o sin variaciones), lo que supone hablar de valor añadido en el servicio que prestan y en la imagen que proyectan ante los ciudadanos.

Este conjunto de elementos enmarca y condiciona la necesidad de imagen positiva para los canales de televisión públicos europeos y subraya tres líneas de actividad fundamentales: 
- La necesidad de conectar desde todos los canales. Ya no basta con llegar a una audiencia tradicional, sino que deben manejarse y gestionarse flujos comunicativos en todas las plataformas. La creación de una comunidad online, algo a lo que aspiran marcas de muy distintos sectores, equivale a la creación de una comunidad de seguidores, que respeta y/o estima a la marca televisiva, lo que supondría su respaldo y su recomendación ante otros usuarios potenciales del servicio.

Como recogen Vila-López y Küster-Boluda (2013), a las cadenas televisivas les interesa desarrollar una marca reputada que abrace todos los productos que oferta para lograr elevadas audiencias, y, por otra parte, conseguir el desarrollo de una actitud favorable hacia la aceptación de nuevos productos que la cadena introduzca en el futuro (Alessandri, 2009).

- La necesidad de transparencia para explicar su identidad, su adecuada gestión y persuadir sobre su necesidad en el contexto actual. Transparencia es, en el fondo, sinónimo de predisposición a explicarse, a comunicar en un sentido proactivo sobre todos los aspectos fundamentales de su gestión que puedan interesar a los ciudadanos.

- La necesidad de diferenciarse y singularizarse para que el modelo siga teniendo razón de ser en la actualidad, para crear una marca valiosa para la ciudadanía en términos de orgullo de pertenencia o de representación y, en este caso, de disponer de una programación pública de calidad, que cumpla una función real de servicio público y que conecte con las necesidades de los ciudadanos.

\section{Metodología}

El objetivo del presente trabajo es el de proponer una serie de indicadores compuestos que permitan sistematizar el análisis sobre la gestión de la marca corporativa online de las televisiones públicas europeas. Se prioriza el entorno europeo por ser próximo, cultural y socialmente, al español y continuar la línea de estudios desarrollada en trabajos previos (Costa-Sánchez \& Túñez-López, 2017) limitándonos al ámbito de la digitalización. Además, la construcción de indicadores 
favorece la finalidad comparativa y de benchmarking que deben perseguir análisis de esta índole. Los indicadores compuestos (IC) han sido definidos como aquellas medidas cuantitativas o cualitativas derivadas de una serie de hechos observados que pueden revelar posiciones relativas en un ámbito determinado (OECD, 2008).

Debe tenerse en cuenta que la monitorización y medición de la reputación ha sido, y continúa siendo, objeto de debate entre los estudiosos de la Comunicación Corporativa y aún entre sus profesionales (Castelló-Martínez et al., 2014; Pérez Sampol et al., 2015). No obstante, la presente propuesta pretende contribuir a desarrollar un método de análisis y reflexión que ayude a las televisiones públicas a determinar su situación actual y animar a la correspondiente toma de decisiones.

Escasos estudios previos han abordado la gestión de marca y reputación desde las entidades televisivas. Para Förster (2015), la promesa de marca (que ha de ser verbalizada mediante un claim) y una apuesta estratégica fuerte y diferenciable son factores decisivos de éxito. La autora revisa, en dicho estudio comparativo, tres tipos de instrumentos de comunicación de las televisiones: diseño corporativo, comunicación on-air y comunicación off-air. Sin embargo, en un contexto altamente digital, las organizaciones televisivas se constituyen asimismo como marcas online en las que los medios propios (web corporativa y social media) representan vectores comunicativos de alto impacto para fortalecer y mejorar las relaciones con las audiencias, que ya no son exclusivamente televisivas, sino también usuarias de dispositivos móviles, de la Red y de las redes.

En la primera parte de este estudio, siguiendo el proceso recomendado para la creación de IC (OECD, 2008) se procede a la revisión de la literatura científica que avale el uso de indicadores simples. Los indicadores propuestos se testearán para las principales televisiones públicas europeas, que en una muestra intencional ha sido conformada por las televisiones públicas de los mercados europeos más importantes de nuestro entorno: RTVE (España), RTP (Portugal), France Télévisions (Francia), BBC (Reino Unido), RAI (Italia), ARD, ZDF (Alemania). 


\section{Propuesta de indicadores}

Como se ha explicado al inicio de este análisis, las necesidades de las televisiones públicas en el contexto actual en el marco de la gestión de la marca online, se resumen, fundamentalmente, en: 1) creación de una comunidad online; 2) comunicar su identidad y ser transparente con respecto a su gestión y 3) fomentar el orgullo de representación de todos sus ciudadanos. Como explican Avery y Own (1999), las empresas públicas televisivas de radiodifusión vienen realizando desde mediados de los noventa verdaderos esfuerzos por construir fuertes reputaciones de marca, sobre una plataforma de posicionamiento basado en el valor y en la calidad, pues, en el caso de las cadenas públicas, existe una creciente preocupación por mostrarse como instituciones educativas y culturales de alta reputación. La digitalización traslada el reto a la arena online en la que los canales de comunicación se incrementan y potencialmente favorecen relaciones dialógicas con los públicos (Grunig, 2009; McNamara, 2010).

\subsection{Creación de una comunidad online}

Los cambios tecnológicos y sociales han originado una evolución hacia herramientas participativas en el contexto de la Web 2.0, por lo que las organizaciones necesitan adaptarse. "Frente a la Web 1.0 estática y centrada en la información, este nuevo concepto de Web [la 2.0] está enfocada en el usuario y en aquellas herramientas de creación, producción y difusión de contenidos por parte de una comunidad de interagentes" (Costa-Sánchez, Piñeiro-Otero, 2012: 186). Del modelo 1.0 al 2.0, la web de las organizaciones deja de ser unidireccional y los espacios para las relaciones con los públicos ya no tienden a ser un tablón de anuncios o de comunicados de prensa que se han mandado previamente, sino que pasan a permitir la interacción y participación de los usuarios. Por otra parte, los ámbitos online y offline se configuran como un continuo sobre los que transmitir intangibles positivos vinculados a la entidad. La reputación y la proyección de identidad ha de trabajarse también en el entorno online (Aced, 2013).

En el nuevo contexto, los usuarios se han empoderado y plantean como una necesidad el poder dialogar con las organizaciones de igual a igual. Es habitual ver consultas o críticas en las plataformas de los social media de empresas e instituciones, que deben dar respuesta a cada 
uno de sus efectivos o potenciales clientes. Para ello nacen nuevos perfiles profesionales como el community manager. "Los CM [community manager] escuchan a las comunidades online, se relacionan con ellas en nombre de las organizaciones, trasladan a la compañía lo que se dice de ella en el mundo digital para identificar amenazas u oportunidades, e integran estos espacios en las estrategias de negocio de la empresa", explica Silva Robles (2012: 198).

Se trata también de usuarios más creativos, a los que les gusta participar y utilizar las nuevas herramientas para interactuar, jugar o crear contenidos. Son los llamados prosumers (Toeffler, 1981), un perfil de público al que las organizaciones no pueden ignorar, sino que deben ofrecerle experiencias y contenidos de interés. "Debemos reconocer a los prosumidores como los actores comunicativos de la sociedad de la ubicuidad", concluye Islas (2008: 76).

El nuevo reto consiste en captar la atención de los usuarios y lograr su engagement, es decir, convertirlos en aliados de la marca y de la entidad. "Hay que gestionar bien la comunicación, para que el mensaje llegue a los stakeholders y estos lo reconozcan y puedan devolver valor a la organización en forma de confianza, credibilidad y fidelidad, en definitiva: en forma de reputación" (Carrillo, Castillo y Tato, 2008: 255).

En este sentido necesita conocerse, en primer término, el número de seguidores de la entidad televisiva en las redes sociales para conocer cómo de amplia es su potencial comunidad en la Red. Por supuesto, se trata de un indicador básico, que apunta al grado de interés inicial que genera su conversación en social media, pero que habría que tener en cuenta en un primer término. En este sentido, los datos sobre número de seguidores o comunidad en las redes avalan la buena posición de la BBC frente a la negativa situación de France Télévisions, en un abanico de opciones en el que Facebook y Twitter se presentan como los buques insignia de la presencia en medios sociales. 
Tabla 1. Síntesis comparativa de comunidad potencial online de los principales canales públicos europeos.

\begin{tabular}{|l|r|r|r|r|r|}
\hline \multirow{2}{*}{ CANAL } & \multicolumn{1}{|l|}{$\boldsymbol{F} \boldsymbol{b}$} & \multicolumn{1}{c|}{$\boldsymbol{Y} \boldsymbol{t} \boldsymbol{b}$} & \multicolumn{1}{l}{ Link } & \multicolumn{1}{l|}{$\boldsymbol{I n}$} \\
\hline ARD & 216.663 & $469 \mathrm{~K}$ & 303.908 & - & $17 \mathrm{k}$ \\
\hline BBC & 41.561 .210 & $8.37 \mathrm{M}$ & 1.341 .402 & 773.973 & $100 \mathrm{~K}$ \\
\hline FT & 91.573 & $162 \mathrm{~K}$ & 133.668 & 27.829 & $11,1 \mathrm{~K}$ \\
\hline RAI & 372.531 & $72.1 \mathrm{M}$ & 1.454 .268 & 39.733 & $93 \mathrm{~K}$ \\
\hline RTP & 455.673 & $461 \mathrm{~K}$ & 470.981 & 11.172 & $30,9 \mathrm{~K}$ \\
\hline RTVE & 611.334 & $1.04 \mathrm{M}$ & 208.205 & 4.138 & $29 \mathrm{k}$ \\
\hline ZDF & 584.366 & $1.1 \mathrm{M}$ & 91.302 & 7.799 & - \\
\hline
\end{tabular}

Fuente: Elaboración propia

Otro indicador simple es el del posicionamiento web. Conocer qué puesto ocupa la web corporativa en los rankings nacionales e internaciones supone reconocer su grado de referencialidad. Como fuente de los datos puede emplearse Alexa para la comparativa tanto nacional como internacional.

Tabla 2. Síntesis comparativa del posicionamiento de la web en el ranking internacional

\begin{tabular}{|c|c|c|c|c|c|}
\hline & $\begin{array}{l}\text { Global } \\
\text { rank }\end{array}$ & Visitors & $\begin{array}{l}\text { Bounce } \\
\text { rank }\end{array}$ & Pags. & Time \\
\hline ARD & 7.907 & $13,5 \mathrm{M}$ & 56,77 & 2,22 & $2: 20$ \\
\hline BBC & 1.332 & $444,0 \mathrm{M}$ & 60,56 & 2,42 & $2: 47$ \\
\hline FT & 92.164 & $1020 \mathrm{M}$ & 72,43 & 1,54 & 0.51 \\
\hline RAI & 3.939 & $13,84 \mathrm{M}$ & 52,26 & 6,98 & 8:49 \\
\hline RTP & 14.099 & $7,78 \mathrm{M}$ & 60,10 & 2.66 & $3: 19$ \\
\hline RTVE & 2.941 & $31,21 \mathrm{M}$ & 44,18 & 2.85 & $3: 18$ \\
\hline ZDF & 2.421 & $34.88 \mathrm{M}$ & 45,43 & 2,88 & 3,17 \\
\hline
\end{tabular}

Fuente: Alexa. Elaboración propia

En tercer lugar, ha de medirse el empleo relacional o dialógico de las plataformas promovidas para las relaciones con los públicos en el entorno online. Algunas herramientas permiten monitorizar y 
cuantificar dicha cuestión en términos comparativos. Algunos KPIs utilizables que permiten la comparativa de las páginas de Facebook son el índice de rendimiento de la página, la evolución semanal, el número de likes/comentarios/veces compartida o el engagement por post.

Tabla 3. Propuesta de indicadores de las páginas de Facebook

\begin{tabular}{|l|r|r|r|}
\hline & $\begin{array}{c}\text { Índice de } \\
\text { rendimiento de } \\
\text { la página }\end{array}$ & $\begin{array}{c}\text { Evolución } \\
\text { semanal }\end{array}$ & Compromiso \\
\hline ARD & $21 \%$ & $0,23 \%$ & $0,93 \%$ \\
\hline BBC News & $16,0 \%$ & $0,16 \%$ & $0,74 \%$ \\
\hline $\begin{array}{l}\text { France } \\
\text { Télévisions }\end{array}$ & $6,0 \%$ & - & $0,04 \%$ \\
\hline RTP & $6,0 \%$ & $0,07 \%$ & $0,22 \%$ \\
\hline RTVE & $7,0 \%$ & $0,06 \%$ & $0,35 \%$ \\
\hline Rai1 & $23 \%$ & $0,3 \%$ & $0,82 \%$ \\
\hline ZDF & $10 \%$ & $0,13 \%$ & $0,33 \%$ \\
\hline
\end{tabular}

Fuente: Fanpage Karma. Elaboración propia

Tabla 4. Propuesta de indicadores de las páginas de Facebook

\begin{tabular}{|l|r|r|r|}
\hline & Engagement & Engagement/post & Comentarios \\
\hline ARD & $0,6938 \%$ & $0,0879 \%$ & 10.984 \\
\hline BBC News & $0,394 \%$ & $0,0285 \%$ & 462.911 \\
\hline $\begin{array}{l}\text { France } \\
\text { Télévisions }\end{array}$ & $0,0569 \%$ & $0,032 \%$ & 103 \\
\hline RTP & $0,2094 \%$ & $0,0229 \%$ & 2.627 \\
\hline RTVE & $0,2 \%$ & $0,0187 \%$ & 2.382 \\
\hline Rai1 & $0,6941 \%$ & $0,1731 \%$ & 6.487 \\
\hline ZDF & $0,2675 \%$ & $0,0278 \%$ & 8.817 \\
\hline
\end{tabular}

Fuente: Like Inspector. Elaboración propia

En el caso de Twitter, pueden combinarse datos de sentimiento, posicionamiento en ranking de influencia o su grado de interés para los seguidores de las cuentas de los canales públicos televisivos. La 
combinación de indicadores simples permitirá resultados más certeros en términos de relaciones 2.0 con la comunidad.

Tabla 5. Propuesta de indicadores de los perfiles de Twitter

\begin{tabular}{|c|c|c|c|}
\hline & $\begin{array}{l}\text { Positivity } \\
\text { Score }\end{array}$ & Retweetrank & $\begin{array}{c}\text { Listed/1.000 } \\
\text { followers }\end{array}$ \\
\hline ARD & -43 & 108.032 & 3 \\
\hline BBC News & -27 & 2.618 & 4 \\
\hline $\begin{array}{l}\text { France } \\
\text { Télévisions }\end{array}$ & +2 & 109.310 & 7 \\
\hline RTP & -14 & 16.171 & 2 \\
\hline RTVE & -11 & 89.509 & 12 \\
\hline Rai1 & +9 & 108.032 & 1 \\
\hline ZDF & -42 & 97.271 & 4 \\
\hline
\end{tabular}

Fuentes: TweetAnalyzer, retweetrank, twitonomy

\subsection{Comunicar identidad de forma transparente}

La identidad corporativa es un concepto complejo, suma del comportamiento, la comunicación y el simbolismo que definen a una organización (Van Riel, 1997). Es su personalidad, el conjunto de señales que ésta envía a la sociedad como elementos que la identifican (Chaves, 2005). Las estrategias de las organizaciones actuales han pasado de estar centradas en el producto a pivotar sobre las relaciones con los públicos, por lo que la identidad del emisor ha cobrado valor (Túñez, 2011). Según Capriotti (1999), la Identidad Corporativa representa el conjunto de características centrales, perdurables y distintivas de una organización, con las que la propia organización se autoidentifica (a nivel introspectivo) y se autodiferencia (de las otras organizaciones de su entorno).

Resulta habitual la confusión entre la identidad corporativa y la identidad visual corporativa, pero esta última solo es una parte de aquella, su plasmación gráfica en una serie de signos, símbolos y/o colores con los que la organización se identifica. El concepto de identidad corporativa es más amplio e incluye lo que la organización es (incluidos su misión, visión y valores), su actividad (lo que hace) y cómo 
lo hace (estilo de gestión, cultura corporativa, liderazgo, Responsabilidad Social Corporativa o RSC, etc.).

La identidad está conformada por los actuales atributos de la organización, los que incluyen: su propiedad, el estilo de liderazgo en la gestión, la estructura organizacional, las actividades de negocio y los mercados donde tiene presencia, la variedad y calidad de los productos y servicios que oferta, así como el conjunto de los elementos de negocio. Se acompaña además del conjunto de valores compartidos por la gestión y los empleados (Balmer and Greyser, 2003).

Melewar y Woolridge (2001) identifican seis dimensiones básicas del concepto de identidad corporativa: quién o qué es la organización, hacia dónde va, en qué se diferencia de otras organizaciones, lo que hace, cómo gestiona su actividad y aquello que defiende.

Simoes et al. (2005) se centraron en los elementos controlables de la Identidad Corporativa (IC) y definieron la gestión de la misma como las actividades que la organización desarrolla deliberadamente para mejorar su imagen respecto de las audiencias externas e internas.

La definición de la misión, visión y valores supone el corazón de la identidad de cualquier organización. Le permite hacer consciente su autoconcepción, sus aspiraciones y los principios que guían su actuación. El repaso a las webs corporativas de los principales canales europeos permite observar denominadores comunes y singularidades en todos ellos. Mientras algunos canales mantienen la fórmula clásica de definición del servicio público televisivo en informar, formar y entretener (RTP, BBC, ARD), otros añaden líneas estratégicas específicas. Así, cabe destacar cómo la RAI subraya la importancia de la representación adecuada y respetuosa de la mujer, o la televisión portuguesa destaca la apuesta por la proximidad llevada a su eslogan de marca: Sempre ligados.

No obstante, en algunos casos se difumina la explicación expresa de la identidad corporativa o de alguno de sus componentes. La explicación de la visión que tienen de sí mismas no aparece tan claramente representada y, en muchos casos, se confunde con la misión. Sin embargo, la visión sintetiza los objetivos de la organización a medio plazo; por lo tanto, resulta una herramienta útil como hoja de ruta de 
la estrategia de la organización. La BBC, por ejemplo, establece como visión la de convertirse en la organización más creativa del mundo, lo que condiciona a la entidad a ser innovadora de forma permanente, a diferenciarse y a destacar de forma diferenciada con respecto a otros canales televisivos. Teniendo de su lado el bagaje de la tradición, resulta llamativo que sea la creatividad su apuesta de futuro.

En este sentido pueden operacionalizarse los siguientes indicadores: (1) Enunciación de misión; (2) enunciación de visión; (3) enunciación de valores y (4) Líneas estratégicas identitarias.

\section{Tabla 6. Palabras clave de la misión, visión y valores enunciados por las televisiones públicas europeas}

\begin{tabular}{|c|c|c|c|}
\hline & Misión & Visión & Valores \\
\hline RTVE & $\begin{array}{ll}\text { - } & \text { Servicio público } \\
\text { - } & \text { Información } \\
\text { rigurosa, } \\
\text { independiente y } \\
\text { plural } \\
\text { - Entretenimiento } \\
\text { de calidad } \\
\text { - } \text { Debate, } \\
\text { innovación y } \\
\text { creación } \\
\text { - } \text { Artes, ciencia } \\
\text { cultura } \\
\text { - Cohesión y } \\
\text { participación }\end{array}$ & $\begin{array}{ll}\text { - } & \text { Medio de referencia } \\
& \text { en España } \\
\text { - } & \text { Acontecimientos } \\
& \text { sociales relevantes } \\
\text { - } & \text { Variedad nacional e } \\
& \text { internacional } \\
\text { - } & \text { Profesionalidad } \\
\text { - } & \text { Valores } \\
& \text { constitucionales }\end{array}$ & $\begin{array}{ll}\text { - } & \text { Libertad } \\
\text { - } & \text { Igualdad } \\
\text { - } & \text { Pluralismo } \\
\text { - } & \text { Tolerancia } \\
\text { - } & \text { Democracia }\end{array}$ \\
\hline RTP & $\begin{array}{ll}\text { - } & \text { Servicio público } \\
\text { - } & \text { Calidad y } \\
& \text { diversidad de } \\
& \text { oferta } \\
\text { - } & \text { Referencia } \\
\text { - } & \text { Informa, forma, } \\
& \text { entretiene } \\
\text { - } & \text { Proximidad } \\
\text { - } & \text { Cohesión } \\
& \text { nacional }\end{array}$ & & \\
\hline ARD & $\begin{array}{ll}\text { - } & \text { Independiente } \\
\text { - } & \text { Informar } \\
\text { - } & \text { Educar } \\
\text { - } & \text { Entretener } \\
\text { - } & \text { Plural } \\
\text { - } & \text { Vida cultural }\end{array}$ & & $\begin{array}{l}\text { - Representatividad } \\
\text { - Pluralismo } \\
\text { - Calidad }\end{array}$ \\
\hline
\end{tabular}




\begin{tabular}{|c|c|c|c|}
\hline & $\begin{array}{ll}\text { - } & \text { Calidad } \\
\text { - } & \text { Profesionalidad }\end{array}$ & & \\
\hline France tv & $\begin{array}{ll}\text { - } & \text { Servicio público } \\
\text { - } & \text { Espectador } \\
\text { - } & \text { Información } \\
\text { - } & \text { Educación } \\
\text { - } & \text { Debate } \\
& \text { democrático } \\
\text { - } & \\
\end{array}$ & & $\begin{array}{ll}\text { - } & \text { Independencia } \\
\text { - } & \text { Universalidad } \\
\text { - } & \text { Innovación } \\
\text { - } & \text { Modernidad } \\
\text { - } & \text { Fiabilidad } \\
\text { - } & \text { Credibilidad } \\
\text { - } & \text { Diversidad } \\
\end{array}$ \\
\hline $\mathrm{BBC}$ & $\begin{array}{ll}\text { - } & \text { Información } \\
\text { - } & \text { Educación } \\
\text { - } & \text { Entretenimiento }\end{array}$ & $\begin{array}{l}\text { - Organización más } \\
\text { creativa }\end{array}$ & $\begin{array}{ll}\text { - } & \text { Independencia } \\
\text { - } & \text { Imparcialidad } \\
\text { - } & \text { Honestidad } \\
\text { - } & \text { Calidad } \\
\text { - } & \text { Creatividad } \\
\text { - } & \text { Respeto } \\
\text { - } & \text { Diversidad } \\
\text { - } & \text { Trabajo }\end{array}$ \\
\hline RAI & $\begin{array}{ll}\text { - } & \text { Calidad } \\
\text { - } & \text { Respeto } \\
\text { - } & \text { UE } \\
\text { - } & \text { mujer } \\
\text { - } & \text { dignidad } \\
\text { - } & \text { desarrollo } \\
& \text { crítico } \\
\text { - } & \text { cultura, } \\
& \text { creatividad, } \\
& \text { educación } \\
\text { - } & \text { patrimonio } \\
\text { - } & \text { política } \\
\text { - } & \text { familia } \\
\text { - } & \text { pluralidad } \\
\text { - } & \text { eficiencia }\end{array}$ & & $\begin{array}{ll}\text { - } & \text { Coherencia } \\
\text { - } & \text { Transparencia } \\
\text { - } & \text { Honestidad } \\
\text { - } & \text { Observancia de la ley } \\
\text { - } & \text { Pluralismo } \\
\text { - } & \text { Profesionalidad } \\
\text { - } & \text { Responsabilidad } \\
\text { - } & \text { Lealtad }\end{array}$ \\
\hline
\end{tabular}

Fuente: Webs corporativas. Elaboración propia

Por otra parte, la propia arquitectura de la web corporativa envía mensajes sobre la concepción del canal televisivo de temas clave vinculados a su identidad y a la forma de entender su función de servicio público. En este sentido, el análisis comparativo de los principales canales europeos muestra apuestas estratégicas bien diferenciadas. Mientras la BBC crea un apartado completo sobre la organización y toda la información se organiza en base a dos elementos fundamentales (quiénes somos y cómo trabajamos), la RAI diseña una web corporativa donde el apartado vehicular es la transparencia, del 
que hacen depender todo lo demás. La portuguesa, RTP, por su parte, vincula la transparencia al apartado legal.

Tampoco las audiencias tienen la misma importancia en el conjunto de webs analizadas. En la web francesa se encuentra mayor espacio y mayor detallada la información y el compromiso del canal con sus audiencias, mientras, por ejemplo, la web italiana o la portuguesa no visibilizan ningún apartado específico.

En cuanto a los informes y memorias de responsabilidad social, es quizás la web británica la que ofrece información más detallada a este respecto categorizada y segmentada además en relación a los públicos a los que afecta. Otros indicadores a tener en cuenta son: el alcance (hasta cuando son consultables dichas memorias e informes), el acceso (la organización de los contenidos de la web debe facilitar un acceso rápido y fácil), o el grado de divulgación, que afecta a la facilidad de comprensión de la información proporcionada, de modo que los documentos se presenten y se redacten de un modo comprensible y visualmente atractivo.

\section{Tabla 7. Organización de la información identitaria en las webs corporativas}

\begin{tabular}{|c|c|c|c|c|}
\hline & $\begin{array}{c}\text { IDENTIDAD } \\
\text { CORPORATIVA }\end{array}$ & $\begin{array}{c}\text { RSC/ } \\
\text { SOSTENIBILIDAD }\end{array}$ & TRANSPARENCIA & AUDIENCIAS \\
\hline RTVE & $\begin{array}{l}\text { RTVE } \\
\text { Corporación.- } \\
\text { Sobre nosotros }\end{array}$ & $\begin{array}{l}\text { RTVE } \\
\text { Corporación.-RC.- } \\
\text { Memoria de } \\
\text { servicio público y } \\
\text { responsabilidad } \\
\text { social (hasta 2013) }\end{array}$ & $\begin{array}{l}\text { RTVE } \\
\text { Corporación.- } \\
\text { Transparencia } \\
\text { (información } \\
\text { institucional, } \\
\text { económica y de } \\
\text { relevancia jurídica) }\end{array}$ & $\begin{array}{l}\text { RTVE } \\
\text { Corporación.- } \\
\text { Transparencia.- } \\
\text { Oficina del } \\
\text { defensor } \\
\text { (defensor del } \\
\text { espectador). }\end{array}$ \\
\hline RTP & $\begin{array}{l}\text { A RTP.- } \\
\text { Organigrama, } \\
\text { historia y } \\
\text { misión }\end{array}$ & $\begin{array}{l}\text { Quadro legal.- } \\
\text { Relatorio de } \\
\text { sustentabilidade } \\
\text { (hasta 2014) }\end{array}$ & $\begin{array}{l}\text { Quadro legal. - } \\
\text { Plano de } \\
\text { prevençao de } \\
\text { riscos de } \\
\text { corrupçao } \\
\text { Quadro legal. - } \\
\text { Código ético } \\
\text { Quadro legal.- } \\
\text { Informaçao } \\
\text { financeira }\end{array}$ & $\begin{array}{l}\text { Ningún } \\
\text { apartado } \\
\text { específico }\end{array}$ \\
\hline ARD & $\begin{array}{l}\text { Intern.ARD.de. } \\
\text { - Esto es la } \\
\text { ARD }\end{array}$ & $\begin{array}{l}\text { Responsabilidad } \\
\text { Social Corporativa }\end{array}$ & $\begin{array}{l}\text { Datos financieros } \\
\text { y memorias } \\
\text { anuales }\end{array}$ & $\begin{array}{l}\text { Defensor de la } \\
\text { audiencia }\end{array}$ \\
\hline
\end{tabular}




\begin{tabular}{|l|l|l|l|l|}
\hline FranceTV & $\begin{array}{l}\text { Grupo.- } \\
\text { Historia y } \\
\text { misión }\end{array}$ & $\begin{array}{l}\text { Acciones.- } \\
\text { Responsabilidad } \\
\text { Social y } \\
\text { medioambiental } \\
\text { (informe de } \\
\text { emisiones 2014) }\end{array}$ & $\begin{array}{l}\text { Grupo.- Informe } \\
\text { anual 2015 } \\
\text { (cuentas, cadenas, } \\
\text { audiencias, } \\
\text { programación, } \\
\text { recursos humanos } \\
\text { y gestión) }\end{array}$ & $\begin{array}{l}\text { FranceTelevisio } \\
\text { ns\&Vous.- Es } \\
\text { el apartado más } \\
\text { amplio } \\
\text { dedicado a los } \\
\text { telespectadores } \\
\text { (club, consejo } \\
\text { consultivo, etc.) }\end{array}$ \\
\hline BBC & $\begin{array}{l}\text { About the } \\
\text { BBC.- INside } \\
\text { the BBC.- Who } \\
\text { we are (valores } \\
\text { e historia) }\end{array}$ & $\begin{array}{l}\text { About the BBC.- } \\
\text { Inside the BBC.- } \\
\text { How we work.- } \\
\text { Corporate } \\
\text { Responsability // } \\
\text { Sustainability }\end{array}$ & $\begin{array}{l}\text { About the BBC.- } \\
\text { Inside the BBC.- } \\
\text { How we work.- } \\
\text { Accountability.- } \\
\text { BBC Annual } \\
\text { Report and } \\
\text { Accounts 2015/16 }\end{array}$ & $\begin{array}{l}\text { About the } \\
\text { BBC.- Inside } \\
\text { the BBC.- How } \\
\text { we work.- } \\
\text { Accountability.- } \\
\text { Audience } \\
\text { information }\end{array}$ \\
\hline RAI & $\begin{array}{l}\text { Rai per la } \\
\text { transparenza.- } \\
\text { Misión, } \\
\text { organigrama, } \\
\text { historia }\end{array}$ & $\begin{array}{l}\text { Sin apartado } \\
\text { específico }\end{array}$ & $\begin{array}{l}\text { Toda la web bajo } \\
\text { la etiqueta de } \\
\text { transparencia (web } \\
\text { independiente) } \\
\text { Incluye apartado } \\
\text { específico de } \\
\text { Anticorrupción. }\end{array}$ & $\begin{array}{l}\text { Sin apartado } \\
\text { específico. }\end{array}$ \\
& & &
\end{tabular}

Fuente: Costa-Sánchez \& Túñez-López, 2017

\subsection{Singularización y orgullo de representación}

La necesidad de diferenciarse en un entorno cada vez más competitivo puede suponer un reto para unas televisiones públicas que, tradicionalmente, han sido privilegiadas en términos de acceso, infraestructuras y recursos. Por otra parte, supone asumir su identidad como organizaciones de servicio público con una apuesta que sume una programación de calidad (ámbito profundamente abordado por los estudiosos de la comunicación), una gestión de comunidad online que aporte valor añadido y el orgullo de representación de los ciudadanos, a quien, en última instancia, como toda entidad pública, se deben.

En este sentido, pueden tomarse los datos de Klout como indicadores de influencia en redes de cada uno de los canales analizados.

\section{Tabla 8. Klout score de los canales públicos analizados (sobre 100)}

\begin{tabular}{|l|l|l|}
\hline Canal & Klout score & Ranking \\
\hline ARD & 73 & 5 \\
\hline
\end{tabular}




\begin{tabular}{|l|l|l|}
\hline BBC News & 99 & 1 \\
\hline France Télévisions & 80 & 3 \\
\hline RTP & 62 & 7 \\
\hline RTVE & 86 & 2 \\
\hline Rai1 & 71 & 6 \\
\hline ZDF & 74 & 4 \\
\hline
\end{tabular}

Fuente: Klout. Elaboración propia

También pueden tomarse indicadores sociológicos sobre la aceptación por el público de la estrategia programática planteada desde los canales televisivos europeos que revelarían su grado de respaldo por sus audiencias prioritarias.

En este sentido, en España, el Estudio n 3145 Postelectoral Elecciones Generales 2016 (CIS, 2016) arrojaba un indicador sobre el lugar de TVE en la elección por los ciudadanos a la hora de seguir información política y electoral, lo que puede considerarse sinónimo de su grado de referencialidad como medio informativo para la sociedad española. El medio público era elegido en segundo lugar, por detrás del canal privado La Sexta, lo que supone un dato negativo para el canal que aspira a ser el referente informativo de la sociedad española.

\section{Tabla 9. Cadena de tv preferida para seguir la información política y electoral (2016)}

\begin{tabular}{|l|r|}
\hline Canal & $\mathbf{\%}$ \\
\hline TVE1 & 19,2 \\
\hline TVE2 & 0,3 \\
\hline Antena 3 & 17,9 \\
\hline Cuatro & 5,7 \\
\hline Telecinco & 15 \\
\hline La Sexta & 20 \\
\hline
\end{tabular}

Fuente: CIS. Elaboración propia

En la medición de dicha dimensión, pueden tenerse en cuenta indicadores de audiencia generales (que responderían a la pregunta de si el canal de televisión es referente en términos de programación) o 
específicos (que permitirían conocer si lo es en lo referente a la misión informativa).

El balance de audiencias español de 2017 (Barlovento, 2018) muestra que La1 ha sido la tercera opción de las audiencias en España por detrás de las dos principales cadenas privadas, Telecinco y Antena3. En el terreno de los informativos, La1 se ha disputado el liderazgo en informativos con Telecinco, lo que tampoco la consolida como claro referente en los hábitos informativos de la sociedad española.

Los datos de las audiencias online de las webs corporativas también resultan un indicador de utilidad. Según la última oleada del EGM en España (AIMC, 2018), la web de RTVE figura en el séptimo lugar en el ranking de las marcas periodísticas online más consultadas en nuestro país por detrás de medios deportivos y generalistas, incluidas cadenas televisivas privadas (en concreto, Antena 3).

Tabla 10. Visitantes únicos de las marcas periodísticas en España

\begin{tabular}{|l|r|}
\hline Marca periodística online & $\begin{array}{r}\text { Visitantes únicos } \\
\text { (miles) }\end{array}$ \\
\hline Elpais.com & 5.677 \\
\hline Marca.com & 4.395 \\
\hline Lavanguardia.com & 2.378 \\
\hline As.com & 2.356 \\
\hline Antena3.com & 1.858 \\
\hline 20minutos.es & 1.726 \\
\hline Rtve.es & 1.494 \\
\hline Elperiodico.com & 1.422 \\
\hline Lasexta.com & 1.365 \\
\hline Sport.es & 1.236 \\
\hline
\end{tabular}

Fuente: AIMC (2018). Elaboración propia

\subsection{Indicadores sintéticos}

A raíz de lo expuesto, se recomienda la construcción de indicadores que permitan la síntesis comparativa de los principales retos que se les plantean a las marcas televisivas públicas en Europa. 
En primer lugar, un indicador de comunidad online (I. Comunidad), que determinaría el grado de solidez de las relaciones entre la televisión pública y los usuarios, a raíz de los indicadores simples:

- Alcance potencial

- Ranking web

- Referencialidad de Facebook

- Referencialidad de Twitter

En segundo lugar, la transparencia (I. Transparencia), que combinaría los siguientes parámetros:

- Enunciación de misión

- Enunciación de visión

- Enunciación de valores

- Líneas estratégicas identitarias

- Acceso informes de RSC

- Alcance informes de RSC

- Divulgación informes de RSC

En tercer lugar, la singularización de una apuesta estratégica que se vea respaldada en términos de orgullo de representación (I. Orgullo) que se nutriría de:

- Audiencia programática

-Audiencia online

Tabla 10. Síntesis de indicadores propuestos.

\begin{tabular}{|l|l|}
\hline Indicador sintético & Índicadores simples \\
\hline \multirow{4}{*}{ I. Comunidad } & Comunidad potencial \\
\cline { 2 - 2 } & Ranking web \\
\cline { 2 - 2 } & Influencia Facebook \\
\cline { 2 - 2 } & Influencia Twitter \\
\hline \multirow{4}{*}{ I. Transparencia } & Identidad corporativa \\
\cline { 2 - 2 } & Enfoque transparencia \\
\cline { 2 - 2 } & Informes RSC \\
\hline
\end{tabular}




\begin{tabular}{|l|l|}
\hline \multirow{4}{*}{ I. Orgullo } & Audiencias programación \\
\cline { 2 - 2 } & Audiencias marca corporativa online \\
\cline { 2 - 2 } & Nivel influencia online \\
\hline
\end{tabular}

Fuente: Elaboración propia

\section{Conclusiones}

En el contexto actual, las televisiones públicas europeas ven ampliado el ámbito en el que han de constituirse en medio de referencia para los ciudadanos. La batalla de las audiencias deja paso a la batalla de la reputación en la que la gestión de relaciones y de contenidos online se convierte en un ámbito permanente de construcción de imagen positiva.

Los sistemas de medición tradicionales ya no resultan el único modo posible de analizar el cumplimiento de su misión de servicio público. El presente trabajo propone la consideración de tres indicadores fundamentales para el análisis y la comparativa de sus situaciones a respecto de la competencia: la creación de una comunidad online que apoye a la marca, la transparencia en la gestión de su identidad organizacional y el fomento del orgullo de representación de sus conciudadanos. De esta forma, las televisiones públicas europeas harían frente a su triple crisis actual: tecnológica y de competencia, económica y de credibilidad.

Para la elaboración de un análisis más complejo, se parte del empleo de indicadores simples que han sido desgranados y recolectados a partir de las fuentes primarias correspondientes. Aunque no era objeto del presente trabajo la profundización en la situación de cada una de las cadenas públicas analizadas, la lectura general permite apuntar a necesarios niveles de mejora en la ampliación y consolidación de sus comunidades online, en la presentación de su identidad corporativa (especialmente, en cuanto a su visión) y apuesta estratégica correspondiente, así como en la potenciación de un sentimiento de apropiación y representación por los ciudadanos.

El paso inicial supone el reto de convertirse (y de volver a ser) medios de referencia en un contexto altamente competitivo y de audiencias fragmentadas. Las plataformas online, entendidas como medios propios de cada una de las marcas públicas analizadas, representan la 
oportunidad de cumplir con la misión de servicio público también en la arena digital, por lo que deben integrarse en la estrategia de imagen corporativa. Así se reconoce en el informe de la BBC (2016) A future for public service television, donde se explica que los medios de servicio público (public service media) complementan a la televisión de servicio público y se explicitan los valores que guían su actuación en este ámbito: independencia, universalidad, ciudadanía, calidad y diversidad.

La transparencia debe entenderse no tan necesariamente de modo literal, sino como un paradigma relacional y de estructuración de los contenidos, del relato sobre sí mismas y sobre la propuesta informativa que realizan a los usuarios. Supone el paso del storytelling al storydoing.

La metodología desarrollada se considera una herramienta de partida válida que ofrece una propuesta sistematizada para la construcción de indicadores sintéticos. No obstante, el estudio adolece de limitaciones que obstaculizan el empleo de herramientas profesionales de medición de sentimiento en el entorno online con las que se trabaja en la actualidad desde organizaciones y marcas.

El estudio es una aproximación inicial a la gestión de las relaciones con públicos y audiencias y se enmarca en un amplio proyecto de análisis que pretende identificar y analizar los indicadores de gobernanza, financiación, innovación y calidad de servicio público de las televisiones europeas para, una vez identificados, trabajar sobre la potencial elaboración de indicadores sintéticos aplicables a las televisiones públicas en España.

\section{Bibliografía y fuentes}

Aced, C. (2013). Relaciones Públicas 2.0. Cómo gestionar la comunicación corporativa en el entorno digital. Barcelona: Editorial UOC.

AIMC (2018). Resumen general de resultados EGM. Recuperado el 14 de enero de 2018 de http://www.aimc.es/egm/datos-egmresumen-general/

Alessandri, S. (2009). "Promoting the Net- work Brand: An Exploration of Net- work and Local Affiliate On-Air Pro- 
motion during the Super Bowl 2001- 2006". Journal of Promotion Management, Vol. 15, pp. 150-164.

Avery, Ronald K. \& Owen, Sam M. (1999). "Promotion in public television and radio". En: S.T. Eastman, D.A. Ferguson \& R.A. Klein (Eds), Promotion and marketing for broadcasting and cable. 3rd. Boston: Ed. Focal Press.

BBC (2016). A future for public service television. London: University of London.

Balmer, J. M., \& Greyser, S. A. (Eds.). (2003). Revealing the corporation: perspectives on identity, image, reputation, corporate branding, and corporate-level marketing: an anthology. London: Psychology Press.

Barlovento (2018). Análisis televisivo 2017. Madrid: Barlovento. Recuperado el 20 de enero de 2018 de https://goo.gl/q7iFhn Capriotti, P. (1999). Planificación estratégica de la imagen corporativa. Barcelona: Ariel.

Carrillo, M. V., Castillo, A., \& Tato, J. L. (2008, May). El "valor" de lo intangible. La gestión de la reputación corporativa. El caso de la marca "Telefónica". In Comunicação e Cidadania. Actas do $5^{\circ}$ Congresso da SOPCOM (pp. 317-327).

Castelló-Martínez, A., Pino-Romero, D., \& Ramos-Soler, I. (2014). "Twitter como canal de comunicación corporativa y publicitaria”. Communication \& Society / Comunicación y Sociedad, Vol. 27, n. 2, pp. 21-54.

Cerezo, J. \& Cerezo, P. (2017). La televisión que viene. Madrid: Evoca Comunicación e Imagen.

Chaves, N. (2005). La imagen corporativa. Teoría y práctica de la identificación institucional. Barcelona: Gustavo Gili. Tercera edición. (Primera edición: 1988).

CIS (2016). Postelectoral Elecciones Generales 2016. Madrid: CIS. Recuperado el 18 de febrero de 2018 de https://goo.gl/SmzikV Costa-Sánchez, C., \& Túñez-López, M. (2017). Análisis de la información corporativa en línea de las televisiones publicas europeas y sus relaciones con la audiencia. Comunicación y Medios, 1(36), pp. 125-139. doi:10.5354/0719-1529.2017.45100

Costa-Sánchez, C. Piñeiro-Otero, T. (2013). Estrategias de comunicación multimedia. Barcelona: UOC. 
Fernández Lombao, T., \& Campos Freire, F. (2013). "La

Responsabilidad Social Corporativa en las radio-televisiones públicas de Europa". Cuadernos. info, 33, pp. 145-157.

Fernández Quijada, D. (2007). "Industrias culturales en el entomb digital: una reformulación desde la praxis comunicativa". Zer: Revista de Estudios de Comunicación, 12(22), pp. 119-140.

Förster, K. (2015). "Key success factors of TV brand management: An international case study analysis". Journal of media business studies, 8(4), pp. 1-22.

Grunig, J. E. (2009). "Paradigms of global public relations in an age of digitalization". PRism, 6(2), 1-19.

Lacroix, J. G. y Tremblay, G. (1997). "The institutionalization of cultural commodification: Logics and strategies". Current Sociology, 45(4), pp. 39-69.

Islas, O. (2008). "La sociedad de la ubicuidad, los prosumidores y un modelo de comunicación para comprender la complejidad de las comunicaciones digitales”. Razón y palabra, 13(65), pp. 1-12.

López Cepeda, A. M., y Manfredi, J. L. (2013). “Análisis de la transparencia de las páginas web de los principales medios de comunicación audiovisuales en España". Trípodos, 1(32), pp. 4562.

López-López, P.C.; Puentes-Rivera, I. \& Rúas-Araújo, J. (2017). "Transparencia en televisiones públicas: desarrollo de indicadores y análisis de los casos de España y Chile". Revista Latina de Comunicación Social, 72, pp. 253-272. http://www.revistalatinacs.org/072paper/1164/14es.html DOI: $10.4185 /$ RLCS-2017-1164

Macnamara, J. (2010). "Public communication practices in the Web 2.0-3.0 mediascape: The case for PRevolution". PRism 7(3). Recuperado el 23 de marzo de 2017 de http://www.prismjournal.org/fileadmin/Social media/Macna mara.pdf

Manfredi Sánchez, J. L. (2011). "Escenarios y retos de la televisión pública en España". adComunica. Revista de Estrategias, Tendencias e Innovación en Comunicación, $\mathrm{n}^{\circ} 1$, pp. 49-62.

Melewar, T.C. and Wooldridge, R. (2001), "The dynamics of corporate identity: a review of a process model". Journal of Communication Management, Vol. 5 No. 4, pp. 327-340. 
OECD (2008). Handbook on Constructing Composite Indicators. Methodology and User Guide. OECD Publications: Paris.

Pérez Sampol, C., Gómez-Zorilla, J. M. \& Marco Blanco, J. (2015). "La comunicación empresarial en la Web 2.0. Estrategias para la gestión efectiva de la reputación corporativa". Revista Tecnología, Ciencia y Educación, (1), 62-67.

Silva Robles, C. (2012). "Community managers: la dirección de Relaciones Públicas en la red”. Revista Internacional de Relaciones Públicas, 2(3), 193-216.

Simoes C., Dibb S., Fisk R. P. (2005). "Managing corporate identity: an internal perspective". J Acad Mark Sci 33(2):153-168. doi: $10.1177 / 0092070304268920$

Toffler, A., \& Alvin, T. (1981). The third wave. New York: Bantam books.

Túñez, M (2011). La gestión de la comunicación en las organizaciones. Sevilla/Zamora: Comunicación Social Ediciones.

Van Riel, C. (1997). Comunicación corporativa. Madrid: Prentice Hall.

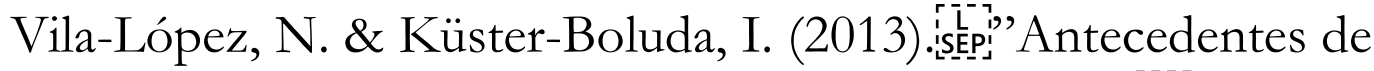

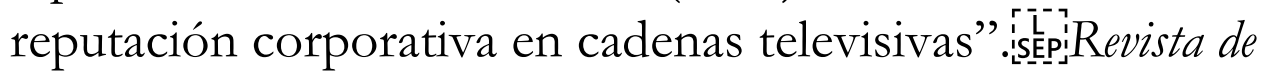
Ciencias Sociales (Ve), vol. XIX, núm. 2, pp. 334-348. 



\title{
Las radiotelevisiones públicas europeas en el entorno web
}

\author{
María-Magdalena Rodríguez-Fernández \\ Universidad de A Coruña \\ Eva Sánchez-Amboage \\ Universidad de A Coruña \\ Carlos Toural-Bran \\ Universidade de Santiago de Compostela
}

PARA CITAR: Rodríguez-Fernández, M.M., Sánchez-Amboage, E. y

Toural-Bran, C. (2018). Las radiotelevisiones públicas europeas en el entorno web. Revista Latina de Comunicación Social, 73, pp. 911 a 926. http:/ www.revistalatinacs.org/073paper/1288/47es.html

DOI: http:/10.4185/RLCS-2018-1288

\section{Resumen}

Las radiotelevisiones públicas se han tenido que adaptar a nuevos escenarios donde internet se ha posicionado como la plataforma fundamental para informar, comunicar y difundir contenidos a sus audiencias. Se analizan los websites de las radiotelevisiones públicas de los países de la Unión Europea teniendo en cuenta los siguientes parámetros: posicionamiento, engagement, procedencia de la audiencia y dispositivos de acceso. En la mayoría de los casos analizados la duración de las visitas a los websites es limitada, la tasa de rebote elevada, los usuarios nacionales y los dispositivos móviles se posicionan como los soportes más utilizados para acceder al contenido de los websites. Los resultados indican que los sitios web de las radiotelevisiones públicas europeas no están cumpliendo con las expectativas de los usuarios. Las corporaciones deben apostar por el desarrollo de 
servicios online más eficientes que reviertan en la generación de un mayor y mejor uso de sus respectivos websites.

Palabras clave: Radiotelevisiones públicas, Unión Europea, Internet, websites.

\section{Introducción}

J OS encontramos ante un entorno caracterizado por la multiplataforma y la consolidación de un modelo de comunicación "de unos muchos para unos muchos" (Roel, 2010). Estos aspectos han impulsado la necesidad por parte de las televisiones de tener que adaptarse a la multicanalidad y multipantalla (Jenkins \& Lazcano 2008).

Internet, tras superar una primera etapa marcada por el desconcierto y el miedo al nuevo medio, se ha consolidado como un importante aliado para las cadenas de televisión (Cham \& Ha, 2003). De manera paralela, los websites ${ }^{1}$ han penetrado con fuerza en el sector hasta el punto de convertirse en plataformas esenciales en la estrategia comunicativa de las televisiones al propiciar la interactividad del medio con el espectador y contribuir así a mejorar la difusión y promoción de los contenidos de los soportes tradicionales.

En lo que respecta a las radiotelevisiones públicas, debido a su papel protagonista en el desarrollo de las sociedades democráticas (Dahlgren, 2007), esta adaptación a los entornos digitales aporta cada vez más valor al servicio público que desarrollan.

En este contexto, se estudia el caso de las radiotelevisiones públicas de la Unión Europea y tras analizar sus respectivos websites oficiales, la investigación determina el estado de estas en relación a los siguientes parámetros: posicionamiento, engagement, procedencia de la audiencia y dispositivo de acceso.

\footnotetext{
${ }^{1}$ Sitio web o Cibersitio es una colección de páginas web relacionadas y comunes a un dominio de internet o subdominio en la World Wide Web dentro de Internet.
} 


\section{Estado de la cuestión}

\subsection{Las radiotelevisiones públicas en el entorno digital}

La fragmentación de la oferta y la demanda, las nuevas formas de consumo, la alteración de los sistemas de financiación y los nuevos modelos de negocio del sector audiovisual son consecuencia de los cambios económicos y tecnológicos acaecidos en el entorno (Campos, 2013).

En este sentido, la tecnología ha supuesto un salto importante desde los medios de comunicación tradicionales hasta los integrados en el nuevo entorno digital, impulso que ha ampliado y mejorado la oferta para la audiencia generando un proceso de comunicación retroalimentado entre ésta y el medio (Debrett, 2009). Internet se ha convertido, por tanto, una herramienta de comunicación y transmisión de información entre las organizaciones y los usuarios (Buhalis, 1998; Obercom, 2014). Como consecuencia de la penetración de internet en el ámbito televisivo, el modelo tradicional de la comunicación unidireccional ha dado paso a un modelo participativo, caracterizado por un papel más activo de las audiencias.

El camino recorrido por internet hasta convertirse en un fenómeno imparable ha sido, en número de años, mucho menor al de cualquier medio de comunicación tradicional. Las televisiones han aceptado el desafío de la red y han optado por adoptar mecanismos que contribuyan a fomentar la participación de las audiencias creando modelos híbridos de televisión e internet (Vinader \& De la Cuadra, 2012). Lejos de lo que se pensaba en un primer momento, internet no resta audiencia a la televisión convencional, sino que suma, gracias a la correlación positiva que existe entre ambos consumos (Meso y Larrondo, 2010).

En este contexto, al analizar la oferta (televisión) y la demanda (usuario/audiencia) como partes implicadas en el proceso comunicativo de las televisiones se observa que el usuario, cuando consume televisión en un entorno digital, busca un contenido informativo $\mathrm{y} / \mathrm{o}$ de entretenimiento concreto con el que poder disfrutar, aspecto por el cual presta más atención (García, Galán \& García, 2015). Según Ortuzar (2007) el espectador se ha convertido en el centro del universo televisivo, tanto por sus posibilidades de 
participación como por la multiplicación de opciones que tiene a su disposición.

De este modo para satisfacer a una demanda cada vez más exigente, las televisiones han tenido que adoptar diferentes estrategias para distribuir sus contenidos pues se da una pérdida de usuarios en directo, a través del televisor, que ganan en diferido, a través de internet, hecho que ha propiciado el alza de los servicios a la carta (Anton \& Guallar, 2014).

Llegados a este punto, podemos constatar que el rápido desarrollo de las TICs, y concretamente el avance de internet, ha generado múltiples cambios para las empresas y usuarios en el ámbito de la comunicación televisiva (Díaz, Consuegra \& Esteban, 2008). Los websites de las televisiones se han convertido en herramientas fundamentales de marketing (Okazaki, 2005) al tratarse de instrumentos básicos capaces de proporcionar ventajas competitivas, realizar transacciones en tiempo real, facilitar la comunicación bidireccional y accesibilidad al público objetivo, mejorar la competitividad de las empresas, crear nuevas oportunidades para reducir costes y, por ende, hacer más eficaz la comunicación (Xing \& Grandt, 2006).

La existencia de los portales de televisiones en internet ha facilitado que el telespectador pueda acceder a los contenidos cuando quiera y donde quiera con una visualización no secuencial y de forma más activa (Anton \& Guallar, 2014). Por este motivo es importante cuidar la calidad de cada web y su vocación informativa (Mendiguren, 2010).

Al extrapolar los cambios tecnológicos producidos en el entorno al caso de las radiotelevisiones públicas cabe destacar que se enfrentan a dos importantes transformaciones. La primera que afecta a la cadena de distribución, la cual se amplia y diversifica al añadir nuevos canales y plataformas (Enli, 2008) y la segunda a los hábitos de consumo al convertir a la audiencia, pasiva en sus inicios, en parte interactiva del proceso de comunicación con sus respectivos medios (Meso, Agirreazkuenaga \& Larrondo, 2015).

Según Enli (2008), las estrategias para adaptar la oferta de estos medios públicos a las nuevas audiencias han de tratar de combinar "tradición 
e innovación" por supuesto sin dejar de lado las misiones y obligaciones de servicio público que estos medios comparten.

Con el fin de aprovechar el potencial de internet, las radiotelevisiones públicas necesitan websites eficaces que sean capaces de mejorar su comunicación. Entre las variables que permiten dicho objetivo se encuentran la interactividad y la usabilidad (Kaplanidou \&Vogt, 2006; Ha \& Love, 2005).

No obstante, según Gómez (2016) las plataformas web públicas están adaptadas a un perfil de audiencia de tipo "consumidor" por lo que todavía ofrecen una escasa interactividad al usuario. Esto es debido a la limitada creación de comunidades, así como a la existencia de una comunicación directa entre los usuarios dentro de la propia web. Son estos aspectos en los cuales todavía queda mucho camino por recorrer.

\subsection{Las radiotelevisiones públicas en Europa}

Antes de adentrarnos en el caso europeo es importante destacar que avanzada la década de los 90 del siglo pasado es cuando el sector televisivo alcanza un importante punto de inflexión empujado por el proceso de sustitución gradual de la radiodifusión analógica por la digital (Bustamante, 1999).

En Europa las tendencias del sector audiovisual, marcadas por la crisis económico-financiera iniciada en el año 2007 y por la convergencia tecnológica, han derivado en una reestructuración de las televisiones públicas, así como en una concentración de los operadores de servicios digitales de ondas hertzianas, de cable y satélite (Campos, 2013). No obstante, las perspectivas señalan al futuro del IPTV (Internet Protocol Television) y al desplazamiento de las redes hertzianas terrestres hacia las comunicaciones telefónicas de movilidad en detrimento de la propia televisión (Campos, 2013).

En la era digital aspectos como la adaptación a la convergencia, la revalorización del carácter social de prestación del servicio público (Campos, 2016) y la apuesta por una mayor credibilidad en cuanto a contenidos son algunos de los elementos fundamentales que las radiotelevisiones públicas europeas han de valorar para garantizar su supervivencia ya que la tendencia futura del sector apunta a modelos de pago. En esta encrucijada Bustamante y García (2017) mencionan 
la existencia de voces a favor de la importancia del servicio público que ofrecen las radiotelevisiones en la era digital (Lowe \& Yamamoto, 2016), así como voces en contra, por el modo en que la Unión Europea está desarrollando su expansión digital (Brevini, 2013).

Llegados a este punto y para entender mejor los motivos por los cuales, en la era digital, han de prevalecer las radiotelevisiones públicas en Europa, conviene que conozcamos cuáles son sus misiones, objetivos, valores y las funciones que desempeñan. Su misión se fundamenta en preservar la cohesión frente a la híper-fragmentación, dándole un sentido de identidad y diversidad cultural a la comunicación de cada país y procurando combinar la diversidad con la universalidad de acceso a los contenidos (Campos, 2016).

Entre los objetivos del servicio público de radiotelevisión se encuentran: el acceso universal y continuado; la promoción de la cultura y la lengua propia, del arte, de la educación y del conocimiento; el fomento del pluralismo, la igualdad y la interculturalidad; la oferta de programación generalista para mayorías y la atención a minorías; la independencia y calidad informativa; la diversidad de géneros y formatos; el énfasis en la información de calidad; la ejemplaridad en el ejercicio de las misiones de servicio público; la gestión democrática y eficiente; la construcción del espacio público y la innovación (Miguel, Zallo \& Casado, 2017).

De acuerdo a la misión y objetivos establecidos, los seis valores esenciales que establece la Unión Europea de Radiodifusión (EBU, 2014) para el servicio de comunicación audiovisual son: la universalidad de acceso, la independencia, la diversidad, la innovación, la excelencia y la rendición de cuentas.

Finalmente, las funciones que desempeñan las radiotelevisiones públicas europeas se articulan en torno a las garantías democráticas, la función política, la función cultural y comunicativa, la función identitaria, la función educativa y formativa, así como alrededor de la innovación (Tabla 1). 
Tabla 1: Funciones de las radiotelevisiones públicas europeas

\begin{tabular}{|l|l|}
\hline $\begin{array}{l}\text { Garantías } \\
\text { democráticas }\end{array}$ & $\begin{array}{l}\text { Acceso universal. } \\
\text { Pluralismo y diversidad de programación para todos los } \\
\text { grupos sociales. } \\
\text { Promoción de la integración de los emigrantes. }\end{array}$ \\
\hline Función política & $\begin{array}{l}\text { Estimular la participación de la ciudadanía. } \\
\text { Debates, espacios de discusión sobre los problemas } \\
\text { económicos, sociales y políticos concretos. }\end{array}$ \\
\hline $\begin{array}{l}\text { Función cultural } \\
\text { y comunicativa }\end{array}$ & $\begin{array}{l}\text { Promoción de la información veraz, objetiva y cercana. } \\
\text { Promoción de contenidos relacionados con las artes en } \\
\text { general. } \\
\text { Promoción de la creatividad (nuevas estéticas). } \\
\text { La televisión autonómica debe ocupar un espacio dentro } \\
\text { del sistema comunicativo de la autonomía. }\end{array}$ \\
\hline $\begin{array}{l}\text { Función } \\
\text { identitaria }\end{array}$ & $\begin{array}{l}\text { Promoción de la lengua. } \\
\text { Promoción del patrimonio. }\end{array}$ \\
\hline $\begin{array}{l}\text { Función } \\
\text { educativa y } \\
\text { formativa }\end{array}$ & $\begin{array}{l}\text { Difusión y divulgación científica. } \\
\text { Promoción de valores éticos y ciudadanos: sostenibilidad, } \\
\text { cooperación, solidaridad. }\end{array}$ \\
\hline Innovación & $\begin{array}{l}\text { No sólo debe utilizar las tecnologías existentes, sino que } \\
\text { debe ser proactiva en el uso, buscando nuevas funciones, } \\
\text { como la participación de la sociedad civil. } \\
\text { Nuevos formatos televisivos (cross, transmedia). } \\
\text { Innovación organizativa. En un momento de convergencia } \\
\text { lo lógico es que se rompa con los clásicos departamentos, } \\
\text { de radio, televisión e Internet separados, cada uno con su } \\
\text { dirección. } \\
\text { Nuevos enfoques informativos: periodismo 360, etc. }\end{array}$ \\
\hline
\end{tabular}

Fuente: Elaboración propia a partir de Miguel, Zallo \& Casado (2017).

El cumplimiento de estas funciones debe articularse en torno a la gobernanza, que promueva la transparencia, una financiación adecuada 
y estable, así como una programación diferenciada (Miguel, Zallo \& Casado, 2017).

En este sentido, las radiotelevisiones públicas europeas están inmersas en un convergente ecosistema global cambiante de medios, tecnologías, sistemas de distribución y nuevas formas de acceso y consumo de contenidos audiovisuales (Campos, 2016).

El uso de la innovación se presenta como una estrategia importante para los siguientes autores ${ }^{2}$ (Steemers, 2003; Van Dijck \& Poell, 2014; Dondeers \&Van den Bulck, 2014 y Glowacki \& Jackson, 2016), citados en (Campos, 2016), en aras de revitalizar y dinamizar la imagen de las radiotelevisiones públicas.

De este modo, radiotelevisiones públicas europeas se encuentran ante un gran desafío: adaptarse a un entorno web cambiante para afianzar su posicionamiento. En este sentido, lo importante es mantener a las audiencias tradicionales y tratar de conseguir nuevos espectadores a través de otras plataformas, estrategias y narrativas, donde la demanda de consumo de contenidos tiende más hacia el ámbito experiencial (Campos, 2016).

\section{Objetivos y Metodología}

El objetivo de esta investigación consiste en analizar los websites de las radiotelevisiones públicas de los 28 países de la Unión Europea, a excepción de Luxemburgo, país que nunca ha contado con un ente de estas características.

\section{Tabla 2: Corporación de las radiotelevisiones públicas de Unión Europea}

\begin{tabular}{|l|l|l|}
\hline \multicolumn{1}{|c|}{ País } & Corporación & \multicolumn{1}{c|}{ Sitio Web } \\
\hline Alemania & ARD & $\underline{\underline{\text { http://www.ard.de/home/ard/ARD }}}$ \\
\hline Startseite/21920/index.html \\
\hline Alemania & ZDF & $\underline{\text { https://www.zdf.de/ }}$ \\
\hline Austria & ORF & $\underline{\text { http://orf.at/ }}$ \\
\hline
\end{tabular}

${ }^{2}$ Los autores Steemers, 2003; Van Dijck \& Poell, 2014; Dondeers \&Van den Bulck, 2014; Glowacki \& Jackson, 2016), aparecen citados en (Campos, 2016). 


\begin{tabular}{|l|l|l|}
\hline Bélgica & BRF & $\underline{\text { https://brf.be/ }}$ \\
\hline Bélgica & RTBF & $\underline{\text { https://www.rtbf.be/ }}$ \\
\hline Bélgica & VRT & $\underline{\text { https://www.vrt.be/nl/ }}$ \\
\hline Bulgaria & BNT & $\underline{\text { https://www.bnt.bg/bg }}$ \\
\hline Bulgaria & BNR & $\underline{\text { http://bnr.bg/ }}$ \\
\hline Chipre & CyBC & $\underline{\text { http://www.riknews.com.cy/ }}$ \\
\hline Croacia & HRT & $\underline{\text { http://www.hrt.hr/ }}$ \\
\hline Dinamarca & DR & $\underline{\text { https://www.dr.dk/ }}$ \\
\hline Eslovaquia & RTVS & $\underline{\text { http://www.rtvs.sk/ }}$ \\
\hline Eslovenia & RTVSLO & $\underline{\text { http://www.rtvslo.si/ }}$ \\
\hline España & RTVE & $\underline{\text { http://www.rtve.es/ }}$ \\
\hline Estonia & ERR & $\underline{\text { http://www.err.ee/ }}$ \\
\hline Finlandia & YLE & $\underline{\text { https://yle.fi/ }}$ \\
\hline Francia & FT & $\underline{\text { https://www.france.tv/ }}$ \\
\hline Grecia & ERT & $\underline{\text { http://www.ert.gr/ }}$ \\
\hline Hungría & MTVA & $\underline{\text { https://www.mediaklikk.hu/m1 }}$ \\
\hline Irlanda & RTE & $\underline{\text { https://www.rte.ie/ }}$ \\
\hline Italia & RAI & $\underline{\text { http://www.rai.it/ }}$ \\
\hline Letonia & LTV & $\underline{\text { http://ltv.lsm.lv/lv/ }}$ \\
\hline Lituania & LRT & $\underline{\text { http://www.lrt.lt/ }}$ \\
\hline Malta & PBS & $\underline{\mathrm{https://www.tvm.com.mt/en/}}$ \\
\hline Países Bajos & NPO & $\underline{\mathrm{https://www.npo.nl/}}$ \\
\hline Polonia & TVP & $\underline{\mathrm{https://polonia.tvp.pl/}}$ \\
\hline Portugal & RTP & $\underline{\mathrm{http://www.rtp.pt/}}$ \\
\hline Gran Bretaña & BBC & $\underline{\mathrm{http://www.bbc.com/}}$ \\
\hline República Checa & CT & $\underline{\mathrm{http://www.ceskatelevize.cz/}}$ \\
\hline Rumanía & TVR & $\underline{\mathrm{http://www.tvr.ro/}}$ \\
\hline Suecia & $\underline{\mathrm{https://www.svt.se/}}$ \\
\hline
\end{tabular}

Fuente: Elaboración propia 
Para el análisis se ha empleado Similar $W e b^{3}$, una herramienta online que permite conocer los datos más importantes de un determinado sitio en internet relativos a su posicionamiento, público y tipo de tráfico. Dicho instrumento ha sido empleado previamente por investigadores como Túñez y Costa (2017) para el estudio de la comunicación online y tráfico web de algunas televisiones públicas en Europa. Para la realización del trabajo de campo se ha optado por someter a observación tres meses consecutivos, concretamente desde el $1 / 9 / 2017$ al 1/12/2017, con la pretensión de no generar distorsiones de discontinuidad.

\section{Figura 1: Parámetros y variables analizadas}

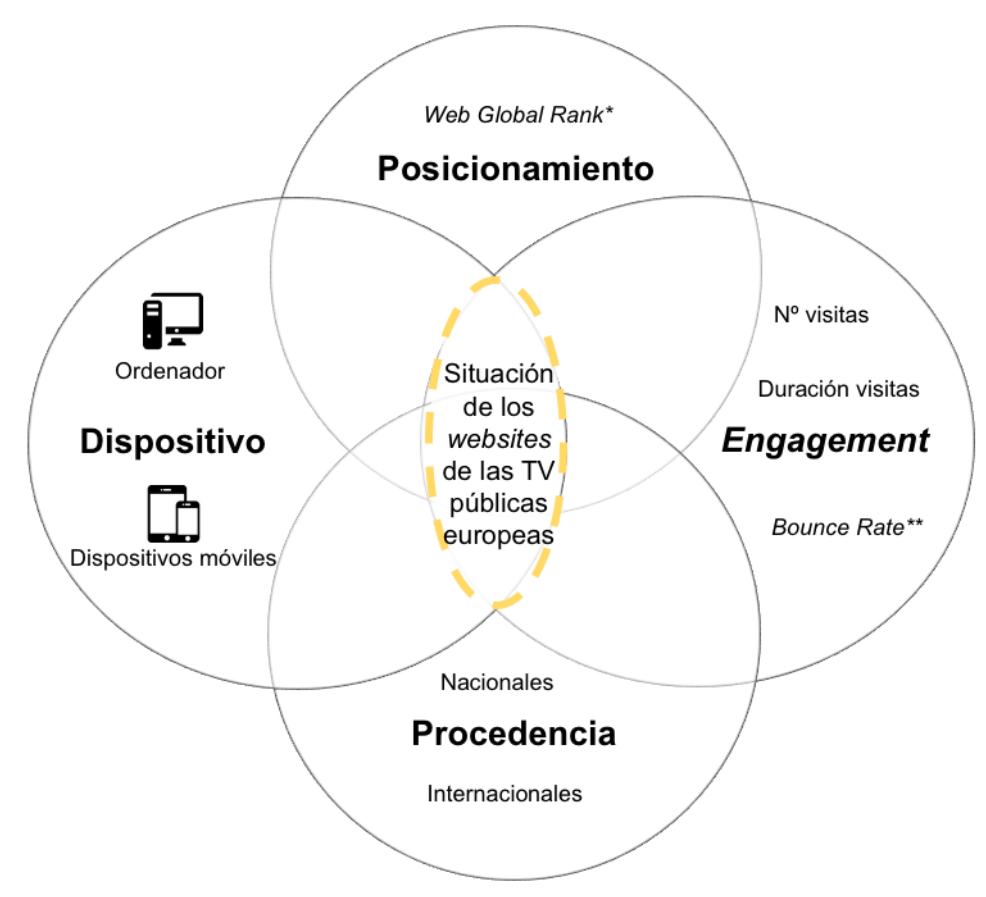
Objetivo principal de la investigación
Fuente Negrita Parámetros
Fuente Regular Variables
* El Web Global Rank es una relación de los sitios web, a nivel mundial, ordenada por su tráfico.
** O tasa de rebote es el porcentaje de visitas que entran en un sitio web y salen del mismo sin visitar ninguna página más del site.

Fuente: Elaboración propia

La foto fija que proyecta la imagen del estado de los websites de las radiotelevisiones públicas europeas se consigue analizando cuatro parámetros y sus variables asociadas (Figura 1) para alcanzar, de este

3 Puede consultarse en https://www.similarweb.com/. 
modo, el objetivo propuesto para esta investigación. Así, se ha estudiado el posicionamiento de los websites de las radiotelevisiones públicas europeas (a través del valor Web Global Rank), su compromiso o engagement (usando el número de visitas, su duración y la tasa de rebote o bounce rate), la procedencia (nacional o internacional) y los dispositivos de acceso (ordenador u otros dispositivos móviles).

\section{Resultados}

El apartado de resultados se estructura en base a los parámetros y variables analizados en esta investigación: posicionamiento, engagement, procedencia de la audiencia y dispositivos de acceso.

\section{Figura 2: Posición de las corporaciones de radiotelevisiones públicas europeas en el Web Global Rank a nivel mundial, ordenadas por cuartiles}

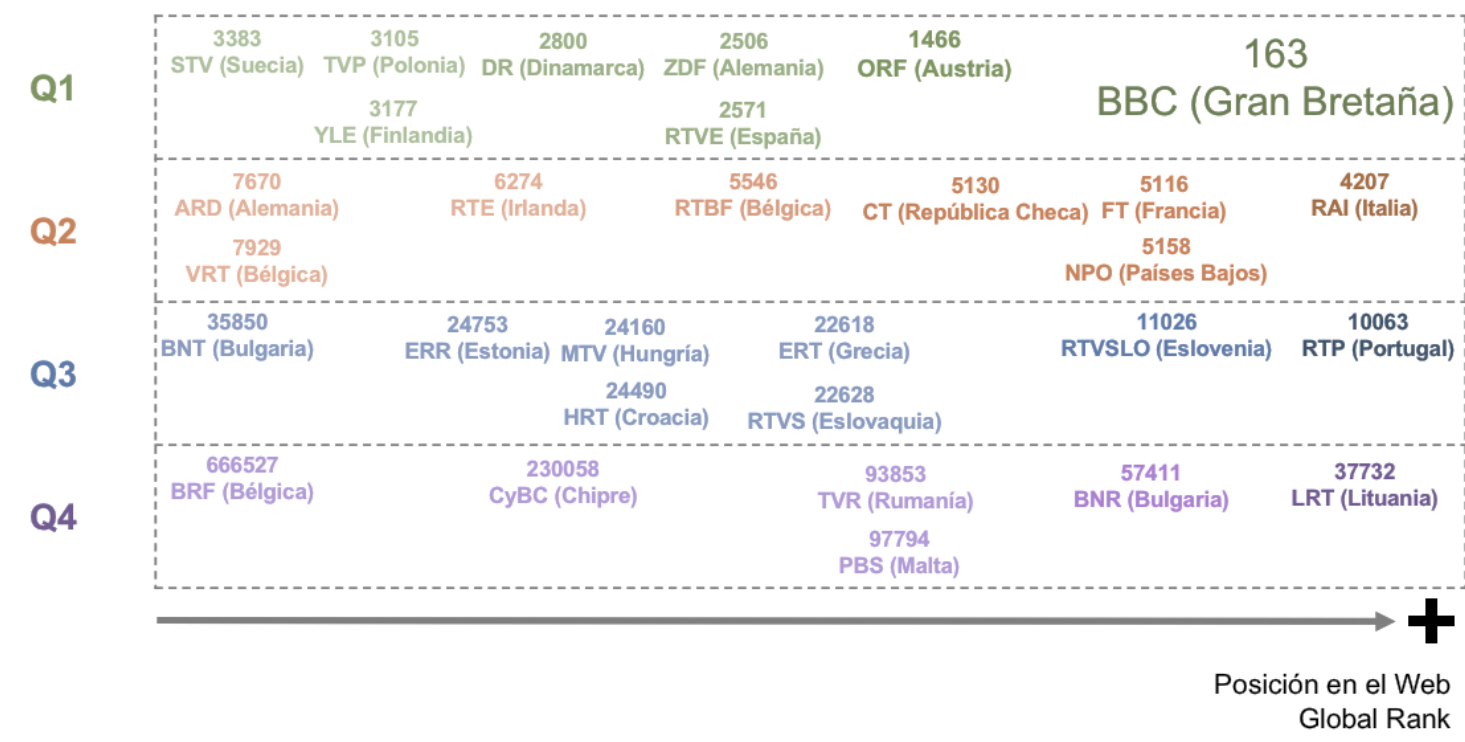

Fuente: Elaboración propia

En primer lugar, se analiza el posicionamiento de los sitios web de las radiotelevisiones públicas de la Unión Europea en el Web Global Rank (WGR) a nivel mundial. Este parámetro es una relación de los sitios web a nivel mundial ordenada por su volumen de tráfico. En la Figura 2 se presenta la posición de los websites de las radiotelevisiones públicas de la Unión Europea en el Web Global Rank a nivel mundial, ordenadas por cuartiles. Q1, Q2 y Q3 contienen el posicionamiento de las 24 radiotelevisiones públicas europeas mejor situadas, contando cada 
cuartil con la información relativa a 8 televisiones. Por su parte, Q4, comprende los datos de las 6 radiotelevisiones restantes de la Unión Europea. Es importante destacar que, aunque no estén visibles, los cuartiles (conjunto de datos ordenados en cuatro partes porcentualmente iguales) cuentan con el posicionamiento de todos los sitios web a nivel mundial, de cualquier categoría, no únicamente de las radiotelevisiones.

En base a lo anterior, la BBC de Gran Bretaña alcanza la mejor posición de todas las radiotelevisiones analizadas al situarse en el ranking global en el puesto 163. El resto de radiotelevisiones de la Unión Europea ocupan un lugar en el ranking mucho más bajo, encontrándose las diferencias más notables en el Q1, entre la BBC y la ORF que ocupan los puestos 163 y 1.466 respectivamente y en el Q4, entre la LRT y la BRF que se sitúan en los lugares 37.732 y 666.527.

El segundo parámetro que se analiza en este estudio es el compromiso o engagement, el cual proporciona información sobre el compromiso entre el sitio web analizado y el usuario que visita la web. Para su estudio se tienen en cuenta tres variables: número total de visitas al sitio web, duración de las mismas (tiempo que pasa el usuario en una determinada web) y el bounce rate o tasa de rebote (porcentaje de visitas que entran en un sitio web y salen del mismo sin visitar ninguna página más del site). Es importante recordar que los datos presentados en este estudio reflejan la situación de las variables durante tres meses.

En la Figura 3, puede observarse el número de visitas que reciben los sitios web de las radiotelevisiones públicas de la Unión Europea. En este caso, la BBC de Gran Bretaña vuelve a destacar frente al resto de televisiones al contar su website, en los tres meses analizados, con más de 1 billón de visitas (1.332.163.500). En el extremo opuesto se encuentra la SVT de Suecia con 13.300 visitas, la cifra más baja de todos los casos analizados. Entre ambos extremos se ha calculado la mediana, cuya cifra se corresponde con 24 millones de visitas. En base a lo anterior el mapa de la Figura 3 se divide en dos mitades. La primera de ellas, de color anaranjado, refleja el $50 \%$ de los países que superan la mediana, los cuales se sitúan en la parte oeste y central de Europa, a excepción de Finlandia e Irlanda, pertenecientes al norte europeo. En este primer caso, sobresale la ORF de Austria con el dato más elevado 
(121.095.400) seguida de la ZDF alemana (104.640.200) y la RTVE española (93.647.600) entre otras. La segunda mitad, correspondiente al 50\% con menos de 24 millones de visitas, aparece representada en el mapa en color azul oscuro. En esta ocasión, salvo Portugal, los países situados en este porcentaje, se ubican en el este de Europa.

Figura 3: Número de visitas al sitio web de las RTV públicas de la UE

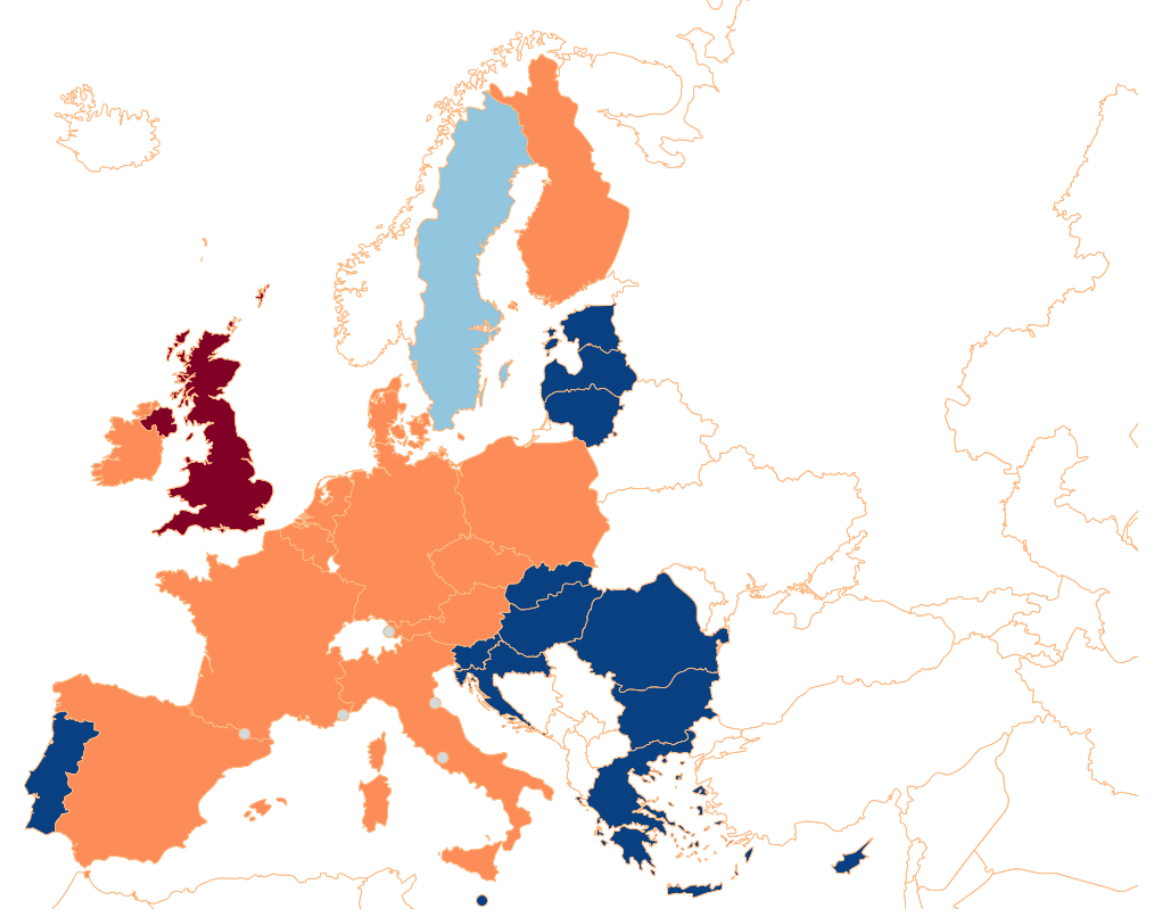

Fuente: Elaboración propia

En lo referente al análisis del compromiso o engagement, otra de las variables a analizar es la duración de las visitas en cada uno de los websites de las radiotelevisiones públicas de la Unión Europea. Es importante destacar que la duración de las visitas informa, de forma indirecta, sobre el interés de los sites, entendiendo que un tiempo de navegación más elevado implica que la web tenga una estructura y contenido más atractivo para sus usuarios.

Si nos detenemos en la Figura 4, en relación a la duración de las visitas de los usuarios a los websites, el dato más llamativo lo presenta la RTVSLO de Eslovenia al alcanzar la cifra de 23 minutos, muy por encima de la media del resto de radiotelevisiones. La RAI italiana y la 
STV de Suecia, son también dos corporaciones que destacan en esta variable con 8 y 7 minutos respectivamente. En último lugar, aparecen representadas la BNR de Bulgaria y la BRF de Bélgica con solamente 1 minuto de permanencia.

\section{Figura 4: Duración de las visitas en los sitios web de las radiotelevisiones públicas de la Unión Europea}

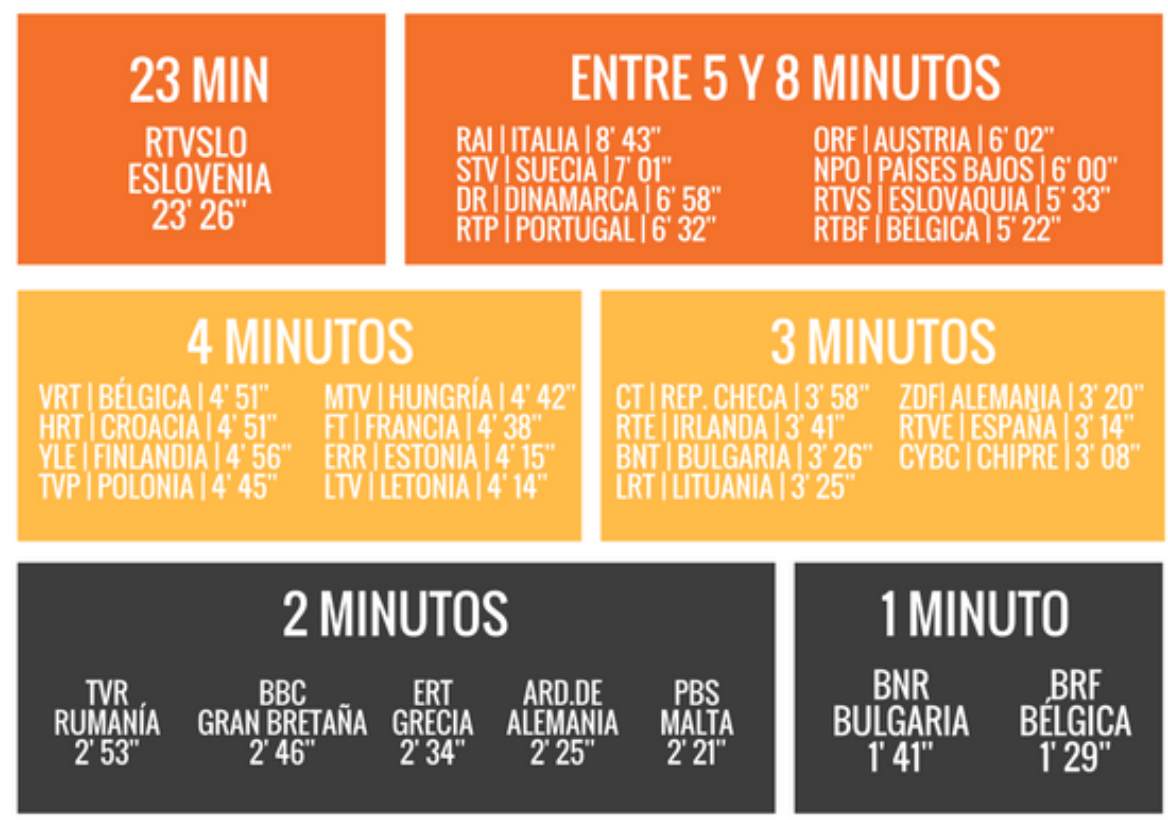

Fuente: Elaboración propia

Es interesante observar cómo el ser el website mejor posicionado en el Web Global Rank y el que suma un mayor número de visitas (Figura 3) no le sirve a la BBC de Gran Bretaña para traducir esa relevancia en tiempo que sus usuarios permanecen en su portal (Figura 4).

Para completar el estudio del engagement falta por incluir la información relacionada con el bounce rate o tasa de rebote. Este dato se expresa de forma porcentual y mide el número de sesiones en las que el usuario ha visitado una sola página del site y se ha marchado sin interactuar con la página. De este modo, si un sitio web tiene una tasa de rebote baja significa que el contenido está en sintonía con lo que el usuario necesita y la estructuración del site invita a seguir consumiendo contenido e interactuando. Por el contrario, un bounce rate demasiado alto, podría indicar que la página no esté cumpliendo con las expectativas del usuario y que, por tanto, los contenidos y/o elementos de navegación estén desestructurados. En este sentido, cabe comentar que un elevado 
bounce rate no necesariamente implica que el usuario quede insatisfecho, en ocasiones, puede significar que ha encontrado rápidamente aquello que necesitaba, por ejemplo, comprobar el horario de un determinado programa de televisión.

Figura 5: Tasa de rebote o bounce rate de los sitios web de las radiotelevisiones públicas de la Unión Europea

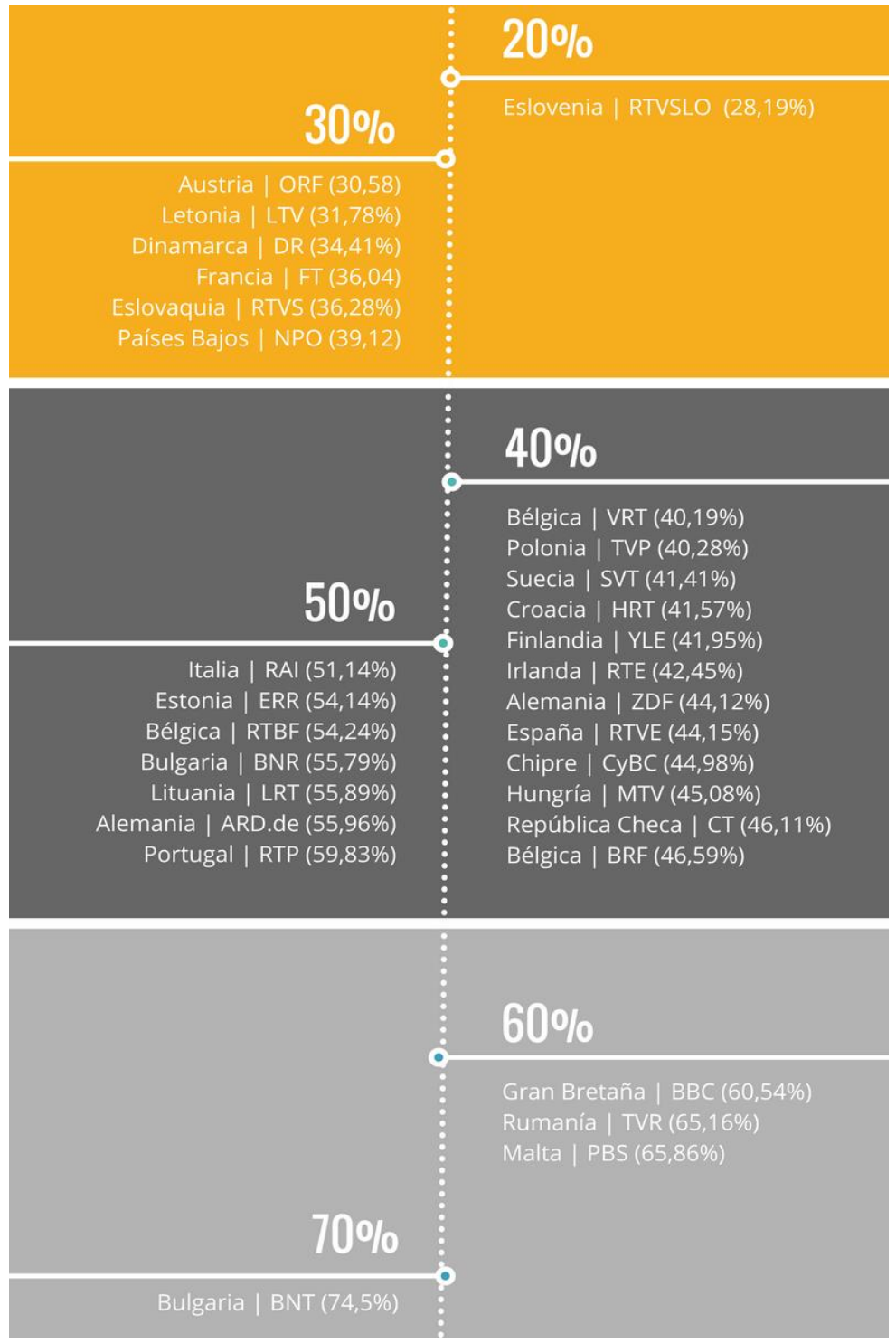

Fuente: Elaboración propia

Tal y como puede observarse en la Figura 5, la mayoría de las corporaciones analizadas obtienen una tasa de rebote entorno al 40\% y al 50\%. Destaca nuevamente RTVSLO Eslovenia, en este caso por un bajo porcentaje de tasa de rebote que, posiblemente, esté relacionado con la variable de duración de la visita, analizada en la 
Figura 4. En esa ocasión se comprobaba que RTVSLO presentaba una duración de las visitas en su site, mucho más elevada que el resto de las corporaciones estudiadas. En base a lo anterior, se presupone que los usuarios de la RTVSLO Eslovenia, encuentran atractivao dicho website.

La procedencia de los usuarios de los sitios web de las radiotelevisiones públicas de la Unión Europea (Figura 6) es otro de los parámetros que permiten conocer el funcionamiento de los websites de las corporaciones analizadas. En base a los datos recabados se determina que el $78 \%$ de los usuarios web de las radiotelevisiones públicas de la Unión Europea comporten nacionalidad con la corporación, mientras que el $22 \%$ tiene una nacionalidad distinta. Entre las corporaciones analizadas, las que cuentan con un porcentaje mayor de usuarios nacionales son NPO Países Bajos (92\%), TVP Polonia (91\%), DR Dinamarca (90\%) y SVT Suecia (90\%). El caso contrario lo representa la BBC de Gran Bretaña cuyos usuarios son mayoritariamente $(93 \%)$ internacionales y en menor medida $(7 \%)$ nacionales. El factor idioma juega, claramente, un rol importante ya que el inglés es el principal idioma a nivel mundial si tenemos en cuenta su difusión. Por lo tanto, las televisiones públicas de los países que cuentan con idiomas propios que no presentan niveles de difusión elevados a nivel internacional no contarán con un plus potencial de usuarios de origen diferente al de su nacionalidad.

Figura 6: Procedencia de los usuarios de los sitios web de las radiotelevisiones públicas de la Unión Europea

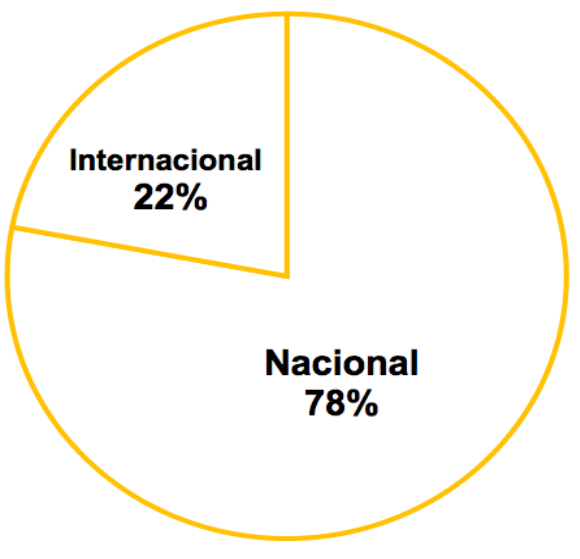

Fuente: Elaboración propia 
Finalmente, para cerrar el análisis del funcionamiento de los portales web de las radiotelevisiones públicas de la Unión Europea, se analizan datos sobre los dispositivos de acceso a los websites empleados por los usuarios (Figura 7). En este sentido, se comprueba que la tendencia general de consumo de contenido a través de dispositivos móviles irrumpe con fuerza también en el ecosistema de las televisiones públicas europeas, puesto que el 53\% de los usuarios accede a los websites a través del smartphone o la tablet. Existen excepciones notables como el caso de RTVSLO Eslovenia, corporación que alcanza el porcentaje de acceso a través del ordenador más elevado con un $85,30 \%$. A pesar de que estos son datos generales y deben ser contextualizados con los datos de penetración de conexión a internet y uso de tecnologías móviles particulares de cada país, sirven para observar una tendencia general de consumo de contenidos desde dispositivos móviles al alza a nivel europeo.

Figura 7: Dispositivos de acceso a los sitios web de las radiotelevisiones públicas de la Unión Europea, por parte de los usuarios

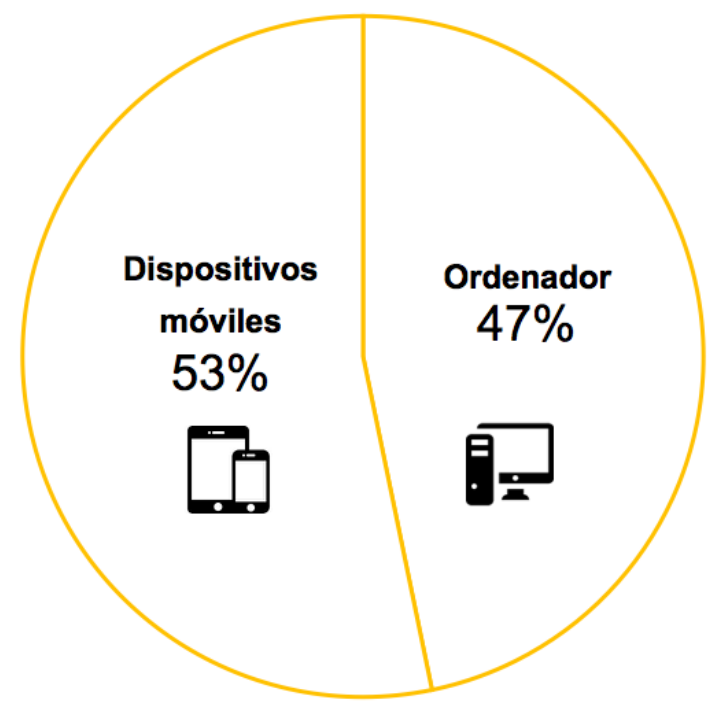

Fuente: Elaboración propia

\section{Discusión y conclusiones}

Las corporaciones de radiotelevisión públicas europeas sufren, al igual que el resto de agentes del ecosistema mediático, los cambios provocados por la adopción de las TICs por una sociedad 
hiperconectada, hiperactiva y que basa su relación con los medios en la interactividad. Este contexto ha fomentado la adaptación de estos entes públicos a los entornos digitales.

De manera global, el acceso a internet y la penetración del uso de dispositivos móviles para el consumo de contenidos en la sociedad actual ha configurado un nuevo perfil de consumidor que demanda contenidos a través de múltiples canales (medios tradicionales, páginas web, redes sociales, etc.) y de múltiples plataformas (televisión convencional, ordenador, dispositivos móviles, etc.). De este modo, la reconfiguración del contexto ha propiciado que las empresas hayan adaptado sus estrategias de difusión a formatos mixtos.

Los websites de las corporaciones de radiotelevisión públicas analizadas compiten a nivel global, como es normal, con el resto de páginas del universo internet. En este sentido, cabe referenciar el buen posicionamiento de alguna de ellas como es el caso de la BBC de Gran Bretaña que ocupa el puesto 163 en el Web Global Rank mundial. Es meritorio que más de la mitad (16) de los sitios web analizados (30) estén situados entre los ocho mil primeros puestos de este ranking mundial teniendo en cuenta que estamos estudiando websites de radiotelevisiones públicas que difunden un contenido de servicio público y enfoque nacional.

En este contexto, de lucha encarnizada entre los productores de contenido por acaparar la atención de los usuarios con el objetivo de que esta se traduzca en tráfico a sus sites y permanencia en ellos, las radiotelevisiones públicas europeas muestran ciertos signos de debilidad. Tampoco las ratios de abandono (medidos a través de la tasa de rebote) suponen un alivio para unos websites que, como tendencia general, necesitan reemprender un proceso de adaptación a los usos y preferencias de consumo de las audiencias desde una perspectiva digital e interactiva que abogue por la usabilidad como piedra angular. Más aún cuando la tendencia general de consumo de contenido a través de dispositivos móviles irrumpe con fuerza también en el ecosistema de las televisiones públicas europeas, puesto que según los datos recabados el $53 \%$ de los usuarios accede a los websites a través del smartphone o la tablet. 
El nuevo mundo, global e interconectado, redistribuye las nacionalidades a través de sus individuos por lo que ya no están asociadas de manera única e inequívoca a demarcaciones geográficas. Los websites de los entes de radiotelevisión públicos europeos deben dar respuesta, también, a unas audiencias emigrantes que demandan contenido nacional desde el extranjero. Tal y como se ha observado a partir de esta investigación, existen porcentajes relevantes de comunidades que viven fuera de los países de procedencia y se muestran ávidas de contenido que producen y distribuyen los medios públicos.

Las radiotelevisiones públicas europeas se enfrentan, en los próximos años, a grandes desafíos en forma de necesidad de dar respuesta a su esencia de servicio público en un mundo globalizado. Para ello cobra una relevancia vital el uso acertado de todas y cada una de las potencialidades que presenta internet como herramienta de creación de contenido, difusión y gestión del mismo e interacción con unas audiencias que asumen un nuevo rol activo en el proceso comunicativo.

\section{Referencias bibliográficas}

A Ortuzar (2007): "La televisión pública en la era digital", en Transformaciones de la radio y la televisión en Europa, (Ed C Peñafiel Saiz). Vitoria: Servicio Editorial de la Universidad del País Vasco.

B Brevini (2013): "European Commission media policy and its promarket inclination: The revised 2009 Communication on State Aid to PSBs and its restraining effect on PSB online". European Journal of Communication, 28(2), pp. 183-197.

D Buhalis (1998): "Strategic use of information technologies in the tourism industry". Tourism management, 19(5), pp. 409-421.

E Bustamante (1999): La Televisión Económica: Financiación, Estrategias y Mercados. Barcelona: Gedisa.

E Bustamante \& MT García Leiva (2017): "La TDT de servicio público estatal y RTVE: balance y futuro", en Televisión Abierta. Situación actual y Tendencias de futuro de la TDT. Madrid: Colegio Oficial de Ingenieros de Telecomunicación.

EBU (2014): PSM V alues Review: The tool. Ginebra: EBU Press. 
F Campos Freire (2013): "El futuro de la TV europea es híbrido, convergente y cada vez menos público". Revista Latina de Comunicación Social, 68, pp. 89-118.

F Campos Freire (2016): Situación actual y tendencias de la radiotelevisión pública en Europa. Santiago de Compostela: Universidad de Santiago de Compostela / FORTA.

G Lowe \& N Yamamoto (2016): Crossing Borders and Boundaries in Public Service Media. Goteburgo: Nordicom.

GS Enli (2008): "Redefining Public Service Broadcasting: MultiPlatform Participation. Convergence". The International Journal of Research into New Media Technologies, 14(1), pp. 105-120.

H Jenkins \& PH Lazcano (2008): Convergence culture. La cultura de la convergencia de los medios de comunicación. Barcelona: Paidós.

H Van den Bulk (2008): "Can PSB stake its claim in a media world of digital convergence? The case of the flemish PSB management contract renewal from an international perspective". Convergence, 14(3), pp. 329-343.

JC Miguel, R Zallo \& MA Casado (2017): "Las televisiones autonómicas públicas y privadas", en Televisión Abierta. Situación actualy Tendencias de futuro de la TDT. Madrid: Colegio Oficial de Ingenieros de Telecomunicación.

K Kaplanidou \& C Vogt (2006): “A structural analysis of destination travel intentions as a function of web site features". Journal of travel research, 45(2), pp. 204-216.

K Meso \& A Larrondo (2010): Cambios en las estrategias de las audiencias de las páginas web de televisión. Análisis de la participación en los entes públicos autonómicos en España. "II Congreso Internacional Comunicación 3.0”. Universidad de Salamanca, 4 y 5 de octubre de 2010.

K Meso, I Agirreazkuenaga \& A Larrondo (2015): Active audience and journalism. Analysis of the quality and regulation of the user generated contents. Bilbao: Universidad del País Vasco.

L Anton \& J Guallar (2014): "Análisis de los archivos audiovisuales en Internet de las televisiones autonómicas españolas". Revista española de documentación cientifica, 37(1), p. 033.

M Debrett (2009): "Riding the wave: public service television in the multiplatform era. Media", Culture and Society, 31(5), pp. 807827. 
M Ha \& C Love (2005): "Exploring content and design factors associated with convention and visitors bureau web site development: An analysis of recognition by meeting planners. Journal of convention and event tourism, 7(1) pp. 43-59.

M Roel (2010): "Desafíos de la televisión ante la consolidación del ecosistema digital", Ambitos. Revista Internacional de Comunicación, 19, pp.25-42.

MT García Nieto, A Galán Ruiz Santa Quiteria \& I García

Castellanos (2015): “Televisión y redes sociales. ¿'Oportunidad o amenaza?". Telos: Cuadernos de comunicación e innovación, 102, pp. $37-44$.

OberCom (2014): A Internet em Portugal: Sociedade em Rede 2014. Portugal: Publicações OberCom

P. Dahlgren (2007): Media and Civic Engagement: Citizens, Media and Communication. Nueva York: Cambridge University Press.

P Gómez Domínguez (2016): "Era digital y televisión autonómica: un estudio comparativo de las plataformas web, aplicaciones móviles y redes sociales de TV3y BBC One". Communication \& Society, 29(4), 85-106.

R Vinader Segura \& E De la Cuadra de Colmenares (2012):

"Televisión 2.0: las estrategias comunicativas en la Web social". Estudios sobre el mensaje periodístico, 18, núm. Especial noviembre, pp. 909-918.

S Karanasios \& S Burgess (2008): "Tourism and Internet adoption: a developing world perspective". International Journal of Tourism Research, 10(2), pp. 169-182.

S Okazaki (2005): "Searching the web for global brands; How Anerican brands standardize their websites in Europe". European Journal of Marketing, 39 (1/2), pp. 87-109

SM ChanOlmsted \& LS Ha (2003): "Internet business models for broadcasters: How television stations perceive and integrate the Internet”. Journal of Broadcasting \& Electronic Media, 47(4), pp. 597-616.

T Mendiguren Galdospin (2010): “Análisis comparativo de las páginas web de las televisiones locales de la comarca del Gran Bilbao". Zer: revista de estudios de comunicación, 15(29).

JM Túñez-López \& C Costa-Sánchez (2017): "Comunicación online y trafico web de las televisiones públicas en Europa", en JM 
Túñez- López, F Campos-Freire \& A Silva-Rodríguez A. (Eds.). (2017) Estudios sobre financiación, legislación e innovación en la Televisión Pública. Cuadernos Artesanos de Comunicación, cac126, pp. 127-142. La Laguna (Tenerife): Latina.

Y Xin \& Grandt, D. (2006). Developing a framework for measuring physical distribution service quality of multi-channel and "pure player" Internet retailers. International. Journal of Retail and Distribution Management, vol 34, no 4/5, pp. 278-289.

\section{Reconocimientos de la investigación}

Los resultados de este artículo corresponden al proyecto de "Indicadores de gobernanza, financiación, rendición de cuentas, innovación, calidad y servicio público de las RTV europeas aplicables a España en el contexto digital" (Referencia CSO2015-66543-P) del Programa estatal de Fomento de la Investigación Científica y Técnica de Excelencia, subprograma estatal de Generación de Conocimiento del Ministerio de Economía y Competitividad de España, cofinanciado por el Fondo Europeo de Desarrollo Regional (FEDER) de la Unión Europea. Así como de la actividad de la Red Internacional de Investigación de Gestión de la Comunicación (REDES 2016 G-1641 XESCOM) apoyada por la Consellería de Cultura, Educación e Ordenación Universitaria de la Xunta de Galicia (referencia ED341D R2016/019). 


\title{
Reconectar con la audiencia joven. Narrativa transmedia para la transformación de la televisión de servicio público en España, Francia, Alemania y Reino Unido
}

\author{
Ana Azurmendi \\ Universidad de Navarra
}

PARA CITAR: Azurmendi, A. (2018). Reconectar con la audiencia joven.

Narrativa transmedia para la transformación de la televisión de servicio público en España, Francia, Alemania y Reino Unido. Revista Latina de Comunicación Social, 73, pp. 927 a 944.

http:/ www.revistalatinacs.org/073paper/1289/48es.html

DOI: $\underline{10.4185 / R L C S-2018-1289}$

\section{Resumen}

Las televisiones de servicio público de los países europeos están realizando un gran esfuerzo para reconectar con las audiencias jóvenes. El dato de la pérdida dramática de espectadores jóvenes (Ofcom 2016) empuja a los operadores televisivos hacia una adaptación del medio televisivo al entorno cultural convergente. Se realizará una revisión tanto de la literatura sobre las audiencias jóvenes y narrativa transmedia, como de los principios de las instituciones de la Unión Europea sobre el servicio público audiovisual en la era digital. Finalmente, a partir de las aportaciones de la literatura y de la regulación europea, se examinarán los contenidos transmedia más exitosos de las televisiones públicas europeas, como los informativos webdocs de "Lab.rtve.es", "Guernika. Pintura de Guerra" (2007) y "A History of Scotland" (2008); además de los contenidos de entretenimiento "El Ministerio del Tiempo" (2015-2016), "Fais pas ci, fais pas ça", "Sherlock" (2010-2017), "Doctor Who" (2005-2017), "EastEnders" 
(1985), “Goazen!” (2016) y “Alpha 0.7 - Der Feind in dir” (2010). Las iniciativas transmedia en las televisiones públicas europeas, siendo limitadas en su cantidad, representan un esfuerzo por integrar las nuevas narrativas en el servicio audiovisual público y por llegar al público joven.

Palabras clave: Televisiones públicas europeas, audiencia joven, narrativa transmedia, contenidos informativos, contenidos de entretenimiento.

\section{Introducción}

T AS TELEVISIONES de servicio público de los países europeos 1 -entre ellas las televisiones públicas regionales, de gran importancia en el sector audiovisual español- están realizando un gran esfuerzo para reconectar con las audiencias jóvenes, en una situación en la que una mayoría de adolescentes y jóvenes adultos utiliza como dispositivo habitual el móvil, accede a las noticias a través de las redes sociales (Informe Reuters, 2016) y se entretiene y relaciona en Youtube y en Facebook principalmente (Sjöberg y Rydin 2013). El dato de la pérdida dramática de espectadores jóvenes (Ofcom 2016) empuja a los operadores televisivos hacia una adaptación del medio televisivo al entorno cultural convergente. $\mathrm{Y}$ esto significa reflexionar sobre qué transformación debe afrontar la televisión pública para mantener su identidad en un momento de cambio de escenario (cfr. Jenkins 2006, Fanthome 2008, Moe 2008, Tambini 2014).

Desde la eclosión de las redes sociales en 2006, la convergencia digital en las televisiones públicas se ha reconducido hacia la experimentación de nuevos formatos y contenidos transmedia tanto para informar como para entretener, algunos ejemplos son:

a)en la información, el laboratorio multimedia de RTVE (Lab.rtve.es) es una de las mejores expresiones de experimentación transmedia en productos informativos. De forma puntual otras televisiones públicas han logrado éxitos con productos informativos transmedia como "Guernika. Pintura de Guerra" (2007) de la CCMA de Cataluña y "A History of Scotland" (2008) de la BBC One Scotland, en Reino Unido 
b)en el entretenimiento, algunos productos exitosos han sido, Televisión Española La 1 con "El Ministerio del Tiempo" (2015), France 2 con su serie "Fais pas ci, fais pas ça", en antena durante 9 años (desde 2007), la BBC con la serie "Sherlock" (2010), "Doctor Who" (2005) y "EastEnders" (1985) y entre las televisiones regionales, EITB del País Vasco con "Goazen!" (2016) y la SWR (BadenWürttemberg y Renania-Palatinado, Alemania) con "Alpha 0.7 - Der Feind in dir" (2010). Las siete series adoptan una narrativa transmedia en la que el juego, la participación de la audiencia y el visionado de la película se retroalimentan.

Nuestras preguntas de investigación son:

¿Los medios de servicio público pueden cumplir mejor su obligación de promover comunidad, participación y diversidad mediante la adopción de nuevos formatos de la cultura convergente? ¿ ¿ofrecen estos formatos mayores posibilidades para involucrar a las audiencias de forma que pasen de ser espectadores pasivos a ciudadanos participantes? ¿los contenidos transmedia consiguen reconectar la televisión pública con audiencias jóvenes?

Metodología:

En primer lugar, se realizará una revisión de la literatura existente sobre las audiencias jóvenes y los intentos de acercamiento por parte de las televisiones públicas mediante el uso de narrativas transmedia. Con este fin se analizarán publicaciones entre 2010-2017 sobre el tema, además informes de Autoridades Audiovisuales (España, Francia, Alemania, Reino Unido y la European Broadcasting Unión-EBU ${ }^{4}$ y dos de empresas centradas en audiencias (Nielsen, Barvolento) en las mismas fechas.

Una vez delimitadas las aportaciones del transmedia -en términos de valores, contenidos, posibilidades narrativas- especialmente adecuadas para la conexión con los jóvenes, se contrastarán con la definición de servicio público televisivo, tal y como lo interpreta el Tribunal de

\footnotetext{
${ }^{4}$ En particular, el informe EBU, (2017): Vision Project 2020. Connect, grow and influence. Introduction, p. 3. Accesible en https://www.ebu.ch/files/live/sites/ebu/files/Publications/Vision2020_Strate gic Objectives 2017 EN.pdf [con acceso 27 Enero 2018]
} 
Justicia Europeo y la Comisión Europea, con el objeto de determinar si las inversiones en esta área por parte de las televisiones públicas están justificadas.

Finalmente se estudiarán los programas de éxito, previamente seleccionados, de las televisiones públicas (Nacionales: RTVE España, France 2, BBC. Regionales: EITB (Basque Country, Spain), CCMA (Cataluña, Spain), SWR (Baden-Württemberg y Renania-Palatinado, Alemania) y BBC One Scotland (UK). Se tratará de comprobar si esos programas con narrativa transmedia -tanto informativos como entretenimiento-: han tenido éxito, a qué se atribuye su éxito, qué valores de servicio público -creación de comunidad, participación, diversidad- promueven.

\section{Una visión de los contenidos transmedia y su conexión con el público joven}

Desde los estudios sobre las aportaciones de la narrativa transmedia a la producción y difusión televisiva (Garambato, 2017; Rodríguez Fidalgo, Paíno Ambrosio y Jiménez Iglesias 2016; Scolari, Jiménez y Guerrero 2012; y a Meso Ayerdi, Larrondo Ureta, Peña Fernández y Rivero Santamarina 2014) se coincide en afirmar que el soporte multiplataforma es la clave del éxito de la narración transmedia. Al permitir no solo el desarrollo de diferentes contenidos en diversas plataformas, formando parte del mismo universo narrativo, sino que estos contenidos sean independientes, hasta el punto de que tienen sentido completo en sí mismos y, en consecuencia, pueden ser consumidos de forma autónoma. Junto a esta característica, otra esencial del contenido transmedia es que "los consumidores adoptan un rol activo" en el despliegue del relato. Y esto no sólo participando de una forma u otra, sino estableciendo "un diálogo creativo con el relato base, llegando a modificarlo en el proceso" (Pradanos Grijalvo y Enríquez de Salamanca, 2016, Rodríguez y Molpeceres, 2014, cit por Rodríguez Fidalgo, Paíno Ambrosio y Jiménez Iglesias 2016).

Estos aspectos esenciales de la narrativa transmedia sintonizan con la misión de servicio público audiovisual, en la medida en que obliga a las televisiones públicas a replantearse su propia identidad como señalarán Ingegerd y Sjöberj (2013); y también en la medida en que corresponde 
a los servicios públicos audiovisuales estar a la vanguardia de los nuevos modos de la cultura convergente (Moe 2008).

En particular, con respecto al criterio de identidad, en palabras de Sjöberg y Rydin (2013) en su estudio sobre la televisión pública sueca y sus proyectos transmedia, el servicio público se convierte en un "servicio social" al desarrollarse en espacios distintos al de la transmisión convencional, como son los blogs, las redes sociales. También por el empleo de un estilo comunicativo diferente, más personal y más apto para comunicar con audiencias jóvenes. En medio de este proceso de cambio, la corporación pública, si aspira a tener participación en el mercado audiovisual futuro, "está obligada a examinar y reflexionar sobre su propia imagen, tradiciones, hábitos, prácticas cotidianas y organización” (Sjöberg y Rydin 2013).

Respecto a la función de experimentación que asumen las televisiones públicas al incorporar contenidos transmedia, tanto Sjöberg y Rydin como Moe y Jenkins consideran que, al hacerlo, afrontan un gran desafío. El de crear un contenido que sea atractivo no sólo frente a otras producciones comerciales de televisión sino también frente a otros tipos de servicios de Internet, como YouTube, Facebook, videojuegos (Sjöberg y Rydin 2013). Es decir, la televisión pública sería una especial protagonista de la tensión entre la cultura de la radiodifusión de los Estados nación de la Europa Occidental y la cultura de la convergencia comunicacional (Moe 2008). Del choque entre la comunicación proveniente de organizaciones consolidadas y la cultura aficionada, comparticional, del contenido generado por el usuario (Jenkins 2006).

Sin embargo, este estudio parte de un análisis realista. En lo que respecta a España, a las televisiones públicas -nacional y autonómicasles quedan muchos pasos por dar aún en la experimentación y desarrollo de las narrativas transmedia. Como concluyen Meso Ayerdi, Larrondo Ureta, Peña Fernández y Rivero Santamarina (2014) para avanzar en una "mayor articulación de las estrategias interactivas" es imprescindible una mayor inversión y desarrollo de aplicaciones y formatos audiovisuales para smartphones (Zeiser 2015). Porque hoy por hoy, las aplicaciones móviles de los cibermedios españoles limitan de manera muy significativa las opciones de participación e interacción de los usuarios. Hasta el punto de que lo habitual es un simple traslado 
de contenidos creados para televisión al formato de pantalla de los móviles. Las televisiones públicas francesa, británicas y alemanas, ofrecen un panorama semejante, en el que sólo algunos casos aislados de contenidos transmedia han tenido un notable éxito de audiencia (Carlson, 2014).

\section{E1 servicio público de televisión, demanda de una necesaria implicación para experimentar en fórmulas innovadoras}

El contexto en el que se plantea la discusión sobre los contenidos transmedia en el servicio público audiovisual es el de la crítica hecha por las televisiones comerciales al hecho de que se extienda el calificativo de servicio público a los nuevos servicios de Internet. Una crítica que surge desde el primer momento en el que las televisiones públicas y comerciales- comienzan a construir sus plataformas digitales en la segunda mitad de los 2000. A pesar de que, como señalan Miguel de Bustos, Casado y Galindo (2012) "en general, en Europa existe un viento favorable hacia la existencia del servicio público de radiotelevisión. Sin embargo, comienzan los ataques desde diferentes ángulos".

Un primer paso de la Unión Europea a favor de ampliar el concepto de servicio público a las nuevas posibilidades comunicacionales de Internet está representado por la Sentencia del Tribunal de Justicia sobre la Televisión pública danesa, TV2, $(2008)^{5}$, en la que se afirma que los Estados miembros deben decidir sobre la definición del servicio público. En concreto, se señala, la misión de servicio público puede - debería- ser definida a través de televisión, radio e Internet $(\mathrm{N}$. 115, TV2-Denmark, T-309/04).

Por otro lado, la Comisión Europea, en su "Comunicación sobre ayudas del Estado a las Empresas de Radiodifusión Públicas", de 2 de julio de $2009^{6}$, señala la necesidad de analizar ex-ante el impacto en el mercado de los nuevos servicios audiovisuales en Internet. Aunque, en particular, lo que interesará de este documento no es tanto la defensa que hace de la calificación de "servicios públicos audiovisuales" para los contenidos y acciones de las plataformas digitales, como la llamada

\footnotetext{
${ }^{5}$ Referencia completa al final del artículo, en Referencias.

${ }^{6}$ Referencia completa al final del artículo, en Referencias.
} 
de atención sobre los aspectos que considera incompatibles con el servicio público.

Así la Comunicación defiende que, independientemente de la tecnología, hablar de servicio público es hablar de un nivel determinado de "calidad" en los contenidos y actividades desarrolladas. También señala que estarían bajo la denominación de servicio público "el desarrollo y la diversificación de las actividades en la era digital" que incluirían "servicios audiovisuales en todas las plataformas de distribución" (n. 47 Comunicación sobre ayudas del Estado, de 2 de julio de 2009). De forma que los medios públicos, siguiendo este documento de la Comisión, deben poner «al alcance de los ciudadanos los beneficios de los nuevos servicios audiovisuales y de información y de las nuevas tecnologías» y emprender «el desarrollo y la diversificación de actividades en la era digital" (n. 2 Comunicación sobre ayudas del Estado, de 2 de julio de 2009).

En cuanto a los aspectos que la Comunicación señala como incompatibles con el servicio público audiovisual en la era de la conectividad digital, se señalan aquellos contenidos y servicios que no satisfacen necesidades democráticas, sociales y culturales, como por ejemplo, el comercio online (cfr. n 48 Comunicación sobre ayudas del Estado, de 2 de julio de 2009).

Resumiendo, las líneas dibujadas por el Tribunal de Justicia y la Comisión Europea para el servicio público audiovisual digital, los servicios multiplataforma deben responder como servicio público a las necesidades sociales, culturales y democráticas de una sociedad. Deben aportar un valor añadido de servicio público.

\section{Los programas seleccionados}

Son muchas las perspectivas desde las que un contenido transmedia puede analizarse. En nuestro caso, teniendo en cuenta que lo que buscamos es contrastar si ese tipo de narrativa en los contenidos audiovisuales -y su particular difusión- significa conexión con la audiencia joven y participación de este público, nuestra selección de contenidos transmedia responde al criterio simple de que esos programas o contenidos existan o hayan existido y hayan tenido éxito. 
Se seguirá la división información-entretenimiento con el fin de hacer una comparación más adecuada de los valores de conexión y participación de la audiencia.

\subsection{Contenidos informativos transmedia de las televisiones públicas europeas}

Los contenidos informativos transmedia seleccionados tanto de televisiones públicas europeas nacionales como regionales, tienen en común el haber sido pioneros en la experimentación con nuevas formas de narrar los reportajes y noticias. Es muy notoria la evolución en la complejidad narrativa, de forma que los contenidos primeros, muy simples en su manera de combinar película y contenidos complementarios en Internet, han dado lugar a narrativas totalmente diferentes, que significan una nueva experiencia para el usuario.

\section{1.a. RTVE, Laboratorio de Innovación Audiovisual (Lab.rtve.es)}

El Laboratorio de Innovación Audiovisual, activo desde 2008 con el nombre de Medios Interactivos de RTVE, comenzó con una acción de carácter ciudadano, un portal de vídeos -en alianza con Youtube- para las Elecciones Generales de 2008. Cualquier persona podía enviar preguntas en vídeos que se integraban en el portal. Al mismo tiempo, los usuarios podían votar las preguntas favoritas y, de entre ellas, RTVE hizo una selección para retransmitirlas en las entrevistas a los candidatos que TVE realizaría con motivo de los espacios electorales televisivos asignados a los partidos políticos. La iniciativa estuvo inspirada en el exitoso programa "Tengo una pregunta para usted"7. Pero estos inicios exitosos han derivado en contenidos informativos también experimentales, como los webdocs "Lo que hicimos fue secreto" (2018), en palabras de RTVE.lab " un proyecto transmedia de contenido histórico, musical y social que abarca un webdoc y un largometraje en los que se analiza la influencia de las subculturas punk

\footnotetext{
${ }^{7}$ Rosalía Lloret, directora de Medios Interactivos de RTVE, en declaraciones a la Cadena Ser, 23 enero de 2008, accesible en http://cadenaser.com/ser/2008/01/23/ciencia/1201058667_850215.html [Con acceso 25.1.2018]
} 
y hardcore en Madrid" (lab.rtve.es/webdocs/secreto/) o "Alberto García-Alix, la línea de la sombra" (2017) acerca de la obra y universo del fotógrafo ( lab.rtve.es/webdocs/la-linea-de-sombra/); y vídeos de realidad inmersiva como "Cervantes VR" (2017) (lab.rtve.es/cervantes/), o "Escena 360" La Cocina" (2016) en colaboración con el Centro Dramático Nacional (CDN) y el Instituto Nacional de las Artes Escénicas y de la Música (INAEM) ( lab.rtve.es/escena-360/la-cocina/) con apps que se asemejan más a demos que a un contenido de difusión cultural.

Tal y como apunta Miriam Hernanz, responsable del Lab RTVE, con los formatos renovados como el webdoc, el periodista tiene más recursos para trasladar mejor el mensaje e impactar en el público; al mismo tiempo, y éste sería el cambio más significativo "es el usuario quien decide hasta dónde llegar, cómo consumirlo, qué nivel de profundidad de conocimiento quiere alcanzar, a qué ritmo quiere que le cuenten la historia» (Vázquez-Herrero y López-García 2017, p. 51).

El despliegue de recursos es notorio, como lo es también la diversidad de modos narrativos integrados en cada uno de los contenidos informativos. La calidad, la elección de los temas, sitúan este esfuerzo de RTVE como uno de los mejores exponentes de transmedia informativa de televisiones públicas europeas.

Sin embargo, el acceso a los contenidos de Lab.rtve.es desde teléfonos móviles es muy limitado, en la medida en que muchos de ellos remiten a la web para ordenador. Al final esta limitación incide en una menor difusión de los productos transmedia de Lab.rtve.es entre el público joven.

\section{1. b. “Guernika. Pintura de Guerra” (2007) CCMA}

"Guernika. Pintura de Guerra" (2007) es un documental interactivo de TV3, la televisión de la CCMA de Cataluña. Se emitió en el programa de reportajes "30 minuts". Versa sobre la historia del cuadro de Picasso, con imágenes inéditas como las del interior del pabellón español de París, filmadas por el Partido Comunista de Francia, así como con entrevistas a Maya Picasso, hija del pintor, a Roland Dumas, quien fue su abogado, Luis Iriondo, superviviente del bombardeo de Guernika, entre otros testimonios. El programa permite la interactuación con la audiencia a través de una página web en la que, 
además de poder volver a ver el documental, se accede a material complementario con análisis del cuadro, documentos, entrevistas, biografías y juegos. El acceso desde teléfono móvil consiste en un redireccionamiento a la web del programa "30 minuts" de TV3, no hay un desarrollo específico para este dispositivo de especial conexión con la audiencia joven.

\section{1. c. "A History of Scotland" BBC One Scotland}

BBC One Scotland, la extensión regional de BBC en Escocia, comenzó las emisiones de la serie histórica "A History of Scotland" en noviembre de 2008. Tuvo éxito de audiencia y se emitió también en BBC Two para todo Reino Unido. Contó con una segunda temporada en 2010. Sin embargo, las críticas sobre el sesgo inglés de la serie acompañaron a "A History of Scotland" desde el inicio de su primera temporada. Así, el periódico "The Independent" , entre otros, señalaba que la serie, verdaderamente espectacular daba en la diana de la "Escocia cívica y su élite académica", dividiendo a quienes consideran que representa una perspectiva genuina y "visualmente sorprendente" del pasado de Escocia y quienes ven en ella un deseo de complacer las perspectivas inglesas. Desde el punto de vista del esfuerzo transmedia "A History of Scotland" es un intento incipiente de combinar televisión convencional con web en la que se integran una newsletter, clips, episodios anteriores y contenidos relacionados con la serie. Tiene un desarrollo específico para teléfono móvil, dentro de la web para móvil de la BBC.

\subsection{Contenidos de entretenimiento transmedia de las televisiones públicas europeas}

Es en el entretenimiento donde el despliegue de las nuevas formas narrativas transmedia han tenido más acogida por parte de la audiencia. Entre los productos transmedia exitosos de televisiones públicas europeas, se han seleccionado los que han tenido una mayor

\footnotetext{
8 “The Independent" Paul Bignell, BBC hit by row over 'History of Scotland' Advisers on landmark new television series quit in protest against its 'anglocentric bias' 9 de noviembre de 2008, en http://www.independent.co.uk/news/media/tv-radio/bbc-hit-by-row-overhistory-of-scotland-1003951.html [con acceso 25 de enero de 2018].
} 
permanencia, más de dos temporadas, además de presentar un despliegue de plataformas de difusión con otros contenidos y recursos. En todos los casos se trata de series de ficción: Televisión Española La 1, "El Ministerio del Tiempo" (2015-2017) tres temporadas; France 2 con su serie "Fais pas ci, fais pas ç"a (2007-2016), en antena durante 9 años; la BBC con las series "Sherlock" (2010-2017) con cuatro temporadas hasta 2017 y negociaciones para una quinta temporada en 2019, "Doctor Who" (2005-2017), en la actualidad en su 13 temporada dentro de su segunda edición (la primera edición se emitió entre 1963 y1989) y "EastEnders" telenovela que se emite desde 1985, aunque como contenido transmedia desde 2010. Entre las televisiones regionales, EITB del País Vasco con "Goazen" (2016) y la SWR (Baden-Württemberg y Renania-Palatinado, Alemania) con” Alpha 0.7 - Der Feind in dir" (2010). Las siete series adoptan una narrativa transmedia en la que el juego, la participación de la audiencia y el visionado de la película se retroalimentan.

\section{2.a. "El Ministerio del Tiempo" (2015-2017), RTVE}

"El Ministerio del Tiempo", obra de Javier y Pablo Olivares para RTVE, es una serie de ficción histórica y fantástica al mismo tiempo. Tal y como se presenta en su web (http://www.rtve.es/television/ministerio-del-tiempo/la-serie/) la historia gira alrededor de una agencia gubernamental española, secreta, que gestiona el paso a otras épocas de la historia de España. Esa transición se realiza a través de las puertas vigiladas por las Patrullas del Ministerio. El cometido de estos guardianes es evitar que las personas se muevan de una época a otra, hacia el futuro o hacia el pasado, cuando desean cambiar el curso de la historia para su beneficio. Es la obra transmedia por excelencia del panorama televisivo español. Cuenta con fans, plataformas narrativas diversas - web, miniepisodios, cuentas en redes sociales- ha experimentado con realidad virtual, experiencia audiovisual inmersiva, interactuación con los seguidores de la serie, etc. Paradójicamente su audiencia en televisión convencional, en los episodios más vistos, se ha situado entre los 2,5 millones y 2, 9 millones, y un share entre el 12,8\% y el 14,8\% (Fórmula TV 2018) ${ }^{9}$.

${ }^{9}$ Fórmula TV en http://www.formulatv.com/series/el-ministerio-del-tiempo/ [con acceso 25 de enero de 2018]. 
Quizás una buena audiencia, pero no la esperable para un producto de esta factura. Más aún cuando la actividad en redes sociales tanto por parte de la serie como por parte de los fans y seguidores es muy importante. Hasta el punto de que, como señala Zambrano (2016), su interacción en las distintas plataformas, incluídas el teléfono móvil, ha sido decisiva en términos de trama, valoración de los personajes y de implicación para que se produjera la segunda y tercera temporada de "El Ministerio del Tiempo" (un fenómeno descrito ampliamente por Scolari y Establés, 2017). En junio de 2017, mediante un acuerdo con Netflix, la plataforma streaming se ha quedado con los derechos de la emisión online y gestión internacional de "El Ministerio del Tiempo", una vez que la serie se emita en TVE. En la actualidad Netflix ofrece, en 190 países, las dos primeras temporadas y hará lo mismo con la tercera, una vez transcurridos 18 meses desde su difusión. Se inicia de este modo una nueva etapa para la evolución transmedia de la serie.

\section{2. b. "Fais pas ci, fais pas ça" (2007-2017), France 2}

"Fais pas ci, fais pas ça" ("No hagas esto, no hagas lo otro") es una comedia desarrollada a partir de la historia de dos familias con ideologías y métodos de educación contrapuestas y que, sin embargo, son vecinos en el mismo bloque de pisos. Su amistad les lleva a situaciones en las que se evidencia de forma cómica su diferente modo de afrontar los problemas cotidianos. Se trata de una serie que ha obtenido desde su primer año en antena numerosos premios, el más importante el Emmy Internacional 2015 al Mejor Programa de Comedia. La primera temporada comenzó con una serie de programas de falso documental y reality, en el que se argumentaba acerca de los diversos métodos de educación y sus efectos sobre los niños, para iniciar así la presentación de las dos familias protagonistas de la comedia televisiva. A partir de la cuarta temporada "Fais pas ci, fais pas ça" inauguró su web con contenidos complementarios, con episodios anteriores, más información sobre los personajes, pero en su mayor parte remitía al sitio de la serie en la web de France 2. Para el acceso a la serie y sus complementos de contenido desde el teléfono móvil, tiene una versión reducida de la web que no resulta incómoda para la navegación. El programa tiene presencia limitada en redes sociales, con 176.700 seguidores en Facebook y 4.500 en Twitter, en diciembre de 2017. Contó con una audiencia media ese mismo año de 3,79 millones 
de telespectadores, un 15,2\% rating de audiencia ${ }^{10}$, una cota inferior a sus años de mayor éxito, como en 2014, en los que llegó a alcanzar 5,1 millones de telespectadores, un 19,9\% rating de audiencia ${ }^{11}$. La serie se ofrece completa en Netflix.

\section{2.c. "Sherlock" (2010-2017), “Doctor Who" (2005-2017) y "EastEnders" (1985) BBC}

El gran éxito de la narrativa transmedia de la BBC lo constituye la serie "Sherlock", una versión moderna del clásico de la literatura británica. En opinión de Stein y Busse (2012), además de la interacción con el público que se da en la serie, "Sherlock" es un modelo de nueva narración porque realiza una extensión transmedia de elementos de la película a elementos, en principio, externos a ella como el blog de Watson y la Web del servicio de detective de "Sherlock". A la vez, el uso por parte del protagonista principal de la serie de mensajes de texto, Internet y GPS para resolver los crímenes consigue una narración coherente que traspasa todas las plataformas. Yendo al caso específico transmedia: Watson aparece como un blogero inexperto, un ciudadano digital no demasiado hábil mientras que "Sherlock" mismo mantiene una web "The Science of Deduction" como la web de su servicio de detective donde ofrece su expertise e interactuación con los potenciales clientes. Al final se trata de dos formas narrativas diferentes que completan la película, puesto que en determinados momentos claves los personajes se comunican a través de la web de "Sherlock" o obtienen información importante del blog de Watson. El público puede visitar tanto el blog como la web y explorar los rastros digitales más allá de los límites del programa de televisión. Aunque, como destaca Busse (2012), no se anima a ser fan, ni se pretende hacer un forum entre espectadores y guionistas. Sin embargo, de forma espontánea se han organizado foros de fans de "Sherlock" en Internet. En términos de audiencia, la serie "Sherlock" ha llegado a alcanzar con algunos episodios -en concreto el de Navidad de 2016- un 34,5\% de audiencia, siendo el programa más visto de la televisión británica, con

${ }^{10}$ OZAP.com, en http:/ / www.ozap.com/actu/audiences-bilan-en-nette-baissepour-l-ultime-saison-de-fais-pas-ci-fais-pas-ca/520169, [con acceso 31 de enero de 2018].

11 OZAP.com, en http://www.ozap.com/actu/audiences-record-historiquepour-fais-pas-ci-fais-pas-ca/460080, [con acceso 31 de enero de 2018]. 
11,6 millones de espectadores ${ }^{12}$. Fuera del Reino Unido se ha distribuido en 224 países en el mundo (BBC Report 2014). En la actualidad Netflix ofrece 4 temporadas de la serie. La serie cuenta con una extensión para teléfono móvil en la que todos los contenidos son fácilmente accesibles.

Por su parte, "Doctor Who" es un fenómeno cultural británico (Cuen 2013). Es una serie de ciencia ficción que lleva más de 50 años funcionando en la BBC. Primero como película convencional, entre 1963 y1989 y luego, en 2005, como serie con extensiones en Internet. Su protagonista, el Doctor, es un viajero del tiempo y el espacio que puede regenerarse antes de morir y cambiar su físico y personalidad, aunque conservando su historia y recuerdos (Cuen 2013). Una peculiaridad de "Doctor Who" es que, desde sus inicios, contó con asociaciones de fans que hacían eco del producto televisivo en sus más diferentes aspectos. Junto a esto, también en su etapa pre-Internet, la serie dio lugar a ficciones derivadas -que configuraron el universo "Doctor Who" - como "Dr. Who and The Daleks" y "Daleks Invasion Earth 2150AD", además de una colección de libros, comics y merchandising (Collins 2013). Entre 1990 y 2005, escritores, actores, guionistas, productores de videos, de audios, de libros relacionados con "Doctor Who", impulsados muchas veces por la demanda de los fans, contribuyeron a mantener el universo de la serie. De forma que cuando la BBC decidió el regreso de "Doctor Who", se encontró con una base transmedia que exploraría y ampliaría (Collins 2013). Blogs de los protagonistas, sitios en Internet -buscados por alguno de los actores en el episodio- que podían encontrarse al mismo tiempo en el Google real, ficciones breves descargables en móviles desde el sitio de la serie en la web de la BBC, que añadían información de los episodios, y dos series secundarias en las que se superponían personajes y situaciones de "Doctor Who", como "Torchwood" y "The Sarah Jane Adventures". En términos de aceptación fuera del Reino Unido, se ha distribuído en 98 países, en 15 idiomas diferentes (BBC Report 2014). En el Reino Unido las audiencias, siempre altas, han variado a lo largo de los años. En 2014 llegó a tener un 32.5\% de audiencia, y 6,8 millones

\footnotetext{
${ }^{12}$ Dato obtenido en http://www.bbc.co.uk/mediacentre/latestnews/2016/"Sherlock"consolidated-ratings, [con acceso 25 de enero de 2018].
} 
de espectadores de media durante el año; en 2015, su máximo rating de audiencia fue $21,2 \%$ de audiencia y una media de 4,6 millones de espectadores, unas cifras que se han mantenido en 2016 y 2017 (4 millones de espectadores ${ }^{13}$ ). La serie se ofrecía en su versión clásica y moderna en Netflix, hasta febrero de 2016. A partir de esta fecha es Amazon Prime quien ofrece las 8 últimas temporadas de "Doctor Who" junto con los episodios especiales de $\mathrm{Navidad}^{14}$. Al igual que los demás productos transmedia de la $\mathrm{BBC}$ tiene una extensión específica para teléfono móvil, que permite acceder a todos los contenidos de la serie.

"EastEnders" es una telenovela de BBC One. Se emite desde 1985. La historia gira alrededor de la vida cotidiana en un barrio de una ciudad ficticia, que representa un entorno urbano común al de muchas ciudades británicas. En muchas ocasiones la trama se centra en temas que suscitan polémica o que rompen con las costumbres sociales del momento. Cuenta con un blog -en el sitio de la BBC, http://www.bbc.co.uk/blogs/"EastEnders"-_ que desarrolla contenidos alternativos a la serie, con información sobre los personajes, adelantos de la historia de los episodios próximos; desde 2010 amplía su mundo narrativo mediante un spin-off "EastEnders20", una plataforma que trata de llamar la atención sobre todo a los adolescentes y jóvenes, a quienes invita a crear episodios de la serie para Internet. "EastEnders20" tiene presencia en Twitter (2,5 millones de seguidores, en enero de 2018, dedicado sobre todo, tal y como señala en su perfil a los cotilleos sobre los personajes de la serie), Facebook (3,4 millones de seguidores en enero de 2018) y YouTube. En 2010 y en 2015 tuvo su máxima audiencia con episodios que

\footnotetext{
${ }^{13} \mathrm{http}$ // www.doctorwhotv.co.uk/doctor-who-series-10-2017-uk-ratingsaccumulator-84045.htm y http://guide.doctorwhonews.net/info.php [con acceso 25 de enero de 2018].

${ }^{14}$ Reuters, "Amazon Prime Snags '"Doctor Who"'" Fortune, 22 de marzo de 2016 en http:// fortune.com/2016/03/22/exclusive-bbc-pact-sends-doctorwho-to-amazon-prime/ [con acceso 2 de febrero de 2018].
} 
alcanzaron los 16.6 millones ${ }^{15}$ y 10 millones de espectadores ${ }^{16}$, respectivamente. El episodio de 2015 tuvo además 30.000 tuits en el minuto posterior al desenlace y más de 500.000 tuits $^{17}$ en los episodios previos. En los dos casos el climax lo alcanzó la revelación de la identidad del asesino que había causado una gran alarma en el barrio. La media de espectadores de la serie ha sido de 7.5 millones de espectadores en 2016 y 7.1 millones en $2017^{18}$. Su extensión para teléfono móvil es una excelente herramienta de acceso a los contenidos, también a "EastEnders20", tiene además una app "Walford East-Enders" cuya presentación es "con noticias, vídeos y chismes que necesitaría cualquier fan EastEnders".

\section{2.d. “Goazen!” (2016) EITB (País Vasco)}

La serie transmedia "Goazen" (¡Vamos!) es un musical en euskera, dirigido a adolescentes y jóvenes. Tuvo su origen en la película de 2009 "Goazen!", producida por Pausoka y ETB. Un producto que promovió desde el primer momento el fenómeno fan, mediante la cercanía entre telespectadores y actores. Para su difusión, previamente al estreno en la televisión autonómica vasca, se emitió en 63 pueblos del País Vasco. Según datos de EITB, "Goazen!" en su difusión en televisión obtuvo un 7,5\% de share (en el País Vasco) con 66.000 espectadores. Entre los menores, fue vista por un $24,4 \%$ de la audiencia (del País Vasco). En 2009 se emitió como serie (12 capítulos) en EITB, con buenos niveles

${ }^{15} \mathrm{BBC}$, website, 20 febrero de 2010 , en http://www.bbc.co.uk/pressoffice/pressreleases/stories/2010/02_february/20 /"EastEnders".shtml, [con acceso 31 de enro de 2018].

${ }^{16}$ The Independent, 20 de febrero de 2015, En http://www.independent.co.uk/arts-entertainment/tv/news/"EastEnders"becomes-most-watched-tv-programme-of-the-year-audiences-all-of-a-twitterover-lucy-beale-10059078.html. [Con acceso el 31 de enero de 2018].

${ }^{17}$ The Independent, 20 de febrero de 2015. Datos recogidos por The Independent de Kantar Media) en los episodios previos al del desenlace. ${ }^{18}$ Darvil, David, Latest 2017 viewing figures for "Coronation Street", "EastEnders", Emmerdale. Soap viewing figures 2017, Tellmix news.com RATINGS! En https://tellymix.co.uk/soaps/305276-ratings-latest-2017viewing-figures-coronation-street-"EastEnders"-emmerdale.html [con acceso 31 de enero de 2018. 
relativos de audiencia. La segunda temporada se hizo esperar hasta 2016 (10 episodios), ya con una extensión de los contenidos en Internet, como su web eitb.eus/goazen, en la que era posible volver a ver los mejores momentos de la serie, canciones, galerías de fotos y vídeos extras, así como los episodios completos de 2009 en la sección "Go!azen 2.0.". El incremento de vías de interactuación con la serie en la tercera temporada de 2017 (13 capítulos) se ha traducido en el lanzamiento de una app que ofrece acceso a diferentes contenidos de "Goazen!". Por otro lado, la serie tiene un desarrollo específico para teléfono móvil.

Para esta serie, EITB ha contado con el apoyo del Departamento de Cultura y Política Lingüística del Gobierno Vasco y la Dirección de Igualdad Lingüística de la Diputación Foral de Gipuzkoa, quienes comprenden el proyecto como una forma de incrementar la presencia del euskera en las redes sociales, además de en la producción audiovisual y en el uso entre los jóvenes (EITB 2017).

\section{2.e. "Alpha 0.7 - Der Feind in dir" (2010) SWR (Baden- Württemberg y Renania-Palatinado, Alemania)}

La televisión regional SWR (Südwestrundfunk) de BadenWürttemberg y Renania-Palatinado (sur de Alemania) lanzó en 2010 la serie de ciencia ficción "Alpha 0.7- Der Feind in dir" (Alpha 0.7-El enemigo en ti). Previamente a la emisión de los 6 episodios de 25 minutos cada uno, la SWR realizó una campaña dirigida al público joven para dar a conocer la serie con información, blogs y clips ${ }^{19}$. La historia tiene como protagonista a una joven de un mundo futuro que lucha por el control de su vida. Sin su conocimiento, Johanna Berger nombre de la joven, a quien han colocado un chip en el cerebro- se convierte en el foco de un experimento neurocientífico del departamento Pre-Crime-Centers del Estado. La finalidad de la investigación es el aumento de seguridad para todos los ciudadanos alemanes. Incluso la empresa que realiza la implatanción de chips neuronales, llamada Protecta, se presenta ante el público como un

\footnotetext{
${ }^{19}$ Rainer Tittelbach, Tittelbach.TV, Serie Alpha 0.7 - Der Feind in dir, del 12 de noviembre de 2017, en http:/ / www.tittelbach.tv/programm/serie/artikel1135.html, [con acceso 2 de febrero de 2018].
} 
benefactor de la humanidad. Una imagen positiva que se refuerza por un spot televisivo en el que un violador convicto elogia el sistema de control del cerebro ciudadano y salvándolo de una vida en la cárcel. La protagonista tiene un blog, en el que explicará sus razones para aceptar el contrato para trabajar para Protecta. Desde la película se muestran documentos del mundo real, como entradas de Wikipedia sobre estimulación cerebral o esquizofrenia paranoide, que cobran sentido especial en su relación con la ficción de “Alpha 0.7”. La protagonista, en su intento de escapar del control de Protecta, contará con la ayuda de los activistas de Apollo, una corriente subversiva que lucha contra la vigilancia invasiva de los ciudadanos por parte del Estado.

Lo más relevante de "Alpha 0.7 -Der Feind in dir" es que, desde su inicio, se planteó una narrativa transmedia, en la que se establecieron narrativas independientes de la serie, a través de áreas de acción en Internet (www.alpha07.de) y en radio ${ }^{20}$. De hecho, el anuncio de la serie en noviembre y diciembre de 2010 se hizo bajo el lema "No una serie. Un universo". Por falta de fondos, la serie no ha tenido una extensión en videojuegos de realidad inmersiva, uno de los propósitos iniciales de sus creadores (Leicht, 2017 p.531). Pero tampoco tiene una extensión de contenidos específica para teléfono móvil. El esquema narrativo de "Alpha 0.7 -Der Feind in dir" lo sintetiza Ryan (2013) de a siguiente forma:

${ }^{20}$ Film starts, http://www.filmstarts.de/serien/9427.html [con acceso 31 de enero de 2018]. 


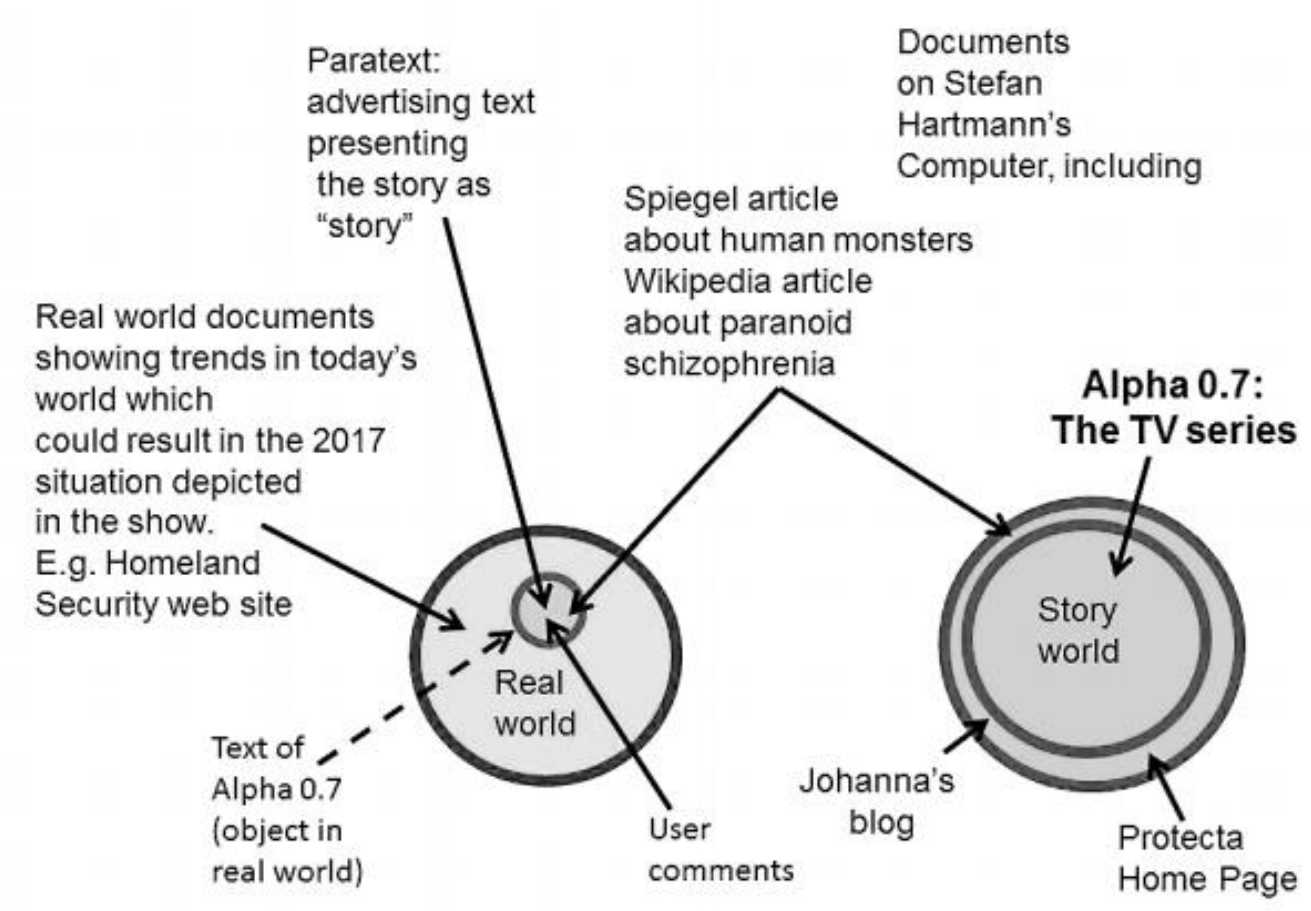

Cuadro obtenido de Ryan, Marie-Laure (2013), Transmedial Storytelling and Transfictionality, p. 376.

En opinión de Ryan (2013, p. 384) el atractivo de "Alpha 0.7" no reside tanto en la acción narrativa -es un thriller bastante convencional- como en la dramatización de cuestiones éticas que preocupan a todos los ciudadanos. Principalmente el dilema entre la seguridad y la libertad personal y la capacidad cada vez mayor de la neurociencia para conocer y controlar el cerebro. Los creadores de “Alpha 0.7” tuvieron más éxito creando un universo que una historia (Ryan, p. 384). Sin embargo, de forma paradójica, los fans de la serie han seguido mucho más la película que los contenidos periféricos transmedia. En este sentido "Alpha 0.7" representa un fracaso como fenómeno popular (Ryan 2, p. 34).

\section{Aplicación a estos contenidos transmedia de los principios sobre servicios públicos audiovisuales europeos}

Tal y como nos planteamos en el inicio del estudio, quedarían por aplicar los principios de servicio público televisivo establecidos por la Sentencia del Tribunal de Justicia sobre la Televisión pública danesa, TV2, (2008) ${ }^{21}$ y por la Comunicación de la Comisión Europea de 2009, sobre "Ayudas del Estado a las empresas públicas de radiodifusión",

${ }^{21}$ Referencia completa al final del artículo, en Referencias. 
de 2 de julio ${ }^{22}$, con el fin de determinar si la innovación que representa la narrativa transmedia con sus aportaciones -desde el punto de vista de la conexión con la audiencia joven y con la promoción de la participación- puede incluirse también dentro de la misión de servicio público televisivo.

Los programas transmedia de las televisiones públicas estudiadas sí entrarían en el área conceptual de servicio público audiovisual desde el punto de vista de que son experimentos de innovación narrativa en el entorno convergente mediático. Significan un esfuerzo notable dentro del "desarrollo y la diversificación de las actividades en la era digital" para "incluir servicios audiovisuales en todas las plataformas de distribución” (Comunicación Comisión Europea 2009: n 47).

En cuanto a los contenidos transmedia informativos como "Laboratorio de Innovación Audiovisual RTVE (Lab.rtve.es)", "Guernika. Pintura de Guerra" (2007) de CCMA y "A History of Scotland" (2008) de BBC One Scotland, las referencias a la información de actualidad, a las realidades culturales ("Laboratorio de Innovación Audiovisual RTVE" y "Guernika. Pintura de Guerra" de CCMA) e históricas ("Guernika. Pintura de Guerra" y "A History of Scotland" de BBC One) cumplen con el objetivo de servicio público de poner «al alcance de los ciudadanos los beneficios de los nuevos servicios audiovisuales y de información y de las nuevas tecnologías».

En lo que se refiere a la conexión con el público más joven, sólo "Laboratorio de Innovación Audiovisual RTVE (Lab.rtve.es)" cumpliría esa condición.

Respecto a los programas de entretenimiento, se plantearían dos aspectos. En primer lugar, si resulta suficiente la experimentación con nuevas herramientas tecnológicas y formas de narración para justificar que se ofrece un servicio público. En segundo lugar, si el intento de reconexión con el público joven también responde a una misión de servicio público.

La Sentencia del Tribunal de Justicia Europeo sobre la Televisión pública danesa, TV2, (2008) confirma que "es legítimo que los servicios públicos de radiodifusión hagan lo posible para llegar a una amplia

${ }^{22}$ Ibidem. 
audiencia" (N. 106, TV2-Denmark , T-309/04)23. Considera como funciones adecuadas de una televisión pública ofrecer "noticias, información, instrucción, arte y entretenimiento" (N.115, TV2Denmark, T-309/04).

La Comunicación de la Comisión Europea "sobre ayudas del Estado", de 2 de julio de 2009, clarifica que, independientemente de la tecnología, hablar de servicio público es hablar de un nivel determinado de "calidad" en los contenidos y actividades desarrolladas; en este sentido quedarían descartados los contenidos y servicios que no satisfacen necesidades democráticas, sociales y culturales, como por ejemplo, el comercio online (cfr. n 48 Comunicación sobre ayudas del Estado, de 2 de julio de 2009). Por lo tanto, no sería suficiente sólo el esfuerzo por hallar nuevas narrativas a partir de la tecnología disponible, tal y como todas las televisiones públicas estudiadas han hecho, si los contenidos no fueran de calidad.

En esta línea, entre los contenidos transmedia de entretenimiento estudiados, destacarían los que cumplen una función de difusión cultural-histórica, como "El Ministerio del Tiempo" (2015) de RTVE y los que contribuyen al incremento de uso de una lengua propia, caso de "Goazen!" (2016) EITB del País Vasco. Por otro lado el tema planteado por "Alpha 0.7. -Der Feind in dir" (2010) de SWR (BadenWürttemberg y Renania-Palatinado, Alemania) acerca de la libertad de los ciudadanos frente al control de los Estados, contribuye al debate social y político. E incluso en la serie francesa "“Fais pas ci, fais pas ça"' (2010-2017) de France 2, y en la telenovela británica "EastEnders" (1985) de la BBC, existe un intento de coadyuvar a la cohesión social, a partir de la presentación de conflictos, puntos de vista diferentes de los ciudadanos, temas polémicos que se tratan de conciliar en el transcurso de los episodios. En cuanto a "Sherlock" (2010-2017) BBC, la calidad del contenido está avalado por el hecho de ser una recreación de un clásico de la literatura británica. Mientras que "Doctor Who" (2005-2017) BBC, con su trayectoria previa entre 1963 y 1989, es un fenómeno cultural en sí mismo (Cuen 2013).

${ }^{23} \mathrm{El}$ Tribunal de Justicia recoge en este caso el texto del "Protocolo de Amsterdam, Anexo 11, Sobre el Servicio Público de Radiodifusión” de 1997. 
La reconexión de la televisión pública con la audiencia más joven es evidente en los casos en los que se da el fenómeno fan "El Ministerio del Tiempo", "Fais pas ci, fais pas ça", "Sherlock", "Doctor Who", "EastEnders"; también es significativo el éxito de audiencia directa joven y de presencia de jóvenes en eventos relacionados con la serie, como ocurre con "Goazen!".

\section{Conclusiones}

1. Las iniciativas transmedia en las televisiones públicas europeas, siendo limitadas en su cantidad, representan un esfuerzo por integrar las nuevas narrativas en el servicio audiovisual público y por conectar con el público joven. Responden a los criterios establecidos por las instituciones europeas para las televisiones públicas de: calidad en el contenido (n. 48 Comunicación sobre ayudas del Estado, de 2 de julio de 2009) y accesibilidad universal de los nuevos formatos y tecnologías (n. 2 Comunicación sobre ayudas del Estado, de 2 de julio de 2009); también responden a la necesidad planteada de llegar a una audiencia amplia (n. 106 Sentencia Tribunal de Justicia Europeo caso TV2 Dinamarca, TV2-Denmark, T-309/04).

2. La mayoría de adolescentes y jóvenes adultos utiliza como dispositivo habitual el móvil (Informe Reuters 2016), en esa medida es particularmente adecuada la extensión de los contenidos transmedia a este dispositivo para que las televisiones públicas reconecten con la audiencia joven. Tal y como han hecho la mayor parte de los programas informativos y de entretenimiento de las televisiones europeas estudiados.

3. Los productos transmedia conectan con la audiencia joven, porque conectan con su forma de comunicarse y con sus deseos de participación. Una característica esencial del contenido transmedia es que "los consumidores adoptan un rol activo" en el despliegue del relato. Y esto no sólo participando de una forma u otra, sino estableciendo "un diálogo creativo con el relato base, llegando a modificarlo en el proceso" (Pradanos Grijalvo y Enríquez de Salamanca, 2016, Rodríguez y Molpeceres, 2014, cit por Rodríguez Fidalgo, Paíno Ambrosio y Jiménez Iglesias 2016). 
En consecuencia promueven una actitud participativa en los ciudadanos jóvenes (cfr. Jenkins 2006).

4. El proceso de cambio hacia el empleo de un estilo comunicativo diferente, más personal y más apto para comunicar con audiencias jóvenes, obliga a las televisiones públicas "a examinar y reflexionar sobre su propia imagen, tradiciones, hábitos, prácticas cotidianas y organización” (Sjöberg y Rydin 2013). Sólo así podrán aspirar a tener participación en el mercado audiovisual. Los contenidos transmedia exitosos que se han estudiado constituyen un ejemplo positivo del replanteamiento en este sentido de las televisiones públicas europeas.

5. Hace falta un mayor esfuerzo de inversión: dinero, talento creativo, extensión de los contenidos transmedia a smartphones o a los nuevos dispositivos que sean principal vía de comunicación de los jóvenes. La comparación de los programas transmedia de éxito evidencia que una mayor inversión por parte de las televisiones genera productos transmedia de mayor calidad.

\section{Bibliografía citada}

Azurmendi, A., y Muñoz Saldaña, M. (2016): “Televisiones públicas: ¿Nuevas obligaciones del servicio público de televisión en el entorno digital? Identidad y diversidad cultural, pluralismo, participación y Sociedad de la Información", Cetina Presuel, R., Corredoira y Alfonso, L., y Gutiérrez Atala, F., Informar ¿Derecho o deber? ¿de qué hablamos cuando hablamos del derecho a informar?, Madrid, Universidad Complutense, Cyberlaw Clinic accesible en www.eprints.ucm.es/39990/, [con acceso 25 de enero de 2018].

Carlson, U., (2014): Public Service Media and the Young. EBU Knowledge Exchange, EBU Geneva, pp. 1-11.

Collins, F. (2013): “Doctor Who': The Transmedia Experience”, Television Heaven en 
http://www.televisionheaven.co.uk/doctor who transme dia.htm, [con acceso 25 de enero de 2018]

Cuen, D., (2013): “11 Claves para entender 'Doctor Who”, El Mundo, 10.11.2013 en

http://www.bbc.com/mundo/blogs/2013/11/131120 bl og un mundo feliz doctor who [con acceso, 25 de enero de 2018].

EBU, (2017): Vision Project 2020. Connect, grow and influence.

Introduction, p. 3. Accesible en

https://www.ebu.ch/files/live/sites/ebu/files/Publication s/Vision2020 Strategic Objectives 2017 EN.pdf [con acceso 27 de enero de 2018].

EITB-Goazen,

http://www.eitb.eus/es/television/detalle/5178598/laserie-goazen-cuenta-su-propia-app/ [con acceso 25 de enero de 2018].

EUROPEAN COMMISSIÓN, (2009): Communication from the Commission on the Application of State Aid Rules to Public Service Broadcasting, accessible en http://ec.europa.eu/competition/state aid/reform/broad casting communication en.pdf [con acceso 27 enero 2018].

EUROPEAN COURT OF JUSTICE, (2008): Sentence, TV2-

Denmark , T-309/04 - TV 2/Denmark v Commission accessible en http://eur-lex.europa.eu/legalcontent/ES/TXT/HTML/?uri=CELEX:62004TJ0309\&from= EN con acceso 2 de febrero de $2018^{\wedge} *$.

Fanthome, Ch., (2008): "What do young people want from today's $\mathrm{BBC}$ ? Initial observations from outreach work carried out by the BBC's Regional Audience Council for London", Young Consumers, Vol. 9 Iss 4 pp. 254-264 doi.org/10.1108/17473610810920470

Garambato, R. R. y Andreevich Medvede, S., (2017): “Transmedia Storytelling Impact on Government Policy Change", Ibrahim, Y. (ed.) Politics, Protest, and Empowerment in Digital Spaces, IGI Global Books, Hershey, Pennsylvania. DOI: 10.4018/978-15225-1862-4.ch003, pp. 31-51. 
Jenkins, H., (2006): Fans, Bloggers and Gamers. Exploring participatory culture. New York University Press. New York.

-Convergence culture: Where old and new Media collide. New York University Press. New York.

Larrondo Ureta, A., (2016): "The advance of autonomous public televisions in the convergent scenario: analysis of transmedia journalistic experiences in EITB and CCMA", Communication \& Society, Vol. 29, 4, 107-118.

Leitch, Th. (ed)., (2017): The Oxford Handbook of Adaptations Stories. Oxford University Press, Oxford.

Loader B. B., Vromen, A., Xenos A. M. (2016): "Performing for the young networked citizen? Celebrity politics, social networking and the political engagement of young people", Media, Culture and Society Vol. 38(3) 400-419 DOI:

$10.1177 / 0163443715608261$

Meso Ayerdi, K., Larrondo Ureta A.; Peña Fernández, S., Rivero Santamarina, D. (2014): "Audiencias activas en el ecosistema móvil. Análisis de las opciones de interacción de los usuarios en los cibermedios españoles a través de la web, los teléfonos móviles y las tabletas". Hipertext.net [online], 12, accesible en http://raco.cat/index.php/Hipertext/article/view/274309/364 489 [Con acceso 27 Enero 2017].

DOI: $10.2436 / 20.8050 .01 .9$

Miguel De Bustos, J.C., Galindo Arranz, F. y Casado Del Río, M.A., (2012): "Servicio público y nuevas tecnologías. La adaptación de las autonómicas al nuevo escenario". Miguel De Bustos, J.C. y Casado Del Río, M.A. (Coords.) Televisiones autonómicas. Evolución y crisis del modelo público de proximidad. Barcelona. Gedisa. pp.251276.

Miranda Galbe, J. y Figuero Espadas, J. (2016): “El rol del prosumidor en la expansión narrativa transmedia de la historia de ficción en televisión: el caso de 'El Ministerio del Tiempo", Index.Comunicación, vol. 6, n.2, pp.115-134.

Moe, H., (2008): "Public Service Media Online? Regulating Public Broadcasters' Internet Services. A Comparative Analysis", Television \& New Media, 9, pp.220-238. 
OFCOM, (2016): Public Service Broadcasting in the Internet Age, https://www.ofcom.org.uk/ data/assets/pdf file/0018/8004 6/psb-annual-report-2016.pdf [con acceso 21 de enero de 2018] PradanoS Grijalvo, E. y Enríquez De Salamanca, P., (2016): “Claves para la innovación creativo-estratégica a través de la metodología transmedia", Icono 14, 14, pp. 1-30. DOI: 10.7195/ri14.v14i1.945.

Ryan, M-L., (2013): “Transmedial Storytelling and Transfictionality", Poetics Today, vol. 34, n. 3, pp.361-388. DOI 10.1215/033353722325250

- (2017): “The aesthetics of proliferation", Boni, M. (ed.), (2017):

World Buildings: Transmedia, Fans, Industries. Amsterdam

University Press, Amsterdam, pp. 31-46.

Reuters Institute, (2016): Digital News Report, http://reutersinstitute.politics.ox.ac.uk/sites/default/files/Digit al-News-Report-

2016.pdf?utm source $=$ digitalnewsreport.org\&utm medium $=$ re ferral [con acceso 21 de enero de 2018]

Rodríguez Fidalgo, M. I., Paíno Ambrosio, A., Jiménez Iglesias, L. (2016): "El soporte multiplataforma como clave de éxito de la Narración Transmedia. Estudio de caso del webdoc 'Las Sinsombrero"' Icono14, vol.14, 2, pp.304-318. DOI: ri14.v14i2.967

Scolari, C.A., Establés, M-J., (2017): El ministerio transmedia: expansiones narrativas y culturas participativas, Palabra Clave, vol. 20, 4, pp. 1008-1041. DOI: 10.5294/pacla.2017.20.4.7

Scolari, C., Jiménez, M. y Guerrero, M., (2012): Narrativas transmediáticas en España: cuatro ficciones en busca de un destino cross-media, Comunicación y Sociedad, vol. 25, 1, 2012, 137-164.

Sjöberg, U. y Rydin I., (2013): Transmedia storytelling and the young audience. Public Service in the Blogosphere Era. OLSON, T. (ed.), Producing the Internet. Critical Perspectives of Social Media. Nordicom, Göteborg, pp. 103-120.

Stein, L.E. y Busse, K. (ed), (2012): "Sherlock" and Transmedia Fandom: Essays on the BBC Series, McFarland, London. 
Tambini, D., (2014): Public Media and Digitization: Seven

Theses, Dragomir, M. y Thompson, M. (eds), Mapping

Digital Media: Global Findings, Open Society Foundations,

New York-London, pp.75-106

Vázquez-Herrero, J. y López-García X., (2017): El documental

interactivo como formato en los medios audiovisuales:

estudio de caso de RTVE y Al Jazeera. Anàlisi. Quaderns de

Comunicacio i Cultura, 57, pp. 47-61. DOI:

https://doi.org/10.5565/rev/analisi.3100

Zambrano, M., (2016): Narrativas transmedia en la ficción televisiva

española, Universidad de Valladolid, Trabajo fin de grado,

Grado publicidad y relaciones públicas.

Accesible en

https://uvadoc.uva.es/bitstream/10324/13146/1/TFG-

N.264.pdf, con acceso 25 mayo 2017.

Zeiser, A., (2015): Transmedia marketing. From Film and TV to

Games and Digital Media Abingdon, Taylor \& Francis

\section{Reconocimientos de la investigación}

Proyecto Programa de I+D+I Orientado a los Retos de la Sociedad, Ministerio de Economía y Competitividad, IP Ana Azurmendi, Transformación de la televisión autonómica: debilitamiento del servicio público y perspectivas de desarrollo tecnológico en un entorno de crisis, $\underline{\mathrm{CSO} 2013-42270-\mathrm{R}}$ 



\title{
El discurso reproducido como indicador del pluralismo interno de los medios de comunicación: el caso de los telediarios de TVE y TV3
}

\author{
$\mathrm{M}^{\mathrm{a}}$ Ángeles García Asensio \\ Carlos Aguilar Paredes \\ Lucía Jiménez Iglesias \\ Universitat de Barcelona \\ Cristina Ruiz Moreno \\ Universitat Ramon Llull \\ Lydia Sánchez Gómez \\ Universitat de Barcelona
}

PARA CITAR: García Asensio, M.A., Aguilar Paredes, C., Jiménez Iglesias, L., Ruiz Moreno, C. y Sánchez Gómez, L. (2018). El discurso reproducido como indicador del pluralismo interno de los medios de comunicación: el caso de los telediarios de TVE y TV3. Revista Latina de Comunicación Social, 73, pp. 991 a 1015. http://www.revistalatinacs.org/073paper/1293/52es.html

DOI: $10.4185 /$ RLCS-2018-1293

\section{Resumen}

El objetivo de este trabajo es analizar la incidencia del discurso reproducido en el tratamiento de la información política de los telediarios para estudiar su relevancia como indicador del grado de pluralismo interno. Se realiza un análisis lingüístico y discursivo de las noticias políticas emitidas por dos televisiones públicas (TVE1 y TV3) en periodo preelectoral, y se compara el acceso a la narración 
periodística de voces representativas de la actividad política. A través de una metodología cuantitativa-cualitativa, secuencial y anidada se analiza el uso del discurso reproducido para representar las voces de los actores políticos. Los resultados muestran desviaciones en la construcción de la imagen de los actores políticos y en la reproducción de sus discursos públicos. Se hace necesario incorporar el discurso reproducido como indicador de la calidad democrática del medio.

Palabras clave: Discurso reproducido, pluralismo, telediarios, discurso político, citas, palabras, verbos.

\section{Pluralismo y discurso reproducido}

$\mathrm{E}$ STE TRABAJO estudia si el análisis y la evaluación del grado de pluralismo interno de los medios de comunicación deben incluir el modo en que los medios representan a los actores políticos y sus discursos públicos a través de las distintas formas de discurso reproducido. Desde nuestra perspectiva, pluralismo interno y discurso reproducido están profundamente relacionados, pues el discurso reproducido es uno de los procedimientos discursivos más eficaces al servicio de los medios para elaborar una imagen de la realidad, que es plural en sus formas de vida y presenta "convicciones axiológicas rivales" (Habermas, 2000, p.130). Concretamente, en el periodismo que se realiza en los telediarios, medir el pluralismo interno solo en términos de tiempo de aparición en la pantalla de los diferentes actores políticos, si bien resulta necesario, se revela también insuficiente.

$\mathrm{Al}$ respecto, esta investigación aporta nuevos datos -sustentados cualicuantitativamente- a los estudios que vienen demostrando que el periodista que construye el andamiaje polifónico de su discurso informativo no solo tiene potestad de hacer o no hacer comparecer en su discurso periodístico voces ajenas y darles un tiempo en la pantalla (Santander, 2003, p.26). También, con el recurso a operaciones discursivas de cita directa o indirecta, el periodista puede desactivar argumentativamente estas voces ajenas mediante evaluaciones desautorizadoras, de manera que la elección de una determinada forma de cita o el recurso a uno u otro verbo de comunicación pueden dejar inoperante una voz política, su imagen pública y su planteamiento ideológico (Casado Velarde y de Lucas Vicente, 2013). Todo ello, como 
consecuencia, puede afectar al compromiso con el pluralismo interno adquirido por el medio.

Son todavía escasos los estudios con corpus de telediarios emitidos en España que apuntan a este sesgo en el recurso al discurso reproducido (Fernández García, 2003). Al contrario, son abundantes los estudios sobre el uso (y abuso) del discurso reproducido realizados sobre corpus de prensa escrita o digital en español (Méndez, 2000b; Casado Velarde, 2008; Escribano, 2009; Sánchez García, 2012; Casado Velarde y de Lucas Vicente, 2013; Repede, 2015).

\subsection{El concepto de pluralismo interno}

El concepto de pluralismo tiene una aproximación cualitativa (Llorens y Costache, 2013) que dificulta no solo su definición, sino también su medición y evaluación. La inexistencia de una definición consensuada con que vehicular su observación y regulación en los medios lleva al Consejo de Europa a abordar la definición por primera vez en 1994, recogiendo dos tipos de pluralismo, el externo y el interno:

"Pluralism may be internal in nature, with a wide range of social, political and cultural values, opinions, information and interests finding expression within one media organisation, or external in nature, through a number of such organisations, each expressing a particular point of view" (Consejo de Europa, 1994, p.8).

El pluralismo interno es aquel que tiene que ver con la diversidad de valores políticos, sociales y culturales, y la diversidad de informaciones, opiniones e intereses, expresados dentro de un medio. Esta diversidad, tratada con rigor periodístico y con valores de informatividad y factualidad (Waugh, 1995), repercute directamente en la imagen que los ciudadanos reciben de los acontecimientos de los que son informados, y configura en la ciudadanía distintos estados de opinión fundamentados en una concepción plural de la realidad.

En este sentido, en el contexto europeo se han creado diversos órganos reguladores audiovisuales para observar y proteger el pluralismo interno que la sociedad reclama de los medios, especialmente si se tratan contenidos que atañen a la vida política nacional o internacional (Almirón, Capurro y Santcovsky, 2010). Algunos ejemplos son el Conseil Supérieur de l'Audiovisuel (CSA) en Francia, o el Consell de 
l'Audiovisual de Catalunya (CAC) en Cataluña. El CSA francés vela por garantizar la reforma llevada a cabo en el país galo en 2009, por la que se garantiza un 50\% del tiempo total de cobertura televisiva a la oposición parlamentaria, tanto en períodos electorales como no electorales (Almirón et al., 2010). Por su parte, el CAC emplea también una metodología cuantitativa basada en contar el tiempo total de las noticias dedicadas a un mismo tema, o los tiempos y frecuencia de aparición en imagen de los actores políticos y sociales. Sin embargo, esta vigilancia solo opera en período electoral (López, 2006).

Con todo, estos mecanismos cuantitativos, si bien regulan la aparición de una diversidad de actores políticos, no garantizan por sí solos la pluralidad en un sentido estricto. Obligan, además, a modificar el criterio periodístico estableciendo cuotas que no tienen que responder a criterios informativos, sino a un acuerdo político para la regulación de los medios públicos (Almirón et al., 2010, p.28). De igual modo, no existe ningún elemento cualitativo o de agenda que deba supervisar la presencia de los actores políticos en los medios públicos, lo que hace aún más difícil determinar el grado real de pluralismo.

España, en este marco, carece incluso de un órgano específico que regule la actividad informativa de los medios de comunicación. La Ley General de la Comunicación Audiovisual (LGCA) (2010) propuso la creación del Consejo Estatal de Medios Audiovisuales (CEMA), pero el proyecto nunca llegó a materializarse (Fernández, 2016). Aun así, este texto legal es el único que menciona el concepto de pluralismo en el sentido mediático y que hace referencia a su dualidad (Aguilar et al., 2016). Posteriormente, la implementación de la Comisión Nacional de los Mercados y la Competencia (CNMC) como órgano regulador único y multisectorial no ha logrado superar grandes carencias en la supervisión de la pluralidad del contenido audiovisual (Gavara de Cara, 2013).

De hecho, en la caracterización del sistema mediático español suele reiterarse esta ausencia de órgano regulador específico, y su incidencia en la falta de pluralismo interno. Concretamente, Hallin y Mancini (2004) presentan a España como un caso de modelo Mediterráneo o Pluralista Polarizado, que, como tal, y en estas circunstancias, muestra un alto grado de intervención estatal y, también, de paralelismo 
político: carece de una diversidad de informaciones o de opiniones políticas expresadas dentro de cada medio porque el periodismo político está altamente polarizado hacia ideologías concretas. Humanes et al. (2013) mencionan también el caso español al observar que el pluralismo interno es escaso en los sistemas mediáticos que muestran un fuerte paralelismo político. Y concluyen que el sistema mediático español, que sigue girando en torno a la televisión, se encuentra a caballo entre el deber de servicio público y de televisión comercial. Así, aunque la televisión -especialmente la cadena pública- tiene asignada la tarea de garantizar el pluralismo interno (Strömbäck y Luengo, 2008; Fernández y Fernández, 2012), las investigaciones realizadas siguen cuestionando la garantía de pluralismo interno en los medios españoles.

Más aún. Berganza, Van Dalen y Chaparro Domínguez (2010) y Van Dalen (2012) aportan a la discusión sobre el pluralismo en los medios españoles la opinión de los periodistas políticos, quienes destacan que la principal restricción a su autonomía profesional son las presiones políticas y económicas que surgen desde dentro de las organizaciones mediáticas. A ello se añade la evidencia de que entre los periodistas políticos y los mismos políticos existe una relación simbiótica -y no de competencia o watchdog-, por la cual ambos actores se necesitan mutuamente: los políticos, para obtener visibilidad mediática, por un lado; y los periodistas, para obtener noticias de primera mano susceptibles de generar audiencia, por el otro (Berganza et al., 2010).

En definitiva, la repercusión de las presiones políticas y económicas, la relación simbiótica entre periodistas y políticos, así como la ausencia de órganos reguladores específicos caracterizan el panorama mediático español actual y repercuten necesariamente en la calidad de la información de las noticias políticas. Las acciones reguladoras en este contexto se muestran inoperantes, y son un mero reflejo de los equilibrios de las fuerzas políticas. Por ello, el análisis temporal utilizado como referente cuantitativo de pluralismo interno se ha convertido en un instrumento de salvaguarda de la acción de los servicios informativos que puede ocultar la narrativa real de los actores políticos, así como la configuración de su agenda política.

En este contexto, analizar los mecanismos de discurso reproducido a los que recurren los periodistas para representar la voz de los agentes 
políticos en su discurso periodístico puede añadir una perspectiva cualitativa al estudio del grado de pluralismo interno real que manifiesta cada medio, un complemento imprescindible para salvaguardar la ecuanimidad y pluralidad en el tratamiento de las noticias.

\subsection{E1 discurso reproducido}

Las noticias que se suceden en el discurso de un telediario recogen, fundamentalmente, dos tipos de contenidos: los hechos a los que se refieren -noticias de acontecimiento-y las declaraciones -actos de habla- de los actores principales relacionados con los hechos, lo que deviene un mecanismo persuasivo que subraya la naturaleza factual de los acontecimientos narrados y confiere credibilidad al discurso periodístico (Van Dijk, 1990; Vicente Mateu, 2007). Estas declaraciones, en el ámbito político, a menudo se convierten en el propio núcleo noticiable (Martínez Pasamar, 2010). Esto es así porque son dichas por agentes sociales de relevancia pública y porque su valor es decisivo para el funcionamiento de la actividad política (Escribano, 2001; Charaudeau, 2003; Sánchez García, 2010; de Lucas Vicente, 2014).

El recurso al discurso reproducido permite a los periodistas, en el desarrollo narrativo de una noticia, interpretar y reproducir segmentos completos o seleccionados de declaraciones ajenas, y representar la situación comunicativa en que cada declaración fue dicha originariamente. Como se afirma en Escribano (2009) y se recoge en de Lucas Vicente (2014), un periodista no solo transmite las palabras dichas en una declaración cuando realiza una operación de discurso reproducido, sino que también interpreta la intención con que se han dicho las palabras. Esta reproducción del discurso ajeno puede realizarse con mayor o menor fidelidad al contenido, a la intención y a la forma de los discursos originales (Méndez, 2000a). El resultado es que en el relato informativo convergen dos tipos de voces: la voz del periodista, que selecciona, reelabora y transmite las declaraciones, y la voz del político, actor principal de los hechos o dichos ajenos que se relatan (Waugh, 1995; Santander, 2003; Sánchez García, 2010). De este modo, el discurso político queda representado dentro del discurso periodístico (Sánchez García, 2010). 
Algunos estudios realizados sobre corpus de noticias escritas (Méndez, 2000a; Casado y de Lucas Vicente, 2013; de Lucas Vicente, 2014 y 2015) ponen de relieve cómo a través del discurso reproducido y de verbos de pensamiento (creer, pensar, opinar, considerar, recordar) o de percepción sensible (ver), el periodista llega a atribuir a otro sujeto un discurso que nunca ha sido emitido verbalmente, pero que se representa como si este sujeto lo hubiera pensado y dicho. Es un discurso nunca pronunciado que el periodista parece inferir, con procedimientos interpretativos libres y creativos, fruto de su subjetividad, a partir de informaciones contextuales o de enunciados originales previamente verbalizados -lo que, en principio, no debería tener cabida en las convenciones del género, ligadas a los hechos y a los valores de objetividad y de verdad-.

De ahí que, siguiendo a de Lucas Vicente (2014), en esta investigación entendamos por discurso reproducido -reproducción de discurso ajeno o cita- la atribución de un discurso a una enunciación textual distinta de la del locutor. Abarcamos así discursos que han sido necesariamente enunciados y también discursos nunca dichos, pero que han sido inferidos por el periodista en su tarea de interpretación de la realidad.

En este sentido, se considera a los verbos de percepción intelectual (verbos de pensamiento y de percepción) los más altamente valorativos y, por tanto, los más altamente subjetivadores (Méndez, 2000a), frente al recurso al verbo decir, el más altamente objetivador y archilexema de los verbos de comunicación (Kerbrat-Orecchioni, 1986). Entre los verbos de percepción intelectual y el verbo decir, existe, por un lado, un continuum de verbos que imprimen objetivación al discurso periodístico: verbos declarativos como afirmar, declarar, exponer, añdir, etc., que tienen como significado principal el expresar una aserción; por otro lado, existe un continuum de verbos de carácter subjetivador: reconocer, admitir, confesar, advertir, prometer, amenazar, destacar, acusar, denunciar, criticar, reclamar, exigir, lamentar, etc., que se usan según el periodista quiere que se interpreten las palabras dichas $-\mathrm{O}$ inferidas- que reproduce en su discurso.

De hecho, es sobre todo a través de los verbos subjetivadores como el periodista puede posicionarse a favor o en contra de una determinada 
voz política y, por tanto, potenciar su imagen, si los verbos muestran un contenido positivo; o desvalorizarla y desautorizarla, si el contenido del verbo es negativo (Casado Velarde y de Lucas Vicente 2013; de Lucas Vicente, 2015). Cabe tener en cuenta que las citas son gestionadas en el discurso fundamentalmente por los verbos de comunicación, y que, por tanto, su análisis resulta imprescindible si se incluye el discurso reproducido en la investigación sobre el grado de pluralismo interno de un medio de comunicación.

Así, mediante las operaciones textuales que requiere al discurso reproducido $\mathrm{y}$, muy específicamente, a través de una selección consciente de ciertos verbos de comunicación, el periodista tiene la potestad de evaluar el contenido con mayor o menor sesgo ideológico o con mayor o menor rigor profesional. A ello se añade la selección previa de las voces políticas que el periodista quiere que se escuchen, o su potestad para determinar una jerarquía de voces que puede afectar al procesamiento cognitivo que realiza el público receptor (Rosier, 2002; Santander, 2003; Fernández García, 2003; Escribano, 2009). Más aún: según Charaudeau (2003), el periodista, asimismo, puede o no seleccionar para su reproducción determinados contenidos dichos por los agentes políticos para crear también de ellos distintas imágenes: una imagen de agente que toma decisiones (sus palabras son performativas), que analiza la actualidad (palabras de análisis o explicativas), o que evalúa y expresa un juicio sobre hechos y dichos (palabras evaluativas). Podemos añadir la imagen de un agente que busca una reacción por parte del destinatario (palabras directivas), o que ofrece una aserción (palabras declarativas).

En suma, la presencia o ausencia de voces representativas de agentes políticos, la construcción de una determinada imagen de estos y la potestad de selección, ocultación o de manipulación de las declaraciones -de sus contenidos o de sus intencionalidades comunicativas - son a menudo indicativo de la afinidad de un medio con uno u otro partido político. Estas variables pueden constituirse, por tanto, como indicador del grado de pluralismo interno del propio medio, porque pueden afectar tanto a la presencia en el discurso periodístico de las voces de ideologías dispares que configuran el conjunto del mapa político, como a la imagen de los agentes de relevancia social (Moirand, 2007). 
Solo cabe aún especificar cómo las formas de cita que seleccionan los periodistas para integrar en su discurso la voz de los políticos también influye en la percepción de los ciudadanos sobre los políticos, y, por tanto, en el grado de pluralismo interno que muestra cada medio. Así, en las noticias televisadas se distinguen cuatro grandes tipos de citas (Charaudeau, 2003; Santander, 2003): citas audiovisuales, citas directas, citas indirectas y citas narradas. La cita audiovisual corresponde a las declaraciones grabadas en imagen y sonido, en su contexto comunicativo originario, y difundidas en vídeo en el desarrollo narrativo de una noticia: a no ser que exista manipulación, las imágenes y sonidos grabados no alteran lo dicho originariamente. Por otra parte, la cita directa es expresada mediante la voz del periodista, que reproduce con una ficción discursiva de literalidad las palabras dichas originariamente, aunque carezca de imágenes del momento en que estas palabras fueron dichas o estas imágenes se estén emitiendo de fondo. La cita indirecta es dicha mediante la voz del periodista, así como la cita narrada. Esta última reduce el discurso que reproduce a un verbo de comunicación y a un sintagma nominal o preposicional (Méndez, 1999; Santander 2003). Las citas audiovisuales, por su pretensión de literalidad y características enunciativas, son, en realidad, un tipo de cita directa; las narradas, a su vez, un tipo extremo de cita indirecta.

Concretamente, optar por una cita audiovisual en un telediario o por una cita directa expresada mediante la voz del periodista (efecto de objetivación); o por una cita indirecta (efecto de manipulación o de interpretación) o por una cita narrada (efecto de dramatización), conlleva diferentes grados de subjetividad periodística (Charaudeau 2003). Este grado de subjetividad, muy acusado en las citas indirectas y narradas, y debilitado en las citas directas y audiovisuales, implica que los ciudadanos concederán mayor credibilidad a los agentes políticos que son citados mediante una cita directa o audiovisual. No en vano, cuanto más indirecto sea un discurso, más posibilidades de manipulación dispone el periodista de transmitir sus propias valoraciones y puntos de vista sobre las palabras que está refiriendo (Fairclough, 1988; Waugh, 1995; Ruiz, 2006; Escribano, 2001 y 2009; Sánchez García, 2010 y 2012; Bednarek y Caple, 2012). 


\section{Objetivos y metodología}

El objetivo de este trabajo es analizar la relevancia de incluir el análisis del discurso reproducido como indicador del grado de pluralismo interno en los informativos televisados. Para ello, se ha realizado un análisis de contenido desde el punto de vista lingüístico y discursivo, tomando como base tres elementos del discurso reproducido: tipos de citas, tipos de palabras y tipos de verbos.

Se analiza un corpus formado por 91 noticias del bloque de política nacional, documentadas en los contenidos de información generalista de los telediarios de la televisión autonómica catalana (subcorpus TV3), y de la televisión estatal española (subcorpus TVE1), en horario de tarde-noche, de máxima audiencia. Se trata, pues, de un corpus de noticias procedentes de informativos de cadenas públicas cuya elección responde a criterios de proximidad y de servicio público.

Concretamente, la muestra incluye los telediarios emitidos entre el 24 de noviembre y el 3 de diciembre de 2015. El motivo por el que se eligieron estas fechas, a pesar de su proximidad a un período de campaña electoral, es por quedar libres de cualquier imperativo legal sobre el tiempo en pantalla que dedican a cada actor político. Hay que tener en cuenta que el 20 de diciembre de 2015 se celebraron elecciones generales, y que la Junta Electoral Central obligó a las televisiones a respetar el tiempo estipulado de aparición en pantalla de agentes políticos solo durante los quince días previos al 20 de diciembre; esto es, durante el período de campaña electoral. Este período no comprende nuestra muestra de telediarios. Con todo, no dejamos de considerar que la proximidad a la campaña electoral podría conllevar que los telediarios del corpus manifestaran cierto grado de instrumentalización política.

De las 91 noticias, 47 fueron emitidas por TVE1 y 44 por TV3. La extensión total del corpus es de 581 citas. Este corpus de noticias fue sometido a una transcripción ortográfica normalizada y completa del componente verbal oral y escrito (rótulos) de cada noticia y de su sumario. Cada texto transcrito viene, además, presentado por un encabezamiento identificativo constituido por un código que remite al telediario en el que se difunde la noticia, la fecha de emisión, el minutaje y la duración. En la cabecera de cada pieza informativa transcrita se 
especifica, asimismo, si se trata de una noticia de acontecimiento o de acto de habla. La transcripción del componente verbal oral se etiqueta para distinguir si el texto pertenece a la entradilla leída por el presentador en el plató o a la voz en off del periodista contenida en el vídeo, que son textos leídos; o a las voces de los protagonistas de las noticias (declas o totales), de reporteros, corresponsales o enviados especiales, que son textos dichos espontáneamente o con mayor o menor grado de espontaneidad.

El análisis de las unidades de texto de este corpus pretende los siguientes objetivos específicos:

- Identificar las voces políticas que se escuchan y clasificarlas según se adscriban a los diferentes actores políticos, diferenciando si aparecen en representación de una administración del estado o como representantes de un partido político.

- Identificar los tipos de cita que introducen en el discurso periodístico las voces de los agentes políticos y los contenidos dichos por estos agentes $-\mathrm{O}$ inferidos a partir de lo dicho-, y clasificarlos según sean citas audiovisuales, directas, indirectas o narradas.

- Identificar los verbos de comunicación que introducen las citas, y clasificarlos según sean verbos objetivadores o subjetivadores.

- Identificar los contenidos dichos por los agentes políticos, y clasificarlos según sean palabras performativas, explicativas, evaluativas, directivas o declarativas.

Para ello, en la transcripción del corpus se etiquetan las variables que se manejan para este análisis, que incluyen los indicadores y valores del discurso reproducido (Tabla I). Estas variables se añaden a la matriz de análisis de telediarios tomada del estudio realizado por Aguilar et al. (2016). 


\begin{tabular}{|c|c|}
\hline INDICADORES & VALORES \\
\hline Voz citada & $\begin{array}{l}\text { Miembros del Poder Ejecutivo } \\
\text { Representantes de la Administración } \\
\text { Autonómica } \\
\text { Representantes de la Administración Local } \\
\text { Representantes del Poder Judicial } \\
\text { Representantes del Poder Legislativo } \\
\text { Representantes de una institución política } \\
\text { (partido político o coalición) } \\
\text { Representantes de una institución pública } \\
\text { Representantes de una institución privada } \\
\text { Sindicatos } \\
\text { Movimientos sociales } \\
\text { Otros }\end{array}$ \\
\hline Tipo de cita & $\begin{array}{l}\text { Cita audiovisual } \\
\text { Cita directa } \\
\text { Cita indirecta } \\
\text { Cita narrada }\end{array}$ \\
\hline $\begin{array}{l}\text { Verbo de } \\
\text { comunicación }\end{array}$ & $\begin{array}{l}\text { Verbos objetivadores } \\
\text { Verbos subjetivadores }\end{array}$ \\
\hline Contenido de la cita & $\begin{array}{l}\text { Palabras performativas } \\
\text { Palabras explicativas } \\
\text { Palabras evaluativas } \\
\text { Palabras directivas } \\
\text { Palabras declarativas }\end{array}$ \\
\hline
\end{tabular}

Fuente: elaboración propia.

Así, para cada cita incluida en una pieza informativa se identifica el agente al que hace referencia la pieza, el tipo de cita, las palabras y los verbos de comunicación utilizados, clasificándolos igualmente según la categorización mostrada en la Tabla I. Las voces citadas correspondientes a miembros de partidos o coaliciones se agrupan para este estudio como voces de agentes políticos de los partidos políticos del arco parlamentario nacional o autonómico, según corresponda.

Además, se dedicaron 5 sesiones de 2 horas a la unificación de criterios que sirvieron para comprobar que todas las codificadoras etiquetaban el corpus de forma consensuada. Con posterioridad a la clasificación, se realizaron dos sesiones de unificación que contaron con la presencia 
de un experto que validó los criterios y los resultados obtenidos en los procesos de transcripción y clasificación.

\section{Resultados}

El análisis de las noticias permitió identificar las diferentes voces citadas por los periodistas, así como el tipo y el contenido de las citas asociadas a cada una de esas voces, y los verbos de comunicación que se emplean para introducir sus palabras.

\subsection{Voces citadas}

Respecto a la primera variable de análisis, los resultados muestran que el arco de voces citadas es amplio, si bien solo son significativos los resultados que corresponden a las categorías de Miembros del Poder Ejecutivo (tanto estatal como autonómico) y a la categoría de los que actúan como representantes de partidos políticos (Tabla II). El resto de las categorías presentan muy pocas citas y no permiten realizar un análisis estadístico, por lo que el resto de los actores políticos (sindicatos, fuerzas sociales, poder legislativo, etc.) son meramente accesorios para la información política.

Tabla II. Identificación y clasificación de las voces políticas citadas en TVE1 y TV3.

TVE3 TVE1

Miembros del Poder Ejecutivo

Ministros $18 \quad 26$

$\begin{array}{lll}\text { Presidente del Gobierno } & 7 & 25\end{array}$

Vicepresidente del Gobierno $\quad 5 \quad 5$

Representantes de la Administración Autonómica

$\begin{array}{lrr}\text { Presidente de Comunidad Autónoma } & 9 & 8 \\ \text { Consejeros } & 15 & - \\ \text { Gobierno Catalán } & 1 & -\end{array}$

Representantes de una institución

política (partido político o coalición)

$\begin{array}{lrr}\text { Catalunya Sí que es Pot } & 2 & 2 \\ \text { Ciudadanos } & 16 & 23 \\ \text { CUP } & 32 & 9 \\ \text { Democràcia i Llibertat } & 6 & - \\ \text { En Comú-Podem } & 7 & 13 \\ \text { ERC } & 4 & - \\ \text { Junts pel Sí (JxSí) } & 47 & 9\end{array}$




\begin{tabular}{lrr} 
Podemos & 7 & 14 \\
PP & 10 & 47 \\
PSC & 4 & - \\
PSOE & 15 & 42 \\
Unió Democràtica & 2 & 1 \\
UPyD & - & 4 \\
\hline Total general & 215 & 236
\end{tabular}

Fuente: elaboración propia.

En total, son citadas 43 voces en TV3 y 37 en TVE1. La Tabla III recoge los actores políticos que tienen mayor número de apariciones; entre ellos, es significativo observar que algunos son citados en dos facetas diferentes, ya sea ejerciendo el rol de miembros del Gobierno o de representantes de sus partidos políticos.

\section{Tabla III. Personas citadas en TVE1 y TV3.}

TV3 TVE1

Miembros del Poder Ejecutivo

\begin{tabular}{lrr}
\hline Mariano Rajoy & 5 & 25 \\
Cristóbal Montoro & 11 & 10 \\
Jorge Fernández Díaz & 7 & 6 \\
Soraya Sáenz de Santamaría & 6 & 8 \\
José Manuel García-Margallo & 1 & 4
\end{tabular}

Representantes de la Administración Autonómica

Artur Mas

$9 \quad 8$

Andreu Mas-Colell

$7-\quad-$

Neus Munté

$5 \quad 1$

Santi Vila

Representantes de una institución

\begin{tabular}{lrr} 
política (partido político o coalición) & \\
\hline Albert Rivera & 10 & 16 \\
Artur Mas & 22 & 4 \\
Pedro Sánchez & 3 & 22 \\
Mariano Rajoy & 1 & 23 \\
Raül Romeva & 13 & 5 \\
David Fernández & 14 & - \\
Pablo Iglesias & 3 & 11 \\
Alberto Garzón & - & 13 \\
Carme Chacón & 10 & 1
\end{tabular}


Francesc Homs

Xavier García Albiol

Antonio Hernando

Inés Arrimadas

María Dolores de Cospedal

$\begin{array}{ll}8 & - \\ 4 & 4 \\ - & 7 \\ 4 & 3 \\ - & 7\end{array}$

Fuente: elaboración propia.

A nivel individual, los actores políticos más citados en TV3 y TVE1 son Artur Mas y Mariano Rajoy, respectivamente. No obstante, no siempre es fácil diferenciar el rol que ejercen en la reproducción discursiva de sus declaraciones públicas, pues, en la pieza noticiada, la condición de Presidente siempre está presente (aun cuando actúan como representantes de su partido político). Así, pues, contabilizando ambos roles, Mas y Rajoy son los personajes más citados, y es en torno a ellos y su agenda como se construyen los discursos de la mayoría del resto de los actores que aparecen en las noticias. Pero para ahondar en el estudio del respeto al pluralismo, sigue resultando especialmente relevante observar cómo se construye el discurso reproducido a través de los diferentes tipos de citas, tipos de verbos y tipos de palabras.

\subsection{Tipos de citas}

En términos absolutos, el comportamiento general de ambas televisiones muestra simetría en cuanto al tipo de citas utilizadas (Tabla IV). En ambos casos, la mayoría de las citas son audiovisuales, seguidas de las citas indirectas y narradas, si bien TVE1 recurre a las citas narradas en casi el doble de casos que TV3, en el mismo período.

Tabla IV. Distribución de los tipos de cita.

\begin{tabular}{lrr|rr} 
Tipos de citas & \multicolumn{2}{c|}{ TV3 } & \multicolumn{2}{c}{ TVE1 } \\
\hline Narrada & 44 & $16,1 \%$ & 73 & $23,7 \%$ \\
Indirecta & 98 & $35,9 \%$ & 107 & $34,6 \%$ \\
Directa & 8 & $2,9 \%$ & 5 & $1,6 \%$ \\
Audiovisual & 123 & $45,1 \%$ & 123 & $40,0 \%$ \\
\hline Total general & 273 & & 308 &
\end{tabular}

Fuente: elaboración propia.

Con más detalle (Tabla V), es, asimismo, relevante observar que la cadena estatal muestra un tratamiento diferenciado para la figura del Presidente del Gobierno, para quien predominan las citas indirectas 
(40\%), seguidas de las audiovisuales (36\%) y las narradas (24\%). Por otro lado, respecto del conjunto de partidos políticos, predominan las audiovisuales (45\%), y hay un equilibrio entre citas indirectas y narradas $(24 \%)$, con un pequeño porcentaje de citas directas (2\%). Con todo, este tratamiento no es homogéneo, pues el PSOE tiende a representarse con un mayor número de citas narradas (31\%), y Podemos y la CUP con un porcentaje muy elevado de citas audiovisuales $(56 \%)$.

Por su parte, TV3 también ofrece un tratamiento diferenciado para el Presidente de la Generalitat, con un $45 \%$ de citas audiovisuales, seguidas de indirectas (33\%) y, finalmente, narradas (22\%). Este tratamiento queda muy alejado del de la CUP, para la que predominan las citas indirectas (41\%) y las audiovisuales (37\%), mostrando así unos valores muy parecidos a los de En Comú Podem. En ambas televisiones, los partidos de la oposición reciben un número de citas indirectas muy por debajo de las que se utilizan para presentar la figura del jefe del Ejecutivo.

\section{Tabla V. Tipos de cita según el origen de la voz citada ${ }^{24}$.}

\begin{tabular}{|c|c|c|c|c|c|c|c|c|}
\hline & \multicolumn{2}{|c|}{ Narrada } & \multicolumn{2}{|c|}{ Indirecta } & \multicolumn{2}{|c|}{ Directa } & \multicolumn{2}{|c|}{ Audiovisual } \\
\hline & TV3 & TVE & TV3 & TVE & TV3 & TVE & TV3 & TVE \\
\hline \multicolumn{9}{|l|}{ Miembros del Poder Ejecutivo } \\
\hline Ministro & 3 & 4 & 5 & 7 & - & 1 & 10 & 14 \\
\hline Presidente del Gobierno & 1 & 6 & 3 & 10 & - & - & 3 & 9 \\
\hline Vicepresidenta del Gobierno & - & 1 & 1 & - & 1 & - & 3 & 4 \\
\hline \multicolumn{9}{|c|}{ Representantes de la Administración Autonómica } \\
\hline Consejeros & - & - & 4 & - & - & - & 9 & - \\
\hline Presidente de la Generalitat & 3 & 3 & 2 & 2 & - & - & 4 & 3 \\
\hline \multicolumn{9}{|c|}{ Representantes de partidos políticos } \\
\hline Catalunya Si que es Pot & - & 1 & - & - & - & - & - & 1 \\
\hline Ciudadanos & 3 & 5 & 4 & 6 & - & - & 7 & 11 \\
\hline CUP & 5 & 1 & 8 & 3 & 2 & - & 12 & 5 \\
\hline Democràcia i Llibertat & 1 & - & 2 & - & - & - & 3 & - \\
\hline En Comú-Podem & 1 & - & 3 & - & - & - & 3 & - \\
\hline ERC & - & - & 2 & - & - & - & 2 & - \\
\hline IU & - & 4 & - & 1 & - & - & - & 6 \\
\hline Junts pel Si (JxSî) & 6 & 4 & 16 & 1 & 2 & - & 23 & 4 \\
\hline Podemos & 1 & 1 & - & 4 & 1 & - & 5 & 8 \\
\hline
\end{tabular}

${ }^{24}$ Solo se presentan las voces con un número de apariciones significativo. 
PP

PSC

PSOE

Unió Democràtica

UPyD

\begin{tabular}{r|r|r|r|r|r|r|r}
1 & 9 & 5 & 14 & - & - & 4 & 21 \\
1 & - & 2 & - & - & - & - & - \\
6 & 13 & 2 & 7 & - & 1 & 7 & 18 \\
- & - & 2 & 1 & - & - & - & 3 \\
- & - & - & 1 & - & - & - & 3
\end{tabular}

Fuente: elaboración propia.

\subsection{Verbos de comunicación}

El desglose de los verbos utilizados por los diferentes actores, atendiendo a si su carácter es objetivador o subjetivador, se puede observar en la Tabla VI.

Tabla VI. Verbos de comunicación según origen de la voz citada.

\begin{tabular}{|c|c|c|c|c|}
\hline & \multicolumn{2}{|c|}{ Objetivadores } & \multicolumn{2}{|c|}{ Subjetivadores } \\
\hline & TV3 & TVE1 & TV3 & TVE1 \\
\hline \multicolumn{5}{|c|}{ Miembros Poder Ejecutivo / Administración del Estado } \\
\hline Ministro & 6 & 5 & 2 & 8 \\
\hline Presidente del Gobierno & 2 & 12 & 2 & 4 \\
\hline Vicepresidenta del Gobierno & 1 & - & - & . \\
\hline \multicolumn{5}{|c|}{ Representantes de la Administración Autonómica } \\
\hline Consejeros & 4 & - & 2 & - \\
\hline Presidente de Comunidad Autónoma & 2 & 2 & 3 & 3 \\
\hline \multicolumn{5}{|l|}{ Representantes de partidos políticos } \\
\hline Catalunya Si que es Pot & - & 1 & - & - \\
\hline Ciudadanos & 2 & 6 & 5 & 6 \\
\hline CUP & 14 & 1 & 5 & 3 \\
\hline Democràcia i Llibertat & 3 & - & - & - \\
\hline En Comú-Podem & 1 & - & 3 & \\
\hline$E R C$ & 1 & - & 1 & \\
\hline IU & - & 3 & - & 3 \\
\hline Junts pel Si (JxSi) & 9 & 1 & 15 & 4 \\
\hline Podem & - & - & 1 & 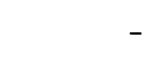 \\
\hline Podemos & 1 & 6 & 1 & 1 \\
\hline$P P$ & 2 & 10 & 3 & 16 \\
\hline$P S C$ & 1 & - & 2 & . \\
\hline PSOE & 2 & 14 & 7 & 13 \\
\hline$U P y D$ & - & 1 & - & \\
\hline
\end{tabular}

Fuente: elaboración propia. 
Como se puede observar en el Gráfico I, en TVE1 hay una correlación fuerte entre los verbos objetivadores y subjetivadores $\left(\mathrm{R}^{2}=0,678\right)$. Por ello, llama la atención la existencia de tres casos muy alejados de esta tendencia: el Presidente del Gobierno, el PP y Podemos. Por su parte, si bien la correlación en el caso de TV3 es moderada $\left(\mathrm{R}^{2}=0,56\right)$, se identifican dos deviaciones similares en el comportamiento de JxSí y la CUP.

\section{Gráfico I. Correlación entre verbos objetivadores y subjetivadores (TVE1 y TV3).}

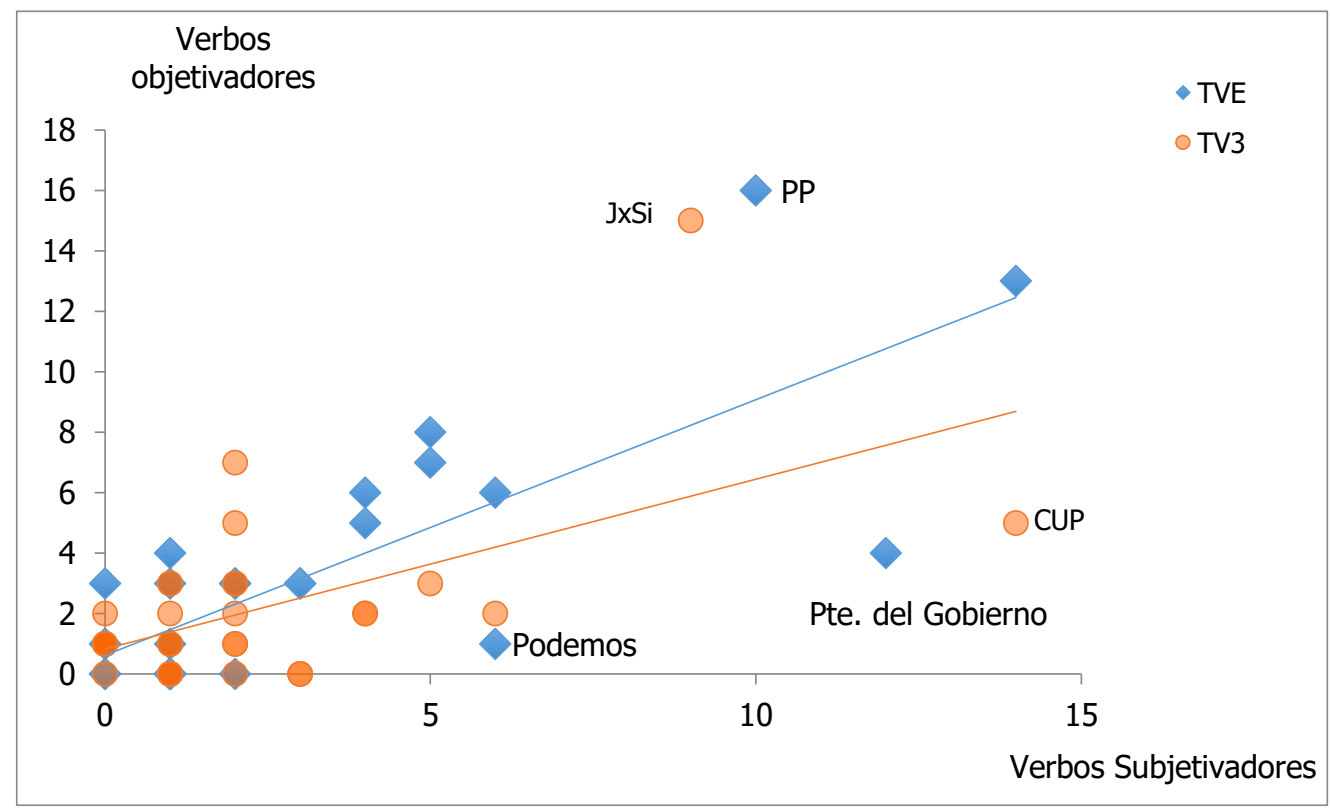

Fuente: elaboración propia.

Aún más significativo es el tratamiento de los verbos combinado con el tipo de cita empleado (Tabla VII). Las combinaciones de citas indirectas con verbos objetivadores son características de las representaciones institucionales y del Presidente del Gobierno. Destaca sobremanera el tratamiento del Presidente de la Generalitat en TV3, con un gran número de citas narradas con verbos subjetivadores. Respecto a los partidos, existen de nuevo grandes diferencias (especialmente para la CUP y JxSî). En TV3, las citas con verbos subjetivadores son el 62\% para el PP, mientras que Podemos es presentado sobre todo con citas indirectas y verbos objetivadores, y el PSOE y JxSí con citas indirectas y verbos subjetivadores. 
Tabla VII. Citas narrada e indirecta y verbos de comunicación (en \%)

\begin{tabular}{|c|c|c|c|c|c|c|c|c|}
\hline & \multicolumn{4}{|c|}{ TV3 } & \multicolumn{4}{|c|}{ TVE1 } \\
\hline & \multicolumn{2}{|c|}{ Narrada } & \multicolumn{2}{|c|}{ Indirecta } & \multicolumn{2}{|c|}{ Narrada } & \multicolumn{2}{|c|}{ Indirecta } \\
\hline & Obj. & Sub. & Obj. & Sub. & Obj. & Sub. & Obj. & Sub. \\
\hline Miembros del Poder & & & & & & & & \\
\hline Ejecutivo & 7 & 21 & 64 & 7 & 7 & 21 & 41 & 15 \\
\hline Ministro & 13 & 25 & 63 & - & - & 31 & 23 & 31 \\
\hline Presidente del Gobierno & - & 25 & 50 & 25 & 13 & 25 & 63 & - \\
\hline $\begin{array}{l}\text { Representantes de la } \\
\text { Administración }\end{array}$ & & & & & & & & \\
\hline Autonómica & 17 & 33 & 17 & 33 & - & 43 & 57 & - \\
\hline Presidente de Comunidad & & & & & & & & \\
\hline Autónoma & 20 & 40 & 20 & 20 & - & 60 & 40 & - \\
\hline $\begin{array}{l}\text { Representantes } \\
\text { de partidos políticos }\end{array}$ & 9 & 23 & 32 & 29 & 10 & 33 & 33 & 17 \\
\hline Ciudadanos & - & 42 & 29 & 29 & 8 & 33 & 42 & 17 \\
\hline CUP & 11 & 11 & 53 & 16 & - & 25 & 25 & 50 \\
\hline Democràcia i Llibertat & 33 & - & 67 & - & 33 & - & 42 & 17 \\
\hline En Comú - Podem & - & 25 & 25 & 50 & - & 25 & 25 & 50 \\
\hline ERC & - & - & 50 & 50 & - & - & 17 & - \\
\hline JxSí & 4 & 21 & 25 & 42 & - & 80 & 20 & - \\
\hline Podemos & 50 & - & - & - & 14 & 14 & 71 & - \\
\hline PP & 20 & - & 20 & 60 & 4 & 31 & 27 & 31 \\
\hline PSC & - & 33 & 33 & 33 & - & - & - & - \\
\hline PSOE & 11 & 56 & 11 & 11 & 19 & 30 & 26 & 11 \\
\hline
\end{tabular}

Fuente: elaboración propia.

\subsection{Tipos de palabras}

Por último, respecto del tipo de palabras que el periodista selecciona para representar el discurso del actor político, los representantes de la Administración del Estado pronuncian fundamentalmente palabras explicativas y evaluativas (Tabla VIII). Por el contrario, la CUP y Podemos pronuncian un número descompensado de expresiones de tipo performativo y evaluativo: estas dos últimas formaciones acumulan un porcentaje mucho mayor de palabras performativas y evaluativas reproducidas que el resto de los partidos políticos. Por otro lado, JxSí posee un índice anormalmente elevado de expresiones 
evaluativas y directivas (que quintuplican a cualquier otro partido político en TV3).

Tabla VIII. Tipos de palabras (en \%).

\begin{tabular}{ll|l|l|l|l|l|l|l|l|l} 
Performt. & Explicat. & Evaluat. & Declarat. & \multicolumn{2}{l|}{ Direct. } \\
\hline TV3 & TVE1 & TV3 & TVE1 & TV3 & TVE1 & TV3 & TVE1 & TV3 & TVE1 \\
\hline
\end{tabular}

\begin{tabular}{lllllllllll}
\hline Miembros del Poder Ejecutivo & 17 & 7 & 56 & 48 & 22 & 26 & 6 & - & - & 19
\end{tabular}

$\begin{array}{lllllllllll}\text { Pte. del Gobierno } & 14 & 20 & 14 & 20 & 71 & 44 & - & 16 & - & -\end{array}$

Vicepte. del Gobierno $\quad-\quad \begin{array}{llllllllll}20 & 33 & 20 & 67 & 60 & - & - & - & -\end{array}$

Administración Autonómica

$\begin{array}{lllllllllll}\text { Consejeros } & 14 & 50 & 14 & - & 50 & 50 & 7 & - & 14 & -\end{array}$

$\begin{array}{lllllllllll}\text { Presidente de la } & 11 & - & 0 & 13 & 78 & 75 & - & - & 11 & 13 \\ \text { Generalitat } & & & & & & & & & & \end{array}$

$11 \quad-\quad 0 \quad 13 \quad 78 \quad 75 \quad-\quad \begin{array}{llllll}11 & 13\end{array}$

Representantes de partidos políticos

\begin{tabular}{|c|c|c|c|c|c|c|c|c|c|c|}
\hline Ciudadanos & 12 & 13 & 6 & 13 & 59 & 58 & 12 & 8 & 12 & 8 \\
\hline CUP & 29 & 30 & 25 & 30 & 39 & 20 & 4 & 10 & 4 & 10 \\
\hline Democràcia $i$ Llibertat & - & - & 50 & - & 50 & - & - & - & - & 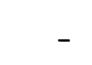 \\
\hline En Comú-Podem & - & - & - & - & $\begin{array}{r}10 \\
0\end{array}$ & - & - & - & - & \\
\hline ERC & 33 & - & 33 & - & 33 & - & - & - & - & \\
\hline IU & - & 13 & - & 13 & - & 47 & - & 13 & - & 13 \\
\hline Junts pel Si (JxSî) & 6 & 9 & 8 & 27 & 49 & 27 & 19 & 18 & 19 & 18 \\
\hline Podemos & 43 & 7 & 14 & 21 & 43 & 57 & - & 7 & - & \\
\hline PP & 14 & 7 & 29 & 23 & 57 & 52 & - & 9 & - & \\
\hline PSC & - & - & 20 & - & 40 & - & 20 & - & 20 & \\
\hline PSOE & 8 & 18 & - & 5 & 92 & 68 & - & 5 & - & \\
\hline Unió Democràtica & - & 100 & 50 & - & 50 & - & - & - & - & \\
\hline UPyD & - & - & - & 25 & - & 75 & - & - & - & \\
\hline
\end{tabular}

Fuente: elaboración propia.

\subsection{Análisis conjunto de las tres variables}

Para poder apreciar las diferencias en la configuración de las citas es necesario recurrir al conjunto de las tres variables, y a su combinación a la hora de establecer el criterio narrativo (Tablas IX y X). 
Tabla IX. Tipos de citas, palabras y verbos TV3 (\% sobre total de citas).

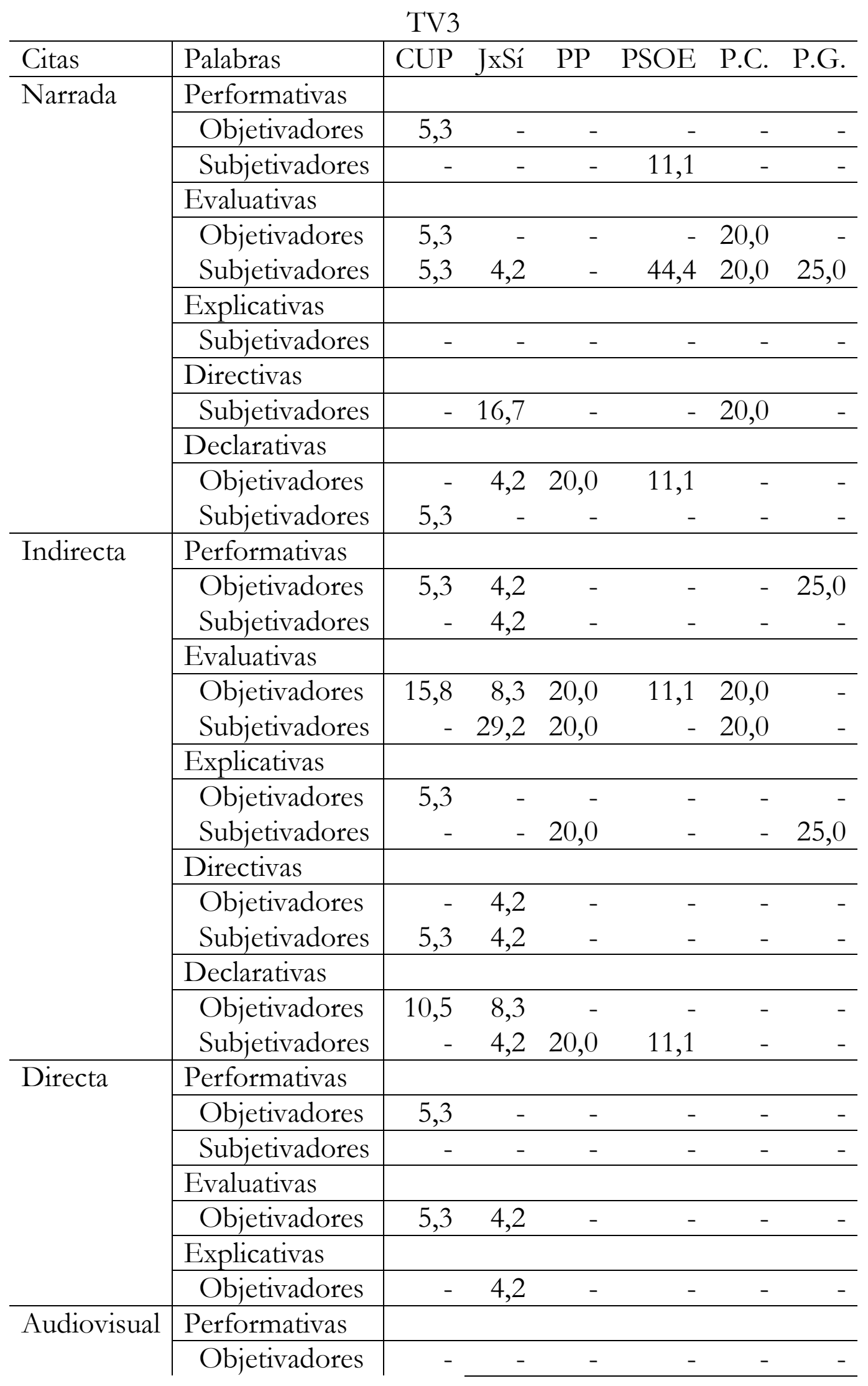




\begin{tabular}{|c|cccccr} 
Evaluativas & \multicolumn{6}{|c}{} \\
\hline Subjetivadores & - & - & - & 11,1 & - & - \\
\hline Explicativas & & & & & & \\
\hline Subjetivadores & - & - & - & - & - & - \\
\hline Declarativas & & & & & & \\
\hline Objetivadores & - & - & - & - & - & -
\end{tabular}

Fuente: elaboración propia (no se incluyen citas mixtas).

\section{Tabla X. Tipos de citas, palabras y verbos TVE1 (\%).}

\begin{tabular}{|c|c|c|c|c|c|c|c|c|}
\hline & & & $\mathrm{TT}$ & & & & & \\
\hline Citas & Palabras & $\mathrm{IU}$ & JxSí & Podem. & $\mathrm{PP}$ & $\overline{\text { PSOE }}$ & P.C. & P. G. \\
\hline Narrada & Performativas & & & & & & & \\
\hline & Objetivadores & . & - & - & - & 3,7 & - & 6,3 \\
\hline & Subjetivadores & 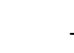 & 20,0 & - & 3,8 & 7,4 & - & - \\
\hline & Evaluativas & & & & & & & \\
\hline & Objetivadores & 20,0 & - & - & - & $\overline{14,8}$ & - & - \\
\hline & Subjetivadores & 20,0 & 20,0 & 14,3 & 11,5 & 11,1 & 40,0 & 12,5 \\
\hline & Explicativas & & & & & & & \\
\hline & Subjetivadores & 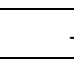 & - & - & 3,8 & - & - & 6,3 \\
\hline & Directivas & & & & & & & \\
\hline & Subjetivadores & 20,0 & 40,0 & - & 7,7 & 3,7 & 20,0 & - \\
\hline & Declarativas & & & & & & & \\
\hline & Objetivadores & - & 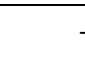 & 14,3 & 3,8 & - & - & 6,3 \\
\hline & Subjetivadores & . & - & - & 3,8 & 7,4 & - & 6,3 \\
\hline Indirecta & Performativas & & & & & & & \\
\hline & Objetivadores & . & 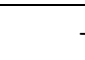 & - & - & 3,7 & - & 12,5 \\
\hline & Subjetivadores & - & 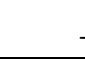 & - & - & - & - & - \\
\hline & Evaluativas & & & & & & & \\
\hline & Objetivadores & 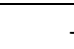 & 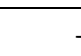 & 14,3 & 11,5 & 14,8 & 40,0 & 25,0 \\
\hline & Subjetivadores & - & . & - & 15,4 & 3,7 & - & - \\
\hline & Explicativas & & & & & & & \\
\hline & Objetivadores & & 20,0 & 28,6 & 7,7 & - & - & 12,5 \\
\hline & Subjetivadores & . & 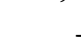 & - & 3,8 & - & - & - \\
\hline & Directivas & & & & & & & \\
\hline & Objetivadores & 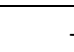 & 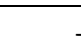 & 14,3 & - & 3,7 & - & - \\
\hline & Subjetivadores & . & 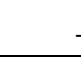 & - & 3,8 & - & - & - \\
\hline & Declarativas & & & & & & & \\
\hline & Objetivadores & 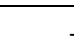 & 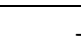 & - & 3,8 & - & - & 12,5 \\
\hline & Subjetivadores & 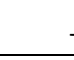 & - & - & 3,8 & - & - & - \\
\hline Directa & Performativas & & & & & & & \\
\hline & Objetivadores & . & . & - & - & - & - & - \\
\hline & Subjetivadores & . & . & - & - & - & - & - \\
\hline & Evaluativas & & & & & & & \\
\hline & Objetivadores & . & 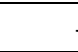 & - & 3,8 & 3,7 & - & - \\
\hline & Explicativas & & & & & & & \\
\hline & Objetivadores & 20,0 & 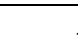 & - & - & - & - & - \\
\hline
\end{tabular}




\begin{tabular}{|c|c|c|c|c|c|c|c|c|}
\hline \multirow[t]{8}{*}{ Audiovisual } & \multirow{2}{*}{$\begin{array}{l}\text { Performativas } \\
\text { Objetivadores }\end{array}$} & & & & & & \multirow[b]{2}{*}{-} & \multirow[b]{2}{*}{-} \\
\hline & & - & - & - & 3,8 & - & & \\
\hline & Evaluativas & & & & & & & \\
\hline & Subjetivadores & - & - & - & - & 3,7 & - & - \\
\hline & Explicativas & & & & & & & \\
\hline & Subjetivadores & - & - & - & - & 3,7 & - & - \\
\hline & Declarativas & & & & & & & \\
\hline & Objetivadores & - & - & - & - & 3,7 & - & - \\
\hline
\end{tabular}

Fuente: elaboración propia (no se incluyen las citas mixtas).

En los dos casos (TVE1 y TV3), se observa que los tres ítems analizados (tipos de citas, verbos y palabras) están relacionados entre sí. Coincide que para los actores políticos cuyo discurso se reproduce sobre todo con citas narradas y verbos subjetivadores (PP en TVE1, JxSí en TV3), se seleccionan tipos de palabras evaluativas para presentar su discurso.

\section{Discusión y conclusiones}

Los datos obtenidos son tratados, por un lado, cuantitativamente, a través de un procedimiento mixto de análisis anidado (Verd y Pérez, 2008) para establecer relaciones de regresión entre las variables y, por otro lado, cualitativamente, para corroborar las hipótesis planteadas. Más allá del nivel de confianza que los datos cuantitativos pueden aportar, se analizan de manera cualitativa las citas seleccionadas para analizar hasta qué punto su utilización (sin analizar específicamente el sentido) posibilita la creación de una narrativa ad hoc para cada sujeto político, y modela la agenda que es ofrecida al espectador, contraviniendo de este modo la función de pluralidad encomendada a los medios. Finalmente, se comparan los comportamientos de las dos televisiones para establecer si existe algún tipo de relación en el tratamiento de los actores políticos que ambas ofrecen.

\subsection{Voces citadas}

Al identificar las voces políticas citadas en TVE1 y TV3 fue posible observar la amplitud de actores políticos representados en ambas cadenas (Tabla III). No obstante, al analizar en detalle la frecuencia de aparición de las principales figuras políticas, se comprobó que los discursos de Mariano Rajoy en TV3 y de Artur Mas en TVE1 apenas aparecen representados. Se evidencia así un panorama mediático en que cada una de estas cadenas presenta un escenario político distinto, 
cediendo espacio a los debates y luchas políticas propias del territorio que abarcan.

Por otra parte, al analizar las voces citadas también se observó que, tanto en TVE1 como en TV3, en la mayoría de las ocasiones no queda claro en calidad de qué hablan los políticos a los que se da voz en los telediarios. Así, la concepción personalista queda por encima de la institucional; los políticos son representados más como personajes que como instituciones, lo que redunda en la creación de una narrativa. Esta preponderancia de la figura sobre la institución muestra cómo los telediarios dan por supuesto que los espectadores distinguirán por sí mismos en calidad de qué está hablando cada político. Como resultado, acaba triunfando la idea de institución, que confiere un nivel de credibilidad más elevado, aun cuando, en realidad, el actor político esté representando a su propio partido.

Por este motivo, al comprobar los resultados arrojados tras analizar las voces citadas, comprobamos que, más que observar a quién se cita, lo verdaderamente relevante es analizar cómo se construye el discurso reproducido a través de los diferentes tipos de citas, tipos de verbos y tipos de palabras.

\subsection{Tipos de citas}

La distribución de citas en las dos televisiones estudiadas sigue patrones muy similares, como muestra la Tabla IV. Además, presentan tratamientos diferenciados para los actores institucionales y el resto de los actores políticos.

En cuanto al tipo de citas en sus patrones diferenciados, se observa un mayor uso de la cita narrada en TVE1. La cita narrada es una forma de reproducción del discurso muy sintética, altamente interpretativa, en la que no prima tanto reproducir qué se ha dicho, sino destacar el tema sobre el que se ha hablado al tiempo que, mediante un verbo subjetivador, se ofrece interpretada la intención comunicativa de lo dicho. El uso de este tipo de cita permite al periodista dotar de una narrativa al personaje que introduce, dándole peso en la agenda del medio como generador de una acción verbal, de un acto de habla, del que destaca específicamente cómo el periodista valora, interpreta, evalúa, su intención comunicativa. Es la cita más frecuente en la reproducción de los discursos de Artur Mas en TV3, y frecuente para 
los discursos de Mariano Rajoy en TVE1. Ambos presidentes reciben este tratamiento diferenciado, acaso porque su relevancia política exige mayor esfuerzo interpretativo por parte del periodista (o porque el periodista se esfuerza en ofrecer bajo su tamiz interpretativo lo dicho y, sobre todo, la intención de lo dicho por los agentes de más alta jerarquía en la esfera política). Respecto de esta variable, la cadena estatal muestra, igualmente, el mismo tratamiento diferenciado para dos partidos políticos (PSOE y JxSî), cuyos discursos se reproducen también con más citas narradas que en lo que atañe al resto de las formaciones: son los partidos que se oponen a la línea política que encabeza el presidente Mariano Rajoy y, por tanto, sus rivales dialógicos. De nuevo, estos discursos merecen la atención interpretativa y evaluadora del periodista. En la misma línea, TV3 acumula las citas indirectas, altamente interpretativas, para los partidos de la oposición -cuyos discursos se reproducen, además, con menor número de citas audiovisuales, las más objetivadoras-.

Resulta relevante que, en ambas cadenas, la utilización de recursos a priori más objetivos (como verbos objetivadores o citas audiovisuales) no está necesariamente ligada a una mejor representación de los actores políticos en términos de pluralismo interno. La selección de las piezas y su presentación en formatos más objetivos responde en la mayoría de los casos a réplicas de elementos de la agenda de los ejecutivos o de los partidos que les dan apoyo. Estas piezas informativas son tratadas con un mayor nivel de complejidad en su elaboración, configurando un discurso propio dominante sobre el conjunto de las noticias que relegan a los partidos que no son de gobierno al papel de actores secundarios, cuyas propuestas no requieren un tratamiento elaborado al estar siempre enmarcadas en las discusiones de otras fuerzas políticas.

\subsection{Verbos de comunicación}

Los periodistas recurren tanto a verbos objetivadores como a verbos subjetivadores para introducir el discurso referido en la narración de las piezas informativas. Sobre los verbos objetivadores, es de remarcar su uso mayoritario $(75 \%)$ en las citas indirectas que se atribuyen al Presidente del Gobierno en TVE1. Sorprendentemente, en TV3 (60\%) ocurre algo similar con los verbos objetivadores en citas indirectas atribuidas al Presidente de la Generalitat. Estos verbos no revelan la 
interpretación periodística de las intenciones comunicativas originarias, con lo que el peso de la cita recae no tanto en el verbo y, por tanto, en la interpretación de la intención comunicativa del discurso público del actor político, como en la reproducción del contenido -que, eso sí, es resumido o parafraseado- de lo dicho por tal actor y, por tanto, en el tipo de palabras que se reproducen. Se gana así en apariencia de objetividad periodística, si bien la cita, indirecta, por alejarse de pretensiones de literalidad, sigue sintiéndose, en su conjunto, fruto de la subjetividad del periodista.

De hecho, el actor político más subjetivado en TVE1 es Mariano Rajoy, por el empleo de la fórmula: cita narrada con verbo subjetivador. Para la reproducción de sus discursos se utilizan verbos como: defender, destacar, insistir o advertir. Estos verbos presentan al presidente del Poder Ejecutivo como un hombre de ley, un agente que hace avanzar la acción en pro del mantenimiento del orden y el respeto por la legislación vigente. Mediante estos verbos subjetivadores del discurso narrado se construye la imagen del presidente. Por el contrario, el discurso del líder de la oposición, Pedro Sánchez, aparece representado con verbos de comunicación mayormente objetivadores, dándose así un trato diferenciado para ambos actores políticos.

En TV3 tiene lugar el mismo fenómeno respecto de la figura de Artur Mas. El Presidente de la Generalitat es representado también con citas narradas y verbos subjetivadores como lamentar, acusar, pedir, instar, o insistir. Son, de nuevo, verbos cargados de interpretación de intenciones comunicativas que, en este caso, construyen al presidente como una víctima que valora negativamente hechos o dichos por otros. En efecto, Artur Mas, a partir de su discurso reproducido, se muestra en constante defensa de los ataques del Gobierno central -en este caso, por lo que respecta a los pagos del FLA-, por un lado, y de la oposición de la CUP a su investidura, por otro. Y encontramos nuevamente una elaboración asimétrica de la representación de los actores políticos, compleja para los miembros del Poder Ejecutivo y mucho más directa y objetivada para la oposición.

En ambas televisiones se observa, finalmente, una tendencia al recurso a verbos subjetivadores en las citas atribuidas a los partidos políticos que apoyan las acciones de gobierno del PP y de JxSí, respectivamente; 
y en el caso de TV3, a utilizar los verbos objetivadores para las citas referidas a la CUP, que concentra el 45\% todos los verbos objetivadores utilizados en la muestra.

\subsection{Tipos de palabras}

Los representantes de la Administración del Estado pronuncian el mayor número de palabras de análisis (explicativas) en el corpus de telediarios, y abundan también en palabras evaluativas (Tabla VIII). Por el contrario, la CUP y Podemos pronuncian un número descompensado de expresiones de tipo performativo, además de evaluativo. Por otro lado, JxSí posee un índice anormalmente elevado de expresiones evaluativas y directivas (que quintuplican a cualquier otro partido político en TV3).

En cuanto al tipo de palabras, se confirma que TVE1 ofrece un tratamiento diferenciado para PP y PSOE: predominan ostensiblemente las palabras evaluativas del PSOE, que apenas pronuncia palabras explicativas. En el caso de la cadena autonómica, predomina para todos los actores las palabras evaluativas, existiendo un equilibrio en la selección de palabras performativas y explicativas. Esto es así para todas las formaciones excepto para la CUP, que aparece representada con mayor tendencia hacia palabras declarativas o directivas. El tipo de palabras seleccionadas preponderantemente de los discursos públicos de cada actor político construye también su imagen social.

\subsection{Construcción de una narrativa a través del discurso reproducido}

Tras identificar los actores políticos representados en el corpus de noticias, y analizar tres ítems: tipo de citas, tipo de verbos de comunicación y tipos de palabras, con que se reproducen sus discursos públicos, se comprueba que en los dos casos (TVE1 y TV3) los ítems están relacionados entre sí. Destaca en el corpus el recurso a la cita narrada con verbo subjetivador que introduce palabras evaluativas, por su repercusión en la construcción diferenciada de la imagen de los actores políticos.

Por otro lado, la utilización de citas indirectas se relaciona con una elevada elaboración del discurso, y es utilizada con los partidos de la oposición (en el caso TV3, también con la figura de Mariano Rajoy). 
En todos estos casos, es significativo el proceso de elaboración del contenido, que parece estar orientado a un procesado de la información previa a su emisión. Por lo que respecta a los partidos políticos, el caso más extremo de desviación se da en el tratamiento del PSOE en TVE1: este partido aparece diferenciado del resto de las formaciones políticas en los tres elementos del discurso referido analizados: tipo de cita, tipo de verbo de comunicación y tipo de palabras seleccionadas del discurso de sus dirigentes (más evaluativas/subjetivas que el resto de partidos). Por otro lado, existe también un tratamiento diferenciado en el tipo de palabras que emiten los miembros del PP en tanto que expresan más palabras explicativas que el resto de partidos, como sucede con los actores institucionales.

En el caso de TV3, cabe recordar el contexto de negociaciones entre JxSí y la CUP para la investidura de Artur Mas como Presidente de la Generalitat. La realidad antagónica entre estas dos formaciones aparece representada en el informativo a través de un tratamiento diferenciado en el tipo de verbo empleado para representar a cada una de ellas. Mientras que las citas de los miembros de la CUP aparecen introducidas por verbos en su mayoría objetivadores, el discurso de los dirigentes de JxSí se presenta con verbos subjetivadores. Además, existe también un tratamiento diferenciado en el tipo de citas para Podemos, PP (más audiovisuales/objetivas en estos dos) y PSOE (más narradas/subjetivas).

Así, tras haber analizado las diferentes voces políticas citadas y los tres elementos que integran el discurso reproducido (citas, palabras y verbos), los resultados de esta investigación muestran que los informativos de ambas cadenas, en su discurso, dan un tratamiento a los miembros del ejecutivo (en particular, al Presidente del Gobierno, en TVE; y al Presidente de la Generalitat, en TV3) diferente del que dan a los partidos políticos. Esta diferenciación pone de manifiesto que no todos los actores políticos pueden ser representados de la misma forma debido a que la realidad de los actores con mayor carga institucional es limitada (actos oficiales, declaraciones...). Por ello, la variedad de citas que se puedan emplear para reproducir su discurso también lo es. Por lo tanto, no es sorprendente hallar que ministros, miembros del Tribunal Constitucional o el Presidente del Gobierno / Presidente de la Generalitat sean representados con tipos de cita, 
verbos o fragmentos de su discurso -seleccionando palabras explicativas, por ejemplo o verbos objetivadores- que en ocasiones tiendan a objetivarlos o a presentarlos como más objetivos respecto al resto de actores políticos.

Sin embargo, esta circunstancia no permite justificar la asimetría que dicho tratamiento supone respecto del resto de los actores. En definitiva, lo que sucede es que la elaboración permite la construcción de un relato. El tipo de citas utilizadas y su combinación permiten la orientación de las noticias a conformar un discurso que tiene como centro a los jefes del Ejecutivo, y que gira en torno a los elementos de la agenda que estos introducen. El resto de los actores políticos no son agentes activos en la introducción de elementos en la agenda y, por tanto, reciben un tratamiento narrativo mucho más directo que impide a los espectadores la posibilidad de evaluarlos más allá del marco propuesto por el actor principal. La responsabilidad de esta presentación reside en las televisiones y, si bien no se puede negar que en cuestión de tiempo y representación siguen pautas aceptablemente plurales, no lo hacen a la hora de estructurar el discurso de los actores representados. Un telediario plural no debería conformarse únicamente con hacer aparecer a todos los actores políticos y cuantificar su tiempo de aparición en pantalla, sino en crear narrativas para todos ellos acordes con la visión objetiva de los periodistas, pero coherentes con la imagen que cada actor quiere trasmitir en términos de agenda. Es decir, los telediarios deberían visualizar las diferentes agendas políticas en los términos en los que los diferentes actores políticos quieren que sean presentadas al espectador. Desde esta perspectiva, hemos de concluir que el pluralismo interno en los telediarios está sesgado por el uso que hacen del discurso reproducido.

Así, y aunque la distribución proporcional del tiempo para cada partido sea correcta, el análisis realizado muestra la existencia de un sesgo en el tratamiento de los diferentes actores políticos, lo que genera dudas sobre el grado de pluralismo de los informativos. Por eso, se deben buscar otros elementos objetivables que permitan observar la calidad democrática del medio. Hablar de pluralismo no es una tarea sencilla y debe tenerse en cuenta que el concepto es complejo e incluye muchas dimensiones (siendo una de ellas la creación de la imagen). En este sentido, este artículo prueba que la manera de referir el discurso es un 
elemento que permite determinar desviaciones en el tratamiento de actores políticos o, lo que es lo mismo, en la forma de construir su imagen en los telediarios.

Por otro lado, si los telediarios construyen la imagen de los actores políticos a través de referir sus discursos, en el contexto de esta investigación se entiende por pluralismo interno el trato homogéneo en el uso de las citas para con todos los partidos. Sin embargo, -y como muestran los resultados-, existe una tendencia de representación de ciertas formaciones políticas que es contraria a la tendencia general, por lo cual se podría sospechar de un tratamiento informativo discrecional. De ser así, al tratarse de dos televisiones públicas cuyo deber es el de ofrecer un servicio informativo de calidad al ciudadano, los resultados obtenidos tendrían una implicación más grave.

En último término, la definición de pluralismo mediático en la literatura -cuya única precisión es la distinguir entre pluralismo externo e interno- apela a conceptos difícilmente objetivables o mesurables en los términos de pluralismo que requiere la democracia. Así, la laxitud del término dificulta su regulación y observación en los medios de comunicación, y pone de manifiesto la insuficiencia de los procedimientos cuantitativos utilizados hasta ahora para garantizar la pluralidad de los contenidos políticos. Los resultados de este trabajo evidencian la necesidad de recurrir a elementos cualitativos para medir la calidad democrática de los informativos y muestran la relevancia de incluir el discurso reproducido, uno de los procedimientos discursivos más eficaces al servicio de los medios para elaborar una imagen de la realidad, como un indicador del pluralismo interno.

\section{Bibliografía}

Almirón, N., Capurro, M. y Santcovsky, P. (2010): “The Regulation of Public Broadcasters' News Coverage of Political Actors in Ten European Union Countries/La regulación de la información sobre los actores políticos en los medios públicos de diez países de la Unión Europea". Comunicación y Sociedad, 23(1), 205.

Bednarek, M. y Caple, H. (2012): News Discourse. Londres/New York: Continuum. 
Berganza, R., Van Dalen, A. y Chaparro Domínguez, M. Á. (2010): “La percepción mutua de las relaciones entre periodistas parlamentarios y miembros del Congreso y de su influencia en las agendas política y mediática". Revista de Comunicación, 9, 7-25.

Casado Velarde, M. (2008): "Algunas estrategias discursivas en el lenguaje periodístico de hoy”. Boletín Hispánico Helvético, 12, 71-97. Casado Velarde, M. y de Lucas Vicente, A. (2013): "La evaluación del discurso referido en la prensa española a través de los verbos introductores". Revista Signos. Estudios de lingüistica, 46(83), 332360 .

Consejo de Europa (1994): “4éme Conference Ministerelle Europeenne sur la Politique des communications de masse. Les media dans une société démocratique”. Praga, 7-8.XII.1994. MCM (94)5. Estrasburgo: Consejo de Europa.

Charaudeau, P. (2003): El discurso de la información. Barcelona: Gedisa.

De Lucas Vicente, A. (2014): "Verdad y argumentación en la cita periodística". Revista Española de Lingüística, 44(1), 39-64.

De Lucas Vicente, A. (2015): "Hacia la construcción del paradigma léxico de los verbos introductores de discurso. Análisis de su tratamiento lexicográfico actual". En C. Álvarez López, B. Garrido Martín y M. González Sanz (Coords.), Jóvenes aportaciones a la investigación lingüistica. Sevilla: Ediciones Alfar.

Escribano, A. (2001): Pragmática e ideología en las informaciones sobre conflictos politicos. Salamanca: Universidad Pontificia de Salamanca.

Escribano, A. (2009): Las voces del texto como recurso persuasivo. Madrid: Arco Libros.

Fernández, I. (2016): "Independent Audiovisual Regulators in Spain: A Unique Case in Europe". International Journal of Communication, 10, 359-376.

Fernández, I. y Fernández, A. (2012): "Internal pluralism in the governance of public service broadcasters in Spain and the role of social groups and professionals. The case of RTVE". Comunicación y Sociedad, 25(2), 203.

Fernández García, F. (2003): Así son las cosas... Análisis del discurso informativo en televisión. Jaén: Universidad de Jaén.

Gavara de Cara, J. C. (2013): Autoridades Independientes del Audiovisual: del CEMA a la CNMC. [Blog] Blog de la Revista catalana de Dret Públic. Recuperado de: http://eapc- 
rcdp.blog.gencat.cat/2013/05/21/autoridades-independientesdel-audiovisual-del-cema-a-la-cnmc-juan-carlos-gavara/

Habermas, J. (2000): Aclaraciones a la ética del discurso. Madrid: Trota.

Hallin, D. C. y Mancini, P. (2004): Comparing media systems: Three models of media and politics. Cambridge university press.

Humanes, M. L., Montero, M.D., Molina, R. y López, A. (2013): "Pluralismo y paralelismo político en la información televisiva en España". Revista Latina de Comunicación Social, 68, 566-581.

Kerbrat-Orecchioni, C. (1986): La enunciación. De la subjetividad en el lenguaje. Buenos Aires: Edicial.

Martínez Pasamar, C. (2010): "Donde dije digo digo Diego: un recurso de desautorización de la prensa". En C. Martínez Pasamar (Ed.), Estrategias argumentativas en el discurso periodístico (87-117). Frankfurt: Peter Lang.

Méndez, E. (1999): “Análisis de la reproducción del discurso ajeno en los textos periodísticos”. Pragmalingüistica, 7, 99-128.

Méndez, E. (2000a): "La literalidad de la cita en los textos periodísticos". Revista Española de Lingüistica, 30(1), 147-167.

Méndez, E. (2000b): "Análisis de las formas de introducir el discurso ajeno en los textos periodísticos: el contexto reproductor". En J. J. Bustos Tovar (Ed.), Lengua, discurso, texto (2081-2098). Madrid: Visor.

Moirand, S. (2007): Les discours de la presse quotidienne: observer, analyser, comprendre. París: Presses Universitaires.

Repede, D. (2015): "El discurso directo como estrategia de interpretación de la palabra ajena en los textos periodísticos". Lengua y Habla, 19, 77-92.

Rosier, L. (2002): "La presse et les modalités du discours rapporté: l'effet d'hyperréalisme du discours direct surmarqué". L'information gramaticale, 94, 27-32.

Ruiz, L. (2006): Hechos pragmáticos del español. Alicante: Publicaciones de la Universidad de Alicante.

Sánchez García, F. (2010): "Usos y abusos del discurso referido en la prensa política". Cuadernos de periodistas: revista de la Asociación de Prensa de Madrid, 19, 96-112.

Sánchez García, F. (2012): El discurso referido en la prensa española. Madrid: Octaedro. 
Santander, P. (2003): “Acceso y discurso referido en el periodismo televisivo". Revista iberoamericana de Discurso y Sociedad, 4(2), 9-32.

Strömbäck, J. y Luengo, O. (2008): "Polarized pluralist and democratic corporatist models: A comparison of election news coverage in Spain and Sweden". International Communication Gazette, 70(6), 547562.

Van Dijk (1990): La noticia como discurso. Comprensión, estructura y producción de la información. Barcelona: Paidós Comunicación.

Van Dalen, A. (2012): "Structural Bias in Cross-National Perspective How Political Systems and Journalism Cultures Influence Government Dominance in the News". The International Journal of Press/Politics, 17(1), 32-55.

Verd, J. M. y López, P. (2008): "La eficiencia teórica y metodológica de los diseños multimétodo". Empiria. Revista de Metodología de las Ciencias Sociales, 16.

Vicente Mateu, J. A. (2007): "Discurso reproducido e interpetación de la fuerza ilocutiva en la prensa escrita". Revista de investigación linguïstica, 10, 225-242.

Waugh, L. (1995): "Reported speech in journalistic discourse. The relation of function and text". Text, 15(1), 129-173.

\section{Reconocimientos de la investigación}

El desarrollo de este trabajo se enmarca en el proyecto de investigación: Desarrollo de la formación sociopolítica para una ciudadanía democrática: diseño e implementación de materiales didácticos en Ciencias Sociales (EDU201565621-C3-3-R), financiado por el Ministerio de Economía y Competitividad. 



\title{
La Europa de dos velocidades reflejada en la financiación del servicio audiovisual público: un análisis basado en los presupuestos
}

\author{
Óscar Juanatey-Boga \\ Universidade da Coruña \\ Valentín-Alejandro Martínez-Fernández \\ Universidade da Coruña \\ Marta Rodríguez-Castro, \\ Universidade de Santiago de Compostela
}

PARA CITAR: Juanatey-Boga, O., Martínez-Fernández, V.A. y Rodríguez-

Castro, M. (2018). La Europa de dos velocidades reflejada en la financiación del servicio audiovisual público: un análisis basado en los presupuestos. Revista Latina de Comunicación Social, 73, pp. 1054 a 1071.

http://www.revistalatinacs.org/073paper/1296/55es.html

DOI: $10.4185 /$ RLCS-2018-1296

\section{Resumen}

El sistema audiovisual público (SAP) europeo se enfrenta a retos de innovación, legitimidad y financiación. Este artículo analiza la evolución de la financiación de las radiotelevisiones públicas (RTVP) europeas entre 2010 y 2016, además de abordar la necesidad de legitimización y actualización de los distintos modelos de financiación vigentes en la UE. Se han analizado los presupuestos de las RTVPs en relación a habitantes, hogares y PIB en PPA. Los resultados constatan el impacto de la crisis económica en el SAP. Se distinguen dos trienios con tendencias diferentes: el primero (2010-2013), marcado por la constricción presupuestaria (-4,1\%), y el segundo (2013-2016) por una cierta recuperación (4\%); así como fuertes diferencias entre la Europa del Norte y la del Sur. Se concluye que es necesario reformular los 
modelos de negocio del SAP, de forma que se alcance una mayor estabilidad, adecuación y legitimidad.

Palabras clave: Servicio audiovisual público, financiación, canon, legitimidad, análisis comparativo.

\section{Introducción}

प.

L SISTEMA audiovisual público europeo lleva décadas haciendo frente a retos emergentes ante los que está abocado a reflexionar sobre su papel en la sociedad para poder adaptarse a un entorno cambiante y difícilmente predecible. Algunos de los problemas más recurrentes durante la década de 1990, relacionados con una triple crisis de identidad, financiación y problemas operativos (Achille, 1994), están todavía presentes en la lista de desafíos que se concitaron a lo largo de los últimos años, derivados fundamentalmente de la adaptación al nuevo ecosistema digital, lo que Bardoel y Ferrell Lowe (2007) denominaron transición del Public Service Broadcasting al Public Service Media.

\subsection{Los retos del servicio audiovisual público en el entorno digital}

Los principales retos que impregnan la gobernanza y la actividad del servicio audiovisual público en la actualidad se concentran en los ámbitos de la innovación, la legitimidad y la crisis de los distintos modelos de financiación vigentes en Europa. El primero de ellos se manifiesta, por ejemplo, en la emergencia de mecanismos de regulación como las pruebas de valor público, empleadas para decidir sobre la aprobación (o no) de propuestas de nuevos servicios de los organismos públicos en el ámbito de los nuevos medios, en un intento por legitimar su actividad pionera en el campo de la innovación (Moe \& Donders, 2011, Rodríguez-Castro, 2017).

Los esfuerzos de las radiotelevisiones públicas por renovar continuamente su legitimidad ante sus distintos grupos de interés han estado influidos en gran parte por las presiones ejercidas desde el sector privado de los medios de comunicación. Uno de los argumentos más esgrimidos por los medios privados es la obsolescencia del razonamiento del fallo de mercado: un sistema audiovisual no regulado, puramente comercial, desembocaría en un fallo de mercado, donde 
algunos gustos mayoritarios contarían con una oferta sobredimensionada, mientras que aquellos minoritarios o poco atractivos para el gran público quedarían marginados (Brown, 1996). Este vacío de contenido justificaría la existencia de los medios de comunicación públicos.

A pesar de que el argumento del fallo de mercado parece haber pasado a un segundo plano, lo cierto es que sigue presente en el actual debate sobre el sistema audiovisual público en conexión con las transformaciones derivadas del convulso entorno digital, donde la oferta (tanto de pago como gratuita) se multiplica al mismo tiempo que se personaliza, allanando el camino a los críticos de los medios de comunicación públicos. En Irlanda, durante la celebración del Forum on Broadcasting en 2002, el lobby del sector privado expuso su posición para marginar la actividad de la RTÉ en cuestiones de audiencia, contenidos y financiación (Coppens \& Saeys, 2006), al limitar a la radiotelevisión pública irlandesa a aquellos sectores a los cuales los medios privados no llegaban. Por otra parte, esta retórica también salió a relucir en Reino Unido en 2015, durante el proceso de renovación de la Royal Charter de la BBC. Justin Lewis (2015) criticó la nueva posición asumida en el documento de consulta pública elaborado por el Departamento de Cultura, Medios y Deporte durante dicho proceso, pues se retomaba el argumento del fallo de mercado para contemplar la posibilidad de modificar la misión y los propósitos públicos de la BBC a fin de focalizar su actividad en audiencias específicas $y$ desatendidas (Department for Culture, Media \& Sport, 2015).

Por su parte, los defensores de los medios de comunicación públicos han respondido a los ataques dirigidos a reducir su actividad utilizando, entre otros, el argumento del value for money; es decir, la relación calidadprecio (Hultén, 2003). Ferrell Lowe y Berg (2013) analizan los datos económicos de las principales radiotelevisiones públicas europeas y, tras contrastarlos con los resultados obtenidos por sus homólogas privadas, concluyen que las primeras consiguen sacar un rendimiento a sus presupuestos mucho mayor las segundas, de modo que refutan así los argumentos de los críticos en torno a la sobrecompensación. Además, este rendimiento no es sólo económico, sino que también se concibe a partir de la creación de valor público y social (Crespo, Martínez \& Campos, 2017). Consiguientemente, los beneficios sociales 
que debe aportar hoy el sistema audiovisual público acompañan a otros de tipo económico, como la contribución a un mercado audiovisual nacional o la promoción de la innovación y el talento (Bardoel \& d'Haenens, 2007; Ferrell Lowe \& Berg, 2013; Bonini \& Pais, 2017).

Tras la elevación al nivel europeo de las protestas del sector privado, ya en la década de 1990, la Comisión Europea ha tenido que mediar en el conflicto entre críticos y defensores de unos medios públicos en el contexto digital. Así, la Comisión Europea ha aplicado sus principios de competencia a las políticas de radiodifusión (Comisión Europea, 2009), al mismo tiempo que ejerció presión sobre los Estados miembros para que legitimasen sus medios públicos a través de la adaptación de su misión de servicio público al nuevo ecosistema digital y de un aumento de la rendición de cuentas ante sus distintos grupos de interés (Donders, 2010).

Las quejas del lobby privado, que como ya apuntamos antes se suceden desde hace dos décadas, se intensificaron a raíz de la crisis económica detonada en 2008. El impacto de la recesión en el mercado publicitario fue drástico, encontrándose los medios impresos entre los más afectados (Juanatey, Martínez y Castellanos, 2017). Por el contrario, dentro de un contexto de disminución de los ingresos publicitarios, los medios digitales vieron cómo sus beneficios procedentes de esta fuente aumentaban (Ferrell Lowe \& Berg, 2013). Este desplazamiento de los ingresos publicitarios activó la alerta en los medios impresos, que empezaron a trasladar su actividad a los nuevos medios. Las radiotelevisiones públicas estaban entonces en pleno proceso de creación de su propio espacio en Internet, de forma relativamente exitosa, lo que el sector privado entendió como un obstáculo en el camino hacia su propia transición digital y motivó una nueva oleada de protestas ante la Comisión Europea.

A este continuo cuestionamiento de la legitimidad del servicio audiovisual público se ha sumado además la crisis de sus diversos modelos de financiación. 


\subsection{Los modelos de financiación del servicio audiovisual público europeo}

El proceso de digitalización de los medios públicos coincidió con importantes recortes en sus presupuestos, fruto de la situación de crisis, así como de una mayor demanda de transparencia en la gestión de los recursos (Moe, 2011). A pesar de que los modelos de financiación presentes en el sistema audiovisual público europeo son diversos, en todos se ha notado el impacto de la crisis y actualmente se desarrolla un debate en torno al futuro de la financiación de los medios públicos.

Puede elaborarse una primera aproximación a los modelos de financiación a partir de sus fuentes de ingresos. En su estudio, Ferrell Lowe \& Berg (2013) detectan cuatro vías principales de financiación del sistema audiovisual público europeo: el canon, la subvención directa, la publicidad y el sistema de suscripción o pay-per-view, a lo que deberíamos añadir otras fuentes de tipo comercial como la comercialización de los derechos de emisión. Mientras que las dos primeras fuentes se conforman a partir de dinero público y, por tanto, favorecen la orientación de la organización hacia los ciudadanos, las dos últimas inclinan la balanza hacia una orientación al consumidor. Además, el peso excesivo de los ingresos comerciales puede suponer un mayor impacto en los presupuestos generales, especialmente en épocas de crisis, debido al descenso, por ejemplo, de los beneficios publicitarios, tal y como ejemplifica Ramsey (2017) con el caso irlandés, país en el que el mercado publicitario en televisión cayó un $10 \%$ entre 2007 y 2013, mientras que en los últimos años la publicidad digital y el patrocinio también sufrieron un descenso del 11\%.

El canon, en sus distintas variantes, es actualmente la vía de financiación más extendida en Europa. Este sistema proporciona una mayor estabilidad, se considera una fuente de financiación transparente y acrecienta el deber de rendir cuentas ante los ciudadanos. Aunque el canon no está exento de problemáticas, como las tasas de evasión (O’Hagan \& Jennings, 2003; Ramsey, 2017), sí que cuenta con mejor reputación que la subvención directa. Un sistema de financiación basado en la subvención directa puede ser más vulnerable ante presiones políticas, al afectar tanto al contenido editorial de la radiotelevisión pública como a la estabilidad presupuestaria, más 
sometida a las voluntades del gobierno de turno. Las diferencias entre ambos sistemas se pueden ejemplificar a través del caso de los Países Bajos, que en el año 2000 sustituyeron el canon por un modelo basado en la subvención pública (Benson \& Powers, 2011), un cambio que supuso un fuerte descenso en el presupuesto de la NPO durante los primeros años y que ha sido cuestionado por aportar vulnerabilidad y restar estabilidad.

Los cambios que se producen actualmente en los sistemas de financiación del servicio audiovisual púbico europeo pueden estudiarse a partir de la tipología que proponen Berg \& Lund (2012). Estos autores hablan de tres tipos de aproximaciones políticas a los medios de comunicación públicos: la orientación de mercado, caracterizada por la externalización o subcontratación de servicios; la convencional, marcada por la producción y gestión propia; y la competitiva, en la que los medios públicos compiten directamente con los privados. El modelo de orientación de mercado se está abriendo paso en un entorno en el que tradicionalmente había imperado el modelo convencional. En Dinamarca, por ejemplo, se da una combinación de ambos modelos que ha afectado a la forma en la que se gestiona y distribuye el canon, que ya no sólo se destina a la radiotelevisión pública danesa, la DR, sino también a algunas iniciativas privadas como los servicios regionales de la TV2 o la radio 24 syv.

Dentro del debate en torno al futuro de la financiación del servicio audiovisual público europeo es precisamente el canon uno de los temas más discutidos. El cobro de una tasa por la posesión de un televisor constituye una idea obsoleta considerando las nuevas formas de consumo audiovisual actuales (Herzog \& Karppinen, 2014). El futuro el canon está siendo definido a través de tres alternativas (Nissen, 2006): su expansión a todo tipo de dispositivos de consumo de medios públicos, como ha sido el caso de Suecia; su completa eliminación, pasando a financiarse el servicio audiovisual público a través del subsidio directo (Países Bajos); o bien su conversión en un impuesto especial aplicable a todos los ciudadanos y hogares, algo que se ha implantado en Alemania y Finlandia. En otros países, como Irlanda, el debate, político y social, sigue en marcha (Ramsey, 2017).

Las reflexiones sobre la situación del canon también han dado lugar a propuestas innovadoras como la de Bonini \& Pais (2017), quienes 
plantean la fusión de este modo de financiación con estrategias de crowdfunding, de forma que los ciudadanos pudiesen decidir en qué programas investir una cuota del 20\% del canon, lo que supondría un incremento de la participación estructural de la sociedad en la gestión de sus medios públicos.

La Unión Europea de Radiodifusión publicó recientemente un informe en el que establece cuatro principios esenciales que debe cumplir el sistema de financiación del servicio audiovisual público: la estabilidad y la adecuación de sus presupuestos; la independencia de interferencias políticas; su carácter justo y justificable; y su transparencia $y$ responsabilidad, necesarias para poder rendir cuentas ante la ciudadanía (EBU, 2017). Una financiación en conformidad con estos cuatro criterios contribuiría a la legitimación de los medios de comunicación públicos europeos, consolidándolos como los espacios mediáticos con mayor autonomía e independencia con respecto a influencias externas del conjunto del ecosistema mediático actual (Karppinen \& Moe, 2016). En definitiva, para conseguir unos medios de comunicación públicos fuertes y legitimados se requiere una financiación adecuada y con capacidad de adaptación al entorno volátil en el que está inmerso.

Este artículo se enmarca en los estudios sobre financiación, regulación y legitimad del servicio audiovisual público europeo, analizando los datos presupuestarios de las radiotelevisiones públicas de los 28 países de la Unión Europea entre 2010 y 2016.

\section{Metodología}

Además de la revisión teórica recogida en los párrafos anteriores, a la hora de desarrollar este artículo se ha optado por analizar los datos de ingresos de todas las radiotelevisiones públicas europeas desde 2010 a 2016, a partir de la base de datos del Observatorio Audiovisual Europeo (OBS, 2017). Esta información se ha complementado con las publicaciones de la Unión Europea de Radiodifusión y las memorias anuales de gestión de las propias compañías que en algunos casos han servido para completar algún dato. Por tanto, se ha optado por una investigación a través del análisis de la evolución temporal de tres variables, los ingresos totales, los ingresos públicos y otros ingresos de los 28 países que conforman la Unión Europea, conformando un 
análisis estadístico descriptivo que permite llevar a cabo una comparación del comportamiento de los distintos territorios analizados respecto a la financiación del servicio público audiovisual.

Para afinar el análisis comparativo del sistema de financiación por países y modelos es necesario ponderar los ingresos de cada una de las corporaciones y países con respecto a sus habitantes, número de hogares y PIB en paridad del poder adquisitivo (PIB/PPA) para lo cual, y dado su absoluto reconocimiento por parte de la comunidad investigadora y su oficialidad, se ha optado por tomar los datos procedentes de la Oficina Europea de Estadística, Eurostat.

De este modo, se han podido cruzar las diferentes cifras de ingresos de los servicios públicos audiovisuales con ciertas variables socioeconómicas que caracterizan a sus respectivos países, todo ello para todos los años del período analizado (todos los que conforman la década actual), lo que permite identificar de forma adecuada la actual situación y tendencias de la financiación del servicio público de radiotelevisión en la Unión Europea.

\section{Resultados}

Al analizar los datos de la financiación de los servicios públicos de radiotelevisión en los países de la Unión Europea, la primera cuestión a reseñar es que estos han estado sujetos e influenciados por las variables y vicisitudes económicas experimentadas por las economías de dichos territorios y, por tanto, se puede apreciar con relativa claridad el impacto de la crisis económica que afectó con especial virulencia a los países occidentales durante los últimos años de la pasada década y los inicios de la actual.

Conviene señalar en todo caso que, conforme se va a reflejar en los resultados abordados a continuación, el comportamiento de los países en este período ha presentado importantes divergencias en lo referido a la financiación de sus sistemas de radiotelevisión pública frente al señalado impacto de la crisis económica, de modo que tras un primer análisis agregado de los datos a nivel de la Unión Europea, resulta absolutamente necesario plantear un análisis más profundo de los datos procedentes de los distintos países.

En una primera aproximación a la evolución de los presupuestos manejados por los servicios públicos de radiotelevisión en la década 
actual, y recogidos en los datos desde el año 2010 hasta el 2016 en la tabla 1, podría pensarse que entre los años señalados se ha atravesado un período de absoluta estabilidad, pues los ingresos totales entre en año 2010 y el año 2016 apenas variaron un exiguo -0,3\%; es decir, prácticamente permanecieron invariables.

Este aparente estancamiento oculta, por el contrario, el paso por dos etapas bien diferenciadas. En primer lugar, un trienio de constantes caídas en la financiación del sistema de radiotelevisión pública, con una disminución de ingresos del 4,1\% entre 2010 y 2013, y un crecimiento posterior del 4\% en los siguientes 3 años, del 2013 al 2016, que compensa la contracción anterior y devuelve el volumen de financiación prácticamente a la situación inicial.

\section{Tabla 1. Evolución de la financiación del Servicio Audiovisual Público en la UE (en millones de euros)}

\begin{tabular}{|c|c|c|c|}
\hline Total UE & $\begin{array}{c}\text { Ingresos } \\
\text { públicos }\end{array}$ & $\begin{array}{c}\text { Otros } \\
\text { ingresos }\end{array}$ & $\begin{array}{c}\text { Ingresos } \\
\text { totales }\end{array}$ \\
\hline $\mathbf{2 0 1 0}$ & $25.732,2$ & $7.886,5$ & $33.618,8$ \\
\hline $\mathbf{2 0 1 1}$ & $25.621,7$ & $7.700,0$ & $33.321,7$ \\
\hline $\mathbf{2 0 1 2}$ & $25.503,5$ & $7.341,5$ & $32.845,0$ \\
\hline $\mathbf{2 0 1 3}$ & $25.305,7$ & $6.926,8$ & $32.232,6$ \\
\hline $\mathbf{2 0 1 4}$ & $25.710,8$ & $7.328,3$ & $33.039,0$ \\
\hline $\mathbf{2 0 1 5}$ & $26.305,9$ & $7.482,1$ & $33.699,1$ \\
\hline $\mathbf{2 0 1 6}$ & $26.034,3$ & $7.458,8$ & $33.519,5$ \\
\hline $\mathbf{\%} \mathbf{\Delta 1 6 / 1 0}$ & $\mathbf{1 , 2}$ & $\mathbf{- 5 , 4}$ & $\mathbf{- 0 , 3}$ \\
\hline $\mathbf{0} \mathbf{\Delta 1 3 / 1 0}$ & $\mathbf{- 1 , 7}$ & $\mathbf{- 1 2 , 2}$ & $\mathbf{- 4 , 1}$ \\
\hline $\mathbf{0} \mathbf{\Delta 1 6 / 1 3}$ & $\mathbf{2 , 9}$ & $\mathbf{7 , 7}$ & $\mathbf{4 , 0}$ \\
\hline
\end{tabular}

Fuente: Elaboración propia a partir de datos del OEA.

Si atendemos a la desagregación de los datos que facilita el Observatorio Europeo del Audiovisual entre ingresos públicos y otros ingresos, donde la primera partida se refiere a la financiación a través de los distintos mecanismos establecidos para hacer llegar fondos al servicio público de radiotelevisión $\mathrm{y}$, bajo el concepto de otros ingresos, se recogen principalmente los procedentes de la actividad comercial, tales como publicidad, patrocinios, venta de contenidos propios y otros similares; nos encontramos con una situación similar a la de los datos agregados, si bien conviene indicar en este caso que la importante bajada de la variable conceptualizada como "otros 
ingresos", durante el primer trienio de más de un 12\%, no ha sido todavía corregida en los tres años posteriores, donde el crecimiento ha sido solo de un $7,7 \%$, consecuencia de diferentes factores y entre los cuales se encuentra el de la mayor competencia por la tarta publicitaria, al igual de fenómenos ya muy arraigados como Internet y otros en pleno desarrollo, tal es el caso de las plataformas de contenidos a la carta como Netflix o HBO.

Para compensar esto, los ingresos públicos recogen en los últimos tres años una mejora de la financiación $(2,9 \%)$ que amortigua con cierta holgura la anterior caída en el primer trienio analizado $(-1,7 \%)$.

\subsection{La financiación por países}

En una segunda aproximación al análisis de la financiación del servicio público de radio televisión en la Unión Europea, conforme se recoge en la tabla 2 y en el gráfico 1, se puede constatar la aparición de comportamientos divergentes entre países en la evolución de dicha financiación en los últimos años.

De este modo, parece apreciarse con claridad lo que en otros ámbitos y sectores viene denominándose en los últimos años como la Europa de las dos velocidades (Comisión Europea, 2017). Por un lado, los países principalmente del sur, cuyas economías se vieron más sacudidas por la crisis y que incluso en algunos casos precisaron de los denominados "rescates" de la Unión Europea y el FMI, países como Grecia, España, Portugal, Chipre o incluso Italia e Irlanda (también rescatada) y gran parte de los del Este, como Polonia, Rumanía, Bulgaria, la República Checa, Croacia o Eslovenia, presentan para el período analizado importantes recortes en sus ingresos para financiar el servicio público de radio televisión, con caídas muy importantes en porcentaje que en muchos casos son de dos dígitos y que no consiguen ni siquiera compensarse con los generalmente modestos incrementos de los últimos años, salvo quizá en el caso de Italia en el último año, del 2015 al 2016, donde se ha producido un fuerte incremento de los ingresos.

Por otro lado, se encuentran la denominada Europa del Norte, conformada principalmente por los países bálticos y escandinavos, como Lituania, Letonia, Estonia, Suecia, Dinamarca, Finlandia o Bélgica, con moderadas subidas de los ingresos en los últimos años, a 
los cuales cabría añadir economías más potentes como Alemania, Reino Unido y Francia, que muestran también crecimientos de la financiación para el sistema público de radio televisión, aunque ciertamente algo más modestos.

Detrás de esa cifra, que parece arrojar una estabilidad cuasi absoluta, como es que el valor de la variación para la Unión Europea entre 2016 y 2010 sea prácticamente nulo, lo que realmente se esconde es un absoluto desequilibrio entre el comportamiento de esos dos perfiles de países susceptibles de caracterizarse dentro de la Unión Europea: la Europa del Norte frente a la Europa del Sur; al fin y al cabo, como ya se apuntó, una Europa de dos velocidades también en lo referido a la financiación de los servicios públicos de radiotelevisión.

\section{Tabla 2. Ingresos del Servicio Público de Radiotelevisión por países (en millones de euros)}

\begin{tabular}{|c|c|c|c|c|c|c|c|c|}
\hline ESTADO & 2010 & 2011 & 2012 & 2013 & 2014 & 2015 & 2016 & $\% \Delta 16 / 10$ \\
\hline Alemania & $9.034,5$ & $8.787,2$ & $8.591,2$ & $8.823,5$ & $9.445,9$ & $9.212,4$ & $9.177,7$ & 1,6 \\
\hline Austria & 971,2 & 991,6 & $1.001,9$ & $1.008,1$ & 984,3 & 978,1 & 968,7 & $-0,3$ \\
\hline Bélgica & 716,1 & 726,5 & 765,7 & 775,9 & 795,9 & 782,6 & 787,3 & 9,9 \\
\hline Bulgaria & 66,2 & 63,9 & 65,3 & 62,1 & 62,1 & 62,5 & 61,0 & $-7,9$ \\
\hline Chipre & 45,0 & 36,8 & 37,7 & 30,8 & 31,7 & 30,8 & 33,2 & $-26,2$ \\
\hline Croacia & 202,1 & 190,1 & 188,9 & 183,1 & 179,7 & 180,0 & 179,7 & $-11,1$ \\
\hline Dinamarca & 806,7 & 829,1 & 861,8 & 888,9 & 923,4 & 893,3 & 916,0 & 13,5 \\
\hline Eslovaquia & 101,9 & 114,5 & 97,5 & 100,5 & 104,1 & 112,9 & 115,7 & 13,5 \\
\hline Eslovenia & 133,5 & 109,8 & 118,9 & 116,8 & 117,9 & 118,3 & 118,6 & $-11,2$ \\
\hline España & $2.794,2$ & $2.572,1$ & $2.165,2$ & $1.953,0$ & $1.810,0$ & $1.937,4$ & $2.035,6$ & $-27,1$ \\
\hline Estonia & 28,4 & 28,3 & 28,5 & 30,5 & 29,4 & 33,6 & 40,3 & 41,9 \\
\hline Finlandia & 420,0 & 432,5 & 456,1 & 469,1 & 475,6 & 472,0 & 473,2 & 12,7 \\
\hline Francia & $4.378,5$ & $4.568,5$ & $4.658,7$ & $4.490,7$ & $4.497,8$ & $4.479,6$ & $4.576,0$ & 4,5 \\
\hline Grecia & 386,0 & 328,8 & n.a. & n.a. & 175,6 & 182,0 & 190,3 & $-50,7$ \\
\hline Hungría & 177,6 & 238,4 & 302,0 & 300,5 & 279,6 & 289,2 & 299,7 & 68,8 \\
\hline Irlanda & 408,5 & 388,1 & 374,0 & 364,4 & 364,3 & 369,9 & 374,3 & $-8,4$ \\
\hline Italia & $2.821,0$ & $2.825,0$ & $2.625,0$ & $2.562,0$ & $2.594,8$ & $2.493,1$ & $2.809,5$ & $-0,4$ \\
\hline Letonia & 21,7 & 21,5 & 22,5 & 24,0 & 26,9 & 26,6 & 26,5 & 22,1 \\
\hline Lituania & 17,3 & 19,1 & 20,7 & 20,9 & 22,2 & 25,1 & 32,9 & 90,2 \\
\hline Luxemburgo & n.a. & n.a. & 4,6 & 5,0 & 5,3 & 5,6 & 5,9 & n.a. \\
\hline Malta & 8,2 & 9,1 & 10,1 & 9,6 & 10,3 & 12,2 & 11,7 & 42,7 \\
\hline Países Bajos & 857,2 & 855,9 & 864,5 & 834,0 & 855,0 & 848,4 & 888,2 & 3,6 \\
\hline Polonia & 521,5 & 471,4 & 383,4 & 427,5 & 428,7 & 460,7 & 410,2 & $-21,3$ \\
\hline Portugal & 309,0 & 317,0 & 259,0 & 234,0 & 213,5 & 211,5 & 215,2 & $-30,4$ \\
\hline Reino Unido & $7.076,1$ & $7.053,4$ & $7.539,6$ & $7.135,4$ & $7.230,7$ & $8.115,7$ & $7.386,9$ & 4,4 \\
\hline
\end{tabular}




\begin{tabular}{|l|r|r|r|r|r|r|r|r|}
\hline Rep. Checa & 359,6 & 340,6 & 345,0 & 337,2 & 330,9 & 326,5 & 323,5 & $-10,0$ \\
\hline Rumanía & 230,6 & 230,1 & 223,8 & 214,0 & 215,1 & 205,5 & 194,4 & $-15,7$ \\
\hline Suecia & 726,2 & 772,5 & 833,3 & 830,9 & 828,5 & 833,7 & 867,4 & 19,4 \\
\hline Total UE & $33.618,8$ & $33.321,7$ & $32.845,0$ & $32.232,6$ & $33.039,0$ & $33.699,1$ & $33.519,5$ & $-0,3$ \\
\hline
\end{tabular}

Fuente: Elaboración propia a partir de datos del OEA.

Así, de acuerdo al gráfico 1, la variación de ingresos en la Unión Europea refleja un valor prácticamente nulo y con cierta centralidad en la gráfica (prácticamente la mitad de los países por encima de la media y la mitad por debajo de la misma), si bien realmente se observan países como Grecia, Portugal, España o Chipre con recortes de ingresos por encima del 25\% (del 50\% en el caso de Grecia), y esto, como se ha indicado, a pesar del ligero repunte de los últimos años, pero que no sirve para amortiguar la importantísima caída de los años correspondientes a la crisis económica que sacudió con mayor virulencia a las economías de estos países y que consecuentemente se vieron abocados a establecer políticas de recortes con significativo impacto en la financiación del servicio púbico de radiotelevisión.

\section{Gráfico 1. Variación porcentual de ingresos por países 2016/2010}

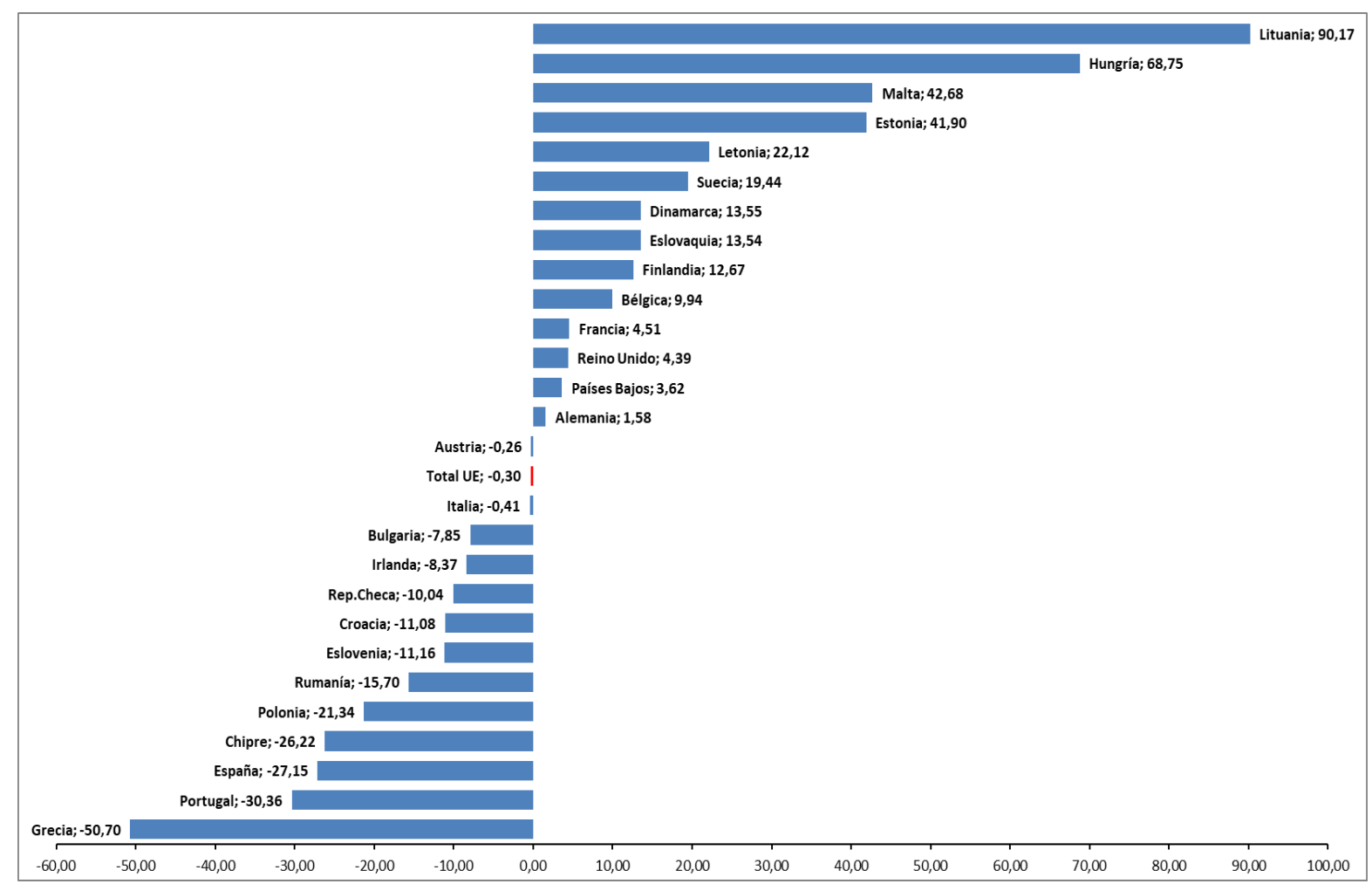

Fuente: Elaboración propia a partir de datos del OEA 


\subsection{La financiación per cápita}

Una vez analizadas las cifras globales de ingresos del servicio público de radiotelevisión en la Unión Europea, resulta fundamental contextualizar las mismas en función de una serie de características de los países estudiados.

Relativizar las cifras en función del número de habitantes del país respectivo es esencial, pues parece lógico pensar que el tamaño de la población condiciona de alguna forma la financiación del servicio público. Así, ponderar las cifras en función del número de habitantes ayuda a comprender qué países llevan a cabo una apuesta más fuerte por su radiotelevisión pública.

En este sentido, y como dato medio, el servicio público de radiotelevisión dispone en la Unión Europea de 65,7 euros por habitante para el año 2016, aproximadamente 1 euro menos $(66,9)$ de la cantidad del 2010, una cifra que ha permanecido bastante estable en los últimos 6 años moviéndose alrededor de esos 65-66 euros, tal y como se recoge en la tabla 3 .

Ahora bien, ese valor medio refleja una importante dispersión del presupuesto por habitante del que disponen las corporaciones públicas en los diferentes países, de modo que quedan plasmadas importantes diferencias en los ingresos por habitante.

Los que bien pudiera catalogarse nuevamente como países nórdicos (Dinamarca, Suecia o Finlandia), así como las dos grandes economías europeas (Alemania y Reino Unido) ofrecen valores muy por encima de la media europea. Frente a esta situación hay casos como el de España o Italia que, pese a ser la cuarta y quinta potencias económicas en Europa, presentan unos presupuestos por habitante para el servicio público de radiotelevisión muy por debajo de la media europea, conforme se aprecia en el gráfico 2 .

De hecho, en el caso de España, se ha bajado de unos 60 euros por habitante, muy cerca de la media europea en el año 2010, a menos de 44 euros en el año 2016, un tercio menos que la media europea. 
Tabla 3. Ingresos del Servicio Público de Radiotelevisión por habitante

\begin{tabular}{|c|c|c|c|c|c|c|c|c|c|c|}
\hline & \multicolumn{10}{|c|}{ Presupuesto por Habitantes (Euros) } \\
\hline & 2010 & 2011 & 2012 & 2013 & 2014 & 2015 & 2016 & $\% \Delta 16 / 10$ & $\% \Delta 13 / 10$ & $\% \Delta 16 / 13$ \\
\hline Alemania & 110,4 & 109,5 & 107,0 & 109,6 & 117,0 & 113,5 & 111,7 & 1,1 & $\overline{-0,8}$ & $\overline{1,9}$ \\
\hline Austria & 116,3 & 118,4 & 119,2 & 119,3 & 115,7 & 114,0 & 111,5 & $-4,1$ & 2,6 & $-6,5$ \\
\hline Bélgica & 66,1 & 66,0 & 69,0 & 69,5 & 71,0 & 69,8 & 69,6 & 5,4 & 5,2 & 0,1 \\
\hline Bulgaria & 8,9 & 8,7 & 8,9 & 8,5 & 8,6 & 8,7 & 8,5 & $-4,4$ & $-4,4$ & 0,0 \\
\hline Chipre & 54,9 & 43,8 & 43,7 & 35,6 & 37,0 & 36,4 & 39,1 & $-28,8$ & $-35,2$ & 9,9 \\
\hline Croacia & 47,0 & 44,3 & 44,2 & 43,0 & 42,3 & 42,6 & 42,9 & $-8,7$ & $-8,5$ & $-0,2$ \\
\hline Dinamarca & 145,8 & 149,1 & 154,4 & 158,7 & 164,1 & 157,8 & 160,5 & 10,1 & 8,9 & 1,2 \\
\hline Eslovaquia & 18,9 & 21,2 & 18,0 & 18,6 & 19,2 & 20,8 & 21,3 & 12,8 & $-1,7$ & 14,8 \\
\hline \begin{tabular}{|l|} 
Eslovenia \\
\end{tabular} & 65,2 & 53,5 & 57,8 & 56,7 & 57,2 & 57,3 & 57,5 & $-11,9$ & $-13,0$ & 1,3 \\
\hline España & 60,1 & 55,1 & 46,2 & 41,8 & 38,9 & 41,7 & 43,8 & $-27,1$ & $-30,5$ & 4,9 \\
\hline \begin{tabular}{|l|} 
Estonia \\
\end{tabular} & 21,3 & 21,3 & 21,5 & 23,1 & 22,3 & 25,6 & 30,6 & 43,8 & 8,4 & 32,6 \\
\hline Finlandia & 78,5 & 80,5 & 84,4 & 86,4 & 87,2 & 86,3 & 86,2 & 9,9 & 10,1 & $-0,2$ \\
\hline Francia & 67,7 & 70,3 & 71,4 & 68,5 & 68,3 & 67,4 & 68,5 & 1,2 & 1,1 & 0,1 \\
\hline Grecia & 34,7 & 29,6 & n.d. & n.d. & 16,1 & 16,8 & 17,6 & $-49,2$ & n.d. & n.d. \\
\hline Hungría & 17,7 & 23,9 & 30,4 & 30,3 & 28,3 & 29,3 & 30,5 & 71,9 & 71,0 & 0,5 \\
\hline Irlanda & 89,8 & 84,9 & 81,6 & 79,4 & 79,1 & 79,9 & 79,2 & $-11,8$ & $-11,6$ & $-0,2$ \\
\hline Italia & 47,7 & 47,6 & 44,2 & 42,9 & 42,7 & 41,0 & 46,3 & $-2,8$ & $-9,9$ & 7,9 \\
\hline \begin{tabular}{|l|} 
Letonia \\
\end{tabular} & 10,2 & 10,4 & 11,0 & 11,9 & 13,4 & 13,4 & 13,5 & 31,5 & 15,8 & 13,5 \\
\hline \begin{tabular}{|l|} 
Lituania \\
\end{tabular} & 5,5 & 6,2 & 6,9 & 7,0 & 7,6 & 8,6 & 11,4 & 106,9 & 27,8 & 61,9 \\
\hline \begin{tabular}{|l} 
Luxemburgo \\
\end{tabular} & n.d. & n.d. & 8,8 & 9,3 & 9,6 & 10,0 & 10,2 & n.d. & n.d. & 9,6 \\
\hline Malta & 19,8 & 21,8 & 24,2 & 22,9 & 24,2 & 28,4 & 26,9 & 36,0 & 15,4 & 17,8 \\
\hline Países Bajos & 51,7 & 51,4 & 51,7 & 49,7 & 50,8 & 50,2 & 52,3 & 1,2 & $-3,9$ & 5,2 \\
\hline \begin{tabular}{|l|} 
Polonia \\
\end{tabular} & 13,7 & 12,4 & 10,1 & 11,2 & 11,3 & 12,1 & 10,8 & $-21,2$ & $-18,1$ & $-3,8$ \\
\hline \begin{tabular}{|l|} 
Portugal \\
\end{tabular} & 29,2 & 30,0 & 24,6 & 22,3 & 20,5 & 20,4 & 20,8 & $-28,8$ & $-23,6$ & $-6,7$ \\
\hline Reino Unido & 113,2 & 111,9 & 118,7 & 111,7 & 112,4 & 125,3 & 113,0 & $-0,2$ & $-1,4$ & 1,2 \\
\hline \begin{tabular}{|l} 
República \\
Checa
\end{tabular} & 34,4 & 32,5 & 32,8 & 32,1 & 31,5 & 31,0 & 30,7 & $-10,8$ & $-6,7$ & $\overline{-4,4}$ \\
\hline Rumanía & 11,4 & 11,4 & 11,1 & 10,7 & 10,8 & 10,3 & 9,8 & $-13,4$ & $-5,9$ & $-8,0$ \\
\hline Suecia & 77,7 & 82,0 & 87,9 & 87,0 & 85,9 & 85,5 & 88,1 & 13,3 & 11,8 & 1,3 \\
\hline Media UE & 66,9 & 66,3 & 66,6 & 65,2 & 65,2 & 66,3 & 65,7 & $-1,8$ & $-2,5$ & 0,7 \\
\hline
\end{tabular}

Fuente: Elaboración propia a partir de datos del OEA y Eurostat

Conviene matizar, de acuerdo con la tabla 3, que las caídas más pronunciadas en el presupuesto por habitante se producen entre 2010 y 2013, período en el que países como España, Chipre, Polonia, Portugal, Irlanda o Italia acumulan una importante reducción que, en la mayoría de casos, da paso a un periodo de estabilidad o ligero crecimiento de dichos valores. 


\section{Gráfico 2. Ingresos del PSM por habitante 2016 (Euros)}

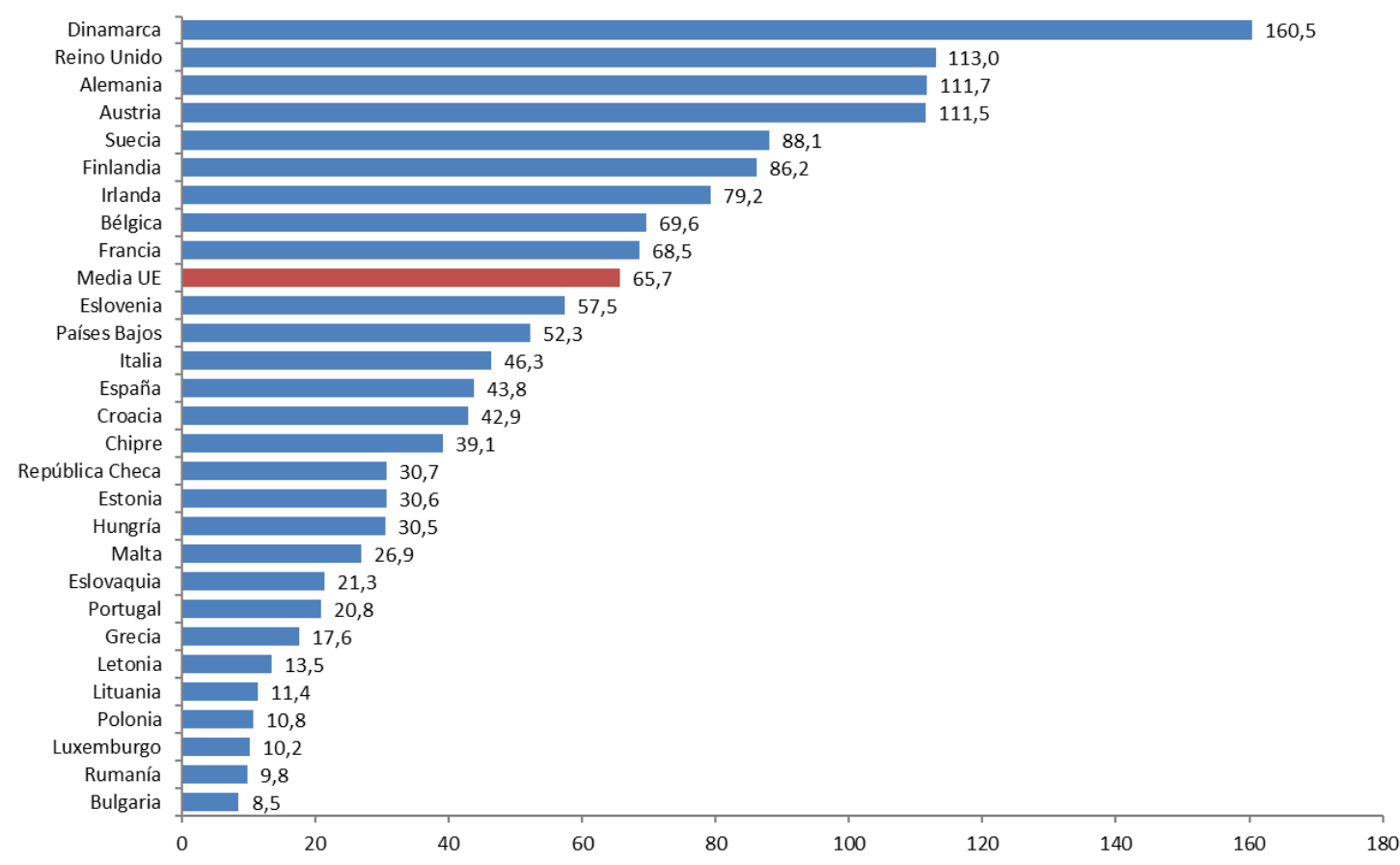

Fuente: Elaboración propia a partir de datos del OEA y Eurostat

\subsection{La financiación en función de los hogares}

A la hora de abordar el análisis de la financiación del servicio público de radio televisión, se antoja conveniente relativizar las cifras en función del número de hogares. En la medida en que la mayoría de países recurrentes a la aplicación de un canon han utilizado el concepto de hogar como sujeto impositivo, dado que tradicionalmente se ha considerado que es precisamente en ese lugar donde se produce el principal consumo de productos televisivos, resulta fundamental a la hora de tratar la evolución de la financiación de los diferentes países, a los efectos de poder establecer posibles comparaciones, tomar en consideración el número de hogares de cada uno de esos países para ponderar adecuadamente el volumen presupuestario del cual disponen para financiar la actividad de la radiotelevisión pública.

Aún así, no se puede obviar el cuestionamiento del concepto de hogar como sujeto impositivo del canon, ya que la irrupción de producciones multisoporte, multipantalla y de consumo deslocalizado desafían el modelo de consumo tradicional basado en el hogar. En este sentido, Finlandia ha sido pionera al adoptar un sistema impositivo basado en el individuo y no en el hogar, pero en la actualidad la mayoría de países 
con canon consideran el hogar como eje de su política para aplicar el mismo, por lo cual parece relevante considerar dicha variable para comparar la situación de los distintos países que conforman la Unión Europea.

Con base en los datos mostrados en la tabla 4 y en el gráfico 3, la media de ingresos de que dispone el servicio público de radiotelevisión es de 152 euros por hogar en la Unión Europea para el año 2016, ligeramente por debajo de los 160 de que se disponía como media a comienzos de la década.

No obstante, tras esa media para la UE, nuevamente se encuentra una importante polarización entre las que se podrían considerar economías más avanzadas y fuertes del norte, como los países escandinavos, Alemania, Reino Unido, Francia o Bélgica, con valores en muchos casos superiores al 50\% de la media, frente a los países menos poderosos del este y del mediterráneo, incluyendo incluso a dos países como España e Italia que, pese a ser las cuarta y quinta economías de Europa, presentan valores de financiación del servicio público de radiotelevisión muy por debajo de la media europea, en ambos casos alrededor de los 110 euros por hogar, muy lejos, en el caso de España, de los casi 160 que dedicaba en el año 2010.

Conviene subrayar la constatación de que los países con mayores recortes en el período analizado se sitúan en las economías más afectadas por la crisis. Por tanto, nuevamente Grecia, Portugal, España y Chipre, reflejan caídas de más de un 30\% en los últimos 6 años, los que corresponden a la década actual, si bien ha de matizarse que en casos como el de España, Chipre, Italia o incluso Irlanda, cuya economía también estuvo en el ojo del huracán, gran parte de esa caída se produjo en los primeros años del período analizado, y en el caso de Grecia hubo una etapa directamente sin servicio público dada la intervención de la economía helena, por lo que no se dispone de datos para los años 2012 y 2013.

Nuevamente los países del norte, principalmente los escandinavos, así como las fuertes economías de Alemania, Reino Unido y Francia, muestran una evolución de sus ingresos respecto al número de hogares mucho más estable, aunque en cualquier caso, y como recoge la media de la Unión Europea, ha habido una cierta tendencia a la reducción en 
este indicador, explicada por el hecho de que frente al estancamiento de los ingresos en el período, el número de hogares en la Unión Europea, según los datos de Eurostat, creció en casi 10 millones, al pasar de menos de 210 millones de hogares a casi 220 millones entre 2010 y 2016.

\section{Gráfico 3. Ingresos del PSM por hogar 2016 (Euros)}

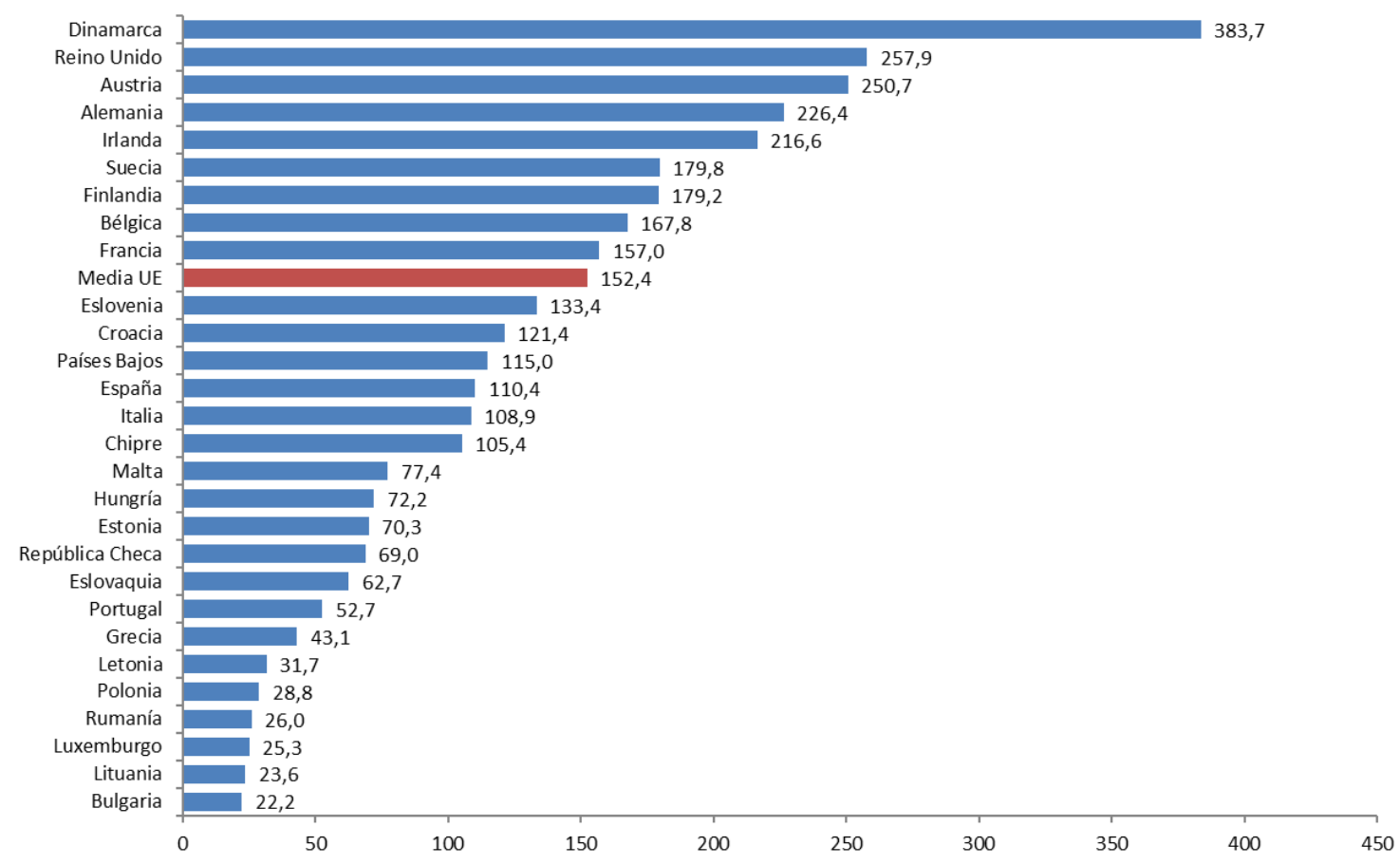

Fuente: Elaboración propia a partir de datos del OEA y Eurostat

Como ya se señaló, este análisis tiene especial relevancia dado que el canon en aquellos países donde se aplica se hace generalmente sobre los hogares. Para el año 2016, y tal y como se puede apreciar en el gráfico 4, fueron 17 los países de la Unión Europea que optaron por esta vía de financiación del servicio público de radiotelevisión, situándose el canon medio en 135,2 euros por hogar, muy próximo a los ingresos del servicio también por hogar, que fueron de 146,2 euros.

Conviene indicar que casi todos los países muestran una gran proximidad de las cifras entre el canon aplicado por hogar y los ingresos del servicio público por hogar, con algunas excepciones llamativas como el caso belga, donde se produce una cierta distorsión porque el canon solo se aplica en la región francófona y no en la comunidad flamenca. 


\section{Gráfico 4. Canon e ingresos por hogar del PSM 2016}

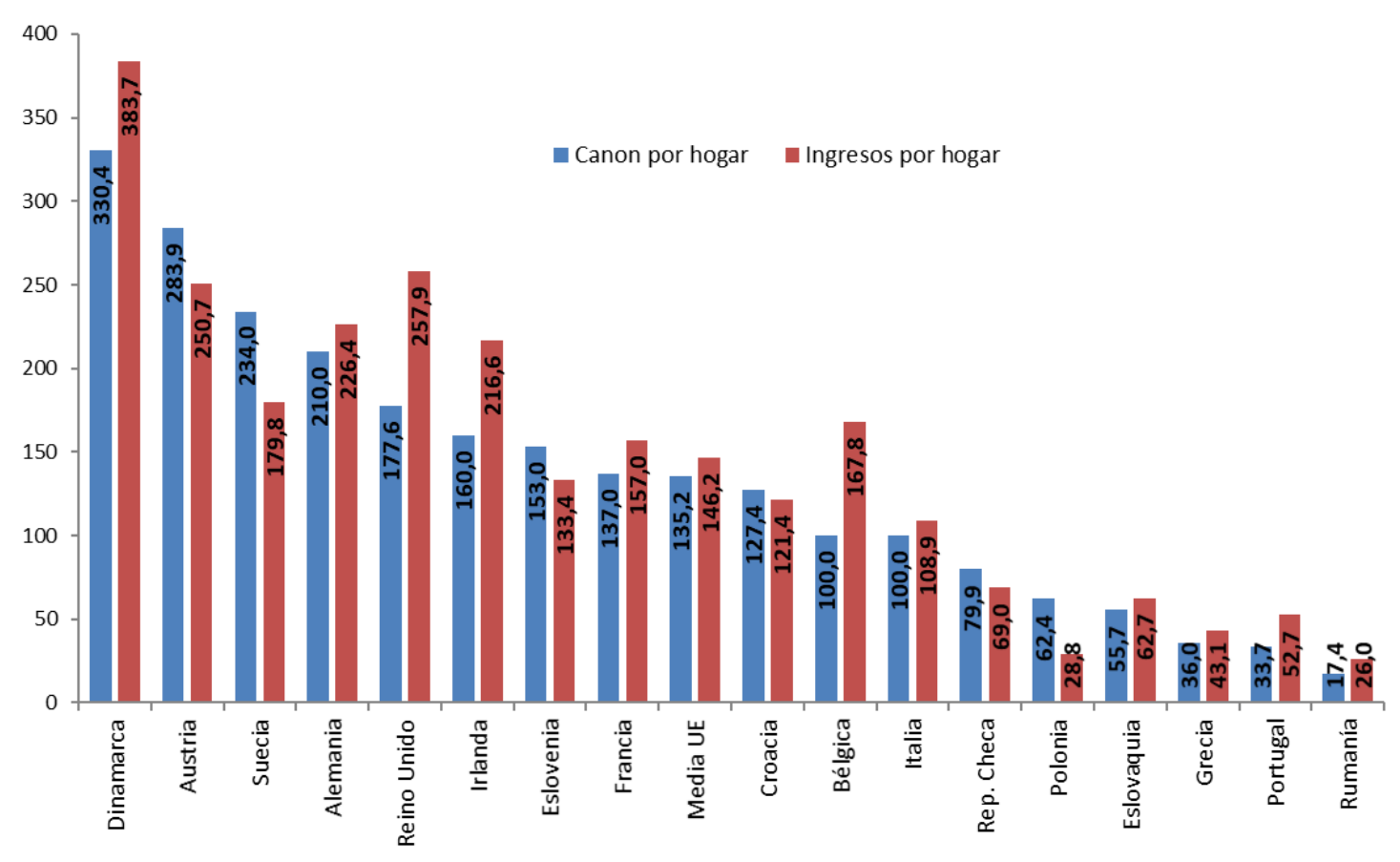

Fuente: Elaboración propia a partir de datos del OEA y Eurostat

\subsection{La financiación en función del tamaño de las economías}

Por último, es necesario relativizar los ingresos del servicio público de radiotelevisión en función del tamaño de las economías de los distintos países. Para ello, se han cruzado los datos procedentes del Observatorio Europeo del Audiovisual sobre ingresos de la radiotelevisión pública con los valores del PIB en paridad de poder adquisitivo (PPA) que facilita Eurostat, al considerarse que este valor es el que mejor representa el tamaño de las distintas economías nacionales analizadas.

La media de la Unión Europea se sitúa en 2,2 euros por cada 1000 de PIB en PPA para el año 2016, un valor que se ha visto mermado de forma importante para el período analizado, ya que en 2010 este índice se situaba en 2,6 euros por cada 1000 euros de PIB, de acuerdo con la tabla 5. Así, se pone de relieve la existencia de un reducido grupo de países, como una vez más los países del norte de Europa como Dinamarca, Finlandia o Suecia, así como Reino Unido y Alemania, que junto a Austria, Croacia y Eslovenia son los únicos por encima de la media. 
Tabla 5. Ingresos del Servicio Público de Radiotelevisión por PIB en PPA

\begin{tabular}{|c|c|c|c|c|c|c|c|c|c|c|}
\hline & \multicolumn{10}{|c|}{ Presupuesto por PIB en PPA (\%o) } \\
\hline & 2010 & 2011 & 2012 & 2013 & 2014 & 2015 & 2016 & $\% \Delta 16 / 10$ & $\% \Delta 13 / 10$ & $\% \Delta 16 / 13$ \\
\hline Alemania & 3,7 & 3,4 & 3,2 & 3,3 & 3,4 & 3,1 & 3,1 & $-16,0$ & $-10,6$ & $-6,1$ \\
\hline Austria & 3,6 & 3,5 & 3,4 & 3,4 & 3,2 & 3,0 & 3,0 & $-17,5$ & $-6,5$ & $-11,7$ \\
\hline Bélgica & 2,1 & 2,1 & 2,2 & 2,2 & 2,2 & 2,0 & 2,0 & $-5,3$ & 1,2 & $-6,4$ \\
\hline Bulgaria & 0,8 & 0,7 & 0,7 & 0,7 & 0,7 & 0,6 & 0,6 & $-22,9$ & $-10,7$ & $-13,6$ \\
\hline Chipre & 2,1 & 1,7 & 1,8 & 1,6 & 1,7 & 1,5 & 1,6 & $-24,1$ & $-25,5$ & 1,8 \\
\hline Croacia & 3,1 & 2,8 & 2,8 & 2,7 & 2,6 & 2,5 & 2,5 & $-20,5$ & $-13,5$ & $-8,1$ \\
\hline Dinamarca & 4,4 & 4,4 & 4,6 & 4,6 & 4,6 & 4,3 & 4,4 & 0,3 & 4,4 & $-3,9$ \\
\hline Eslovaquia & 1,0 & 1,1 & 0,9 & 0,9 & 0,9 & 0,9 & 1,0 & $-4,0$ & $-8,4$ & 4,9 \\
\hline Eslovenia & 3,1 & 2,5 & 2,6 & 2,6 & 2,5 & 2,4 & 2,4 & $-22,3$ & $-15,6$ & $-7,9$ \\
\hline España & 2,5 & 2,3 & 1,9 & 1,7 & 1,6 & 1,6 & 1,6 & $-33,3$ & $-28,8$ & $-6,3$ \\
\hline Estonia & 1,3 & 1,2 & 1,1 & 1,1 & 1,1 & 1,2 & 1,4 & 8,3 & $-11,3$ & 22,2 \\
\hline Finlandia & 2,6 & 2,6 & 2,7 & 2,8 & 2,8 & 2,7 & 2,7 & 2,2 & 7,6 & $-5,1$ \\
\hline Francia & 2,4 & 2,5 & 2,5 & 2,3 & 2,3 & 2,2 & 2,2 & $-8,1$ & $-4,1$ & $-4,2$ \\
\hline Grecia & 1,6 & 1,5 & n.d. & n.d. & 0,8 & 0,8 & 0,9 & $-44,4$ & n.d. & n.d. \\
\hline Hungría & 1,1 & 1,4 & 1,7 & 1,7 & 1,5 & 1,5 & 1,6 & 44,2 & 56,8 & $-8,1$ \\
\hline Irlanda & 2,7 & 2,5 & 2,3 & 2,2 & 2,1 & 1,5 & 1,5 & $-44,6$ & $-17,5$ & $-32,9$ \\
\hline Italia & 1,8 & 1,7 & 1,6 & 1,6 & 1,6 & 1,5 & 1,6 & $-7,6$ & $-9,8$ & 2,4 \\
\hline Letonia & 0,8 & 0,7 & 0,7 & 0,7 & 0,8 & 0,7 & 0,7 & $-6,7$ & $-7,2$ & 0,5 \\
\hline Lituania & 0,4 & 0,4 & 0,4 & 0,4 & 0,4 & 0,4 & 0,5 & 43,6 & $-0,6$ & 44,5 \\
\hline Luxemburgo & n.d. & n.d. & 0,1 & 0,1 & 0,1 & 0,1 & 0,1 & n.d. & n.d. & 2,3 \\
\hline Malta & 0,9 & 1,0 & 1,1 & 1,0 & 1,0 & 1,0 & 1,0 & 3,1 & 6,6 & $-3,3$ \\
\hline Países Bajos & 1,5 & 1,5 & 1,5 & 1,4 & 1,4 & 1,3 & 1,4 & $-7,5$ & $-8,4$ & 1,0 \\
\hline Polonia & 0,9 & 0,7 & 0,6 & 0,6 & 0,6 & 0,6 & 0,5 & $-37,0$ & $-27,3$ & $-13,4$ \\
\hline Portugal & 1,4 & 1,5 & 1,2 & 1,1 & 1,0 & 0,9 & 0,9 & $-33,9$ & $-21,9$ & $-15,3$ \\
\hline Reino Unido & 4,1 & 4,0 & 4,2 & 3,9 & 3,7 & 4,0 & 3,6 & $-12,6$ & $-6,3$ & $-6,8$ \\
\hline $\begin{array}{l}\text { República } \\
\text { Checa }\end{array}$ & 1,6 & 1,5 & 1,5 & 1,4 & 1,3 & 1,2 & 1,2 & $-26,2$ & $-11,7$ & $-16,4$ \\
\hline Rumanía & 0,9 & 0,8 & 0,8 & 0,7 & 0,7 & 0,6 & 0,6 & $-32,9$ & $-15,4$ & $-20,7$ \\
\hline Suecia & 2,4 & 2,5 & 2,6 & 2,6 & 2,5 & 2,4 & 2,4 & $-0,2$ & 6,0 & $-5,9$ \\
\hline Media UE & 2,6 & 2,5 & 2,5 & 2,4 & 2,4 & 2,3 & 2,2 & $-14,4$ & $-8,2$ & $-6,7$ \\
\hline
\end{tabular}

Fuente: Elaboración propia a partir de datos del OEA y Eurostat

Por el contrario, por debajo de la media y con valores de tan solo alrededor de 1,5 euros por cada 1000 de PIB encontramos economías tan relativamente fuertes como España o Italia, ya señalados anteriormente, pero también otros como Irlanda, Países Bajos e incluso Bélgica se sitúan por debajo de la media de la Unión Europea, como se puede apreciar en el gráfico 5. 
No obstante, en este caso conviene poner de manifiesto que, si bien la caída más importante en el conjunto de los países se produce en el primer trienio del período analizado, los datos del segundo período, es decir, entre 2013 y 2016, también reflejan una importante caída en la mayoría de países. De hecho, la media de la Unión Europea cae un $6,7 \%$ en este trienio tras el anterior descenso de un 8,2\% entre 2010 y 2013.

\section{Gráfico 5. Ingresos del PSM en relación al PIB en PPA (\%0)}

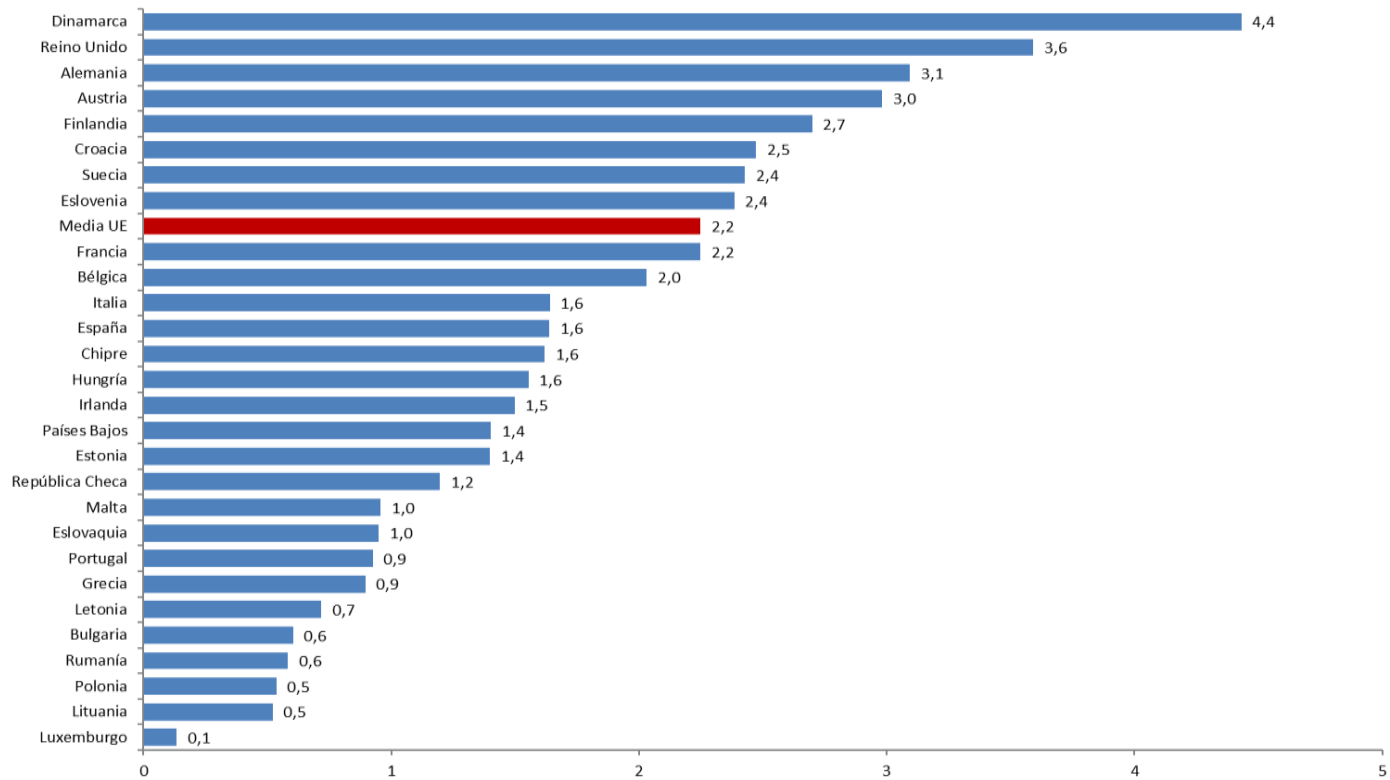

Fuente: Elaboración propia a partir de datos del OEA y Eurostat

Como en el análisis de los apartados anteriores se apreció que por lo general los ingresos entre 2013 y 2016 en los servicios públicos de radiotelevisión habían ya apuntado a una cierta estabilidad e incluso leve crecimiento, resulta evidente que la caída de ingresos respecto a PIB en PPA vendría explicada por un crecimiento más intenso de esta variable; es decir, conforme las economías europeas han ido abandonando la etapa de recesión económica y acumulando crecimientos paulatinos del tamaño de sus economías, estos crecimientos no se han trasladado en la misma proporción a la disposición de ingresos por parte de las corporaciones públicas de radiotelevisión, de modo que podría establecerse que la crisis económica trajo un importante impacto en los recursos disponibles de las corporaciones a través del recorte de ingresos tanto procedentes de la financiación pública como de otros ingresos como la publicidad que 
parece no encontrar una compensación equivalente en el posterior período de recuperación económica, al menos en la misma medida y proporción.

\section{Conclusiones}

El impacto de la crisis económica, los cambios en las formas de producción, distribución y consumo mediático y el aumento del constante cuestionamiento de su legitimidad sitúan al sistema audiovisual público en una encrucijada ante la que urge adecuar los distintos modelos de financiación presentes en la Unión Europea. La asignación directa de fondos a partir de los presupuestos generales ha sido ampliamente cuestionada por el margen que concede a la interferencia política. Esta influencia podría mitigarse mediante el establecimiento de cantidades específicas para periodos cerrados, algo que además otorgaría una mayor estabilidad.

Países como Finlandia o Alemania ya han reaccionado ante la crisis del sistema de financiación predominante en Europa, el canon, extendiéndola a todos los ciudadanos mediante un impuesto progresivo, en el primer caso, y a todos los hogares, en el segundo. La propuesta de incluir el crowdfunding en la financiación de los medios de comunicación públicos también apela a la reflexión sobre una actualización de los mecanismos de financiación que respeten los principios de universalidad.

El estancamiento de la financiación del servicio público de radiotelevisión en la Unión Europea en el período analizado pone de manifiesto la necesidad de reformular los modelos de negocio, con una puesta en valor de dicho servicio que gira en torno a parámetros como su legitimidad, independencia, calidad, reputación o confianza.

Si bien la evolución de las cifras de financiación en la década actual, como se ha señalado, muestra a nivel medio de la Unión Europea una cierta estabilidad o estancamiento, esto no debe ocultarnos las importantes diferencias que existen en la dotación y consolidación del servicio público audiovisual entre lo que se podría apuntar como un modelo de los países del Norte fuerte frente a la debilidad que muestra el sur de Europa en este análisis.

En cualquier caso, parecen poder encontrarse dentro del período analizado del 2010 al 2016 dos etapas diferenciadas, que 
corresponderían con un primer trienio de claras y profundas reducciones en muchos países, coincidente con la fase de crisis que caracterizó las economías occidentales en esos años; y un segundo trienio que comprendería los años desde 2013 a 2016, en el que, en general, la financiación del servicio audiovisual público mejora tanto en la media de la Unión Europea como en la mayoría de países incluidos en el análisis, si bien de una forma moderada respecto a las fuertes caídas de la etapa anterior en algunos países.

Los análisis en función del número hogares o habitantes de los países analizados arrojan conclusiones muy similares. El asiduo concepto de la Europa de dos velocidades, la brecha entre la fuerte Europa del Norte y la débil Europa del Sur, se muestra nítidamente al analizar la disposición y estabilidad de ingresos para financiar el servicio público de radiotelevisión.

Estas mismas conclusiones se alcanzan al tomar en consideración el tamaño de las economías, si bien en este caso se evidencia además una cierta rigidez al alza en los ingresos en las fases de auge económico frente a la poca resistencia a los ajustes que tuvo la financiación del servicio público audiovisual en la etapa de ajustes en las economías europeas, lo que pone de manifiesto la necesidad de un modelo de financiación que facilite la estabilidad de cara a facilitar cuestiones como la previsibilidad, independencia, confianza y legitimidad del sistema para que sea sostenible en el medio y largo plazo.

\section{Bibliografía}

Y Achille (1994): Les Télévisions publiques en quête d'avenir. Grenoble: Presses Universitaires de Grenoble.

R Benson \& M Powers (2011): Public Media and Political Independence: Lessons for the Future of Journalism from Around the World. Nueva York: Free Press.

CE Berg \& AB Lund (2012): "Financing public service broadcasting: A comparative perspective", en Journal of Media Business Studies, 9(1), pp. 7-22.

T Bonini \& I Pais (2017): "Hacking Public Service Media Funding: A Scenario for Rethinking the License Fee as a Form of Civic Crowdfunding", en International Journal on Media Management, 19(2), pp. 123-143. 
A Brown (1996): "Economics, public service broadcasting, and social values", en Journal of Media Economics, 9(1), pp. 3-15.

Comisión Europea (2009): Comunicación de la Comisión sobre la aplicación de las normas en materia de ayudas estatales a los servicios públicos de radiodifusión. Bruselas: Comisión Europea.

Comisión Europea (2017): Libro blanco sobre el futuro de Europa.

Reflexiones y escenarios para la Europa de los Veintisiete en 2025.

Bruselas: Comisión Europea.

T Coppens \& F Saeys (2006): "Enforcing performance: new approaches to govern public service broadcasting", en Media, Culture \& Society, 28(2), pp. 261-284.

V Crespo-Pereira, VA Martínez-Fernández \& F Campos-Freire (2017): "La neurociencia para la innovación de contenidos en la televisión pública europea”, en Comunicar, XXV (52), pp. 09-18. Department for Culture, Media and Sport (2015): BBC Charter Review. Public Consultation. Londres: Department for Culture, Media and Sport.

K Donders (2010): “The benefits of introducing European competition principles into national public broadcasting policy", en info, 12(6), pp- 56-68.

EBU (2017): Public Funding Principles for Public Service Media. GrandSaconnex: EBU.

C Herzog \& K Karppinen (2014): "Policy streams and public service media funding reforms in Germany and Finland", en European Journal of Communication, 29(4), pp. 416-432.

O Hultén (2003): "Value for money: Auditing public broadcasting performance in Sweden", en Javnost - The Public, 10(3), pp. 97108.

Ó Juanatey-Boga, VA Martínez-Fernández \& P Castellanos (2017): "La edición en papel de la prensa local ante el fin de su ciclo", en Estudios sobre el Mensaje Periodístico. 1 (23), pp. 91-100.

K Karppinen \& H Moe (2016): "What we talk about when talk about 'media independence"', en Javnost - The Public, 23(2), pp. 105119.

J Lewis (2015): "Future of the BBC: why the 'market failure' model is a flop in broadcasting", en Media Policy Project Blog, London School, Agosto: https://goo.gl/WnqhWm. 
GF Lowe \& CE Berg (2013): “The Funding of Public Service Media: A Matter of Value and Values", en International Journal on Media Management, 15(2), pp. 77-97.

GF Lowe \& J Bardoel (2007): "From public service broadcasting to public service media. The core challenge", en VV AA, From public service broadcasting to public service media (Eds., GF Lowe y J Bardoel). Gotemburgo: Nordicom.

H Moe (2011): "Defining public service beyond broadcasting: The legitimacy of different approaches", en International Journal of Cultural Policy, 17(1), pp. 52-68.

Ch S Nissen (2006): Public service media in the information society. Estrasburgo: Consejo de Europa.

OEA (2017): Yearbook 2016. Estrasburgo: Observatorio Europeo del Audiovisual.

P Ramsey (2017): "Public service media funding in Ireland faces continuing challenges", en Media Policy Project Blog, London School, Septiembre: https://goo.gl/1jQkMB.

M Rodríguez-Castro (2017): "Public Value Test. La adaptación de la gobernanza a los nuevos medios", en VV AA Estudios sobre legislación, financiación e innovación en la Televisión Pública (Eds., $\mathrm{M}$ Túñez López, F Campos Freire y A Silva Rodríguez). La Laguna: Latina.

VV AA (2011): Exporting the public value test. The regulation of public broadcasters' new media services across Europe (Eds., K Donders y $\mathrm{H}$ Moe). Gotemburgo: Nordicom.

\section{Reconocimientos de la investigación}

Los resultados de este artículo corresponden al proyecto de "Indicadores de gobernanza, financiación, rendición de cuentas, innovación, calidad y servicio público de las RTV europeas aplicables a España en el contexto digital" (Referencia CSO201566543-P) del Programa estatal de Fomento de la Investigación Científica y Técnica de Excelencia, subprograma estatal de Generación de Conocimiento del Ministerio de Economía y Competitividad de España, cofinanciado por el Fondo Europeo de Desarrollo Regional (FEDER) de la Unión Europea. Así como de la actividad de la Red Internacional de Investigación de Gestión de la Comunicación (REDES 2016 G-1641 XESCOM) apoyada por la Consellería de Cultura, Educación e Ordenación Universitaria de la Xunta de Galicia (referencia ED341D R2016/019). La autora Marta RodríguezCastro es beneficiaria de un contrato de Formación de Profesorado Universitario (FPU16/05234) del Ministerio de Educación, Cultura y Deporte. 


\title{
E1 tratamiento de la información política e institucional en TVE
}

\author{
Xosé Soengas-Pérez \\ Universidade de Santiago de Compostela \\ Carlos Elías-Pérez \\ Universidad Carlos III \\ Ana María López-Cepeda \\ Universidad de Castilla-La Mancha
}

PARA CITAR: Soengas-Pérez, X., Elías-Pérez, C. y López-Cepeda, A.M. (2018). El tratamiento de la información política e institucional en TVE. Revista Latina de Comunicación Social, 73, pp. 1072 a 1089.

http://www.revistalatinacs.org/073paper/1297/56es.html

DOI: $\underline{10.4185 / R L C S-2018-1297}$

\section{Resumen}

Esta investigación analiza la información política e institucional en los telediarios de TVE para conocer el tratamiento de los acontecimientos que protagonizan los partidos políticos, las instituciones y sus representantes. Trabajamos con una metodología mixta. El análisis cuantitativo es necesario para determinar el grado de pluralidad formal y el cualitativo sirve para conocer los detalles de los enfoques de las noticias. Además, incluimos un grupo de discusión formado por cinco redactores para averiguar cómo funciona el proceso informativo en la televisión pública. Los datos demuestran que el $97 \%$ de las noticias tienen un tratamiento formal correcto, pero estas cifras contrastan con los resultados del análisis de contenido. El 74\% de los temas de información institucional tienen un enfoque que favorece, refuerza o avala la imagen del Gobierno y de los organismos afines. 
Palabras clave: información política; información institucional; televisión pública; censura; manipulación.

\section{Introducción}

T A INFORMACIÓN es un bien necesario que afecta de manera diferente a cada persona y en cada circunstancia adquiere valores distintos que dependen de muchos factores. Los medios de comunicación conocen los efectos y las posibilidades de la información y tratan de explotarlos de la manera más adecuada, según sus intereses, que en muchas ocasiones no coincide con lo que más beneficia a la sociedad en general (Campos-Freire, 2012; Fernández-Lombao \& Campos-Freire, 2013). La importancia de la información también es algo conocido y apreciado por el poder político, de ahí la necesidad y las intenciones de los partidos de influir en la selección y en el enfoque de las noticias para orientar los contenidos en el sentido que les favorezcan. Quien tiene la capacidad de convencer es capaz de influir en la opinión y en el comportamiento de los ciudadanos. Esta premisa, aplicada en unas elecciones o en lo cotidiano, puede favorecer o perjudicar, a través de los medios de comunicación, la imagen de determinados líderes, con consecuencias importantes para los partidos o para los sectores a los que representan (Quintana-Paz, 2005; CaseroRipollés, 2009).

Los estudios sobre la importancia de los medios no son algo reciente. Noëlle-Neuman ya consideraba en 1974 que los periodistas pueden decidir el resultado de unas elecciones. Y en 1982 Chaffee y Hochheimer hablaban abiertamente de la influencia de los medios en la política y de la relación entre ambos. Estos autores conciben el rol de la prensa, de la radio y de la televisión principalmente como informativo para la gente, más que persuasivo, pero insisten en la capacidad de influencia, una particularidad que motivó que McCombs \& Shaw (1972) iniciaran el estudio de la agenda setting, que equipara la información con el poder.

La teoría de fijación de la agenda de McCombs y Shaw (1986) nos parece válida para abordar varios planteamientos teóricos de nuestro trabajo. Los principios de esta teoría concuerdan con muchos de los aspectos que analizamos en esta investigación sobre los contenidos de 
los informativos, y más concretamente sobre el tratamiento de la información política e institucional en TVE.

McCombs (1992:820-821) mantiene que "las noticias no sólo nos dicen qué pensar sino cómo pensarlo (McCombs deja ver que hay una configuración de la opinión pública). Tanto la selección de temas para la agenda informativa como la selección de marcos sobre esos temas son potentes roles de la agenda setting y estremecedoras responsabilidades éticas". Luego McCombs y Shaw (1993:63) afirman que "cualesquiera que sean los atributos de un tema presentado en la agenda de los medios, las consecuencias sobre el comportamiento del público son considerables. La agenda setting es un proceso que puede afectar tanto a los temas en que pensamos como en la forma en que pensamos en ellos". Precisamente, uno de los aspectos de nuestra investigación coincide con uno de los ejes centrales de la agenda setting: los medios nos indican qué pensar y afectan a cómo pensar (Edelstein, 1993).

McCombs y Shaw (1986) consiguieron demostrar que el orden del día o agenda de campaña en los medios influía en la opinión pública. Por lo tanto eran los medios quienes dirigían la agenda setting. Esta es una de las claves que explica el enorme interés que hay en controlar los medios de comunicación, especialmente por parte de los partidos políticos y de las instituciones. Y muchas de las ingerencias que se localizan en algunas informaciones consideradas sensibles, sobre todo noticias políticas e institucionales, hay que explicarlas desde esta perspectiva.

El poder y la capacidad de influencia de los medios sobre la opinión pública genera de forma automática una necesidad de control de los contenidos por parte de aquellos que desean mantener su posición privilegiada o conquistar las riendas de la sociedad (Murciano, 2004; Casero-Ripollés, 2009; Soengas, 2015). Según Valbuena (2005), desde la agenda setting se explica el poder que tienen los medios sobre la opinión pública con un recurso psicológico, argumentando que los ciudadanos tienen una necesidad de orientación. Y la audiencia puede encontrar esa orientación en los medios (Quintana-Paz, 2005). Pero como existen varios medios, las posibilidades de orientación son múltiples, y entonces aparece el conflicto y la competencia por controlar sectores concretos (Murciano, 2004). Este planteamiento 
sirve para explicar las alineaciones de algunos medios de comunicación con determinados partidos políticos y cómo se convierten en los altavoces de sus postulados ideológicos y económicos (De-Miguel \& Pozas, 2009; Humanes, Montero-Sánchez, Molina-de-Dios \& LópezBerini, 2013; Humanes \& Fernández-Alonso, 2015; Soengas, 2015). Pero en esta investigación nos vamos a centrar exclusivamente en TVE porque nos interesa conocer cuál es la línea editorial de la televisión pública con respecto a la información política e institucional.

Los medios no seleccionan temas en abstracto, por eso sus agendas permiten identificar el rol que ocupan los protagonistas de la actualidad en la sociedad, además de sus posiciones ideológicas y de sus intereses particulares o colectivos (León-Gross, 2006).

La gran pregunta es ¿quién establece la agenda informativa? Encontrar la respuesta a esto permite identificar quién controla la información y, por extensión, quién ejerce el poder político y económico en la sociedad, porque la pregunta inicial que se hizo McCombs (1992) era quién establece la agenda pública, que luego transformó en un planteamiento más preciso: ¿quién establece la agenda informativa?, lo cual le permitía adaptar muchas de sus investigaciones al proceso de comunicación.

También nos interesan los planteamientos sobre los efectos movilizadores de los medios, establecidos por Lazarsfeld, Berelson y Gaudet (1948) y, sobre todo, los trabajos de Hovland (1957), que investigó las fórmulas para que un mensaje persuadiese más que otro. Hovland, entre otras cosas, analizó la influencia que podía tener el orden de presentar los contenidos para persuadir más a la gente. Esto, hoy, se puede aplicar a la jerarquización de las noticias y al diseño de la escaleta de un telediario. Aunque la persuasión no debería estar vinculada a la información, debemos entender estos planteamientos en el contexto en el que fueron formulados, la Segunda Guerra Mundial, donde las noticias tenían una finalidad muy concreta: convencer, algo que todavía sigue vigente en los informativos de hoy (FernándezBaena, 2005). Para adaptar la teoría de Hovland a la actualidad es muy importante diferenciar entre la responsabilidad social que le corresponde a una televisión pública y las actuaciones y los propósitos de los responsables de informativos, que no responden siempre a 
criterios periodísticos (Laverón \& Goñi, 2009; Fernández-Lombao \& Campos-Freire, 2013; Núñez-Ladeveze, Irisarri \& Morales, 2015).

La agenda setting hace hincapié en el poder de los medios, pero tampoco se trata de un poder absoluto ni gratuito. Depende de muchos factores, porque los medios también dependen de quien los utiliza para seguir siendo poderoso (Reig, 2011). Se trata de una espiral que pone de manifiesto el precio de la independencia informativa y la dificultad para aplicar los criterios periodísticos sin condicionantes (Soengas \& Rodríguez, 2015). Por eso, a la hora de analizar los informativos de TVE, concretamente el tratamiento de la información política e institucional, procede recordar la responsabilidad social de la televisión pública (Manfredi, 2009; Fernández-Lombao \& Campos-Freire, 2013).

\subsection{El valor de las noticias}

El valor de las noticias es relativo porque los factores que determinan la importancia de un hecho son muy diversos: criterio periodístico, criterio comercial, interés de un sector de la audiencia por un acontecimiento, etc. Elaborar una noticia siempre implica un planteamiento ideológico que obliga a incorporar unos elementos y descartar otros. Y luego, dentro de los elementos seleccionados, también se establecen unas preferencias, unas categorías y un orden, según el enfoque (Soengas, 2008). Por lo tanto, el discurso de la noticia dependerá también del criterio utilizado por el redactor y no sólo de la naturaleza de los hechos. Sería inocente olvidar que en la elaboración de la información conviven criterios ideológicos y profesionales, pero en toda información hay un margen de enfoque tolerable, cuyo resultado es una versión personalizada que, precisamente, marca la diferencia y evita la homogenización de los contenidos que sirven las agencias de información (Rodrigo-Alsina, 1989).

Durante el proceso informativo confluyen una serie de circunstancias, muchas de ellas, aparentemente, contradictorias. Por una parte, el control exhaustivo de los contenidos y, por otra, la descuidada producción en serie, consecuencia de los sistemas de trabajo implantados en la mayoría de las redacciones (Villafañe, Bustamante \& Prado, 1987). Pero para comprender esta dualidad es necesario recordar que en la agenda de los medios existen dos tipos de contenidos: los comprometidos y los rentables (León-Gross, 2006). En 
el primer caso se trata de informaciones relacionadas casi siempre con asuntos políticos o económicos que afectan a sectores que tienen influencia en los medios, y esos temas son revisados de forma rigurosa (De-Miguel \& Pozas, 2009). La información política e institucional, que es nuestro objeto de estudio, es una de las temáticas más sensibles dentro de las diferentes áreas que integran las redacciones de los informativos y se enmarca en los contenidos catalogados como comprometidos (Pestano-Rodríguez, 2008). Por esta razón, en la mayoría de los casos, está sujeta a una revisión permanente, para garantizar que el enfoque se ajusta a la línea editorial establecida.

Por otra parte, existen contenidos que no afectan directamente a los intereses políticos de la empresa, pero tienen audiencia por su componente espectacular y por eso son rentables desde el punto de vista comercial. Sobre estos temas apenas existe control informativo y la mayoría de las veces se emiten tal como los sirven las agencias internacionales de información, sin ninguna modificación para adaptarlos a las normas del medio. De hecho, no es difícil localizar en varias emisoras la misma noticia redactada de forma idéntica, e incluso esta coincidencia se da en soportes diferentes (García-Avilés, 2007).

Pero al control político de la información, con frecuencia, se añaden otros condicionantes que también afectan a la selección temática y a los enfoques, algo que redunda en la calidad de los contenidos. TVE, aunque es un medio de comunicación público, asume criterios de las televisiones privadas (Laverón \& Goñi, 2009; Gómez-Montano, 2013). Considerar los índices de audiencia una referencia conlleva unas exigencias que contaminan todo el proceso informativo y merman la calidad. Los nuevos valores audiovisuales marcan unas pautas que condicionan la selección y el tratamiento de las informaciones para adecuarlas a los intereses de la empresa, que son, principalmente, reducir los costes de producción y satisfacer las necesidades del mercado para garantizar una audiencia elevada. Estos planteamientos fomentan la inclusión de temas-espectáculo y la falta de rigor en el tratamiento de los hechos, transformando muchas veces los enfoques informativos en enfoques interpretativos (Cebrián-Herreros, 2004; Ortells-Badenes, 2009).

Rodrigo Alsina (1989) destaca dos fases fundamentales en el proceso de producción de la información: la selección y la jerarquización de los 
contenidos. La selección determina de forma decisiva qué hechos o qué aspectos de un tema conocerá la audiencia, mientras que la jerarquización otorga mayor o menor importancia a un tema y, por lo tanto, condiciona su valor informativo, al mismo tiempo que indica las preferencias de la emisora.

Los profesionales de la información están condicionados por una serie de circunstancias, desde las rutinas productivas, que imponen una celeridad incompatible con el contraste de fuentes, hasta los intereses específicos del medio, que determinan el enfoque de los contenidos y el rigor de las noticias, como ya se ha dicho. Las condiciones de producción de la información también influyen directamente en el contenido de la noticia. Este aspecto ha sido investigado por numerosos autores, algunos de ellos pioneros como Elliot (1981) y Tuchman (1983). Pero aquí destacamos los trabajos de Villafañe, Bustamante \& Prado (1987), cuyo modelo de análisis sigue siendo una obra de referencia en la actualidad, aunque la informatización de las redacciones ha cambiado sustancialmente las condiciones del proceso informativo.

\subsection{El rigor y la manipulación}

El rigor informativo es incompatible con el sensacionalismo, con la televisión espectáculo, con la manipulación y con la censura, que impide que se conozcan versiones de fuentes acreditadas. Y la obligación de los medios de comunicación es ofrecer una información veraz, rigurosa y plural (Gómez-Montano, 2013; López-Olano, 2016). Evitar la manipulación no es una tarea fácil. Primero es necesario definirla para poder identificarla y luego comprobar si existe. Durante este proceso es fundamental aplicar métodos que permitan determinar desde un punto de vista científico si una información está manipulada. Las apreciaciones subjetivas sobre el tratamiento informativo de un hecho suelen responder a criterios interesados y, además, a veces, es muy difícil marcar la barrera que separa la manipulación de los posibles puntos de vista desde los que se puede abordar un tema. Por eso es muy importante diferenciar entre la censura, la manipulación y el enfoque de una noticia. Para ello es necesario determinar cuáles son los elementos esenciales y obligatorios que hay que incluir en el relato informativo de un hecho y cuáles son los matices que permiten construir los diversos enfoques posibles, que sirven para identificar la 
línea editorial y las preferencias de los medios. Destacar los aspectos negativos de un acontecimiento o minimizar los problemas de un personaje responde a un deseo de crear una determinada imagen para la opinión pública, pero eses planteamientos no se pueden asociar automáticamente con la censura y con la manipulación, ni tampoco la ausencia de algunos detalles. Los medios tienen derecho a publicar todo aquello que no esté sujeto a restricciones legales y enfocarlo de la forma que consideren más oportuna, siempre que no traspasen las barreras que marcan los códigos deontológicos.

Es importante dejar constancia de que es imprescindible respetar el criterio profesional del redactor, que es el que le otorga un enfoque particular a cada tema y así se evita la homogenización de la información. Los libros de estilo recogen las normas que deben aplicarse durante el proceso informativo (Manual de Estilo de RTVE). Todas las noticias tienen que ser tratadas con criterios periodísticos, pero cuando la información se gestiona con unos intereses distintos, se está usurpando uno de los derechos fundamentales de los ciudadanos, que es disponer de información de calidad y acceder a ella en igualdad de condiciones. La censura y la manipulación, además de ofrecer una versión sesgada y parcial de la realidad, impiden conocer datos que pueden ser esenciales para algunas personas.

La estructura actual de RTVE está configurada por un organigrama que dispone de los elementos y de los recursos necesarios para garantizar una información veraz, rigurosa y plural, por eso, para que exista censura o manipulación, tienen que darse una serie de circunstancias: que haya redactores dispuestos a transgredir las normas que se contemplan en el Manual de estilo de RTVE o directivos con la capacidad de imponer un enfoque que no se corresponde con criterios periodísticos. Cuando los elementos que han sido pensados para garantizar la calidad de la información se convierten en aliados de intereses políticos o ideológicos, desaparece el rigor.

\subsection{La interpretación de los hechos y la influencia de la información}

La complejidad de los mensajes, tanto desde el punto de vista de su elaboración, como desde la perspectiva de la descodificación, hace que sea muy difícil controlar las consecuencias de los mismos. El proceso 
informativo lleva implícitos una serie de riesgos que se escapan a las posibilidades de control del medio una vez que se emite la noticia, y uno de esos riesgos son los efectos imprevistos, debidos a la respuesta directa de la audiencia o a la ampliación del tema que puedan realizar otros medios, aireando aspectos que no interesan y desautorizando así la versión original.

Domke y Shah (1995) comprobaron que la audiencia interpreta los temas basándose en preocupaciones éticas o sociales y los ciudadanos apoyarán a un candidato o a otro según los valores que defienda. Por lo tanto, existen dos modalidades genéricas de interpretaciones de los hechos que influyen en la configuración de una opinión posterior: la interpretación ética y la interpretación social. Extrapolando esto a la información política e institucional, tendríamos dos grandes campos de análisis que nos sirven para determinar cómo van a ser descodificadas las noticias según los condicionantes.

Los valores y las creencias actúan como un filtro, pero también influyen en el procesamiento de la información. Al hablar de noticias tenemos que contemplar dos niveles o dos fases diferentes: los filtros que incluyen los periodistas, de forma consciente o inconsciente, y los filtros de la audiencia, que muestra preferencias por determinados asuntos o por versiones concretas de un hecho. La clave está en qué hacer para influir en la interpretación de los temas. Este planteamiento puede considerarse la base de la manipulación porque se está orientando la opinión de la audiencia de forma inconsciente y perjudicando o favoreciendo la imagen de una persona o de un organismo de una manera artificial.

Cuando interesa construir una versión, lo primero que se hace es diseñar el marco adecuado para que el mensaje sea creíble (Humanes, 2001) y, además, capte la atención de una audiencia numerosa. McCombs y Shaw (1993) admiten que la manera en que un objeto es enmarcado en la agenda puede tener consecuencias, por ejemplo cuando los atributos de un tema resaltado en la cobertura de las noticias influyen directamente en la opinión pública. Así se consigue trasladar la idea deseada a un número elevado de espectadores capaces de crear una corriente de opinión y, por lo tanto, suficientes para influir en resultados que implican apoyos explícitos. Pero es importante recordar 
que los diferentes sectores de la audiencia no son susceptibles de convencer de la misma forma: los grados de dificultad varían.

\subsection{La responsabilidad social de los informativos de TVE}

Los planteamientos teóricos realizados hasta ahora se refieren a los medios de comunicación en general, pero nuestra investigación se centra en los telediarios de TVE y conviene recordar que los medios de comunicación públicos tienen una responsabilidad social que conlleva una serie de obligaciones, entre ellas ofrecer a los ciudadanos una información plural y de calidad, en la que aparezcan representadas todas las sensibilidades y se mantenga el respeto a la diversidad y a las minorías (Manfredi, 2009; Campos-Freire, 2012; Fernández-Lombao \& Campos-Freire, 2013). Además, también deben dar prioridad a la información útil, aquella que tiene validez inmediata o futura para los ciudadanos porque les permite acceder a recursos o tener conocimiento de hechos o de oportunidades que pueden repercutir en su bienestar. Y la información política e institucional se puede incluir dentro de la categoría de información útil porque las decisiones y los acuerdos parlamentarios de los representantes políticos afectan a la vida cotidiana de los ciudadanos.

Los textos a los que nos hemos referido hasta ahora permiten crear una base sólida para realizar un análisis riguroso de la información política e institucional que se emite en la televisión pública. Las conclusiones a las que han llegado los autores consultados facilitan una visión panorámica que ayuda a construir el contexto necesario para situar adecuadamente la investigación. Además, la literatura revisada sobre este tema demuestra que en TVE existe un control de la información política e institucional, un aspecto que consideramos necesario para el planteamiento, el enfoque y el desarrollo de nuestro trabajo. Varias publicaciones, entre ellas las de Casero-Ripollés (2009); Humanes, Montero-Sánchez, Molina-de-Dios \& López-Berini (2013) y Soengas \& Rodríguez (2015), llegan a conclusiones muy similares y acreditan que existe un control permanente de los contenidos de los telediarios, particularmente de la información política e institucional, aunque los índices de censura y de manipulación varían sustancialmente si se comparan diferentes etapas (Gómez-Montano, 2013). Estos resultados, además, reflejan los diferentes grados de intervencionismo del Gobierno en cada una de las legislaturas y nos hacen reflexionar 
sobre la independencia de TVE y cuestionar el papel real que cumple la televisión pública en la sociedad. Y, al mismo tiempo, nos sugieren preguntas como ¿quién controla la información?, ¿cómo se controla? y ¿por qué existe interés en controlarla? (Azurmendi, 2007; Zallo, 2010). El grupo de discusión con el que hemos trabajado, compuesto por cinco redactores de los servicios informativos de TVE, cuyas opiniones incluimos en el apartado de análisis de datos, nos ayudará a dar respuesta a estas cuestiones.

\section{Objetivos}

El objetivo de esta investigación es analizar la información política e institucional de los telediarios de TVE para conocer el tratamiento de las noticias referidas a los cuatro partidos mayoritarios y a sus líderes, a los sindicatos, al Gobierno, a la Casa Real y a las demás instituciones autonómicas. Además, a través de un grupo de discusión formado por cinco redactores, nos interesa averiguar cómo funciona el proceso informativo en la televisión pública para saber cuáles son los factores, los elementos y los protocolos que garantizan la calidad de la información y, al mismo tiempo, comprobar si existen carencias en el organigrama que permiten que exista censura y manipulación. También queremos saber si acontecimientos extraordinarios como el proceso independentista catalán focalizan demasiado la atención y distorsionan el equilibrio informativo entre las diferentes secciones.

\section{Objeto de estudio}

Situamos nuestro objeto de estudio en las informaciones sobre el Estado, la Casa Real, el Gobierno central y los autonómicos, la Administración central y autonómica, los cuatro partidos políticos mayoritarios y los sindicatos y sus respectivos líderes, emitidas durante el mes de septiembre de 2017 en el telediario de TVE de las 15 horas, de lunes a viernes. Prescindimos de los informativos del fin de semana porque los sábados y los domingos no hay actividad parlamentaria y esta circunstancia alteraría los resultados. También analizaremos las noticias que hagan referencia a la política o a las instituciones españolas, que influyan en ellas o que afecten a los intereses de España, aunque sus protagonistas sean extranjeros. Nos interesa comprobar cómo se tratan en la televisión pública los apoyos y las críticas que puedan hacerse desde terceros países o desde líderes no españoles a situaciones 
internas, a medidas que se adoptan desde el Gobierno de España o a declaraciones realizadas por algún político español.

Trabajamos con las siguientes ideas y conceptos: el tratamiento de la información en televisión, el tratamiento de la información política e institucional en la televisión pública, el control de los medios públicos, el control de la información en televisión, la politización de la información, el pluralismo en los informativos y la responsabilidad social de los medios públicos.

\section{Hipótesis}

Partimos de la hipótesis de que en TVE existe control de los contenidos, especialmente de la información política e institucional, y politización de la información. La censura y la manipulación no se manifiestan en el tratamiento formal de las noticias, pero sí se detectan en la selección temática y en el enfoque. Otra de las hipótesis es que TVE dispone de los recursos necesarios para ofrecer una información rigurosa, pero las estructuras que han sido pensadas para garantizar la calidad, a veces, se utilizan para defender intereses incompatibles con los criterios periodísticos.

\section{Metodología}

Consideramos que para conseguir los objetivos planteados en esta investigación es necesario aplicar una metodología mixta. El análisis cuantitativo nos permitirá conocer los aspectos formales y el cualitativo o de contenido es necesario para profundizar en las particularidades de los enfoques de las noticias.

En primer lugar, calculamos el tiempo que dedica TVE a la información política e institucional para saber cuál es el grado de presencia de estos contenidos con respecto a las demás informaciones que se emiten en el telediario. Además, como disponemos de datos de las mismas características obtenidos en otras épocas, podemos compararlos y comprobar si el volumen de las diferentes secciones se mantiene estable o si se ven afectadas por acontecimientos extraordinarios como el proceso sobre la independencia de Cataluña.

En el análisis de contenido contemplamos las tres posibilidades que pueden darse en el planteamiento y desarrollo de una información, a saber, enfoque neutral, crítico o favorable. Y para identificar cada una 
de estas modalidades trabajamos con una serie de elementos que consideramos indicadores objetivos esenciales para analizar el tratamiento de una noticia. Estos referentes ya han sido utilizados en otras investigaciones de características similares (Humanes, 2001; Soengas 2015) y, por lo tanto, está contrastada su validez para determinar el rigor y la calidad de los contenidos. Son los siguientes: enfoque del tema; contextualización; tratamiento de los puntos de vista; grado de equilibrio entre las versiones a favor y en contra; características, calidad, pertinencia, tratamiento y pluralidad de las fuentes utilizadas; número de intervenciones de cada personaje y duración de cada una; asociación del tema o del personaje, directa o indirecta, con elementos positivos o negativos; correspondencia entre la relevancia de la noticia y su ubicación en el informativo; tipo de plano de cada personaje; tratamiento formal; utilización de recursos que favorecen la comprensión de la información y actitud de los presentadores a la hora de narrar el tema.

También consideramos que es necesario separar el tratamiento informativo de los partidos, sindicatos e instituciones del tratamiento de los líderes o representantes, ya que puede haber diferencias sustanciales que merecen ser conocidas y comentadas.

Completamos la investigación con un grupo de discusión formado por cinco redactores de TVE que conocen bien el proceso informativo en la televisión pública y, además, están especializados en nuestro objeto de estudio porque llevan más de cinco años trabajando con información política e institucional. Así disponemos de los referentes necesarios para contrastar y completar los resultados del análisis de datos obtenidos de la muestra. Estas entrevistas nos permitirán conocer cómo funciona la estructura de TVE, concretamente el organigrama de los informativos, y valorar si se respetan siempre las exigencias y las recomendaciones sobre los protocolos que figuran en el Manual de estilo de RTVE. Y también podremos conocer el grado de libertad con que trabajan los redactores, si reciben presiones, permanentes o puntuales, quién las realiza y a qué temas afectan. 


\section{Resultados}

\subsection{Los tiempos y los aspectos formales}

Al analizar los informativos de TVE se observa que existe un incremento importante de las noticias de contenido político e institucional emitidas en los telediarios de las 15 horas del mes de septiembre de 2017 con respecto al volumen de noticias de las mismas características registradas en periodos similares de años anteriores. La información política e institucional del informativo de las 15 horas en 2015 y en 2016 ocupaba el 25\% y el 27\%, respectivamente, con respecto a las demás secciones, mientras que en 2017 alcanza el 38\%. Estos datos demuestran que existen elementos nuevos que han adquirido un protagonismo extraordinario y han desplazado a otros temas. Atribuimos estos cambios a la situación de Cataluña porque el $65 \%$ de las noticias de información política e institucional emitidas en septiembre de 2017 están relacionadas con el proceso independentista, lo que supone un incremento del $51 \%$ de noticias referidas a esta comunidad autónoma con respecto al mismo periodo del año anterior.

También consideramos necesario destacar que el 17\% de las noticias de carácter político referidas al Partido Popular integran información institucional en el mismo relato, una fórmula que permite reforzar la presencia de esta formación en los informativos y, al mismo tiempo, vincular la acción de Gobierno con las propuestas del partido que lo apoya. Al no separar la información política de la institucional se produce una politización de la información y un tratamiento inadecuado de los hechos porque ambos contenidos corresponden a ámbitos diferentes.

A continuación, realizamos un análisis detallado de los diferentes aspectos que conforman las noticias, tanto estructurales y narrativos como formales, para conocer en profundidad el tratamiento de la información política e institucional en TVE.

El grado de presencia de los diferentes partidos políticos en los telediarios coincide con su representación parlamentaria, como se puede comprobar en el gráfico 1, un detalle que confirma que, para mantener una pluralidad formal, la televisión pública diseña la escaleta aplicando una fórmula pensada para regular los espacios de propaganda de los partidos políticos durante los periodos electorales, que consiste 
en asignarle a cada formación un tiempo proporcional a los escaños obtenidos en la legislatura anterior. Esta fórmula implica que la selección de las noticias y la jerarquización de los temas no se realizan siempre con criterios periodísticos, una práctica que ha denunciado de forma reiterada en Consejo de Informativos de TVE.

\section{Gráfico 1}

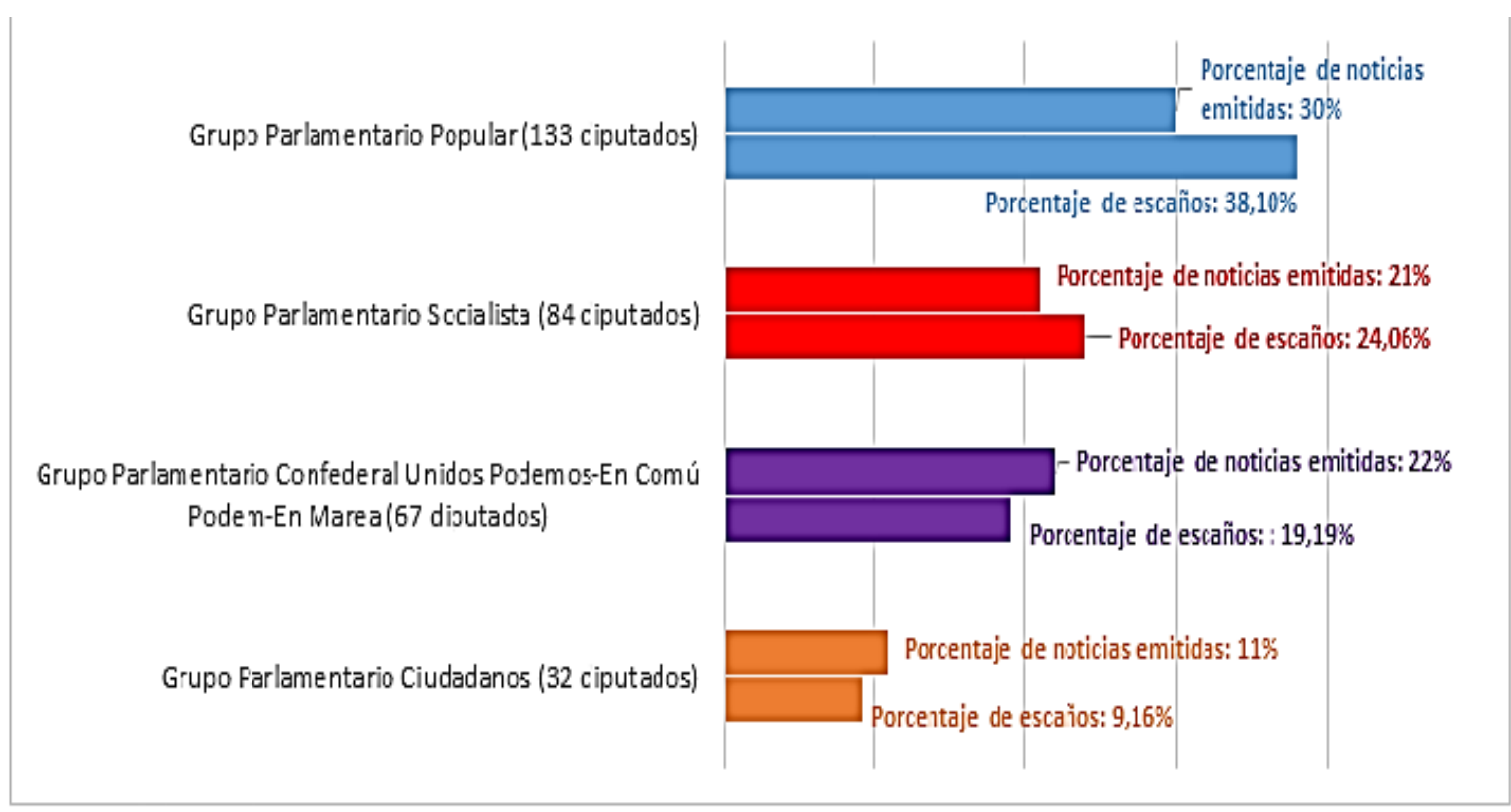

Fuente: Elaboración propia

El 30\% de las noticias de información política corresponden al Partido Popular (sus diputados ocupan el 38\% de los escaños del Parlamento), el 21\% al PSOE (sus diputados suman el 24\%), el 22\% a Podemos (a sus diputados les corresponden el 19\% de los escaños), el 11\% a Ciudadanos (esta formación tiene un $9 \%$ de parlamentarios) y el 16\% restante se distribuyen de forma desigual entre los demás partidos minoritarios y los sindicatos. Estos valores demuestran que la presencia diaria de los diferentes partidos en los telediarios está garantizada, independientemente de la importancia informativa de las noticias que generen.

El grado de presencia de los líderes políticos en los telediarios no se corresponde siempre con los porcentajes de noticias de sus respectivos partidos. Si tomamos como referencia los datos anteriores, Mariano Rajoy acapara el 37\% del tiempo con respecto a los minutos que ocupa el Partido Popular, seguido de Pablo Iglesias con el 30\% con respecto al tiempo de Podemos, Albert Rivera con el 26\% con respecto al tiempo de Ciudadanos y Pedro Sánchez con el 23\% con respecto al 
tiempo del PSOE. Estos resultados se explican porque las noticias de los partidos políticos no las protagonizan siempre sus líderes. Muchas veces son los portavoces de la formación los que informan a los medios, una estrategia utilizada habitualmente para unificar el mensaje y para evitar sobreexponer al líder y desgastar su imagen cuando hay que abordar temas complicados.

El 97\% de las noticias analizadas reúne los requisitos formales necesarios: la estructura del relato es correcta y contiene todos los puntos de vista relacionados con los hechos. En este aspecto no se aprecian diferencias sustanciales en el trato que reciben los partidos políticos, sus líderes, la información institucional y los sindicatos. Pero la corrección formal no se corresponde siempre con el enfoque de todas las noticias, como se puede comprobar en el análisis de contenido.

\subsection{Análisis de contenido: el enfoque y la jerarquización}

En el enfoque es donde mejor se aprecian las peculiaridades de los tratamientos informativos. Por eso nos interesa saber cómo están enmarcados los temas y los personajes para comprobar en qué entornos aparecen situados porque para valorar el enfoque es determinante la contextualización. Como ya se ha dicho, el 97\% de las noticias analizadas reúnen los requisitos formales. Pero esta corrección aparente no se corresponde con los resultados obtenidos en el análisis de contenido, que reflejan disparidad de criterios en algunos casos y, además, se aprecian detalles que evidencian que en TVE existe politización de la información.

El 74\% de las noticias de información institucional tienen un enfoque que favorece, refuerza o avala la imagen, la gestión o los criterios del Gobierno, del Estado o de la Casa Real. Y el 62\% de los enfoques críticos corresponden a hechos protagonizados por instituciones de comunidades autónomas que no son afines al Gobierno central. El tratamiento del 98\% de los temas sobre la independencia de Cataluña es crítico con el Gobierno de la Generalitat y en el relato se reiteran argumentos sobre las consecuencias negativas que conlleva el proceso secesionista, tanto para Cataluña como para el resto de España. Los aspectos en los que más se incide son la economía, la fractura social y la imagen externa. 
Estos datos demuestran que desde TVE se pretende dar una imagen positiva del Gobierno y del Estado.

En la información política, el 80\% de las noticias referidas al Partido Popular tienen un enfoque favorable para el propio partido, el 11\% un enfoque neutral y el $9 \%$ un enfoque crítico. En el caso del PSOE, el $59 \%$ de los enfoques son favorables, el 10\% neutrales y el 31\% críticos. En las noticias protagonizadas por Podemos los enfoques favorables suponen el 17\%, los neutrales el 25\% y los críticos el 58\%. Y los temas vinculados con Ciudadanos tienen un enfoque favorable el $65 \%$, un enfoque neutral el 20\% y un enfoque crítico el $15 \%$.

En el tratamiento informativo de los líderes también hay diferencias. Los enfoques de Mariano Rajoy son favorables el 89\%, neutrales el 6\% y críticos el 5\%; los de Pedro Sánchez son favorables el 42\%, neutrales el 31\% y críticos el 27\%; los de Pablo Iglesias son favorables el 25\%, neutrales el 41\% y críticos el 34\%; y los de Albert Rivera son favorables el $54 \%$, neutrales el $29 \%$ y críticos el $17 \%$.

El orden en que se emiten las noticias les atribuye un valor añadido, al margen de su contenido. La ubicación, normalmente, responde a razones operativas para facilitar el raccord y favorecer el ritmo del informativo, pero en otras ocasiones esconde la intención de destacar, magnificar o minimizar el impacto de un tema. Y para conseguir ese propósito se busca un sitio estratégico en la escaleta. A veces también se pretende que se produzca una transferencia connotativa entre dos informaciones. Si la audiencia vincula dos hechos, la relación que se establece afecta a la descodificación y puede repercutir en la imagen de un partido o de un líder. Para valorar la jerarquización, así se denomina la posición que ocupa cada noticia con respecto a las demás, tomamos como referencia el número total noticias del telediario y luego comprobamos en qué lugar se han emitido las informaciones referidas a los diferentes partidos, a las instituciones y a los sindicatos.

El 81\% de las noticias sobre el Partido Popular emitidas entre las cinco primeras tienen un enfoque favorable. En cambio, la mayoría de informaciones de los demás partidos analizados que aparecen en las mismas posiciones tienen enfoques críticos, aunque con porcentajes diferentes: $79 \%$ Podemos, 54\% PSOE y 52\% Ciudadanos. 
El 56\% de la información institucional que tiene un enfoque positivo también está destacada entre las cinco primeras noticias.

En el 73\% de los casos la ubicación de los temas, por sus características, favorece el raccord de continuidad del informativo, por lo tanto el lugar que ocupan en la escaleta puede considerarse una decisión lógica. El orden en que se emiten los demás contenidos, según los criterios aplicados en esta investigación, puede interpretarse como una intención de TVE de modificar el impacto de los acontecimientos situándolos en lugares estratégicos.

Si analizamos las noticias relacionadas con España que tienen el foco informativo en el extranjero, comprobamos que la línea editorial de la televisión pública coincide con los criterios políticos del Gobierno sobre la situación actual de las relaciones internacionales. En este ámbito destacan las diferencias entre Venezuela y España, que se evidencian en los enfoques de las declaraciones del presidente Nicolás Maduro y de su Gobierno (el 92\% son críticos), y en el tratamiento informativo de la oposición venezolana cuando opina sobre los mismos temas (el 89\% son favorables). Las intervenciones públicas del Gobierno británico sobre España tienen un enfoque crítico en el 68\% de los casos, mientras que el $87 \%$ de las noticias que relatan la posición del Gobierno alemán sobre asuntos españoles tienen un enfoque favorable. Además, en todas las informaciones sobre el Brexit se avalan los argumentos de Alemania. Y las referencias del Gobierno francés a España también tienen un enfoque favorable en el 83\% de los casos.

\subsection{Las temáticas, las fuentes y los protagonistas}

En la información política e institucional analizada hay poca diversidad temática. Independientemente de los enfoques, la mayoría de los contenidos se repiten de forma sistemática durante todo el mes objeto de estudio porque TVE se nutre de la agenda institucional y de la actividad de los partidos. La gestión del Gobierno, la independencia de Cataluña y los problemas de Europa ocupan el 78\% del tiempo destinado a la información política e institucional. En el 63\% de las noticias aparecen los mismos personajes y el $81 \%$ de las declaraciones que se utilizan para documentar los relatos proceden de fuentes oficiales. También se repiten los entornos que enmarcan los hechos. El $55 \%$ de los temas se desarrollan en los mismos escenarios. 


\subsection{Resultados del grupo de discusión}

Los cinco periodistas seleccionados para el grupo de discusión tienen una trayectoria profesional que les permite conocer la estructura, el organigrama, los procedimientos y los protocolos del telediario de TVE porque llevan más de cinco años trabajando como redactores de información política e institucional. En primer lugar, consensuamos con ellos que existe control de la información cuando un redactor selecciona un tema porque considera que tiene interés periodístico y luego se veta su emisión o se le pide que varíe el enfoque para ofrecer una versión incompleta o manipulada, adaptada a unos intereses concretos. Este supuesto implica que un periodista no trabaja libremente, de acuerdo con sus principios éticos y con su criterio profesional, y se ve obligado a realizar un tratamiento informativo que altera la realidad de los hechos o que oculta una parte de ella.

De acuerdo con los objetivos de la investigación, se les preguntó a los cinco redactores si consideran que existe control de la información política e institucional en TVE. En caso de respuesta afirmativa, estaban previstas las siguientes preguntas: ¿quién controla la información?, ¿cómo se controla? y ¿por qué existe interés en controlarla?

Para diferenciar las respuestas y mantener el anonimato de los participantes en el grupo de discusión, los codificamos como redactor 1 , redactor 2 , redactor 3 , redactor 4 y redactor 5 .

Los cinco coinciden en que, en muchos casos, es difícil saber si existe control de la información porque a veces resulta complicado demostrar si el enfoque de un tema responde exclusivamente al punto de vista y al criterio profesional del redactor o si obedece a indicaciones de alguien más. De todas formas, admiten que siempre ha habido supervisiones de algunas noticias, aunque discrepan sobre el grado de libertad que existe para trabajar en los informativos de TVE.

Los redactores 1, 2 y 4 dicen que la vigilancia de los contenidos es permanente porque los sistemas de control están instalados de forma estratégica para que funcionen automáticamente. En cambio, sus compañeros 3 y 5 sostienen que no toda la información política e institucional está sometida a los mismos filtros porque no todas las noticias son igual de sensibles. Por eso puntualizan que, sólo en casos 
concretos, cuando se tratan temas delicados, los criterios políticos predominan sobre los periodísticos para salvaguardar intereses externos.

Cuando les preguntamos quién controla la información y cómo se controla, tampoco mantienen un criterio unánime. Los cinco aseguran que la estructura de los informativos de TVE dispone de elementos y recursos suficientes y adecuados para garantizar una información plural, rigurosa y de calidad, pero para los redactores 2 y 4 el organigrama tiene puntos débiles y favorece las intervenciones en los contenidos porque no existe un mecanismo o un protocolo que impida las intromisiones de los directivos en el trabajo de los redactores, para que se respete siempre su criterio profesional y se garantice su independencia. Para el redactor 5 la complejidad del proceso informativo facilita los controles porque están activados unos procedimientos pensados para garantizar la calidad que a veces no cumplen las funciones que les corresponden. Esta observación también la hace el redactor 1 . Y el redactor 3 , redundando en lo que ya habían apuntado los redactores 2 y 4, cree que sería necesario definir mejor las funciones de los jefes de área para que sus responsabilidades se limitaran a cuestiones estrictamente profesionales.

Los redactores 3 y 5 afirman que la clave está en los nombramientos de los responsables de área porque su ubicación les permite realizar un control directo sobre todo lo que sucede en la redacción e intervenir cuando consideran que algún tema debe ser tratado de forma especial. El redactor 4 coincide con ellos y puntualiza que, además de los responsables de área, que ocupan puestos clave y son los que realmente ejercen de filtros ideológicos y de comisarios políticos durante el proceso informativo, lo más preocupante es la autocensura.

Los cinco redactores critican que se hagan nombramientos con criterios políticos porque eso conlleva una serie de compromisos y de obligaciones e impide trabajar con libertad y con criterios profesionales. Además, también reconocen que las indicaciones que se hacen desde los puestos intermedios de la redacción liberan de responsabilidades políticas a los altos directivos, aunque las órdenes de intervenir en los contenidos procedan de la cúpula. $\mathrm{Y}$ así es como se contamina el organigrama. 
Los enfoques de las noticias también son importantes. Para los redactores 2 y 4 con frecuencia se incluyen detalles innecesarios que pueden alterar la naturaleza de los hechos y condicionar la descodificación de los contenidos. Además, añaden que las decisiones sobre la jerarquización de las noticias no se toman siempre con criterios periodísticos. Respecto a este punto, los redactores 3 y 5 señalan que la mayoría de la información política e institucional suele ser relevante y por eso ocupa una posición preferente en la escaleta. Y también les parece normal que las informaciones sobre el Partido Popular aparezcan destacadas porque es el partido que en estos momentos tiene más responsabilidades. Por eso no ven nada extraño en el orden de emisión de las noticias. El redactor 1 es más crítico y cree que la jerarquización, a veces, conlleva unas intenciones concretas que obedecen a intereses que no se reflejan en los criterios establecidos en la línea editorial.

Los cinco redactores admiten que siempre se intenta que todas las sensibilidades políticas tengan voz diariamente en los telediarios. El redactor 3 y el redactor 5 justifican los datos sobre el grado de presencia de los diferentes partidos en los informativos argumentando que las formaciones con mayor representación parlamentaria suelen tener mayor actividad y más presencia pública porque les corresponde más tiempo de intervención en el Congreso de los Diputados. Ambos sostienen que esa es la razón principal por la que aparecen destacados. Esta fórmula supone una desventaja para los partidos minoritarios porque reduce las posibilidades de dar visibilidad a sus propuestas a través de la televisión pública.

Respecto a la tercera pregunta, ¿por qué existe interés en controlar la información?, los cinco redactores coinciden en los argumentos principales, aunque con algunos matices. En donde hay unanimidad es en las razones por la que existe interés en controlar la información. Todos insisten en que los políticos son conscientes de la importancia de la televisión y de su capacidad para influir en la sociedad y en la construcción de la opinión pública, especialmente en amplios sectores de la población que se pueden enmarcar dentro de lo que se denomina audiencia pasiva, que son los más influenciables, tal como reconocen los redactores 1, 3 y 5 . Así, para el redactor 2 controlar la información aumenta las posibilidades de orientar las decisiones de muchos 
ciudadanos y para el redactor 4 el dominio de la opinión pública ayuda a conquistar el poder o a mantenerse en él, por eso interesa controlar la televisión.

\section{Discusión y conclusiones}

El 97\% de las noticias analizadas tienen un tratamiento formal correcto porque incluyen todos los puntos de vista. En este aspecto no se aprecian diferencias sustanciales en el trato que reciben los partidos, sus líderes, la información institucional y los sindicatos. Además, todas las formaciones políticas tienen una presencia en el telediario proporcional a sus escaños porque TVE, para mantener una pluralidad formal, aplica una fórmula pensada para regular los espacios de propaganda durante los periodos electorales, que consiste en asignar a cada partido un tiempo equivalente a su representación parlamentaria.

Los repartos de los tiempos favorecen a los partidos mayoritarios, por eso el grado de presencia de la información política no se puede considerar siempre un indicador de la relevancia de los contenidos. Algunos acontecimientos no se emiten por su interés periodístico, sino por la necesidad de mantener en el telediario una pluralidad aparente. Por eso la corrección formal que mencionábamos antes no garantiza un enfoque riguroso de las noticias, ni una selección adecuada de los temas.

El tratamiento de la información política e institucional refleja que TVE tiene una línea editorial progubernamental. Los análisis demuestran que los informativos transmiten una imagen positiva, eficaz y moderna del funcionamiento de la mayoría de las instituciones públicas, especialmente la Casa Real, el Gobierno central y las comunidades autónomas en las que gobierna el Partido Popular. Este retrato no se corresponde con la realidad si comparamos los resultados de la investigación con los datos de las encuestas del Centro de Investigaciones Sociológicas. En cambio, en las noticias relacionadas con los partidos de la oposición predominan los enfoques críticos. Los mismos criterios que definen la línea editorial se repiten en la jerarquización. La mayoría de las noticias que se emiten en lugares preferentes con enfoques positivos benefician al Partido Popular, a las instituciones donde gobierna o al Estado, mientras que la mayoría de 
los temas que son críticos con el discurso o con la gestión del Gobierno quedan relegados a posiciones más discretas.

Los redactores que han formado parte del grupo de discusión reconocen que existen intromisiones inadecuadas en los contenidos porque el organigrama de los servicios informativos no está blindado frente a posibles presiones externas. En TVE no existe un procedimiento adecuado para resolver con garantías conflictos profesionales cuando el criterio del periodista choca con los intereses del medio. En estos casos prevalece la opinión de los jefes. Para ellos la clave está en los nombramientos de los cargos directivos, especialmente los responsables de área, que no siempre se realizan atendiendo exclusivamente a méritos profesionales. Los redactores también reconocen que existen diferentes grados de control de la información, que se manifiestan en la selección temática y en el enfoque de las noticias y, además, confirman la segunda hipótesis. Para ellos, los informativos de TVE disponen de los elementos y de los recursos adecuados para ofrecer una información rigurosa y plural, pero las estructuras que han sido pensadas para garantizar la calidad, a veces, se utilizan para controlar los contenidos y satisfacer intereses políticos, económicos o ideológicos, incompatibles con los criterios periodísticos.

\section{Referencias bibliográficas}

A Azurmendi-Adarraga (2007): La reforma de la televisión pública en España. Valencia: Tirant lo Blanch

F Campos-Freire (2012): "Los principales grupos mediáticos europeos amplían su interés por la RSC". Congreso de la Asociación Española de Comunicación. Recuperado de

http://www.aeic2012tarragona.org/comunicacions_cd/ok/238. $\operatorname{pdf}$

A Casero-Ripollés (2009): "El control político de la información periodística". RLCS, Revista Latina de Comunicación Social, 64, pp. 354-366. Recuperado de http://www.revistalatinacs.org/09/art/29_828_47_ULEPICC_ 08/Andreu_Casero.html DOI: 10.4185/RLCS-64-2009-828354-366 
M Cebrián-Herreros (2004): La información en televisión: obsesión mercantil y política. Barcelona: Gedisa.

JC De-Miguel \& V Pozas (2009): “¿Polarización ideológica o económica? Relaciones entre los medios y el poder político y corporativo". Viento Sur, 103, pp. 43-52.

D Domke \& DV Shah (1995): "Interpretation of issues and voter decision-making strategies: a new perspective on issue-oriented election coverage". Journalism and Mass Communication Quarterly (72) pp. 45-71.

AS Edelstein (1993): "Thinking about the criterion variable in agenda-setting research". Journal of communication, 43 (2), pp. 85 99. DOI: $10.1111 /$ j.1460-2466. 1993.tb01264.x

P Elliot (1981): “Organización de los medios y ocupaciones profesionales: visión panorámica”, en Curran, Gurevitch \& Woollacott, (eds.) Sociedad y comunicación de masas, México: Fondo de Cultura Económica.

J Fernández-Baena (2005): "Los informativos en televisión ¿debilidades o manipulación?”. Comunicar: Revista científica iberoamericana de comunicación y educación, 25 (2). Recuperado de https://dialnet.unirioja.es/servlet/articulo?codigo $=2927525$

T Fernández-Lombao \& F Campos-Freire (2013): “La

Responsabilidad Social Corporativa en las Radio-Televisiones Públicas de Europa". Cuadernos.info, 33, pp. 145-157.

Recuperado de http://www.cuadernos.info/index.php/CDI/article/view/cdi.3 3.530 DOI: $10.7764 /$ cdi.33.530

JA García-Avilés (2007): "El infoentretenimiento en los informativos líderes de audiencia en la Unión Europea”, Análisi, Cuaderns de Comunicació i Cultura, 35, pp. 47-63. Recuperado de http://www.raco.cat/index.php/Analisi/article/view/74254/9 $\underline{4423}$

A Gómez-Montano (2013): "Pluralismo y reconocimiento social de los nuevos informativos de RTVE (2006-2012)". Estudios del Mensaje Periodístico (19), pp. 233-242. Recuperado de https://revistas.ucm.es/index.php/ESMP/article/view/42029

ML Humanes (2001): "El encuadre mediático de la realidad social. Un análisis de los contenidos informativos en televisión", ZER. Revista de Estudios de Comunicación, 11 (6). Recuperado de 
http://www.ehu.eus/ojs/index.php/Zer/article/view/6072/57 $\underline{54}$

ML Humanes, MD Montero-Sánchez, R Molina-de-Dios \& A LópezBerini (2013): "Pluralismo y paralelismo político en la información televisiva en España". Revista Latina de Comunicación Social, 68. pp. 566-581.

Recuperado de

http://www.revistalatinacs.org/068/paper/990 Fuenlabrada/2 4 Humanes.html DOI: 10.4185/RLCS-2013-990

ML Humanes \& I Fernández-Alonso (2015): "Pluralismo informativo y medios públicos. La involución de TVE en el contexto del cambio político (2012-2013)". Revista Latina de Comunicación Social, 70, pp. 270 a 287. Recuperado de http://www.revistalatinacs.org/070/paper/1046fu/16es.html DOI: $10.4185 /$ RLCS-2015-1046

CI Hovland (1957): The order of presentation in persuasion. New Haven, Published for the Institute of Human Relations by Yale University Press.

PF Lazarsfeld, B Berelson, \& H Gaudet (1948): The people's choice: How the Voter Makes up His Mind in a Presidential Campaign. Nueva York: Columbia University Press.

T León-Gross (2006): “La agenda de los noticiarios", en Fernández Beamount \& Díaz Nosty (coords.) Tendencias'06. Medios de comunicación. El año de la televisión. Madrid: Fundación Telefónica, pp. 271-279.

C López-Olano (2016): "La pluralitat dels informatius en les televisions públiques i la responsabilitat social corporativa (RSC) amb atenció al cas de RTVV", Comunicació: Revista de

Recerca i d'Anàlisi [Societat Catalana de Comunicació], 33 (2), pp. 9-27. Recuperado de http://revistes.iec.cat/index.php/TC.

DOI: $10.2436 / 20.3008 .01 .146$

Manual de Estilo de RTVE. Enlace: http://manualdeestilo.rtve.es/

ME McCombs \& DL Shaw (1972): "The agenda-setting function of mass media". Public Opinion Quartely, 36 (2), pp. 176-187.

ME McCombs \& DL Shaw (1986): “¿Qué agenda cumple la prensa?”, en Garber (compiladora). El poder de los medios en la politica. Buenos Aires: GEL. 
ME McCombs (1992): "Explorers and survevoyrs: expanding strategies for agenda-setting research". Journalism \& Mass Communication Quarterly, 69 (4), pp. 813-824.

ME McCombs \& D Shaw (1993): "The evolution of agenda-setting research: twenty-five years in the marketplace of ideas". Journal of communication, 43 (2), pp. 58-67. DOI: 10.1111/j.14602466.1993.tb01262.x

MM Laverón \& TO Goñi (2009). "Valoración del servicio público de televisión. Comparación entre la BBC y TVE". Revista Latina de Comunicación Social, (64), 24. Recuperado de http://www.revistalatinacs.org/09/art/24_823_42_ULEPICC_ 11/Medina_y_Ojer.html

JL Manfredi-Sánchez (2009): “Indicadores de RSC en la empresa periodística”, Ámbitos, 18, pp. 138-148. Recuperado de http://www.redalyc.org/html/168/16812722009/

M Murciano (2004): "Poder económico e influencia social: los retos de la concentración mediática para la democracia”, Doxa, 2, pp. 41-51. Recuperado de http://dspace.ceu.es/bitstream/10637/5988/1/N\%C2\%BAII pp41 51.pdf

E Noelle-Neumann (1974): "The spiral of silence: a theory of public opinion". Journal of communications, 24 (2), pp. 43-51.

DOI: $10.1111 / j .1460-2466.1974 . t b 00367 . x$

L Núñez-Ladeveze, JA Irisarri \& B-SB Morales (2015): “The specific social responsibility of big television companies and risk contents". Communication \& Society, 28 (3) pp. 65-81. DOI: 10.15581/003.28.3.65-81

S Ortells-Badenes (2009): "La mercantilización de la información: la nueva era informativa en televisión". Revista Latina de Comunicación Social, 64, pp. 341-353. Recuperado de http://www.revistalatinacs.org/09/art/28 82746 ULEPICC 07/Sara Ortells.html DOI: 10.4185/RLCS-64-2009-827-341353

J Pestano-Rodríguez (2008): “Tendencias actuales en la estructura y contenidos de los informativos de televisión”, Revista Latina de Comunicación Social, 63, pp. 453-462. Recuperado de http://www.revistalatinacs.org/08/38 $79560 \mathrm{TV} / J o s e$ Pesta no Rodriguez.html DOI: 10.4185/RLCS-63-2008-795-453-462 
N Quintana-Paz (2005): "El telespectador, soberano o marioneta del devenir político". Comunicar. Revista Científica de Comunicación y Educación, 25 (13). Recuperado de https://www.revistacomunicar.com/index.php?contenido=deta les\&numero $=25$ \&articulo $=25-2005-046$

R Reig (2011): Los dueños del periodismo. Claves de la estructura mediática mundial y de España. Barcelona: Gedisa.

M Rodrigo-Alsina (1989): La construcción de la noticia. Barcelona: Paidós.

X Soengas (2008): El enfoque informativo. Los puntos de vista de una noticia en televisión. Madrid: Laberinto.

X Soengas-Pérez (2015): "El pluralismo y el control de la información en las televisiones generalistas españolas", Estudios sobre el Mensaje Periodístico (21), pp. 199-207.

X Soengas-Pérez \& AI Rodríguez-Vázquez (2015): “El control gubernamental de RTVE y el pluralismo en los informativos", Estudios sobre el Mensaje Periodístico, 2 (2), pp. 1225-1240. Poner 2015, no 2017

G Tuchman (1983): La producción de la noticia. Estudio sobre la construcción de la realidad. Barcelona: Gustavo Gili.

F Valbuena (2005): Teoría de la fijación de la agenda (Agenda-Setting). Madrid: Facultad de Ciencias de la Información. Universidad Complutense.

J Villafañe, E. Bustamante \& E. Prado (1987): Fabricar noticias. Las rutinas productivas en radio y televisión. Barcelona: Mitre.

R Zallo (2010): "La política de Comunicación Audiovisual del gobierno socialista (20042009): un giro neoliberal". Revista Latina de Comunicación Social, 65, pp. 14-29. Recuperado de http://www.revistalatinacs.org/10/art/880 UPV/02 Zallo.ht ml DOI: 10.4185/RLCS-65-2010-880-014-029

\section{Reconocimientos de la investigación}

Los resultados de esta investigación corresponden al proyecto de "Indicadores de gobernanza, financiación, rendición de cuentas, innovación, calidad y servicio público de las RTV europeas aplicables a España en el contexto digital" (Referencia CSO2015-66543-P) del Programa estatal de Fomento de la Investigación Científica y Técnica de Excelencia, subprograma estatal de 
Generación de Conocimiento del Ministerio de Economía y Competitividad de España, cofinanciado por el Fondo Europeo de Desarrollo Regional (FEDER) de la Unión Europea. Este proyecto se complementa con la actividad de la Red Internacional de Investigación de Gestión de la Comunicación (REDES 2016 G1641 XESCOM), apoyada por la Consellería de Cultura, Educación e Ordenación Universitaria de la Xunta de Galicia (referencia ED341D R2016/019). 


\title{
La innovación en la rendición de cuentas de los medios de comunicación de servicio público (PSM). El caso de la CCMA
}

\author{
Joaquín Marqués-Pascual \\ EAE Business School (UPC) \\ Joan-Francesc Fondevila-Gascón \\ Universitat Pompeu Fabra (UPF) \\ Juan Morillo Bentué \\ EAE Business School (UPC)
}

PARA CITAR: Marqués-Pascual, J., Fondevila-Gascón, J.F. y Morillo Bentué, J. (2018). La innovación en la rendición de cuentas de los medios de comunicación de servicio público (PSM). El caso de la CCMA. Revista Latina de Comunicación Social, 73, pp. 1090 a 1114.

http://www.revistalatinacs.org/073paper/1298/57es.html

DOI: $\underline{10.4185 / R L C S-2018-1298}$

\section{Resumen}

Se analiza la transparencia de los servicios públicos de radiotelevisión y en especial de los medios de comunicación de titularidad pública (PSM), en concreto los sistemas de gobernanza y Responsabilidad Corporativa de los medios audiovisuales públicos catalanes de la Corporació Catalana de Mitjans Audiovisuals (CCMA). Se procede a utilizar técnicas cuantitativas (extraídas de los informes periódicos que presentan los distintos responsables de la CCMA en sus comparecencias públicas) combinadas con cualitativas (una serie de entrevistas en profundidad personalizadas no estructuradas y grabadas). Se detallan los diversos instrumentos de rendición de cuentas, tanto internos como externos, explicando sus dinámicas internas y mecanismos de control. Sobre los instrumentos de rendición de cuentas analizados, válidos pero estancados desde hace una década, 
se especifican medidas de innovación ante la necesidad de implementar cambios en muchos de ellos.

Palabras clave: Innovación, Medios de comunicación, Rendición de cuentas, Servicio público audiovisual, Televisión, Transparencia.

\section{Introducción}

T A LUZ del sol es uno de los mejores desinfectantes ${ }^{25}$, escribió 1 Brandeis (1914: 92). Una metáfora para entender que su antónimo, la oscuridad, se perfila como una gran aliada de la corrupción.

En los tiempos actuales se acrecienta la crisis de legitimidad política y democrática de muchas instituciones públicas, incidiendo en las democracias europeas de manera acentuada (Gómez Urquijo, 2012). En ese contexto, desde hace algunos lustros se ha considerado imprescindible redefinir las políticas de gobernanza, apostando por principios como la transparencia, entendida como elemento de control público, en su doble vertiente de gobierno y gobernantes (Schauer, 2014). Aquí debe entenderse como un proceso de doble vía en el cual los gobernantes tienen la obligación de informar y responder por su gestión, y la ciudadanía tiene el derecho a ser informada y exigir explicaciones sobre las acciones llevadas a cabo por los primeros (Porras, 2007). Es un proceso de diálogo bilateral y directo, sin necesidad explícita de participación de los medios de comunicación. En función de la constancia, profundidad e interacción que se genere mayor será el nivel de transparencia (López, Puentes, Rúas, 2017).

Asimismo, es necesario que la cultura de la transparencia impregne el quehacer de los servidores públicos, potenciando su integridad y ética públicas (Muñoz y Azurmendi, 2016). En previsión que no siempre su comportamiento será del todo correcto, la política de transparencia contempla la necesidad que existan unos elementos rendición de cuentas que obliguen a estos colectivos a explicar de la manera más abierta y detallada posible sus actuaciones.

\footnotetext{
${ }^{25}$ La sentencia completa de Louis D. Brandeis, en su libro Other people's money and how the bankers Use It, fue: "La publicidad es justamente recomendada como un remedio para enfermedades sociales e industriales. Se dice que la luz del sol es uno de los mejores desinfectantes; la luz eléctrica, el policía más eficiente".
} 
La rendición de cuentas (RC) de las instituciones públicas en España, uno de los elementos centrales de la transparencia, ha sido potenciada a raíz de la publicación de la ley de Transparencia (Ley 19/2013, de 9 de diciembre, de transparencia, acceso a la información pública y buen gobierno), consecuencia del mandato contenido en el art. 105 b. de la Constitución española de 1978, y de la legislación comunitaria. Para mayor abunde del tema regulatorio europeo consultar Campos-Freire y Valencia-Bermudez (2017: 109-110). La transparencia y la rendición de cuentas son elementos centrales del servicio público. Mediante este tipo de controles se pretende que los ciudadanos confíen en las políticas públicas que se implementan (Bovens, 2004).

En el plano académico se entiende por rendición de cuentas "el requerimiento para que los representantes respondan frente a los representados sobre el uso de sus poderes y responsabilidades, actúen como respuesta a los requerimientos que les son señalados y acepten la responsabilidad en casos de errores, incompetencia o engaño, es decir, que actúen con un amplio sentido ético" (Martín Delgado, 2017). Considerada por algunos autores (Bovens, 2004; Day \& Klein, 1987) como el sello distintivo de la gobernanza democrática moderna, la RC se emplea en el discurso mediático para referirse al proceso por el cual las organizaciones están obligadas -o deberían estarlo- a rendir cuentas a sus grupos de interés (Pritchard, 2000).

Utilizada como sinónimo de algunas aspiraciones políticas conceptualmente difusas como transparencia, democracia, eficiencia e integridad (Dubnick, 2005), la RC puede ser entendida como un mecanismo de medición de la calidad de la gestión (Miguel de Bustos, 2013, 2012, 2005).

El presente estudio, que se insume en el subprograma estatal de generación de conocimiento del Ministerio de Economía y Competitividad de España, sobre "Indicadores de gobernanza, financiación, rendición de cuentas, innovación, calidad y servicio público de las RTV europeas aplicables a España en el contexto digital", se centra en algunos de los elementos que potencian el sistema democrático, poniendo el foco de manera especial en la transparencia de los servicios públicos de radiotelevisión y en especial de los medios de comunicación de titularidad pública (PSM por su acrónimo en inglés Public Service Media) y en la rendición de cuentas (media accountability). 
Las consecuencias de no aceptar poner en marcha este tipo de medidas se visualizan a través de una creciente desafección de la ciudadanía frente a sus gobernantes (Alfaro y Gómez, 2016).

Los medios de comunicación han desarrollado a lo largo del tiempo diversos instrumentos para rendir cuentas a los ciudadanos sobre la acción que desarrollan especialmente los medios públicos (RodríguezMartínez et altri, 2017: 256). En los últimos años se han prodigado algunas opciones en línea, aspecto que conlleva la posibilidad de interacción más dinámica con los diferentes tipos de públicos: strictu sensu con las audiencias, pero también con la ciudadanía en general (Suárez-Villegas y Cruz-Álvarez, 2016).

El objetivo de esta investigación se focaliza en la profundización sobre los sistemas de gobernanza y RC de los medios audiovisuales públicos catalanes de la Corporació Catalana de Mitjans Audiovisuals (CCMA), organismo público dependiente del Gobierno regional catalán (España). En concreto se analiza la existencia de herramientas de rendición de cuentas tanto desde un plano meramente interno, así como de manera externa. La finalidad del estudio se centra en conocer, de manera pormenorizada, el nivel de utilización que hace la CCMA de este tipo de instrumentos de rendición de cuentas, así como en el nivel de innovación que se haya podido introducir en los últimos años. "Este elemento transformador, en el caso de los medios públicos, debe estar estrechamente ligado a la salvaguarda de los valores de la democracia, libertad, independencia editorial, atención a las minorías y formación de la opinión pública" (Campos-Freire y Valencia-Bermudez, 2017: 112).

De todos modos, se debe apuntar que la transparencia no es un fin en sí mismo "sino un instrumento al servicio de la participación y del control de la ciudadanía sobre los asuntos públicos, y, al mismo tiempo, un mecanismo de prevención de la corrupción" (Colón de Carvajal, 2016: 15). Es un sistema que pretende generar confianza sobre las instituciones públicas en la sociedad (Bovens 2005) pero cuya su finalidad no es perpetuarse. En este sentido, "si consideráramos de forma permanente y sostenida a la transparencia como un objetivo concreto a alcanzar, correríamos el riego de convertirla en un arma arrojadiza en beneficio de intereses desconocidos ajenos a la colectividad” (Martín Delgado, 2017: 170). 
Del mismo modo lo plantean otros autores como Pérez Cisneros (2015) o la misma Oficina Antifraude de Cataluña, organismo público especializado en vigilar la integridad de las administraciones públicas catalanas y luchar contra la corrupción, que en un informe de $2015^{26}$ enumeró algunos de los principios de deben regir los sistemas de transparencia estableciendo una serie de recomendaciones para su regulación.

La CCMA (inicialmente denominada Corporació Catalana de Ràdio i Televisió) se creó mediante una ley del Parlamento catalán, en mayo de 1983 (Ley 10/1983, de 30 de mayo, de creación del ente público Corporació Catalana de Ràdio i Televisió). El organismo fue modificado en 2007 para adaptarse al nuevo entorno sociocultural digital mediante la Ley 11/2007, de 11 de octubre, revisada en 2012 y vigente en la actualidad. El cambio normativo comportó une redefinición de la función y obligación de su servicio público que define en el art. 2: "El servicio público de comunicación audiovisual de la Generalidad consiste en [...] satisfacer las necesidades democráticas, sociales y culturales de los ciudadanos, a garantizar un acceso universal a la información, la cultura y la educación, a difundir y promocionar la lengua catalana y a ofrecer un entretenimiento de calidad".

La CCMA en tanto que PSM con estructuras multiplataforma y multimedios, debe ser un claro exponente social, y como actor público que es y referente de su mercado territorial, han de saber adaptarse a las nuevas demandas sociales. En este sentido, la innovación sigue siendo la mejor opción para preservar su misión (Fernández-Lombao, Valencia Bermúdez y Campos-Freire. 2016: 490).

Tras más de siete lustros de existencia, la CCMA tiene a gala destacar que su misión de servicio público ${ }^{27}$ le lleva a trabajar para ser un modelo de referencia, tanto en calidad como en innovación, de todo el sector

\footnotetext{
${ }^{26}$ Informe de seguimiento de los trabajos de la Comisión de Investigación sobre el Fraude y la Evasión Fiscales y las Prácticas de Corrupción Política (CIFEF), elaborado por la Oficina Antifraude, en fecha 10 de julio de 2015. Se puede encontrar en su web. https://www.antifrau.cat/images/web/docs/publicacions/estudis integricat/2 0150710 informe cifef.pdf

${ }^{27}$ http://www.ccma.cat/corporatiu/es/missio-i-principis/
} 
audiovisual europeo. Junto a ello, destacan el resto de valores por los que apuesta:

- Compromiso con el país que se materializa a través de la promoción de la cultura y de la lengua catalanas, su identidad, así como la proyección internacional de Cataluña.

- Eficiencia en la gestión, función que se compagina con la búsqueda de la máxima aceptación de las diferentes programaciones de sus canales por parte de las audiencias.

- Y transparencia, como consecuencia de la apuesta por los principios éticos y democráticos.

La CCMA está considerada por la ciudadanía catalana una de las instituciones neuronales en la recuperación del autogobierno, así como de la cultura autóctona. Durante décadas ha sido un instrumento central en la divulgación del idioma catalán en el territorio. Tiene, además, encomendada por ley "la difusión de los valores democráticos, cívicos y éticos, y también los derechos humanos" (preámbulo de la ley).

Con datos de 2017, la CCMA es un ente público constituido por una amalgama de medios que se dividen en tres grandes áreas: la televisión (con siete canales), la radio (cuatro canales) y los medios digitales, aunque hoy en día las fronteras entre ellos no están tan claramente delimitadas como antaño (Cebrián-Herreros, 2009). Como consecuencia de los nuevos procesos de digitalización, los medios cada vez son más híbridos (Broullón-Lozano y Alonso-Jiménez, 2016) desarrollándose sinergias transversales entre ellos (Direito-Rebollal, Lago-Vázquez y Rodríguez-Vázquez, 2017). LA CCMA es, de iure, una corporación pública que también actúa como accionista de empresas privadas, no quedando clara la frontera entre el derecho público y el privado.

El máximo órgano de dirección de la CCMA inicialmente fue un consejo de administración, pero con la reforma de la ley de la CCMA y la vigencia de la Ley 11/2007, en época del gobierno tripartito del presidente Maragall, este organismo trastocó en consell de govern (consejo de gobierno) siendo sus miembros elegidos por el Parlament de Catalunya mediante un sistema de votación que demandaba una 
mayoría cualificada y la elección del presidente de la CCMA de manera singular. Este sistema fue cambiado por una reforma legislativa de la ley realizada en 2012, estando al frente del gobierno catalán Artur Mas (Convergencia i Unió), donde, entre otros cambios, se redujo el sistema de elección de los miembros del consejo necesitando solamente la mayoría absoluta de cámara legislativa.

Con esta contrarreforma, como es etiquetada por el presidente del Sindicat de Periodistes de Catalunya/Sindicat de Professionals de la Comunicació, Francesc Ràfols, se trastocó el espíritu con el que fue creada la ley 11/2007. Para Albert Sáez, que fue el primer presidente de la CCMA (2008-2010) en ser elegido de manera directa y singular por el Parlament de Catalunya como máximo responsable de la corporación (118 votos favorables de 135 posibles y ninguno en contra), esa ley instauró un nuevo sistema de gobernanza en la corporación, donde el Parlament adquiría mucho protagonismo. Para Ramon Espuny, que fue presidente del Sindicat de Periodistes y miembro del comité de empresa de TVC, una de las entidades que se integran en la CCMA y responsable de la gestión de los canales de televisión, con esa nueva normativa "el Parlament se convirtió en la patronal de la corporación".

La CMMA se financia principalmente a cargo del presupuesto general de la Generalitat, a través de aportaciones y créditos. De manera secundaria obtiene ingresos publicitarios y rendimientos de la explotación de sus actividades y contenidos. En los últimos ejercicios el déficit ha sido una constante en sus cuentas de resultados que han tenido que ser cubiertas por el erario público.

Existen diversas clasificaciones en torno a la tipología de mecanismos que posibilitan la media accountability. Diversos autores han profundizado en el tema a lo largo del tiempo. Aquí referimos los más recientes $y$, a la vez útiles para los planteamientos de nuestra investigación, desde Shoemaker y Reese (1996), pasando por RussMohl (2003) y Fengler (2008), aunque el que más interés suscita sobre la rendición de cuentas y transparencia de los medios de comunicación en toda Europa es el de Bichler et altri, (2012).

A continuación, se presenta un desarrollo de los diferentes instrumentos de rendición de cuentas, generado por el Grupo de 
Investigación en Periodismo (GRP) de la Universidad Pompeu Fabra, ordenados en dos ejes: en las abscisas (instrumentos externos - a la izquierda - e internos a la derecha); y en el eje de coordenadas (mayor grado de institucionalización - parte superior - instrumentos no institucionalizados - parte inferior). El valor de esta organización de instrumentos estriba en la triple configuración de marcos (sociopolítico / corporativo-profesional / empresarial).

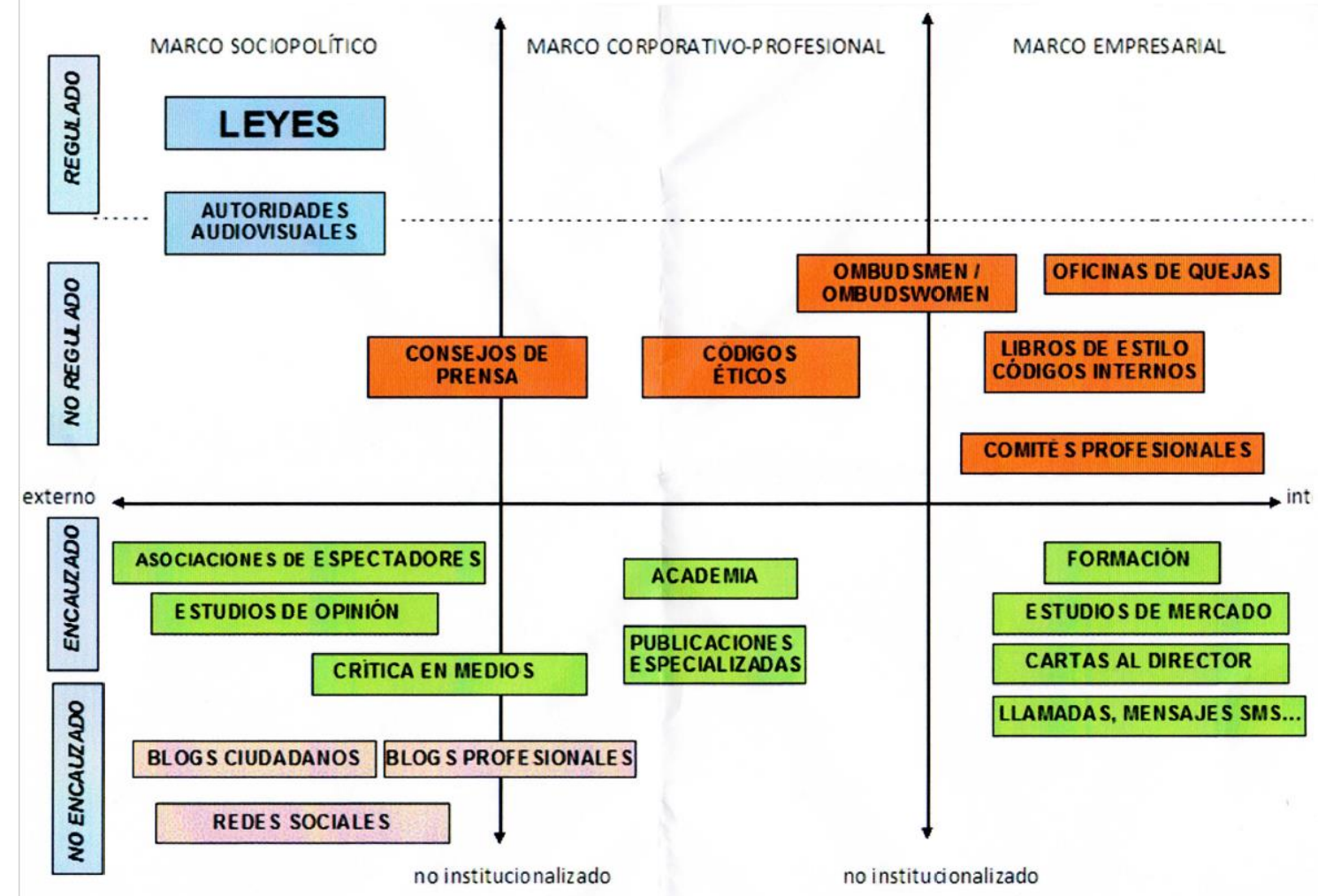

Ilustración $\mathrm{n}^{\mathrm{o}}$ 1. Fuente: Grupo de Investigación en Periodismo (GRP por su acrónimo en catalán) de la UPF.

\section{Metodología}

La metodología utilizada en este trabajo apuesta por una técnica mixta, empleando una combinación de técnicas cualitativas y de recopilación de datos en un contexto descriptivo de la situación de la CCMA. Se decidió elegir esta técnica mixta porque proporciona una mayor comprensión de la realidad analizada (Molina et al., 2012). Además, de manera previa se procedió a una revisión de la literatura aplicada sobre el caso práctico objeto de la investigación.

A partir de las diversas clasificaciones apuntadas más arriba, se realizó una enumeración de los instrumentos de RC existentes: desde los más 
tradicionales (como la atención telefónica a la audiencia), hasta los más innovadores (fundamentalmente basados en redes sociales). Desde la autorregulación más pura, hasta los controles más formales y reglados.

En concreto, se ha establecido un listado de mecanismos de rendición de cuentas que se aporta como apéndice 1 (ver al final del documento) a partir del modelo de indicadores propuesto por López, Puentes y Rúas (2017) concentrado en torno a tres bloques: información institucional, de ámbito económico y los referidos a la propia producción de información. A partir de esa lista la investigación se plantea las preguntas: (Q1) ¿qué mecanismos de los citados utiliza la CCMA? para posteriormente analizar $(\mathrm{Q} 2)$ ¿cómo lo usa?

Para dar respuesta a las cuestiones esbozadas se eligió una metodología cualitativa que provea de datos descriptivos de la situación real, siguiendo los planteamientos de Taylor y Bogdan (1986) mediante entrevistas en profundidad a expertos del sector y a responsables de la institución.

Se han realizado una serie de entrevistas en profundidad personalizadas no estructuradas y grabadas, siguiendo el modelo de conversación abierta, pero reconduciéndolas, cuando es necesario, hacia los escenarios y temas centrales. Se han introducido también algunas preguntas de contraste con la pretensión de conocer los significados que los entrevistados asignan a determinados conceptos y encontrar sus nexos y divergencias. Habitualmente este tipo de entrevistas permiten definir los constructos mentales de las personas entrevistadas que proporciona un imaginario de sus opiniones y de la firmeza de estas.

En concreto se ha entrevistado a:

\begin{tabular}{|l|l|l|}
\hline 1 & $\begin{array}{l}\text { Salvador Alsius i } \\
\text { Clavera }\end{array}$ & $\begin{array}{l}\text { Vicepresidente de Consell de } \\
\text { l'Audiovisual de Catalunya (CAC) y } \\
\text { profesor de la UPF. }\end{array}$ \\
\hline 2 & Laura Baladas Ortíz & $\begin{array}{l}\text { Defensora de la Audiencia de la } \\
\text { CCMA. A cargo también de las } \\
\text { actividades relacionadas con la RSC. }\end{array}$ \\
\hline 3 & $\begin{array}{l}\text { Eduard Boet i } \\
\text { Domènech }\end{array}$ & $\begin{array}{l}\text { Responsable de proyectos estratégicos } \\
\text { corporativos de la CCMA. }\end{array}$ \\
\hline
\end{tabular}




\begin{tabular}{|c|c|c|}
\hline & & $\begin{array}{l}\text { Coordinador de la comisión de } \\
\text { seguimiento del Libro de estilo. }\end{array}$ \\
\hline 4 & Ramon Espuny Solé & $\begin{array}{l}\text { Expresidente del Sindicat de } \\
\text { Periodistes de Catalunya, y miembro } \\
\text { del comité de empresa de TVC }\end{array}$ \\
\hline 5 & $\begin{array}{l}\text { Esperanza García } \\
\text { González }\end{array}$ & $\begin{array}{l}\text { Diputada del Partido Popular en el } \\
\text { Parlament de Catalunya (XI Legislación } \\
\text { 2017-2017). Miembro de la Comisión } \\
\text { de control de la CCMA. }\end{array}$ \\
\hline 6 & Albert Garrido Llort & $\begin{array}{l}\text { Secretario general del Consell de la } \\
\text { Informació de Catalunya (CIC), } \\
\text { fundación creada por del Col·legi de } \\
\text { Periodistes de Catalunya. }\end{array}$ \\
\hline 7 & $\begin{array}{l}\text { Josep María Guerra } \\
\text { Mercadal }\end{array}$ & $\begin{array}{l}\text { Presidente de TAC, Asociación de } \\
\text { Consumidores } \text { de Medios } \\
\text { Audiovisuales de Cataluña. }\end{array}$ \\
\hline 8 & Dav & $\begin{array}{l}\text { Diputado y presidente de la Comisión } \\
\text { de control de la CCMA en el Parlament } \\
\text { de Catalunya (2015-2017). }\end{array}$ \\
\hline 9 & Mar Pons Púbul & $\begin{array}{l}\text { Miembro del consejo asesor de } \\
\text { contenidos y de programación de la } \\
\text { CCMA. }\end{array}$ \\
\hline 10 & $\begin{array}{l}\text { Francesc Ràfols } \\
\text { Sagués }\end{array}$ & $\begin{array}{l}\text { Presidente del Sindicat de Periodistes } \\
\text { de Catalunya/Sindicat de Professionals } \\
\text { de la Comunicació }\end{array}$ \\
\hline 11 & Albert Sáez I Casas & $\begin{array}{l}\text { Presidente de la CCMA durante el } \\
\text { período } 2008-2010 \text {, elegido por el } 87 \% \\
\text { de la cámara parlamentaria. }\end{array}$ \\
\hline 12 & $\begin{array}{l}\text { Josep Vicent Sanchís } \\
\text { i Llàcer }\end{array}$ & $\begin{array}{l}\text { Director de Televisió de Catalunya } \\
\text { (incorpora los siete canales de la } \\
\text { CCMA). }\end{array}$ \\
\hline
\end{tabular}

Las entrevistas se realizaron con diversos profesionales y políticos, muy relacionados con diferentes aspectos de la investigación. En especial se ha pretendido conocer, a través de cada uno de ellos, algún instrumento de rendición de cuentas. 
Se han utilizado técnicas cuantitativas en relación con la recopilación de algunos datos. En concreto, se ha aplicado fundamentalmente sobre los informes periódicos que presentan los distintos responsables de la CCMA en sus comparecencias públicas (memorias de actividades, cuentas de resultados, etc.).

\section{Discusión y resultados}

Después de un análisis de todos los instrumentos de RC existentes podemos concluir que la CCMA tiene implementados los siguientes mecanismos:

- Comité de empresa

- Comité profesional

- Consejo asesor de contenidos y de programación

- Informes anuales:

- Memoria anual de actividades

- Cuenta de resultados anual

- Libro de estilo

○ Comisión de seguimiento del Libro de estilo

- Oficina del Defensor de la Audiencia

- Memoria anual de la Defensora de la Audiencia

Desde el ámbito externo a la CCMA, ésta es evaluada de manera periódica por:

- Asociaciones de consumidores y usuarios, siendo TAC (Telespectadors Associats de Catalunya), la única entidad específica de este tipo que existe en la comunidad catalana.

- Consell Audiovisual de Catalunya (CAC).

- Consell de la Informació de Catalunya (CIC), organismo externo vinculado al Col·legi de Periodistes de Catalunya.

- Parlament de Catalunya, a través de una comisión de control de la CCMA donde se integran todos los grupos de la cámara (con periodicidad mensual durante los períodos lectivos).

Para el director general de Televisió de Catalunya, Vicent Sanchis, uno de los máximos responsables de la corporación catalana, "los instrumentos que tiene la CCMA no es que sean excesivos, es que son una barbaridad [...] dedicamos demasiadas personas (dinero público) para cumplir con todos los compromisos de rendición de cuentas". 
Abunda en su reflexión indicando que "si tanto mecanismo consiguiera convencer a la gente que realizamos una tarea impoluta estaría bien, pero eso no es así [...] aunque tenemos mucha gente en la casa centrando su esfuerzo en ellos, para demostrar que el funcionamiento es el correcto [...] tienen poco efecto en la ciudadanía".

Sáez es de la opinión que "para la dinámica de la corporación los sistemas de rendición de cuentas eran muy complicado porque los máximos ejecutivos de la empresa debían rendir cuentas en el comité de dirección, en el consejo de gobierno y en el parlamento. Había semanas que solamente se dedicaban a rendir cuentas. El sistema, tal como se realizaba no era eficiente. Ahora con la reforma, con un presidente-director general, con competencias del consejo de gobierno y de los directores generales, esta parte se ha simplificado".

A continuación, se detalla cada uno de los organismos o instrumentos de rendición de cuentas que se han analizado.

\section{Comités de trabajadores (de empresa y profesionales)}

Una de las primeras instancias donde casi todas las entidades, tanto en el sector público como en el privado, se ven impelidas a proporcionar información es en el ámbito interno. Suelen son los empleados los que, a través de sus organizaciones sindicales, o mediante el asociacionismo interno, establecen líneas de diálogo con la dirección. La figura del comité de empresa está reconocida como un derecho derivado del mandato constitucional del art. 28. La libertad y actividad sindical en los centros de trabajo ha sido ampliamente defendida por el Tribunal Constitucional a través de múltiples sentencias (Monereo y Fernández Avilés, 2008).

La figura del comité de empresa en relación con la CCMA debe conjugarse en plural ya que existe uno para el ámbito televisivo y otro para el radiofónico, amén del comité de las oficinas centrales, producto todos ellos de la herencia del pasado (distintos convenios colectivos y diferencias salariales) lo cual no ha imposibilitado la existencia de una línea de unidad que se plasma a través de una especie de comité interempresas, más de facto que de iure, y acciones conjuntas cuando es preciso. De todas maneras, desde el ámbito sindical se trabaja para la creación de un único convenio de grupo. 
Los diferentes comités de empresa integran a los profesionales de los diversos centros de trabajo y empresas, ya definidas anteriormente, que componen la estructura de la corporación. Su composición está repartida entre diferentes sindicatos siendo CCOO y el CTTVC los más importantes. Hablaremos en singular (comité de empresa) excepto cuando se trate de algún caso, exclusivo de un tipo de medio.

La interlocución del comité de empresa con el staff directivo se focaliza en la defensa de los puestos de trabajo, así como en la mejora de las condiciones. En la actual etapa, con el vigente equipo de gobierno de la corporación (no en todos los casos ya que hay consejeros con el mandato agotado) se ha visualizado un enfrentamiento entre el comité de empresa y el consejo hasta el punto que los primeros han exigido la dimisión de los segundos ${ }^{28}$. Para Espuny, que lleva 28 años siendo miembro del comité de empresa, la interlocución con la dirección es "todo lo fluida que puede ser una interrelación entre dos fuerzas con intereses opuestos donde la otra parte no te aporta nunca todos los datos ni da explicaciones detalladas".

La elección de los miembros del consejo de administración de la CCMA es competencia directa del Parlament de Catalunya que nombra los consejos en función de criterios políticos y no atendiendo a los méritos profesionales como debería de ser. Ello implica una subordinación de los elegidos a las directrices de los partidos y no en función de las necesidades de los medios de comunicación. Esa práctica, que lleva desarrollándose desde hace muchos años, concita un punto de discrepancia importante con los representantes de los trabajadores que vienen demandando una reforma de la Ley de la CCMA para cambiar la situación. "Hay que despolitizar la corporación, desgubernamentalizarla y despartidizarla a partir de mayorías parlamentarias cualificadas que garanticen la elección de cargos con criterios de independencia y profesionalidad", apunta Ràfols. Esa apuesta significa que los miembros del consejo de gobierno de la CCMA “dejen de depender de los gobiernos de turno que la utilizan para sus intereses particulares [...] Debería estar formado por expertos independientes que dirijan con profesionalidad y conocimiento para que los medios de comunicación públicos estén realmente al servicio

\footnotetext{
${ }^{28}$ https://www.elperiodico.com/es/tele/20160623/trabajadores-catalunya$\underline{\text { radio-piden-dimision-staff-ccma-5225067 }}$
} 
de la ciudadanía en su conjunto". Pero para Sanchis eso no asegura que los expertos no sean también correa de transmisión de los partidos. "El problema no es la regulación sino el comportamiento de las personas elegidas [...] El sistema que tenemos es perfecto. La reforma de la ley permite que ls miembros del consell de govern de la CCMA tengan independencia ya que son nombrados por seis años. Pero los elegidos son los que optan entre la independencia o la obediencia debida a los que les nombraron".

Por su parte Espuny, que es crítico desde hace años con la neutralidad de TV3 y la influencia que han ejercido los diferentes gobiernos de la Generalitat desde su creación, señala que "la etapa de mayor independencia del consejo la cifraría entre 2007 y 2012" que coincide con los mandatos en la presidencia de Albert Sáez y de Enric Marín y el nuevo sistema de gobernanza del ente. Sin embargo, el período no estuvo exento de problemas. Relata Sáez sus desacuerdos con el Parlament y la comisión de control: “Algunos pensábamos que debido al nuevo sistema de gobernanza donde el Parlament había adquirido mucho protagonismo en el nombramiento de la cúpula de la CCMA, debería haber generado un cambio en la comisión de control con un nuevo sistema de funcionamiento. Pero nos encontramos con que los usos y costumbres de la cámara parlamentaria están muy reglados y los diputados consideran que nadie les ha de decir lo que deben hacer. Seguramente es así. [...] Nos encontramos con una nueva forma de gobernanza en la CCMA que cuando iba a rendir cuentas al Parlamento era tratada como anteriormente [...] Realmente aprobaron un sistema de gobernanza que no se creían".

La forma en que se gobierna la corporación no es aceptada de buen grado por muchas instancias. El comité de empresa de este ente público se ha mostrado partidario en algunas ocasiones de estudiar la conveniencia de instaurar un sistema de cogestión, siguiendo el modelo alemán (Pérez-Latre y Sánchez-Tabernero, 2016). La posibilidad de su aplicación al caso de la CCMA incorporaría elementos innovadores de importancia. Sin embargo, como indica Espuny, "la propuesta que surgió en el seno de la CCMA por parte de algunos colectivos de empleados, se debía materializar en que los trabajadores obtuviesen dos puestos de representación en un remodelado consell de govern que tendría nueve sillas [actualmente son seis los consejeros]. Esa propuesta, que 
no se ha evolucionado, tampoco supone una cogestión real ya que para ello los trabajadores deberíamos disponer de la mitad de los puestos en el consejo".

Una propuesta adecuada de elección de la presidencia de la corporación catalana en tanto que también ostenta la dirección general del ente, apunta Ràfols, podría asemejarse al concurso público de méritos, en línea con lo que se hace en la BBC. "Este sistema de elección del máximo ejecutivo se complementa con que los miembros del comité de selección no sean estrictamente políticos, sino que se incorporen también representantes de la sociedad civil, del mundo académico, cultural, de los trabajadores, etc. En suma, que contara con un gran pluralismo social", sugiere Ràfols. Pero para Sanchis "no nos hemos de fijar tanto en lo que hace la BBC. Es verdad que tenemos la obligación de intentar ser mejores, pero nuestra sociedad no es la británica. Somos catalanes y no británicos. Aquí tenemos una forma de hacer y actuar diferente. Hay cosas que pueden servirnos y otras que no, debido a ese diferente comportamiento social". Para Sáez, "los sistemas de rendición de cuentas son muy propios de la cultura anglosajona. Y nos falla la mayor. Podemos tener un instrumento y utilizarlo de 50 maneras diferentes. También pasa con el sistema de gobernanza. Somos muy aficionados a comprar las instituciones, pero no comprar la cultura que va con ella. Me dijeron, esto será como la BBC. No. No porque no somos como Gran Bretaña”.

En relación con el comité profesional, es una representación de los trabajadores que dispone de una capacidad de diálogo con la dirección de cada medio, tratando sobre determinadas cuestiones relacionadas exclusivamente con temas que inciden en la tarea de informativos. En caso que implica muchos esfuerzos por ser recurrente es la problemática de los bloques informativos en los medios de comunicación de titularidad pública durante los períodos electorales que limitan la autonomía de los profesionales (Marqués et altri, 2016). En ese sentido, el comité profesional ha luchado de manera reiterativa para la no aplicación de los criterios de la Junta electoral obteniendo, en los últimos años, algunas victorias ya que, gracias a diversos acuerdos con el consell de govern, no se han aplicado las restricciones informativas durante los períodos electorales. 


\section{Consejo asesor de contenidos y de programación}

Es un órgano consultivo que asiste el consejo de administración (conocido desde 2007 como consell de govern) en la definición y evaluación de las políticas y las estrategias de programación de los diversos medios y servicios de la CCMA. Lo integran dieciséis miembros que son elegidos por el Parlament entre personas de reconocido prestigio, que representan la pluralidad de la sociedad catalana. Como mínimo, deben estar representados los sectores profesionales, educativos, las asociaciones cívicas, culturales y de usuarios, y los trabajadores de la CCMA. "Es más un órgano de expresión. Los responsables de la CCMA que asisten a sus reuniones no tienen la obligación de rendir cuentas de manera expresa", indica Sáez.

Su mandato es de cuatro años. A inicios de 2018 estaba vencido, pero no había sido renovado por lo cual sus miembros desarrollan su labor en funciones a la espera que se estabilice la situación política de la comunidad, en la actualidad suspendida e intervenida por mor del art. 155 de la Constitución española, a la espera de la formación de un nuevo gobierno.

Su principal cometido se centra en la realización de dos informes semestrales que se remiten a la superioridad, sobre la programación emitida por los diferentes canales (radio, televisión, webs, y redes sociales) donde los consejeros aportan ideas de mejora. La importancia de su cometido es muy relativa ya que, según explica una de sus miembros, Mar Pons, elegida en representación de TAC, "tengo la impresión que la repercusión de nuestra labor es escasa. Es verdad que en ocasiones se tienen en cuenta ya que con posterioridad vemos que algunas de las indicaciones aportadas se han implementado. Sin embargo, en reuniones con algunos directivos lo normal es que justifiquen la no implementación de las mejoras propuestas por falta de presupuesto".

$\mathrm{Al}$ ser un consejo muy extenso compuesto por personas con sensibilidades muy diversas, "cada uno de nosotros se centra en alguna temática concreta sobre la que propone los cambios. En mi caso, vigilo la programación televisiva infantil y juvenil, también en web y redes, proponiendo modificaciones y filtros cuando las situaciones lo exigen". 


\section{CAC (Consell de l'Audiovisual de Catalunya)}

EL CAC es el organismo público catalán encargado de velar por el cumplimiento de la normativa reguladora en el sector audiovisual y, en particular, por el pluralismo político, social, religioso, cultural y de pensamiento en los medios.

El último de los informes emitidos corresponde a un mandato del Parlamento catalán sobre el nivel de pluralidad de las tertulias televisivas donde, entre los ocho canales analizados y 125 tertulias, había dos de la CCMA (TV3 y 3/24 con 44 programas). Durante los meses en los que se ha realizado la presente investigación, el CAC han emitido otros informes donde la CCMA era sujeto colectivo. Así el informe sobre el tratamiento informativo de la jornada del 1-O en diversas cadenas de televisión de España ${ }^{29}$.

En concreto, y exclusivamente sobre la CCMA el CAC en su función de garante del cumplimiento de la misión de servicio público, ha solicitado en diferentes ocasiones informes y comparecencias de los diferentes órganos de la CCMA ante algunos hechos concretos que o bien han sido denunciados, o inicialmente han sido considerados irregulares.

A modo de ejemplo, el último caso analizado ${ }^{30}$ por el CAC sobre la programación de la CCMA se refiere a la información sobre el primero de octubre de 2017 (1-O) proporcionada por un telenoticias infantil: InfoK, del canal Super3, el día siguiente, donde no se encontraron infracciones al libro de estilo. En la misma línea, el acuerdo sobre la petición de sanción por presunto incumplimiento de determinados preceptos del Libro de estilo de la CCMA por parte de la conductora del programa "El Matí de Catalunya Ràdio", Mònica Terribes ${ }^{31}$. En

\footnotetext{
${ }^{29}$ Acuerdo 96/2017 de 18 de octubre, del Pleno del Consell de l'Audiovisual de Catalunya.

30 Acuerdo 108/2017, de 29 de noviembre, del Pleno del Consell de l'Audiovisual de Catalunya.

${ }^{31}$ Acuerdo 97/2017 de 18 de octubre, del Pleno del Consell de l'Audiovisual de Catalunya.
} 
otras ocasiones el CAC sí que ha actuado en contra de ciertas noticias o programas emitidos por la $\mathrm{CCMA}^{32}$.

En relación a la función de vigilancia que ejerce el CAC sobre la CCMA, su vicepresidente, Salvador Alsius, considera que "los instrumentos de rendición de cuentas son un todo. No se puede considerar uno a uno. Su mayor o menor eficacia deviene de la combinación de diferentes instrumentos. Es un engranaje donde todas las piezas deben existir para funcionar correctamente".

Además, para que la RC funcione de manera engrasada, es necesario, en opinión de Alsius, que "la ciudadanía esté preparada para exigir esta rendición de cuentas. Y la sociedad actual no lo está. Por eso es necesario exigir previamente una formación mediática a la ciudadanía que le aporte criterio crítico, que sepa valorar la información de calidad y la importancia de ésta para la vida democrática". Frente a esta reflexión, surge la pregunta ¿Por qué la CCMA ha de aportar más transparencia, crear más instrumentos de rendición de cuentas y de más calidad o ser más exhaustiva, si la ciudadanía no está preparada ni lo reclama? Para Alsius es una obligación: "desde la empresa pública hemos de ser conscientes que tenemos una responsabilidad social corporativa y, aunque no exista la demanda, la hemos de suscitar".

Sobre el nivel de pluralidad que tienen los contenidos de la programación en los canales de la CCMA, Alsius es taxativo: "inicialmente se hizo un gran esfuerzo para llegar a toda la audiencia. Después lo han hecho muy mal. Un grupo reducido ha creado una muralla absoluta autolimitando la audiencia, haciendo una televisión que, aunque es plural en algunos aspectos, no lo suficiente en otros. Mucha gente no se la siente suya ni la sentirá jamás". Un problema de muy difícil solución. ¿Tiene arreglo? "Podríamos tener algún indicio de que algo se puede recuperar ampliando la audiencia con contenidos de ocio. Al inicio de las emisiones de TV3 se amplió la audiencia gracias a los partidos del FC Barcelona y a la serie Dallas. Fueron los grandes triunfos que hicieron llegar esta televisión a muchos hogares".

${ }^{32}$ Acuerdo 48/2014 de 9 de abril, del Pleno del Consell de l'Audiovisual de Catalunya. 


\section{Consell de la Informació de Catalunya (CIC)}

Es un organismo externo, encuadro en los consejos de prensa (ver ilustración no 1), que fue creado, en 1997, por el Col·legi de Periodistes de Catalunya (CPC), transformándose en fundación sin ánimo de lucro en 1999, por tanto, con personalidad jurídica propia. Su objetivo se centra en velar por el cumplimiento de los principios de ética profesional periodística contenidos en el código deontológico de la profesión, desarrollado en su día en el seno de este colegio profesional.

Su función principal es arbitrar entre los ciudadanos y sus diversas representaciones, con los medios de comunicación y los periodistas, centrado exclusivamente en el ámbito territorial catalán. Todas sus resoluciones son públicas, pero no tienen fuerza ejecutiva, situándose su cumplimento en el orden estrictamente 'moral' de las personas o medios investigados.

El funcionamiento del CIC, que se rige por un reglamento, está definido en sus normas: "para recibir el arbitraje del CIC cualquier persona o entidad puede presentar una queja por la lesión cometida por parte de un profesional o medio de comunicación. No obstante, la presidencia, a criterio propio, del Patronato o del CIC, puede declarar de oficio cualquier asunto que considere de trascendencia social".

El CIC edita anualmente una memoria, que tiene carácter público, donde se detallan todas las actuaciones con los medios de comunicación, llevadas a cabo a lo largo del ejercicio. El volumen de expedientes ha sido muy exiguo en los últimos ejercicios. No alcanzaron la veintena al año durante 2015 y 2016. El secretario general del CIC, Albert Garrido, apunta que "muchas de las reclamaciones que nos llegan las redirigimos al CAC ya que no tratan sobre temas propios del código deontológico de los periodistas o de temática informativa sino más bien sobre la orientación del medio, en este caso de la CCMA, y en ese tema no tenemos competencia". Sorprendentemente, en 2017 la cifra de expedientes se multiplicó por tres. En relación con este dato, Garrido explica el incremento: "es a causa de la situación política y la radicalización de sociedad y medios. Y en 2018 vamos por el mismo camino".

En relación con la CCMA, sus programas y profesionales, el CIC ha tenido que intervenir en diversas ocasiones. En el pasado ejercicio se 
han dado un par de casos que han sido denunciados por entidades tan importantes como el expediente núm. 10/2017, interpuesto por el F.C. Barcelona (por presunta ausencia de verificación de la información y utilización de cámara oculta para su obtención) y por el Sindicat de Periodistes de Catalunya, expediente núm. 8/2017, (denuncia de una periodista y presentadora por hacer publicidad comercial).

Este último no es la primera vez que el CIC lo ha tenido que analizar; ya tuvo que intervenir en 2016. "El conflicto que se genera entre publicidad e información es un clásico para nosotros. Aparece de forma reiterada. El código deontológico es taxativo sobre este punto”, dice Garrido. Su punto séptimo establece, en su redacción actual, que "no es admisible simultanear el ejercicio del periodismo con otras actividades remuneradas que pongan en peligro los principios de veracidad e independencia”. En su redacción original (de 1992) era más explícito en referencia a la publicidad: "no se ha de simultanear el ejercicio de la actividad periodística con otras actividades profesionales incompatibles con la deontología de la información, como la publicidad, las relaciones públicas y las asesorías de imagen".

El caso del expediente 8/2017 fue revisado por la propia CCMA de manera interna. No dio lugar a ninguna reprobación ya que según el libro de estilo de la corporación no se incumplió ningún precepto del libro ni del código deontológico de los periodistas catalanes ya que: "la Sra. García Melero no es sujeto pasivo del punto 7 del Código dado que no está haciendo programas informativos de actualidad (...) sino un magacín de entretenimiento" "33. Además, justifica la CCMA que la presentadora contaba con el permiso de la dirección. Sin embargo, el CIC indica, después de condenar los hechos, que "hay que atender al espíritu de la norma... que el infotaintment también es información... y que considera urgente una revisión del libro de estilo de la CCMA". Garrido considera que el libro de estilo de la CCMA, en relación a este aspecto, no sigue las indicaciones deontológicas marcadas por el CPC.

${ }^{33} \mathrm{El}$ libro de estilo de la CCMA especifica en su punto 1.2.1.5.4. grabaciones ocultas: "En los contenidos informativos, sólo podemos hacer grabaciones ocultas excepcionalmente cuando sea la única manera de obtener información de gran interés. La difusión del material obtenido debe tener la autorización de la dirección del medio. En contenidos de entretenimiento, podemos recurrir a este tipo de grabaciones siempre que pedimos permiso para difundir el material a las personas que hemos grabado". 
"Es bastante más laxo". Ante esta situación el CIC ha recomendado a la CCMA que proceda a una revisión del libro de estilo.

Sobre esta discrepancia Sanchis, es de la opinión que "deben conjugarse ambos pareceres" a la vez que reconoce "nuestra equivocación en este sentido y veremos de adecuarnos en el futuro. Estamos revisando el libro de estilo, siguiendo el criterio indicado por el CIC pero también porque el manual necesita una adaptación a las nuevas situaciones surgidas a lo largo de la década".

\section{Comisión de control de la CCMA (Parlament de Catalunya)}

Una de las fórmulas de rendición de cuentas externa y de obligado cumplimiento es la comparecencia cada mes de los directivos de la CCMA (normalmente el presidente o presidenta en funciones, y los directores de la televisión y la radio) en el Parlament de Catalunya, ante una comisión de control formada por 17 representantes de los distintos grupos parlamentarios que tiene la cámara catalana. Técnicamente se conoce como la Comissió de Control de l'Actuació de la Corporació Catalana de Mitjans Audiovisuals.

Bien es cierto que estas comparecencias se hacen solamente en periodo lectivo. Entre legislatura y legislatura, no se producen. Y se ha dado el caso que desde septiembre de 2017 no ha habido comparecencias ${ }^{34}$. El presidente de la comisión durante la anterior legislatura (2015-2017) es el diputado David Mejía Ayra, de la organización política Ciutadans, quien considera que "el rendimiento de cuentas que hace la CCMA ante el Parlamento catalán es de obligado cumplimiento, pero de una efectividad casi nula. Los directivos de la corporación comparecen ante los representantes, pero contestan a las preguntas que se les solicita de la manera menos clara que pueden. Por tanto, podría calificar esta rendición de cuentas como de mínima".

Para este joven representante político si los operadores de PSM no son capaces de adaptarse a la evolución de las necesidades y demandas de todos sus ciudadanos, perderán apoyo social y, en consecuencia, su legitimidad para actuar como un servicio público, siendo el caso de la CCMA.

\footnotetext{
${ }^{34}$ https://www.parlament.cat/web/canalparlament/sequencia/index.html?p cp1=8107789
} 
Otro actor político, en este caso la representante del Partit Popular de Catalunya en la anterior legislatura (2015-2017) en esa comisión, Esperanza García González, se pregunta si la obligación legal de ser transparentes que tiene cualquier ente público en virtud de la Ley catalana 19/2014, de la transparencia ¿La están cumpliendo? "En ocasiones sí, y en otras no tanto ya que no cumplen con las exigencias de la ley. En muchas ocasiones sus directivos hacen caso omiso de las indicaciones y reprobaciones del ente del cual depende, del Parlament".

Para García, "la comisión de control hace su tarea. Ahora bien, una vez hecho este control los requerimientos de los representantes políticos no son respondidos. Tampoco se atienden las resoluciones que realizan la comisión o sus miembros en relación con la propia CCMA. No existe ninguna medida que sancione el incumplimiento. Además, las resoluciones adoptadas en el Plenario de la Cámara deben ser de obligado cumplimiento y ahora no se cumplen".

En relación a si esta comisión es un instrumento eficiente en la rendición de cuentas, García es clara: "es del todo insuficiente. En primer lugar, por la propia anomalía del consejo de gobierno de la CCMA. Algunos miembros tienen caducado su mandato y otros están ejerciendo sus responsabilidades en funciones (como el presidente) vulnerando la ley del audiovisual ya que el presidente debe ser nombrado directamente por el Parlament". En este sentido, Mejía explica que "Una de las medidas que se quería implementar La legislatura pasada y que ha sido paralizada por el avance de elecciones, era buscar un consenso mayor para la elección del presidente de la CCMA, dos tercios en primera o segunda vuelta. En la actualidad solamente se exige en primera votación, pero en segunda basta con mayoría absoluta. En el fondo se trata de exigir el respeto de la normativa para la elección de los miembros del consejo de gobierno. Que sean profesionales acreditados".

Así, la efectividad de la comisión de control como elemento de rendición de cuentas no parece que cumpla con todas las expectativas que se tienen en relación con este instrumento. Para Mejía una posibilidad que la comisión cumpliera de una manera más eficiente con su cometido sería convertirla en legislativa. Sin embargo, esta propuesta de innovación no es percibida de la misma manera por García que es de la opinión que debería seguir siendo una comisión no 
y que ello le aporta un plus en cuanto a que sus acuerdos son refrendados directamente por el pleno de la cámara.

Esa opinión, por razones diferentes, también es compartida por el director de TV3. Para Sanchis esta comisión, siendo necesaria, es ineficiente ya que no entiende el contexto del sector, ni la realidad económica del momento. Además, "la dinámica interna de funcionamiento no es la correcta para poder explicar con profundidad la realidad y necesidades de la entidad".

\section{Defensora de la Audiencia}

El Defensor de la Audiencia de la CCMA (en los últimos años defensora ya que la responsabilidad ha sido ejercida por dos mujeres, Adelina Castillejos y Laura Boladas) es un mecanismo de autorregulación periodística del que se dotó la corporación en 2008, con un mandato de tres años, renovable por un segundo período. Su misión es la de velar por los derechos de los espectadores, oyentes y usuarios de los medios de la CCMA, apostando por la transmisión de una información veraz, objetiva y equilibrada, respetuosa con el pluralismo político, social y cultural, y con el equilibrio territorial, tal como se establece en los estatutos.

Este organismo, compuesto en la actualidad por cuatro profesionales, recibe las consultas, sugerencias y reclamaciones de los usuarios de los medios. La presente investigación se ha centrado en el apartado de quejas. Las consultas no pueden ser definidas como rendición de cuentas desde un punto de vista estricto. Hay interacción con la audiencia, pero no hay petición o exigencia de responsabilidades.

Esta oficina recibe la petición de los ciudadanos por varias vías (telefónica, web, redes sociales...) Dispone de un formulario de reclamación en la web de la CCMA que es el mecanismo más habitual. Una vez en conocimiento de un caso, se investigan las quejas bajo los principios de la precisión, la imparcialidad, la veracidad, el rigor y la pluralidad según apunta Baladas, la actual responsable del servicio. La obligación es dar salida a todas. El tiempo de respuesta varía. "Depende de cada caso. Tenemos marcado como máximo 30 días. Necesitamos primero informarnos del caso, contactar con las personas implicadas y reflexionar sobre el por qué han sucedido los hechos de 
esa manera. La inmediatez es enemiga de la reflexión, de la respuesta precisa y exacta (accuracy)" apunta Baladas.

Con este mecanismo la CCMA considera que cumple con el compromiso en la defensa y el ejercicio de los derechos de la ciudadanía. A pesar de que en sus estatutos la corporación declara que el Defensor es una institución independiente ${ }^{35}$, la realidad es que la persona es elegida entre los profesionales de la casa (en su elección, se valora el hecho de pertenecer a la plantilla de la CCMA). Por lo que una vez agotado el mandato debe volver a desempeñar las funciones anteriores. Se vislumbra es difícil que exista una verdadera independencia.

En relación con la evolución de las quejas, con los ejercicios que están disponibles en la web de la CCMA, se puede observar su evolución, desagregada por tipología de medios, en el siguiente cuadro.

\begin{tabular}{|l|l|l|l|l|l|}
\hline QUEJAS & $\mathbf{2 0 1 2}$ & $\mathbf{2 0 1 3}$ & $\mathbf{2 0 1 4}$ & $\mathbf{2 0 1 5}$ & $\mathbf{2 0 1 6}$ \\
\hline TV & 2.613 & 2.171 & 1.819 & 2051 & 1.179 \\
\hline RADIO & 416 & 372 & 449 & 369 & 144 \\
\hline LA MARATÓ & 99 & 71 & 61 & 127 & 41 \\
\hline TOTAL & $\mathbf{3 1 2 8}$ & $\mathbf{2 6 1 4}$ & $\mathbf{2 3 2 9}$ & $\mathbf{2 5 4 7}$ & $\mathbf{1 3 6 4}$ \\
\hline
\end{tabular}

Fuente: Memorias anuales de la Oficina del Defensor de la Audiencia. Elaboración propia.

Se pueden observar dos tendencias: que la televisión absorbe la gran parte (cuatro quintas partes del total, aproximadamente, variando ligeramente el dato en función de los años) y que se produce un descenso paulatino que se acentuó en 2016. Siguiendo a López, Puentes, Rúas, (2017) no se observa una profundización de la relación bilateral sino un estancamiento. La Defensora justifica en parte el descenso porque "estamos ofreciendo mucha más información desde las webs de los programas. Las aclaraciones los puede obtener el ciudadano sin pasar por nuestro servicio". Sin embargo, esa explicación puede ser válida solamente en caso de consultas, no de las

\footnotetext{
${ }^{35}$ En los estatutos se especifica que el Defensor debe ser un profesional de los medios de comunicación audiovisual de reconocido prestigio, credibilidad y solvencia profesionales, con formación universitaria y una amplia experiencia en tareas de dirección, relaciones públicas y ejercicio profesional en medios de comunicación.
} 
reclamaciones que deben tener un proceso de resolución muy preciso y personal.

No ha sido posible obtener una mínima clasificación temática sobre el contenido de las reclamaciones ya que ese dato no se hace público. A la pregunta de si la CCMA podría ser más explícita sobre las temáticas de las reclamaciones, Baladas justifica que "es posible que ese dato se pueda incluir en el informe del último año (2017). La cuestión es si realmente es verdad que los temas sobre los que se queja la audiencia se están realizando realmente mal, o no, ya que pueden ser quejas infundadas". Además, indica que esa información podría ser utilizada por la competencia y por instancias partidistas para menoscabar el prestigio de la CCMA.

Para Sanchis la figura del defensor de la audiencia "antes de la revolución tecnológica era un sistema eficiente. Pero hoy en día no tiene sentido. La existencia de esa figura se ha de revisar [...] Es una figura de origen anglosajón muy interesante que los medios catalanes fueron introduciendo muy lentamente a finales del siglo pasado con públicos que tenían poco acceso a los medios. Hoy las audiencias son emisores muy activos".

\section{Libro de Estilo}

Uno de los instrumentos internos con los que se ha dotado la CCMA es el denominado Libro de Estilo que, en el fondo son tres piezas: se compone de una guía editorial, un manual de uso de cada medio y el portal lingǘstico corporativo ésAdir, para consultas y dudas realizadas con el uso del idioma catalán en los medios.

En su conjunto, se trata de un compendio de normas periodísticas y profesionales de los diversos medios que la integran. Vincula a todos los trabajadores, sean directivos, profesionales y colaboradores fijos o eventuales de todos los medios de la CCMA, con independencia de cuál sea su relación contractual con las empresas del grupo. En suma, es de obligado cumplimiento.

Existe una versión en catalán en línea y en abierto, en la web de la CCMA, para todas aquellas personas que deseen realizar consultas. o solamente se centra en los contenidos, sino también en los comportamientos profesionales y en los métodos de gestión. 
Eduard Boet, periodista y profesional de TV3, fue uno de los redactores del Libro de Estilo, hace aproximadamente una década. Su actual responsabilidad se encuadra en la Dirección de Estrategia Corporativa, teniendo a su cargo, entre otras funciones, la coordinación de la comisión de seguimiento del Libro de Estilo que reúne a una decena de profesionales de distintos departamentos y ámbitos de la corporación.

Esta comisión, única en su género en España, es la que vela por el cumplimiento de los preceptos del Libro de estilo. Cada mes se reúnen para analizar y debatir diversos casos "en relación a si esos contenidos de la radio, televisión e internet se adecuan a lo establecido por el Libro de Estilo", apunta Boet. "Esta comisión es consultiva y no vinculante, aunque muchas veces actúa de oficio cuando la vulneración es muy clara", detalla Boet. Lo que se hace en cada reunión es "tomar una serie de acuerdos que son elevados a la dirección que es la única figura que puede tomar decisiones para hacer cumplir el libro de estilo". Boet indica que se atienden la mayoría de las observaciones que hace la comisión "aunque el pecado ya se ha cometido". Sin embargo, no existen unas penalizaciones establecidas por el incumplimiento del Libro por lo que los profesionales de la CCMA no tienen normas claras en caso de violación de las normas del Libro de Estilo.

David Mejía es de la opinión que "sobre el libro de estilo deberíamos estudiar en el Parlament la manera en que se pudiera exigir su cumplimiento de una manera estricta. Ahora mismo no pasa nada si un trabajador de la CCMA no cumple las exigencias del libro de estilo". Para Esperanza García "el Libro de estilo ha sido un instrumento al servicio del nacionalismo político. Ha sido respetado cuando ha interesado y cuando no, no".

Según detalla Boet, los casos suelen ser detectados gracias a la monitorización de la programación que hacen los miembros de la comisión, especialmente su coordinador (el único miembro que tiene dedicación exclusiva). Además, llegan casos procedentes del exterior, vía defensora de la audiencia (20\%), y por las consultas de los trabajadores.

Otra de las funciones de la comisión es la difusión del Libro de Estilo. Semanalmente en los espacios de comunicación interna de la casa se 
hace difusión de algún artículo que tenga que ver con algunos casos recientes. Otra función es la de prevención recordando cuáles son las pautas del Libro en relación a ciertos temas que pueden estar de actualidad.

La comisión, además de los informes mensuales que remite a la dirección, realiza una memoria anual (que no se hace pública, siendo una decisión de la presidencia) que se remite a la dirección estrategia corporativa (y, por ende, a la presidencia de la CCMA) y a los directores de los tres medios (radio, televisión y medios digitales). Se compone de algo más de un centenar de casos que básicamente se explicitan en forma de tipología. No se recogen todas las incidencias ocurridas sobre posibles vulneraciones del Libro. El 70\% viene de éstas proviene del ámbito televisivo.

Frente a la posibilidad que esta memoria pudiera ser conocida por la población, Boet es de la opinión que esta información debería ser tratada con cierta precaución ya que "es laminera sobre todo para los medios de la competencia. ¿Qué mal uso se puede hacer desde otros medios?". En todo caso, para Boet, la comisión de control del Parlament sería el sitio indicado para mostrarla.

Por último, indica Boet que el Libro "es un documento que debe ser actualizado y modificado. Y en ello estamos trabajando desde hace un tiempo debido en parte a la evolución digital de los medios que conlleva unos nuevos métodos de trabajo inexistentes cuando se creó hace una década". Para él, es una tarea que no se debe externalizar. Tienen previsto presentar la nueva propuesta a la dirección a principios de 2020.

\section{TAC (Telespectadors Associats de Catalunya)}

Una de las posibilidades que tienen los ciudadanos de fiscalizar la actuación de entidades públicas de radio y televisión es a través de las asociaciones de usuarios de medios audiovisuales que defienden sus intereses. Son entidades de carácter privado, sin ánimo de lucro.

En el ámbito europeo existe Euralva (The European Alliance of Listeners and Viewers Associations) que representa el interés de los oyentes y espectadores de la radiodifusión y los nuevos servicios de medios que se pueden recibir en los Estados miembros del Consejo de Europa. Incluye asociaciones de diez países europeos más otras de 
Australia, Canadá y México. Su presidente desde 2011 es el español Josep María Guerra Mercadal que a la vez lo es también de la única asociación en el estado español exclusivamente focalizada en los usuarios de medios audiovisuales: TAC (Telespectadors Associats de Catalunya). Guerra indica que, con 33 años de existencia, "somos la única asociación de consumidores de medios de Cataluña y, a pesar de ser pequeños, somos la más grande e importante de Europa". Son cerca de 4.000 familias afiliadas lo cual supone más de 30.000 personas.

Se creó en 1985 por la preocupación de un grupo de padres de familia por los contenidos de televisión. "A día de hoy trabajamos sobre cualquier contenido que vean los usuarios en Cataluña. Aunque nuestras actuaciones van más allá. Siempre hemos actuado con una visión estatal -comparecemos en el Congreso-, e incluso europea interactuamos en Bruselas cuando se creó la Directiva-“.

"Nuestra interacción con la CCMA es muy escasa. La verdad es que no nos preguntan absolutamente nada", explica Guerra cuando se le pregunta sobre su relación con la corporación "pero participamos activamente en algunas situaciones y regulaciones del sector en su conjunto como, por ejemplo, las modificaciones de horarios de parrilla".

El objetivo de la asociación es dar voz a los usuarios y defender sus derechos. TAC en concreto pone el énfasis en mejorar la calidad de la programación y la defensa del menor en el nuevo entorno digital. No influyen de manera directa sobre los medios "por ser muy costoso. Pero lo hacemos de manera indirecta", indica que Guerra que denuncia "estamos avergonzados de la gestión de la televisión pública (sea catalana o española) en relación con los temas institucionales. Hay una radical exclusión de una parte u otra de la sociedad en cada televisión. Nos parece brutal. Siempre cada una ha obedecido a unas directrices partidistas clarísimas, pero ahora es peor. En los medios privados, sin embargo, es diferente. Es donde se da la máxima pluralidad. Es muy triste que las televisiones públicas sean incapaces de respetar las diferentes sensibilidades de la población. Que, además, es una obligación legal”.

Desde otras instancias no se observa este tipo d entidades como representativas de las audiencias. Para Sanchís, "los espectadores de 
TV3 no están representados por una pequeña entidad como esa". Y Boet lo equipara con un grupo de presión. En línea con la presión que puede hacer la Federació de Productors Audiovisuals (PROA) que "es el lobby de las productoras" para Espuny. PROA agrupa a cinco asociaciones sectoriales catalanas aparte de una valenciana y otro balear.

\section{Cuentas de resultados y Memoria de actividades}

La CCMA tiene en su web, a disposición de los ciudadanos, las memorias de actividades, así como las cuentas de resultados de los últimos ejercicios. En las segundas se incluyen las auditorías de cada ejercicio. A través de estos instrumentos de rendición de cuentas financieras (sobre todo el segundo), -de obligado cumplimiento legal hay que especificar-, se vislumbra la salud económica del ente. Sobre la aportación de los informes de autoría de cada año hay que apuntar que, excepto el primero de las consultadas (2010) que fue realizada por la consultora KPMG, el resto (2011-2016) han sido realizados por PWC.

A modo de resumen, se puede vislumbrar en el siguiente cuadro que, en todos los ejercicios aportados, el resultado final es negativo. En total, en los ocho años, más de 173 millones de euros de pérdidas.

\begin{tabular}{|l|c|c|}
\hline Año & $\begin{array}{l}\text { Importe neto de la } \\
\text { cifra de negocio } \\
\text { (en millones } € \text { ) }\end{array}$ & $\begin{array}{l}\text { Resultado neto } \\
\text { del ejercicio (en } \\
\text { millones } \boldsymbol{€})\end{array}$ \\
\hline 2009 & 94.589 & -11.134 \\
\hline 2010 & 103.296 & -18.048 \\
\hline 2011 & 91.450 & -17.824 \\
\hline 2012 & 70.105 & -31.769 \\
\hline 2013 & 64.307 & -36.345 \\
\hline 2014 & 67.108 & -37.016 \\
\hline 2015 & 69.011 & -17.640 \\
\hline 2016 & 67.530 & -3.737 \\
\hline
\end{tabular}

Fuentes: cuentas de resultados.

Elaboración propia.

En su día se llegó a un acuerdo de financiación estable entre la CCMA y el gobierno catalán, a través de la figura denominada 'contrato- 
programa', un acuerdo plurianual que garantizaba a la corporación una estabilidad en los ingresos que provenían del erario público. El último de ellos (2017-2020) está pendiente de concreción definitiva. Tampoco se llegó a firmar el del período 2013-2017. El último que funcionó corresponde al programa que caducó a finales de 2009.

Sin posibilidad de estabilidad financiera a medio plazo (por falta de concreción de la financiación pública) y frente a un escenario de pérdidas casi permanentes, cabe plantearse si la situación puede ser sostenible por mucho más tiempo o si se deberían tomar medidas urgentes para reconducir la situación. En todo caso los números rojos obligan a reflexionar sobre la viabilidad de la corporación. "La grave crisis económica, la fuerte competencia y la fragmentación del mercado (por la TDT y el consumo multiplataforma) han hecho mella en la justificación de la permanencia de los entes públicos autonómicos" (Muñoz y Azurmendi, 2016: 46).

Vista la solución que se tomó en el caso de la Radiotelevisión Valenciana (RTVV), donde se cerraron sus instalaciones y las emisiones (Marzal, López-Rabadán y Castillo, 2017), una de las alternativas remite a una posible clausura, aunque no existen, al menos por el momento, ninguna voz en ese sentido. Incluso García, representante del PP, marca otra dirección, siendo de la opinión que "la CCMA no es viable porque tiene una plantilla excesiva en comparación con competidores, incluso privados. Hay que afrontar ese problema $[. .$.$] y por tanto se debería replantear una reestructuración del$ ente".

Otro de los expertos consultados, Alsius lo tiene claro: "TV3 y Catalunya Ràdio han sido unas herramientas fundamentales que en su momento hicieron mucha falta, pero podrían dejar de existir algún día y no pasaría nada [...] El concepto de medio público es contingente" (Marqués, 2014: 48). Eso sí en un contexto determinado: "lo que es esencial es el concepto de servicio público, que es diferente. Lo que se tendría que estar haciendo es que todos los medios, incluidos los privados, prestaran la cuota de servicio público que les es exigible. Si dejamos de reivindicar esto y nos concentramos en reivindicar el medio público perderemos hasta la camisa. Las televisiones privadas están desreguladas de una manera atómica". 
La situación económica llevó al presidente actual de la CCMMA, Brauli Duart, cuyo mandato se inició en 2012, a plantear una serie de medidas de ahorro como la apertura de un expediente de regulación de empleo que finalmente se aplicó, pero no en los términos iniciales previstos. "Bajo la presidencia de Duart, la situación de la CCMA se ha deteriorado gravemente" apunta Espuny. Este representante sindical es de la opinión que "desde la reforma de la Ley de la CCMA, en 2012, el nivel de independencia de la corporación se ha reducido substancialmente. Se debería volver a reformar para recuperar los consensos políticos previos a 2012”.

\section{Conclusiones}

A lo largo de las páginas anteriores se ha podido conocer un detallado análisis de los instrumentos de rendición de cuentas con las que se ha dotado la CCMA, tanto en el ámbito interno como en el plano externo. Se ha obviado alguno más, como al Sindicatura de Cuentas, por el retraso que llevan sus informes en relación a la situación presente.

Se parte de la base que el sistema de gobernanza con que se dotó la CCMA no se desarrolla de la manera en la que se ideó lo cual redunda en asincronías profundas. Se observa que todos los instrumentos de rendición de cuentas con los que se ha dotado la CCMA, por propia voluntad o por exigencia legal, están ampliamente consolidados teniendo todos ellos, como mínimo, una década de existencia. Algunos son más válidos que otros, pero casi todos muestran claros síntomas de estancamiento. Se trabaja de la misma manera que se hacía al inicio de la década. No se observan cambios sustanciales en la operativa de cada uno de ellos, comparando cómo se trabajaba al inicio y en la actualidad. En opinión de Baladas: "la innovación en los instrumentos de rendición de cuentas es necesaria. Los actuales tienen algo de obsolescencia. Es verdad que estamos viviendo aún de la tradición del siglo pasado. Bebemos de esas fuentes. Hoy en día la interacción más directa con el usuario es vital y el usuario así lo reclama. Debemos abrirnos más en este sentido".

A continuación, y en la línea que plantea Baladas, se indican algunas ideas que tienen como norte la innovación. La primera tiene que ver con el concepto de jibarización, explicitado por Alsius, sobre la composición de los consejos de administración de algunos entes públicos en Cataluña como pueden ser los del CAC, o la propia CCMA 
y que intentan clonar la composición de las fuerzas parlamentarias. Se debe apostar por una despolitización, eligiendo para esas responsabilidades a profesionales de acreditada experiencia. Los consejeros actuales son serviles con los partidos que los han puesto en el cargo.

Tampoco tiene mucho sentido dotarse de órganos consultivos que no son escuchados. Como el consejo asesor de contenidos. Sus miembros representan determinadas sensibilidades de la sociedad y cuando plantean cambios en las programaciones éstos deberían ser recogidos de manera recurrente, si son viables, en tanto que provienen de demandas de la ciudanía.

En relación a la presentación de las cuentas anuales y las diferentes memorias anuales, incluyendo la de RSC, el reporting corporativo como se conoce en el argot, la CCMA se podría plantear una apuesta de innovación en la presentación, apostando por lo que se ha dado en llamar el informe integrado (IR). Algunas corporaciones empezaron a apostar por él en la década pasada y es "la mejor manera de obtener un panorama completo del valor de las empresas, superando las limitaciones de los informes tradicionales" (Rivera-Arrubla, ZorioGrimab, García-Benau, 2016).

También se deben plantear algunos aspectos de mejora en relación con el Libro de estilo: por ejemplo, dar publicidad a las violaciones que cometen los profesionales de la CCMA redundaría en un mayor respeto al propio libro. El informe anual que remite la comisión de seguimiento a la alta dirección debería estar en abierto y que la ciudadanía pudiera consultarlo. En él deberían referenciarse aquellos casos flagrantes de incumplimiento del Libro ya que no existe un régimen disciplinario referencial. Por otro lado, en relación con la revisión y actualización que se está realizando, sería aconsejable que intervinieran también expertos externos a la CCMA, por ejemplo, del propio CIC, de tal manera que se aporte una visión diferente, no endogámica.

Por otra parte, en relación la Comisión de control del Parlament, y teniendo en cuenta los incumplimientos por parte de la dirección de la CCMA de los requerimientos de los parlamentarios, no se puede por menos de estar de acuerdo con la recomendación que hizo en su día la 
Oficina Antifraude de Cataluña cuando indicó que era necesario "implementar medidas efectivas coactivas para aquellos responsables públicos que no rindan cuentas o no colaboren en les medidas de control" (2015: 37). Es necesario que las observaciones y recomendaciones de los órganos de control sean implementadas de manera efectiva por los directivos. La posibilidad que la Comisión de Control se otorgue de un régimen sancionador no sería descartable.

Sobre la Oficina del Defensor/a de la Audiencia cabe indicar un par de propuestas para mejorar la rendición de cuentas que realiza. Se podría considerar que la memoria anual que realiza la oficina y se remite a la alta dirección, se publique, de tal manera que se puedan conocer cuáles son las quejas que elevan los ciudadanos a la CCMA y, a renglón seguido, saber si esas peticiones son atendidas o postergadas. Por otro lado, recomendar que la defensora tenga presencia en las parrillas de los medios (sea mediante programa propio, o a través de un microespacio dentro de un programa más amplio) al igual que ya hacen otros medios que tienen esa figura implantada y explican los errores, equivocaciones, malentendidos o directamente violaciones se han podido cometer por sus periodistas del libro de estilo. "En los medios audiovisuales, radio y televisión, es frecuente que los defensores cuenten con sus propios espacios y programas" (herrera-Damas, 2008). Además, este tipo de temáticas suelen ser muy bien aceptadas por la audiencia, con altos rating.

Apuntar, en relación con el papel fiscalizador que pueden cumplir determinados organismos externos como: el CAC, el CIC, las asociaciones de consumidores de medios (como el TAC), ciertos colegios profesionales y sindicatos profesionales, etcétera, que un avance en los sistemas de rendición de cuentas es integrar a algunos de sus miembros o representantes en las comisiones de seguimiento de los diferentes instrumentos. La presencia externa, con puntos de vista y sensibilidades diferentes a las internas, potencia la diversidad. Además, la independencia de esas personas contrasta con la dependencia del profesional de la casa, aportando un plus de credibilidad.

En general, se observa que se debe de hacer mucho más en relación con el respeto al sistema de gobernanza con el que la entidad se dotó. Y sobre la rendición de cuentas desde el punto de vista de la 
innovación. En este sentido, se ha detectado una falta de reflexión en torno a la preparación del futuro de la CCMA en el nuevo contexto de la digitalización y distribución de contenidos audiovisuales.

Por último, señalar que, para contextualizar el posicionamiento de mayor o menor modernidad y actualidad de los instrumentos utilizados por la CCMA, sería aconsejable realizar un estudio comparativo (tipo benchmarking) con organismos similares de otros países de nuestro entorno, principalmente, centrado en la Europa comunitaria, con el propósito de implementar aquellas medidas que aún no se han puesto en marcha en el territorio catalán y que hayan arrojado resultados contrastados.

\section{Referencias bibliográficas}

Alfaro, C. y Gómez, J. (2016): “Un sistema de indicadores para la medición, evaluación, innovación y participación orientado a la Administración Pública", Methaodos. revista de ciencias sociales, 4 (2): 274-290. http://dx.doi.org/10.17502/m.rcs.v4i2.124

Bichler, Klaus; Harro-Loit, Halliki; Karmasin, Matthias; Kraus, Daniela; Lauk, Epp; Loit, Urmas; Fengler, Susanne; SchneiderMombaur, Laura (2012). "Best practice guidebook: Media accountability and transparency across Europe". MediaAct. European Commission.

http://www.mediaact.eu/fileadmin/user upload/Guidebook/g uidebook.pdf

Bovens, Mark (2004). "Public Accountability". En, E. Ferlie, L. Lynne \& C. Pollitt (eds.) The Oxford Handbook of Public Management, Oxford: Oxford University Press.

https://www.law.kuleuven.be/plaatsingsdienst/integriteit/egpa Lprevious-egpa-conferences/lisbon-2003/bovens.pdf [accessed Feb 12 2018].

Bovens, Mark (2005). "Evaluating public accountability. International Research Colloquium Accountable Governance". Belfast: Queens University. https://www.researchgate.net/publication/254886383 Evaluati ng public accountability [accessed Feb 02 2018]. 
Brandeis, Louis D. (1914). "Other people's money and how the bankers Use It". New York: Frederick A. Stokes Co.

Broullón-Lozano, Manuel A.; Alonso-Jiménez, Elisa (2016).

"Discursos sobre participación ciudadana y

confianza/desconfianza respecto a la televisión pública en

España”, pp. 235-252, en Barriga-Cano, María-José (coord.),

¿Nuevas alternativas de la comunicación? soportes, contenidos y audiencias.

Sevilla: Egregius. ISBN: 9788494524332

Campos-Freire, F.; Valencia-Bermudez, S. (2017). "Los retos de la

gobernanza, financiación y valor de las radiotelevisiones

públicas”. En, J. Marzal-Felici; P. López-Rabadán y J.

Izquierdo-Castillo (eds.) Los medios de comunicación públicos de

proximidad en Europa. RTVV y la crisis de las televisiones públicas.

Valencia: Tirant Humanidades.

Cebrián-Herreros, Mariano (2009). "Nuevas formas de comunicación: cibermedios y medios móviles". Comunicar, 33, pp. 10-13.

DOI:10.3916/c33-2009-01-001

Colón de Carvajal, Borja (2016). "Más allá de la transparencia:

buscando un enfoque integral hacia la rendición de cuentas".

RET, Revista Española de la Transparencia, 2, 14-19.

https://drive.google.com/file/d/0BzZV66dM4HCTcm11QW

dZOGF2UzQ/view

Day, Patricia y Klein, Rudolph (1987). “Accountabilities: Five Public

Services". London: Tavistock.

Miguel De Bustos, Juan Carlos (2005). "La télévision generaliste en

Espagne", dans P. Moeglin et G. Tremblay, L'avenir de la

télévision généraliste, París: L'Harmattan.

Miguel de Bustos, Juan Carlos y Casado del Río Miguel Ángel

(Coords.) (2012) "Televisiones autonómicas. Evolución y crisis

del modelo público de proximidad". Barcelona: Gedisa. ISBN:

978-84-9784-724-7.

Miguel De Bustos, Juan Carlos (2013). "Evolución y crisis del modelo público de proximidad". Ponencia en Video:

https://www.youtube.com/watch?v=jXkNPLYxTts

Direito-Rebollal S., Lago-Vázquez D., Rodríguez-Vázquez AI. (2017).

"Television and Social Networks: An Analysis of the Influence of Live-Tweeting in the Social Audiences". In: Rocha Á.,

Correia A., Adeli H., Reis L., Costanzo S. (eds) Recent Advances in 
Information Systems and Technologies. WorldCIST 2017. Advances in Intelligent Systems and Computing, vol. 571. Springer, Cham. ISBN: 9783319565415

Dubnick, (2005). "Accountability and the Promise of Performance:

In Search of the mechanisms". Public Performance and Management Review (PPMR), 28 (3), 376-417.

Fengler, Susanne (2008). "Media journalism and the power of blogging citizens”, en: Krogh, Torbjörn (ed.). Media accountability today and tomorrow. Updating the concept in theory and practice. Goteborg: Nordicom, pp. 61-68. ISBN: 9789189471580

Fernández-Lombao, T.; Valencia Bermúdez, A.; Campos-Freire, F. (2016). "Innovation as the Key for the Future of Public Service Media”. En A. Rocha, A.M. Correia, H. Adeli, L.P. Reis e M. Mendonça, Advances in Intelligent Systems and Computing (pp. 489496). Suíza: Springer.

Gómez Urquijo, Laura (coord.) (2012). "Instrumentos innovadores de gobernanza en la Unión Europea: impacto en la gestión pública y en la competitividad regional”. Diputación Foral de Vizcaya / Universidad de Deusto.

Herrera-Damas, Susana (2008). "El defensor de la audiencia como instrumento para la educación en medios". Comunicar, 30 vol. XV, 125-130. DOI:10.3916/c30-2008-02-005

López-López, P C; Puentes-Rivera, I.; Rúas-Araújo, J. (2017).

"Transparencia en televisiones públicas: desarrollo de indicadores y análisis de los casos de España y Chile". Revista Latina de Comunicación Social, 72, 253-272.

http://www.revistalatinacs.org/072paper/1164/14es.html DOI: $10.4185 /$ RLCS-2017-1164.

Marqués-Pascual, Joaquín (2014). "Entrevista a Salvador Alsius", pp.45-52, en: VVAA, La comunicació $i$ la regeneració democrática $i$ política, Col·lecció Lexikon Papers, Generalitat de Catalunya/ACCIEP. ISBN: 978-84-393-9126-5.

Marqués-Pascual, J.; Fondevila-Gascón, JF.; Uribe-Gil, C.; PerellóSobrepere. M. (2016). "Los bloques electorales en España. Una propuesta de modelo alternativo para superar el conflicto". Revista Latina de Comunicación Social, 71, 654-66. DOI: 
10.4185/RLCS-2016-1114.

http://www.revistalatinacs.org/071/paper/1114/34es.html

Martín Delgado, Isaac (2017). "Una panorámica general del impacto de la nueva Ley de Procedimiento Administrativo Común en las relaciones de los ciudadanos con la Administración Pública “, en: Isaac Martín (director): La reforma de la administración electrónica: una oportunidad para la innovación desde el Derecho. Madrid: Instituto Nacional de Administración Pública, Colección INNAP INVESTIGA, Serie INNOVACIÓN ADMISTRATIVA. ISBN 978-84-735 1-575-7.

Marzal, Javier; López-Rabadán, Pablo; Castillo, Jésica (edit.) (2017). "Los medios de comunicación públicos de proximidad en Europa. RTVV y las crisis de las televisiones públicas”. Valencia: Tirant Humanidades.

Molina, J.F., López, M.D., Pereira J., Pertusa E.M. y Tarí J.J. (2012). "Métodos híbridos de investigación y dirección de empresas: ventajas e implicaciones". Cuadernos de Economía y Dirección de la Empresa, 15 (2), 55-62. DOI:10.1016/j.cede.2012.01.001.

Monereo Pérez, J.L. y Fernández Avilés, J.A. (2008). "La libertad sindical en la doctrina del Tribunal Constitucional". Revista del Ministerio de Trabajo y Asuntos Sociales 73, 247-311.

Muñoz Saldaña, Mercedes y Azurmendi, Ana (2016). "El papel de las televisiones públicas autonómicas en el desarrollo de la gobernanza multinivel en Europa". Communication \& Society, 29 (4), 45-58.

Oficina Antifrau de Catalunya (2015). "Informe de seguiment dels treballs de la CIFEF”. Propostes i recomanacions. 10.7.2015

Pérez Cisneros, Francisco (2015). "El contador público como referente para impulsar la transparencia y fortalecer la confianza”. Revista Contaduría Pública (Dic. 2015). Artículo on line. http://contaduriapublica.org.mx/el-contador-publicocomo-referente-para-impulsar-la-transparencia-y-fortalecer-laconfianza/ Consultado el 20 febrero 2018.

Pérez-Latre, Francisco J. y Sánchez-Tabernero, Alfonso (2016). "Claves de gestión del cambio en la era digital, pp. 286-297”. En Ana Azurmendi e Iker Huarte (editores). Retos de futuro de la televisión autonómica: estructura, financiación, contenido y audiencia. Actas 
del XXX Congreso Internacional de Comunicación, CICOM 2015. Pamplona: Universidad de Navarra.

Porras, Oswaldo. (2007). "Lineamientos para la rendición de cuentas de las entidades territoriales". DNP, Seminario internacional de rendición de cuentas y control ciudadano en las entidades territoriales. Bogotá, Departamento Nacional de Planeación, (12 y 13 abril 2007).

Pritchard, David (2000). Holding the Media Accountable. Citizens, Ethics, and the Law. Bloomington: Indiana University Press.

Rivera-Arrubla, Yaismir; Zorio-Grimab, Ana; García-Benau, María (2016). "El concepto de informe integrado como innovación en reporting corporativo". Journal of Innovation \& Knowledge, 1 (3) 144-155. http://dx.doi.org/10.1016/j.jik.2016.01.016

Rodríguez-Martínez, Ruth; López-Meri, Amparo; Merino-Arribas, Adoración; Mauri-Ríos, Marcel (2017). "Instrumentos de rendición de cuentas en España. Análisis comparativo en Cataluña, Galicia, Madrid y Valencia". El profesional de la información, v. 26, n. 2, pp. 255-266. https://doi.org/10.3145/epi.2017.mar.12

Russ-Mohl, Stephan (2003). „Journalismus. Das lehr und handbuch“. Frankfurter Allgemeine Buch. ISBN: 3899812247.

Schauer, Frederick (2014). "Transparencia en tres dimensiones". Revista de Derecho, vol. XXVII (1), 81-103. Texto original en inglés: "Transparency in Three Dimensions", publicado en University of Illinois Law Review (2011, No 4).

Shoemaker, Pamela; Reese, Stephen D. (1996). "Mediating the message: Theories of influences on mass media content" (2nd ed.). White Plains, NY: Longman. ISBN: 9780801312519

Suárez-Villegas, J.C. y Cruz Álvarez, J. (2016). "Los dilemas deontológicos del uso de las redes sociales como fuentes de información. Análisis de la opinión de los periodistas de tres países". Revista Latina de Comunicación Social, 71, 66-84. DOI: 10.4185/RLCS-2016-1084

Suárez-Villegas, J.C.; Rodríguez-Martínez, R.; Mauri-Ríos, M; LópezMeri, A. (2017): “Accountability y culturas periodísticas en España. Impacto y propuesta de buenas prácticas en los medios de comunicación españoles (MediaACES)". Revista Latina de Comunicación Social, 72, pp. 321 a 330. 
http://www.revistalatinacs.org/072paper/1167/17es.html DOI: 10.4185/RLCS-2017-1167.

Taylor, S.J. y Bogdan, R. (1986). Introducción a los métodos cualitativos de investigación. Barcelona: Paidós.

\section{Apéndices}

Cuadro de instrumentos de rendición de cuentas empleado para la determinación de aquellos que son los utilizados por la CCMA.

\begin{tabular}{|l|l|}
\hline \multicolumn{1}{|c|}{ Instrumentos internos } & $\begin{array}{c}\text { Si / } \\
\text { No }\end{array}$ \\
\hline & \\
\hline $\begin{array}{l}\text { DEPARTAMENTO DE ATENCIÓN AL PÚBLICO / } \\
\text { AUDIENCIA }\end{array}$ & \\
\hline Atención telefónica & \\
\hline Atención vía web & \\
\hline $\begin{array}{l}\text { Formulario de sugerencias, reclamaciones y quejas en la } \\
\text { web }\end{array}$ & \\
\hline & \\
\hline DEFENSOR DE LA AUDIENCIA & \\
\hline Programa propio en parrilla (radio / tv) & \\
\hline & \\
\hline LIBRO DE ESTILO & \\
\hline Seguimiento interno de su cumplimiento & \\
\hline Formación interna sobre deontología profesional & \\
\hline & \\
\hline $\begin{array}{l}\text { ORGANISMO/S DE CONTROL (con participación de } \\
\text { empleados) }\end{array}$ & \\
\hline Consejo de profesionales de los medios & \\
\hline Comités de empresa & \\
\hline & \\
\hline ENCUENTROS CON LOS DIFERENTES PÚBLICOS & \\
\hline & \\
\hline PUBLICACIÓN DE INFORMACIÓN & \\
\hline Cuentas financieras públicas & \\
\hline Memoria pública de actividades & \\
\hline & \\
\hline
\end{tabular}




\begin{tabular}{|l|l|}
\hline Instrumentos externos & \\
\hline & \\
\hline ORGANISMO/S DE CONTROL & \\
\hline Parlament de Catalunya & \\
\hline Consell de l'Audiovisual de Catalunya (CAC) & \\
\hline & \\
\hline ASOCIACIONES DE CONSUMIDORES Y & \\
\hline TAC (Telespectadors Associats de Catalunya) & \\
\hline & \\
\hline CONSEJOS DE PRENSA & \\
\hline Consell de la Informació de Catalunya (CIC) & \\
\hline
\end{tabular}

Elaboración propia. 


\title{
Innovación en radiotelevisiones públicas europeas: narrativas inmersivas y organización de los contenidos 360 grados en plataformas digitales
}

\author{
Sara Pérez-Seijo \\ Universidade de Santiago de Compostela \\ María Melle Goyanes \\ Universidade de Santiago de Compostela \\ Francisco Javier Paniagua Rojano \\ Universidad de Málaga
}

PARA CITAR: Pérez-Seijo, S., Melle Goyanes, M. y Paniagua Rojano, F.J.

(2018). Innovación en radiotelevisiones públicas europeas: narrativas inmersivas y organización de los contenidos 360 grados en plataformas digitales. Revista Latina de Comunicación Social, 73, pp. 1115 a 1136.

http://www.revistalatinacs.org/073paper/1299/58es.html

DOI: $10.4185 /$ RLCS-2018-1299

\section{Resumen}

La incorporación de las narrativas inmersivas en medios ha derivado en nuevos modos de producción y distribución. Este trabajo presenta entonces un análisis sobre las estrategias de organización de vídeos $360^{\circ}$ seguidas por las radiotelevisiones públicas europeas en sus plataformas. Se han observado y recopilado las páginas webs y los canales de YouTube de las radiodifusoras que implementan las narrativas inmersivas en contenidos no ficción para advertir las tácticas seguidas a la hora de organizar e identificar los vídeos $360^{\circ}$, así como su peso en la difusión. Se han empleado técnicas cuantitativas y se ha diseñado una ficha de análisis para examinar un total de 27 webs y 32 
canales de YouTube. El estudio concluye que las dos plataformas desempeñan un papel fundamental como vías de difusión y que en ambas se observa una planificación estratégica encaminada a destacar y visibilizar dichos vídeos, aunque más en YouTube.

Palabras clave: Periodismo inmersivo, nuevas narrativas, televisiones públicas europeas, 360 grados, YouTube.

\section{Introducción}

— L ECOSISTEMA mediático actual se caracteriza por un estado tradicionales, los medios de comunicación nacionales e internacionales, entre estos las radiotelevisiones públicas europeas -desde ahora RTPEs- aplican técnicas de producción informativa innovadoras, implementan tecnologías de última generación y experimentan con nuevas formas y formatos en un afán por atraer audiencias en un mercado no solo saturado de entes informantes, sino también de competidores ansiosos por números que puedan ser traducidos en beneficios. La diferenciación es la nueva norma que reina (European Broadcasting Union, 2016).

Mas la búsqueda de distintivos y de formas de comunicar rompedoras e inéditas no es una pretensión exclusiva y propia solo del siglo XXI y de la Sociedad en Red. Desde sus comicios el periodismo ha ido evolucionando según los métodos, técnicas y tecnologías disponibles en cada época. De los Annales a los edictos. Del papel al visionado en pantalla. De la información en el panorama de los social media a los cascos de realidad virtual -desde ahora RV-. Adaptación es, por tanto, la palabra que mejor define a la historia que consigo arrastra el periodismo (Domínguez, 2017). Se trata, pues, de una búsqueda constante de caminos para la reinvención, intensificada si cabe desde finales del siglo XX (Alejandro, 2010).

No obstante, si bien el periodismo ha evolucionado una vez más en la segunda década del tercer milenio, en esta ocasión lo ha hecho al abrigo de la Sociedad en Red. Los formatos tradicionales se hibridan en un ecosistema en donde todo puede ser y todo es. Un mundo intangible 
que aúna todo lo conocido y lo desconocido porque, a diferencia de los contenedores previos, Internet se retroalimenta cada día del feedback social para renovarse y no morir en el acto.

El salto a la red fue el detonante del panorama que en el momento presente (2017) vive la profesión periodística: "la web ha cambiado el mundo y ha revolucionado cómo la información es almacenada, publicada, buscada y consumida" (Alejandro, 2010: 3). Asentada la web como vía de futuro del flujo informativo y consolidados los cibermedios como entes de comunicación del día a día, un nuevo reto aparece: el afianzamiento de los dispositivos móviles como principales herramientas de acceso a la información. Son televisiones, radios, periódicos y ordenadores. Cuatro en uno y, además, portables y ubicuos.

La red y los dispositivos móviles dieron paso a un cambio drástico en el panorama informativo. Con ellos la imagen adquiere más poder que nunca y explosiona una cultura de lo visual sin precedentes: "ver para creer" (Newman \& Fletcher, 2017) como dogma de la nueva doctrina.

La conectividad y el estallido de nuevos modelos de consumo y de producción informativa también adquieren mayor protagonismo gracias a los últimos avances en materia de tecnología y estructura digitales (Peters, 2016). En este sentido, Salaverría (2016) advirtió un panorama informativo caracterizado por la emergencia del periodismo ubicuo, favorecido por el calado social de los dispositivos móviles como herramientas de producción, difusión y consumo de información; por la progresiva expansión de un periodismo más robotizado, en estrecha relación con la grabación con drones y la composición automática de textos a través de algoritmos; y por el desarrollo de un lenguaje multimedia más rico. Precisamente esta última tendencia es una de las que más cambios ha suscitado en las narrativas periodísticas y de no ficción, derivando simultáneamente en grandes permutas también en los modos de consumo del relato informativo.

En un intento por enriquecer un lenguaje multimedia ya rutinario y usual para una audiencia altamente infoxicada, surge la opción de aplicar las técnicas de grabación 360 y de RV (Baía, 2016; Hardee, 2016) en el proceso de producción informativa. Esta acción, en 
estrecha relación con la influencia de los videojuegos como industria cultural en expansión (Domínguez, 2017) y con los procesos de gamificación de sectores (Longhi, 2016; Kapp, 2012; Domínguez, 2015), ha supuesto un cambio radical en la concepción del storytelling.

Apodado periodismo inmersivo por la investigadora estadounidense Nonny de la Peña (2010), esta corriente nace bajo el objetivo de acercar la realidad informativa al espectador más que los formatos convencionales, un ideal que los medios de comunicación han perseguido desde sus orígenes (Baía, 2016; Biocca \& Levy, 1995; Longhi, 2016: Hardee \& McMahan, 2017).

"Los humanos siempre nos hemos contado historias, y cada era del progreso ha traído una expansión del storytelling" (Gillmor, 2004). Con el periodismo inmersivo este desarrollo ha sido exponencial gracias a la hibridación de sectores e industrias. Ya no existe entre el receptor y la realidad informativa la barrera de la pantalla, sino que este puede traspasarla, romper la conocida como frontera liminar o cuarta pared (Murray, 1999; Domínguez, 2013) y sumergirse, así, en el mundo virtual para ser testigo en primera persona del relato noticioso (De la Peña et al., 2010) gracias a la ayuda de un mediador: unos cascos o gafas de RV.

Con la llegada e instauración de esta corriente en las rutinas mediáticas no solo mudan los modos de hacer y narrar, sino que se produce también una revolución en el modelo de consumo. Este último se enmarca, precisamente, en el discurso tecnológico por el que los medios comienzan a abogar: centrarse y concentrar más esfuerzos en la audiencia y, por el contrario, relegar a un segundo plano ese empeño por lograr el engagement de los receptores y que formen parte de los llamados colectivos informados (Peters \& Witschge, 2015).

\subsection{Comunicación móvil y nuevas narrativas en el relato informativo $y$ no ficción: las alternativas del periodismo inmersivo}

El desarrollo de la tecnología ha sido básico para el avance de nuevos perfiles periodísticos. El usuario nunca había estado tan presente en las producciones de los medios como ahora. 
"La adopción de herramientas de participación en la esfera mediática ha creado un nuevo concepto, el del periodismo participativo, en el que los ciudadanos aportan contenidos a partir de las informaciones previamente elaboradas por los medios" (Toural, López \& Silva, 2015: 3).

De este modo, teniendo especialmente en cuenta la función de la audiencia no solo como consumidora, sino también como difusora de sucesos, Campaláns, Renó y Gosciola destacan el papel del receptor como un "prosumidor" -término acuñado por Toffler (1996) en 1980que trabaja con multitud de medios, matizando así una previa definición ofrecida por Jenkins (2003):

"Es interesante que el contenido sea producido por dispositivos móviles, como teléfonos celulares y tablets. Finalmente, es interesante que tenga la posibilidad del actor prosumidor, conocido en los modelos tradicionales de comunicación como receptor, interactuando con el contenido; es decir, fundamentalmente construido a partir de conceptos de interactividad" (Campaláns, Renó \& Gosciola, 2014: 55).

Efectivamente, el papel del prosumidor en el nuevo panorama mediático es fundamental. Los usuarios ya no son solo espectadores de los acontecimientos, sino que se erigen como nuevas fuentes y difusores de información (Cavanilhas, 2010) con la principal baza de que la conexión es inmediata con el lugar del suceso (Espiritusanto \& Gonzalo, 2011).

En paralelo a todo esto, ha surgido el periodismo móvil (MoJo), una corriente en la que también se integran los profesionales de la información y que tiene cada día más peso en el panorama mediático: hoy, el periodista puede actualizar su medio con textos o elementos gráficos como vídeos o imágenes desde el lugar de los hechos y a través de su dispositivo móvil, así como el usuario puede recibir las informaciones y consultarlas en su terminal, en cualquier sitio, al instante siguiente. "La combinación de movilidad e Internet ha surtido éxito. Estamos inmersos en un nuevo contexto comunicativo que bien 
pudiéramos bautizar como la era de los smartphones" (Costa, 2012: 244).

En esta nueva etapa caracterizada por la inmediatez, por información en la palma de la mano y a golpe de clic, los medios tienden a converger en un solo soporte desde el que el usuario tiene acceso a cualquier contenido y desde el que puede compartir sus propias informaciones. Estas nuevas tendencias conllevan también cambios en los modelos de consumo. Para Díaz Noci (2010: 565) "la cultura de la propiedad -y de la necesidad de que la información llegue en un soporte físico- ha dado paso a la cultura del acceso". En este sentido, el autor sostiene que las nuevas pantallas "podrían estar también cambiando la forma de consumo del audiovisual que hasta ahora predominaba: la comunitaria -el cine- o familiar - la televisión- para dar paso a un acceso similar al del libro: individual y en silencio" (2010: 565-566).

Estas nuevas tendencias implican "personalizar, individualizar la comunicación, pues cada receptor tiene un número único y distinto al que se pueden asociar las preferencias y hábitos de uso" (Costa \& Piñeiro citando a Aguado \& Martínez, 2010: 663). Es decir, el periodismo móvil implica cambios en las formas de consumo y producción de información.

"Como dispositivo mediático, ofrece contenidos audiovisuales, incluso el acceso a canales de televisión en algunos casos, o a emisoras de radio en otros [...] Los ciudadanos conectados están cada día más mediatizados full time [...] respondiendo a e-mails, a mensajes a través de Twitter o a través de otras aplicaciones de comunicación como Whatsapp" (Engel \& de Carvalho, 2014: 176).

Pese a que el nuevo y revolucionario panorama de la convergencia ha supuesto una serie de trabas, es innegable que la instantaneidad que domina las nuevas tecnologías ofrece también interesantes novedades y ventajas tanto para los periodistas como para la audiencia.

En medio de este contexto de prosumidores, comunicación móvil e instantaneidad surge el periodismo transmedia. Melle y Pardo (2015) abordan esta tendencia, siguiendo las ideas del ya mencionado Jenkins, 
como "una situación en la que el reportaje se expande a través de múltiples plataformas", y añaden que estas se usan pensando siempre en "la mejor forma de explotar sus capacidades, cada una complementando a la otra para ofrecer un conocimiento completo y rico de los acontecimientos y preocupaciones del mundo real". Así pues, y pese a que en su definición original Jenkins (2003) hablaba solo de narrativas de ficción, con el tiempo su concepción ha evolucionado para abarcar otras posibilidades más allá de la ficción, por lo que ahora entiende las narrativas transmedia como "cualquier relación estructurada a través de los medios. [...] más allá de la narración, tendríamos que hablar sobre marcas, actuaciones, educación, movilización/activismo, periodismo/documental, etc, como alternativas lógicas del transmedia”.

Es interesante revisar también la concepción de periodismo transmedia dada en la guía Mapping the intersection of two cultures: interactive documentary and digital journalism (2014), desarrollada por el MIT Open Documentary Lab, en donde lo definen como un caso donde el reportaje se expande a través de múltiples plataformas, cada una de ellas empleada para explotar sus capacidades, y cada una complementando a la otra para ofrecer un conocimiento completo y rico de los acontecimientos y preocupaciones del mundo real.

En definitiva, se trata de trabajar con diferentes medios usando estrategias de transmedia y crossmedia, de dar enfoques muy diferentes para poder tenerlo todo. En una era de fragmentación de públicos y ofertas, estos enfoques ofrecen una manera de esbozar múltiples audiencias para un proyecto a través de sus distintas manifestaciones y, al mismo tiempo, para hacer frente a las diferentes necesidades de las diversas audiencias de una manera relativamente eficiente.

Recuperando la concepción de Campaláns, Renó y Gosciola (2014: 66), las narrativas transmedia son "un lenguaje que surge naturalmente en la sociedad, y cada día adquiere más fuerza entre los ciudadanos productores de información", es decir, con las narrativas transmedia gana peso una nueva figura de informador: los prosumidores.

Los medios audiovisuales de servicio público no son ajenos a esta situación y se enfrentan entonces al gran reto que supone el contexto de la Sociedad en Red, un panorama de globalización, de consumo bajo 
demanda, de más variados competidores y de un flujo comunicativo cada vez más móvil y ubicuo. La audiencia ya no se encuentra solamente en la pantalla televisiva, el contenedor tradicional, sino que los consumos se han derivado también a plataformas digitales, dando así paso a un ecosistema más social. Y precisamente en este contexto los medios audiovisuales de servicio público europeos se han visto obligados a replantearse las formas de contar, producir y difundir.

$\mathrm{Al}$ abrigo de los últimos avances tecnológicos, nuevas narrativas se ponen sobre la mesa para ofrecer alternativas a los entes ante un ya gastado lenguaje multimedia. En un afán por mejorarlo (Salaverría, 2016) y en buena parte influenciado por el auge de la industria de los videojuegos, especialmente de RV (Domínguez, 2013), y de los procesos de gamificación de sectores (Longui, 2016; Domínguez, 2015; Kapp, 2012), surgen las narrativas inmersivas digitales.

La investigadora Nonny de la Peña (2010: 291) denominó periodismo inmersivo a "la producción de noticias mediante un método que permite a la gente obtener experiencias en primera persona de los eventos o situaciones descritas en los relatos informativos". Esta narrativa, basada principalmente en el empleo de técnicas de grabación $360^{\circ}$ y/o de producción de imágenes sintéticas creadas por ordenador por medio de RV, rompe con los formatos de no ficción existentes hasta el momento de su aparición.

Los recursos de los que se nutre permiten a los usuarios sumergirse en el relato noticioso y experimentar la sensación de presencia en el escenario filmado o mundo virtual (Hardee \& McMahan, 2017; Baía, 2016; Doyle, Gelman y Gill, 2016; Longhi, 2016). Con ello se produce la ruptura de la cuarta pared, frontera liminar o barrera (Murray, 1999; Domínguez, 2013; Longui, 2016) que supone la pantalla de un dispositivo y que, hasta la implementación de dichas técnicas inmersivas en el ámbito periodístico, actuaba como frontera separadora entre el usuario y el mundo narrativo del relato noticioso.

La inmersión sensorial -física en el caso de algunas producciones con RV- en la historia informativa, equiparada en múltiples ocasiones a la experiencia del buceo (Murray, 1999; Ryan, 2004; Bricken, 1993), se produce gracias al empleo de visores o gafas de RV que sitúan al receptor en el centro de la escena y le permiten descubrir el escenario 
a través del movimiento de su cabeza. Estas herramientas aíslan al usuario de su realidad primaria, el lugar en el que se encuentra físicamente, y lo transportan al escenario de la información que visiona (Robson y Costa, 2016), consecuentemente, a una realidad secundaria.

En esta línea, la presente reformulación del formato del relato informativo o de no ficción no solo ha afectado a la forma, sino que también ha tenido consecuencias en la recepción y ha dado paso a un nuevo estadio de consumo: lejos ya de relegarse a leer, visionar y/o escuchar, el usuario ahora puede sumergirse en el escenario o entorno narrativo.

Con todo, dentro de las narrativas inmersivas podemos diferenciar dos tipos de formatos principales y vinculados, precisamente, a los recursos visuales del vídeo esférico, la realidad virtual y el 3D. El formato con más presencia en medios, por su menor coste y tiempo de producción, es el vídeo $360^{\circ}$ (Hardee \& McMahan, 2017; European Broadcasting Union, 2017a), también denominado cinematic VR (Domínguez, 2017) o esférica en movimiento (Doyle, Gelman y Gill, 2016). Estos productos se basan en "una grabación 360 grados de rotación de vídeo" (Kool, 2016: 4) en las que, consecuentemente, el usuario disfrutará de sonido ambiente o real y dispondrá de un movimiento giratorio -aunque limitado por su ubicación en un punto fijo sobre el escenario- al poder visionar arriba, abajo, derecha e izquierda.

Múltiples RTPEs han visto potencial en este formato y ello lo demuestra la creación de aplicaciones específicas para el consumo de estos vídeos $360^{\circ}$. Algunas de las plataformas disponibles para su descarga son: ZDF VR, estrenada en octubre de 2016 por la alemana Zweites Deutsches Fernsehen; Vive Rio: Heorínas, lanzada con motivo de los Juegos Olímpicos de Río de 2016 por Radiotelevisión Española; o mismo Le Goût $d u$ Risque, una aplicación de France Télévisions fruto de un proyecto transmedia de deportes de riesgo que publicó a mediados también de 2016 en colaboración con Radio Télévision Suisse.

Sin embargo, si bien existen entes que no disponen de aplicaciones de consumo inmersivo, estos difunden sus contenidos a través de otros reproductores que soportan este formato, normalmente incrustados en sus propias webs oficiales (European Broadcasting Union, 2017a), o en plataformas digitales como YouTube o Facebook (European 
Broadcasting Union, 2017a, 2017b). Estos dos últimos permiten reproducir vídeos $360^{\circ}$ sin dificultades (Robson y Costa, 2016) y en la actualidad, especialmente YouTube, actúan como importantes repositorios de almacenaje, difusión y consulta de vídeos inmersivos (Pérez-Seijo \& López-García, 2017).

"La experiencia inmersiva abre todo tipo de posibilidades para los productores de contenidos, permitiéndoles apartarse de la narración televisiva lineal a una donde la audiencia puede ganar un mayor contexto gracias a la exploración visual de aquello que suele estar fuera del campo de visión. Además, ahora el contenido de realidad virtual es soportado por YouTube y Facebook, entre otros" (Public Service Media, 2017).

A la hora de consumir estas piezas existen dos vías: a través de unos visores de RV o bien por medio de la pantalla del dispositivo móvil -ya sea mediante interacción táctil en la misma o haciendo uso del giroscopio-, la cual se convierte en una ventana de acceso al mundo virtual (Hardee \& McMahan, 2017).

El segundo formato sería el de los contenidos generados sintéticamente por ordenador. Las piezas de RV o CG-content se basan en la construcción de escenarios esféricos - permiten una visualización $360^{\circ}$-, imaginarios o reales (Owen, Pitt, Aronson-Rath \& Milward, 2015), a través de imágenes sintéticas (Robson y Costa 2016), en ocasiones también tridimensionales. Además, las piezas que consisten en recreaciones de sucesos reales pueden ser enriquecidas con audios de testimonios reales para otorgarle, de esta manera, una mayor verosimilitud a la información.

El usuario accede al escenario narrativo gracias al uso de unas gafas de RV y normalmente en calidad de avatar, una representación animada que actúa como su ser en el escenario de la información (De la Peña et al., 2010). Como el alter ego digital ejerce de cuerpo del receptor, lo habitual es que el participante solo pueda ver las extremidades del mismo, caso de las piernas o de los brazos, para de este modo darle realismo al proceso de inmersión. Se trataría, por ende, de una estrategia de ocularización interna primaria. 
Si bien ambas tipologías de productos inmersivos son muy distintas en cuanto a producción se refiere, tanto los vídeos $360^{\circ}$ como el CGcontent ofrecen, en mayor o menor nivel, recursos para aumentar la sensación de exploración de los escenarios informativos (Domínguez, 2017).

La denominada corriente inmersiva, especialmente la vertiente de RV, se articula alrededor de tres elementos que, combinados, permiten alcanzar la inmersión narrativa (De la Peña et al., 2010): la ilusión de presencia que puede producirse cuando el usuario se traslada a un ambiente virtual aunque este sepa que no está ahí físicamente; la plausibilidad, es decir, la sensación de que algo o una determinada situación es real, pese a que lo que esté visionando sea un vídeo esférico de imágenes reales o sintéticas; $y$, para completar la tríada, la posesión de un cuerpo sintético en el mundo virtual, un avatar con el que acceder al escenario narrativo.

En este último caso, cuando la pieza inmersiva es un vídeo $360^{\circ}$, en la mayoría de los casos el usuario no accede como avatar, pues una animación restaría verosimilitud a la acción grabada, sino que es común el empleo de la técnica de la cámara subjetiva. Este recurso cinematográfico consiste en simular que los personajes que aparecen en la pieza audiovisual se dirigen, miran o hablan con el usuario, simulando que este se encuentra realmente en el escenario filmado (Domínguez, 2017).

\subsubsection{Narrativas inmersivas digitales como fórmula de innovación de las radiotelevisiones públicas europeas}

La obsolescencia es uno de los principales retos a los que los medios audiovisuales de servicio público se enfrentan. Ganar la batalla es una cuestión de recursos, voluntad/iniciativa y cambios en las formas de comunicar y difundir. Innovación, en resumidas cuentas.

La Unión Europea de Radiodifusión -en inglés European Broadcasting Union y desde ahora UER-, la principal alianza de medios de servicio público a nivel internacional, ha ido articulándose y madurando bajo la misión de convertir a sus entes en indispensables para la sociedad. Por ello, la UER presenta en sus Estatutos (2015b) los siguientes objetivos: 
1. Promover y desarrollar el concepto de medios de servicio público, así como sus valores, destacando la universalidad, la independencia, la excelencia, la diversidad, la responsabilidad social y la innovación.

2. Salvaguardar y mejorar la libertad de expresión e información, la base de las sociedades democráticas y del progreso.

3. Potenciar la libertad de expresión y opinión y la pluralidad en los medios.

4. Emplear y desarrollar las últimas tecnologías de información y comunicación con el fin de garantizar a la sociedad el acceso a estos medios.

5. Favorecer la diversidad cultural para promover los valores de tolerancia y solidaridad.

6. Proteger y promover la herencia cultural europea y el desarrollo de sus creaciones audiovisuales mediante una creciente gama de programas y servicios.

7. Reforzar la identidad de los pueblos, la cohesión social y la integración de todos los individuos, grupos y comunidades.

8. Cumplir las expectativas como servicio público en materia de información, educación, cultura y entretenimiento a través de la producción y difusión de una programación ampliamente variada y de alta calidad.

Precisamente los puntos 1 y 4 son los que en esta comunicación interesan por el tema que abarca la misma: las narrativas inmersivas. Entre los valores que los miembros de la UER deben promover se encuentran el de la innovación y el empleo y desarrollo de las últimas tecnologías de información y comunicación. La asociación plantea ambos elementos de la siguiente manera:

"Nos esforzamos por ser una fuerza impulsora de innovación y creatividad. Dirigimos nuestra vista a nuevos formatos, tecnologías y formas de conectar con nuestra audiencia. Queremos atraer, retener y formar a 
nuestro personal para que puedan participar y dar forma al futuro digital, sirviendo a nuestro público" (European Broadcasting Union, 2012).

El equipo de Tecnología e Innovación es el responsable de garantizar estas cuestiones. La UER creó este departamento para poder así investigar, desarrollar e implementar las últimas técnicas, tecnologías y medios de radiodifusión: "nuestro equipo de Tecnología e Innovación está aquí para acelerar la innovación tecnológica y ofrecer una mayor experiencia, calidad y compromiso con los miembros" (European Broadcasting Union, 2015a). Entre las medidas tomadas hasta 2017 estarían: el salto a la radio digital, la apuesta por la televisión de alta definición (HDTV) y la implementación de narrativas inmersivas de RV y $360^{\circ}$.

Mas estas tareas de avance y desarrollo tecnológico digital no se limitan a un grupo reducido de expertos de la UER, sino que para que todos los entes miembros de esta organización puedan estar al día de las últimas novedades en cuanto a formatos, medios y vías de consumo, la UER organiza periódicamente workshops, participa en conferencias internacionales como la Innovation Broadcast Conference (IBC) y crea plataformas de discusión para los entes adscritos a la asociación, así como también propone otros eventos de networking y aprendizaje (European Broadcasting Union, 2017b).

La UER publica anualmente el Informe de Actividad de Tecnología e Innovación en el que recoge los objetivos y propósitos de cada periodo. Desde hace varios años, las narrativas inmersivas forman parte de las principales metas del departamento. En el Informe de 2014-2015 ya mostraban sus primeros pasos en la aplicación estas técnicas en sus productos:

"Este año nos hemos centrado en el debate del espectro, la radio digital, la producción integrada de medios, la producción en red, la neutralidad de la red, la televisión híbrida y la siguiente generación de experiencia de usuario inmersiva en televisión y sonido" (European Broadcasting Union, 2015a: 4). 
Refiriéndose a los productos $360^{\circ}$ y de RV como "la siguiente generación de experiencia", el departamento de Tecnología e Innovación dejaba ya patente los cambios en los modos y modelos de consumo a los que los usuarios harían frente en el futuro próximo. Un reto agilizado por la creciente apuesta de la industria de los videojuegos por la RV y la inmersión sensorial mediante cascos o gafas de RV.

Un año más tarde, en el informe publicado en 2016, y coincidiendo el avance y el progresivo calado de las tecnologías y técnicas inmersivas en las rutinas productivas de medios nacionales e internacionales, el departamento tecnológico de la UER optó por incluir un espacio de "Cámaras de 360 grados y realidad virtual" dentro del apartado dedicado a producción destacada. Con esta acción la principal alianza de medios audiovisuales de servicio público demostraba su interés por las narrativas inmersivas y su apuesta por fomentar la aplicación de dichas técnicas entre sus miembros.

"La UER está investigando esta nueva tecnología y las formas en que puede utilizarse en el futuro para crear nuevos contenidos personalizados para el público. Hemos tenido más de 10 demostraciones de realidad virtual de miembros y fabricantes de la UER en el Seminario de Tecnología de Producción de este año y actualmente estamos proporcionando soporte técnico para extender la actual Plataforma de Intercambio de Noticias de la UER para apoyar esta nueva tecnología" (European Broadcasting Union, 2016a: 9).

En 2016 la UER también lanzó el informe Visión 2020: Conectar, crecer e influir. En dicho documento anunciaba sus objetivos estratégicos de cara a los siguientes cuatro años. Entre estos contemplaba, precisamente, la "producción de realidad virtual/contenido inmersivo" (European Broadcasting Union, 2016b: 15) como una forma o medio potencial encaminado a reconectar con las audiencias (2017b).

Desde entonces, los principales esfuerzos de los miembros de la UER se han centrado en la producción de vídeos por medio de técnicas de grabación $360^{\circ}$, el formato más extendido (Hardee \& McMahan, 2017; European Broadcasting Union, 2017a): "más de la mitad de los miembros han empezado, o están en ello, a facilitar el acceso a 
contenidos 360 grados" (European Broadcasting Union 2017b: 8), aunque la mayoría todavía sigue experimentando u ofreciendo a los usuarios productos primerizos enfocados a tantear la retroalimentación de los mismos.

Mas las razones del calado de los vídeos $360^{\circ}$, conocidos también como cinematic VR (Domínguez, 2017) o piezas esféricas en movimiento (Longui, 2016; Doyle, Gelman y Gill, 2016), se encuentran fundamentalmente en su menor coste de producción y en sus posibilidades de inmediatez frente a los contenidos generados sintéticamente por ordenador con RV, así como en la democratización de su acceso entre los consumidores gracias a la proliferación en el mercado de visores o gafas de realidad virtual de bajo coste (Hardee \& McMahan, 2017), siendo el ejemplo más paradigmático las Google Cardboard.

Si cabe, una de las acciones más relevantes llevadas a cabo hasta 2017 en cuanto a narrativas inmersivas se refiere, ha sido la cofundación del VR Industry Forum (VRIF).

\section{Método}

Esta investigación nace con el objetivo de advertir cómo las RTPEs organizan y categorizan/identifican sus contenidos inmersivos en vídeo $360^{\circ}$ de carácter informativo y no ficción en dos de las principales plataformas de acceso a productos audiovisuales: las páginas webs y YouTube.

Partimos de la hipótesis de que dichos entes tratan de seguir una estrategia enfocada a facilitar el acceso al receptor para obtener cifras de consumo no residuales. Las razones de este afán podrían hallarse en la corta edad de las técnicas inmersivas aplicadas al periodismo digital y en el desconocimiento por buena parte del público tanto del formato como del proceso de consumo. La importancia del periodismo inmersivo y de su estudio es relevante dado que las narrativas de las que se compone están en creciente expansión y paulatina, aunque todavía novel, consolidación en medios.

Al margen de indagar si las RTPEs europeas centran sus esfuerzos en identificar los contenidos inmersivos, también nos propusimos averiguar cómo los organizan, jerarquizan o categorizan. Por lo tanto, 
descubrir qué estrategia o método aplican sus páginas webs y sus cuentas de YouTube.

\subsection{Muestra}

La muestra empleada para este estudio está compuesta por las radiotelevisiones públicas de los 28 países de la Unión Europea y, simultáneamente, adscritas a la UER que implementan las narrativas y técnicas inmersivas de vídeo $360^{\circ}$ en sus contenidos informativos y no ficción. La muestra se corresponde con una ya validada en un estudio previo (Pérez-Seijo \& López-García, 2017) y que está formada por aquellos entes que han aplicado dichas técnicas en al menos una ocasión durante los 18 meses comprendidos entre el 1 de octubre de 2015 y el 31 de marzo de 2017.

El matiz de los miembros de la UER es relevante ya que entre los principales objetivos de esta asociación se encuentra la innovación constante, el enriquecimiento del panorama audiovisual de servicio público y la democratización del acceso a los últimos avances tecnológicos de formas y consumos por parte de la sociedad.

De este modo, los medios audiovisuales de servicio público analizados son los 33 que se recogen en la tabla. Debemos aclarar que durante la exposición de los resultados nos referimos a cada ente por sus pertinentes siglas, también incluidas en el cuadro.

\section{Tabla 1. RTPEs de la muestra que implementan las narrativas inmersivas}

\begin{tabular}{|c|c|c|c|c|c|c|c|}
\hline País & RTPE & & País & \multicolumn{4}{|c|}{ RTPE } \\
\hline \multirow{2}{*}{ Austria } & \multirow{2}{*}{$\begin{array}{l}\text { Österreichischer } \\
\text { Rundfunk }\end{array}$} & \multirow{2}{*}{ ORF } & \multirow{9}{*}{ Alemania } & \multirow{8}{*}{$\begin{array}{l}\text { Arbeitsgemeinschaft der } \\
\text { öffentlich-rechtlichen } \\
\text { Rundfunkanstalten der } \\
\text { Bundesrepublik } \\
\text { Deutschland }\end{array}$} & \multirow{8}{*}{$A R D$} & $\begin{array}{l}\text { Bayerischer } \\
\text { Rundfunk }\end{array}$ & $B R$ \\
\hline & & & & & & $\begin{array}{l}\text { Mitteldeutscher } \\
\text { Rundfunk }\end{array}$ & $M D R$ \\
\hline España & $\begin{array}{c}\text { Radiotelevisión } \\
\text { Española }\end{array}$ & $R T V E$ & & & & Deutsche Welle & $D W$ \\
\hline Portugal & $\begin{array}{c}\text { Rádio e Televisão } \\
\text { de Portugal }\end{array}$ & $R T P$ & & & & $\begin{array}{l}\text { Hessischer } \\
\text { Rundfunk }\end{array}$ & $H R$ \\
\hline \multirow{3}{*}{ Finlandia } & \multirow{3}{*}{ Yleisradio Oy } & \multirow{3}{*}{$Y L E$} & & & & $\begin{array}{l}\text { Norddeutscher } \\
\text { Rundfunk }\end{array}$ & $N D R$ \\
\hline & & & & & & $\begin{array}{c}\text { Rundfunk Berlin- } \\
\text { Brandenburg }\end{array}$ & $R B B$ \\
\hline & & & & & & $\begin{array}{l}\text { Westdeutscher } \\
\text { Rundfunk }\end{array}$ & $W D R$ \\
\hline \multirow[t]{2}{*}{ Bélgica } & $\begin{array}{l}\text { Radio-Télévision } \\
\text { Belge de la } \\
\text { Communauté } \\
\text { française }\end{array}$ & $R T B F$ & & & & Südwestrundfunk & $S W R$ \\
\hline & $\begin{array}{l}\text { Vlaamse Radio } \\
\text { en Televisieomroep }\end{array}$ & $V R T$ & & $\begin{array}{c}\text { Zweites Deutsches } \\
\text { Fernsehen }\end{array}$ & \multicolumn{3}{|c|}{$Z D F$} \\
\hline
\end{tabular}




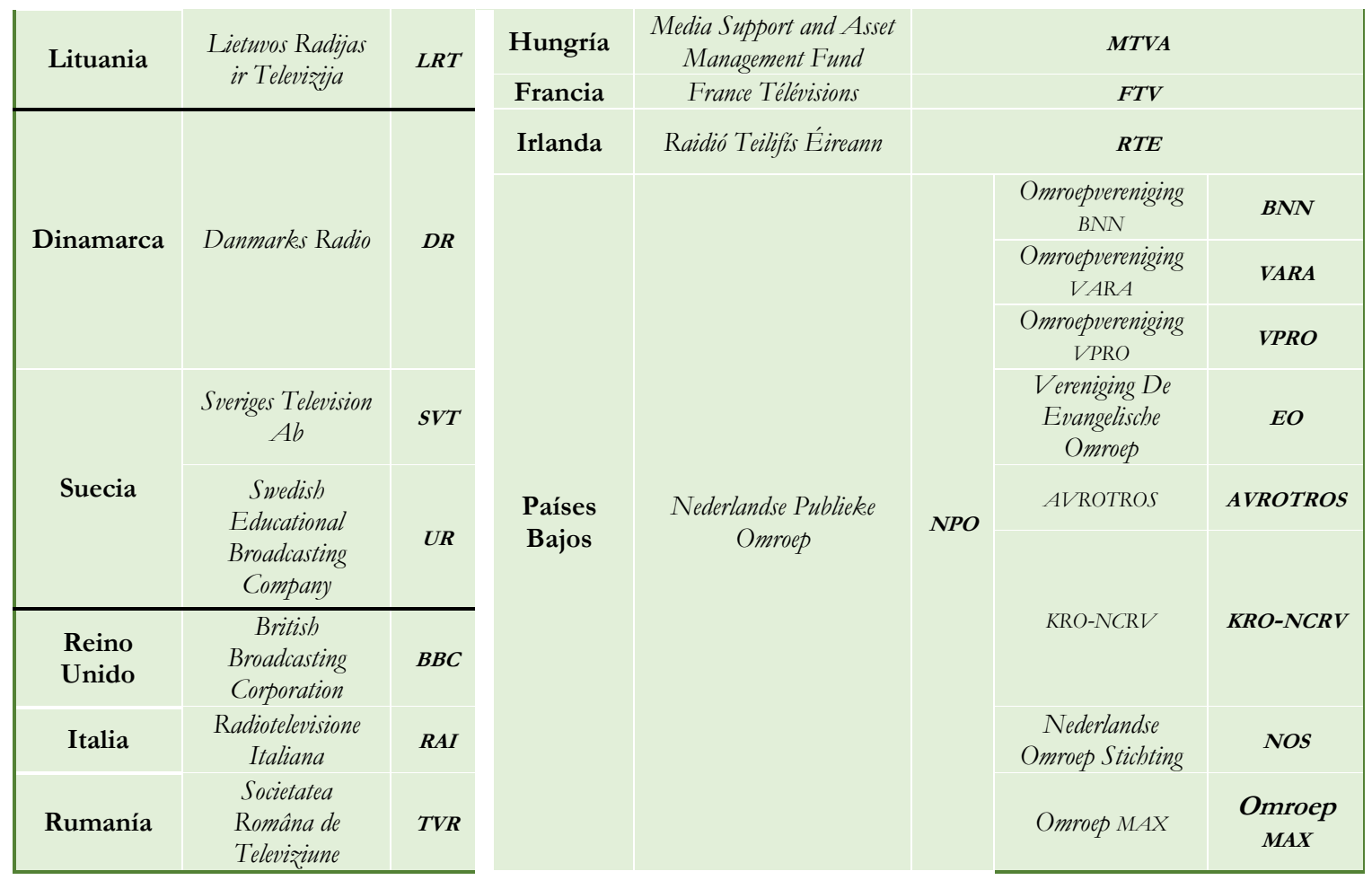

Fuente: elaboración propia.

A la hora de extraer la muestra de plataformas -webs y canales de YouTube- con contenido inmersivo publicado procedimos a una búsqueda directa y posterior codificación en listas por ente. Iniciamos la recopilación el 1 de abril de 2017 y finalizamos el 15 de abril del mismo año. Los posteriores quince días los dedicamos a la identificación de las listas, por lo que estas se corresponden con todas aquellas publicadas y disponibles durante el mes de abril de 2017. En total estudiamos 27 páginas webs, los canales de YouTube vinculados a 32 entes y 30 listas encontradas en las diversas cuentas de YouTube. Los nombres de estos elementos, citados durante la explicación de los resultados, han sido respetados en su escritura original, por lo que se mantienen mayúsculas, guiones y cualquier otro tipo de peculiaridad estilística propia.

El método de análisis seguido para extraer los datos se ha basado en técnicas de metodología cuantitativa. Hemos diseñado una ficha de análisis para agilizar el proceso de recogida de información. 
Tabla 2. Modelo de ficha empleada en el análisis cuantitativo

\begin{tabular}{|c|c|c|}
\hline ÍTEM & \multicolumn{2}{|c|}{ RESPUESTA } \\
\hline \multicolumn{3}{|l|}{ Nombre de la RTPE } \\
\hline Difunde contenido en vídeo $360^{\circ}$ no ficción vía web & Sí & $\mathrm{No}$ \\
\hline \multirow[b]{2}{*}{$\begin{array}{l}\text { En la web tiene una sección dedicada a contenidos en } \\
\text { vídeo } 360^{\circ}\end{array}$} & Sí & $\mathrm{No}$ \\
\hline & $\begin{array}{c}\text { Título de } \\
\text { la } \\
\text { sección: }\end{array}$ & \\
\hline $\begin{array}{l}\text { Emplea titulillos o separadores para destacar en } \\
\text { informaciones los vídeos } 360^{\circ}\end{array}$ & Sí & No \\
\hline \multirow{2}{*}{$\begin{array}{l}\text { Difunde contenido en vídeo } 360^{\circ} \text { en un canal de } \\
\text { YouTube propio o vinculado }\end{array}$} & Sí & $\mathrm{No}$ \\
\hline & ¿Cuáles? & \\
\hline \multirow{2}{*}{ Tiene un canal exclusivo para contenidos inmersivos } & Sí & No \\
\hline & ¿Cuál? & \\
\hline \multirow[b]{2}{*}{ Categoriza los vídeos en listas } & Sí & No \\
\hline & $\begin{array}{c}\text { ¿Qué } \\
\text { listas y en } \\
\text { qué } \\
\text { canales? }\end{array}$ & \\
\hline
\end{tabular}

Fuente: elaboración propia.

\section{Resultados}

Con este estudio pretendíamos advertir cómo las RTPES sus contenidos en formato vídeo $360^{\circ}$ de carácter informativo y no ficción en dos de las principales plataformas digitales de difusión de productos audiovisuales: sus webs oficiales y sus canales de YouTube, todos aquellos vinculados directamente con el ente y sus programas.

En el caso de las webs, examinamos cómo las radiotelevisiones identifican o resaltan estas piezas en las informaciones o páginas, así como si también crean secciones específicas para almacenar dichos contenidos inmersivos. El fin de estas estrategias serían, por tanto, otorgarles mayor visibilidad a estos productos y facilitarle al usuario su acceso y consumo.

En cuanto a la plataforma de vídeos YouTube, nos centramos en advertir cuántos entes han creado canales propios de difusión exclusiva de piezas inmersivas y cuántos, contrariamente, hacen uso de los ya existentes vinculados al medio y sus programas. En este último caso, 
también prestamos especial atención a la categorización e identificación de los vídeos $360^{\circ}$ por medio de listas. Al igual que los métodos de la web, se trata de una estrategia que no solo le agiliza al usuario el proceso de búsqueda e identificación de dichos contenidos, sino también su disfrute.

\subsection{Páginas webs: secciones específicas para almacenar $y$ organizar contenido $360^{\circ}$}

Las webs de las radiodifusoras son importantes repositorios de información y contenido audiovisual. A través de estas puede accederse a gran parte de los productos difundidos por las televisiones, una tarea que se ve facilitada gracias a la categorización por secciones. Mediante esta investigación pretendíamos advertir si la organización de los contenidos se llevaba también al campo de los productos inmersivos y si, por ende, estos se identificaban bajo una sección común facilitando así al espectador su acceso y consumo.

Gráfico 1. RTPES con secciones web dedicadas a contenido inmersivo

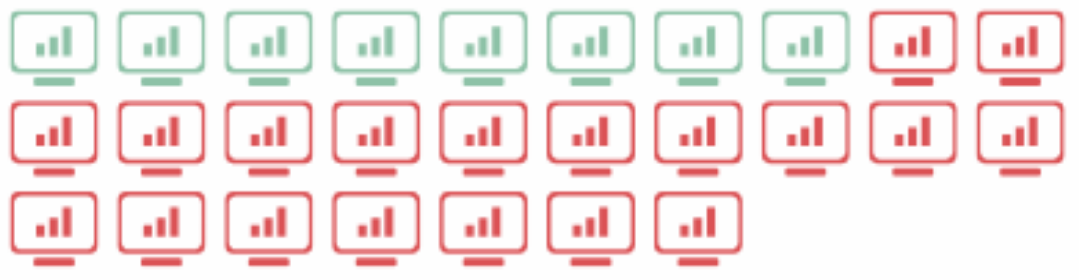

Tienen secciones $360^{\circ}$

No tienen secciones $360^{\circ}$

Fuente: elaboración propia.

El paso inicial consistió en advertir cuántas RPTES difunden contenidos inmersivos a través de sus webs. Finalmente obtuvimos que el 81,82\% las utilizan para publicar sus vídeos $360^{\circ}$ : DW, NDR, BR, WDR, MDR, HR Y RBB del conglomerado ARD (Alemania); RTVE (España); VARA, VPRO, EO, AVROTROS, KRO-NCRV, NOS y Omroep MAX del grupo NPO (Países Bajos); FTV (Francia); YLE (Finlandia); RAI (Italia); RTBF (Bélgica); MTVA (Hungría); RTE (Irlanda); BBC (Reino Unido); LRT 
(Lituania); ZDF (Alemania); VRT (Bélgica); ORF (Austria); y DR (Dinamarca).

Tras bucear y rastrear estas plataformas, nos encontramos con que tan solo el 29,63\% de estas televisiones ha creado un apartado o sección para almacenar y facilitar el acceso a sus vídeos $360^{\circ}$. Por el contrario, el 70,37\% de las radiodifusoras todavía no había creado, hasta la fecha el 30 de abril de 2017, lo que hemos denominado carta de vídeos inmersivos.

\section{Tabla 3. Secciones para vídeos $360^{\circ}$ en las webs de las RTPES}

\begin{tabular}{|c|c|c|c|c|c|}
\hline País & \multicolumn{2}{|c|}{ RTPE } & \multicolumn{2}{|c|}{ Sección } & URL \\
\hline $\begin{array}{l}\text { Países } \\
\text { Bajos }\end{array}$ & \multicolumn{2}{|c|}{$E \boldsymbol{O}$} & \multicolumn{2}{|c|}{ EO Virtual Reality } & eo.nl/virtual-reality/ \\
\hline \multirow{2}{*}{$\begin{array}{l}\text { Reino } \\
\text { Unido }\end{array}$} & \multirow{2}{*}{\multicolumn{2}{|c|}{$B B C$}} & \multirow{2}{*}{$\begin{array}{l}\text { Dentro de } \\
\text { Taster: }\end{array}$} & Immersive stories & $\begin{array}{c}\text { bbc.co.uk/taster/categories/immersive- } \\
\text { stories/ }\end{array}$ \\
\hline & & & & Virtual reality & $\begin{array}{c}\text { bbc.co.uk/taster/categories/virtual- } \\
\text { reality/ }\end{array}$ \\
\hline \multirow{3}{*}{ Alemania } & $\begin{array}{l}A \\
\boldsymbol{R} \\
\boldsymbol{D}\end{array}$ & $\begin{array}{l}W \\
D \\
R\end{array}$ & \multicolumn{2}{|c|}{$360^{\circ}$ videos } & $\begin{array}{l}\text { www1.wdr.de/virtual-reality-uebersicht- } \\
\text { 100.html }\end{array}$ \\
\hline & & $\begin{array}{l}N \\
D R\end{array}$ & \multicolumn{2}{|c|}{$\begin{array}{c}\text { NDR } 360^{\circ} \text { - alle videos mit } \\
\text { Rundumblick }\end{array}$} & $\begin{array}{l}\text { ndr.de/NDR-360-alle-Videos-mit- } \\
\text { Rundumblick,dreisechzig104.html }\end{array}$ \\
\hline & \multicolumn{2}{|c|}{$Z D F$} & \multicolumn{2}{|c|}{$360^{\circ}$ staunen } & vr.zdf.dv \\
\hline \multirow[b]{2}{*}{ Bélgica } & \multicolumn{2}{|c|}{$V R T$} & \multicolumn{2}{|c|}{$360^{\circ}$-video } & deredactie.be/cm/vrtnieuws $/ 360$ \\
\hline & \multicolumn{2}{|c|}{$R T B F$} & $\begin{array}{l}\text { Dentro de } \\
\text { Webcréation: }\end{array}$ & VR et 360 & $\begin{array}{c}\text { rtbf.be/webcreation/archive_vr-et- } \\
\text { 360?dossier }=4839\end{array}$ \\
\hline España & \multicolumn{2}{|c|}{$R T V E$} & $\begin{array}{l}\text { Dentro de } \\
\text { RTVE Lab: }\end{array}$ & VR & rtve.es/lab/realidad-virtual/ \\
\hline
\end{tabular}

Fuente: elaboración propia.

Hasta la fecha, tan solo ocho televisiones han creado secciones dedicadas a contenidos $360^{\circ}$ en sus páginas. Estas funcionan como una suerte de repositorios donde se almacenan y concentran los vídeos $360^{\circ}$, de tal forma que al usuario le resulta más sencillo acceder y consumir piezas producidas mediante este formato. Las radiodifusoras con sección para contenidos $360^{\circ}$ son: $E O$, del conglomerado alemán $N P O$, con "EO Virtual reality"; la británica $B B C$ con dos secciones dentro de su laboratorio Taster, "Immersive stories" y "virtual reality"; WDR, del conglomerado alemán $A R D$, con " $360^{\circ}$ videos"; $N D R$, miembro de $A R D$ también, con "NDR $360^{\circ}$ - alle videos mint rudumblick"; $Z D F$, también alemana, con " $360^{\circ}$ staunen"; la belga $V R T$ con " $360^{\circ}$-video"; RTBF, también belga, con "VR et 360"; y, finalmente, la española RTVE con "VR" dentro de la página del laboratorio Lab RTVE.es 
No obstante, aunque el 70,37\% restante de radiodifusoras que difunden contenidos inmersivos a través de sus webs no los concentren bajo una sección, no implica que no los diferencien igualmente. Entre las alternativas más comunes está el recurso de titulillos para identificar en una información o página las piezas $360^{\circ}$, o la creación de subsecciones con estos contenidos dentro de informaciones especiales. Un claro ejemplo lo constituye RAI (Italia) con su cobertura de los Juegos Olímpicos de 2016. En su sección de deportes Sport preparó un especial en el que incluyó el subapartado "Rio VR 360", donde concentró todos sus videos $360^{\circ}$ sobre las competiciones deportivas.

\subsection{YouTube: organización de los contenidos $360^{\circ}$ en los canales}

YouTube es una de las plataformas digitales más recurridas por las RTPEs a la hora de difundir sus contenidos $360^{\circ}$ informativos y no ficción. Ello lo prueba que el 96,97\% de los entes la han empleado para subir estas piezas: RTP (Portugal); RTVE (España); RTE (Irlanda); BBC (Reino Unido); RAI (Italia); FTV (Francia); RTBF (Bélgica); VRT (Bélgica); DR (Dinamarca); ZDF (Alemania); UR (Suecia); YLE (Finlandia); LRT (Lituania); TVR (Rumanía); MTVA (Hungría); ORF (Austria); SWR, BR, MDR, DW, HR, NDR, RBB y WDR del conglomerado ARD (Alemana); y BNN, VARA, VPRO, EO, AVROTROS, KRO-NCRV, NOS y Omroep MAX del conglomerado NPO (Países Bajos).

$\mathrm{Al}$ igual que con las webs, nuestro objetivo aquí es examinar cómo las televisiones organizan sus productos inmersivos en YouTube. Es decir, si abogan por una centralización de contenidos, si mantienen una suerte de orden o si, por el contrario, impera el desorden y el libre albedrío.

Nos planteamos la pregunta de si las televisiones apuestan por crear canales de YouTube dedicados exclusivamente a sus contenidos $360^{\circ}$ o si, en realidad, hacen uso de los ya existentes asociados/vinculados al propio ente o a alguno de sus programas.

En este sentido, obtuvimos que el 96,87\% de las RTPS no ha creado un canal de YouTube específico para sus contenidos $360^{\circ}$. De este modo, tan solo el 3,13\% de los entes ha creado un canal dedicado única y exclusivamente a sus producciones de no ficción y/o informativas $360^{\circ}$. 
La belga VRT es por tanto la única radiodifusora que ha decidido diferenciar sus contenidos en vídeo 360 mediante la creación de un canal específico: VRT V irtual Reality. Sin embargo, si bien en un primer momento VRT planteó esta acción como una suerte de centralización de sus productos inmersivos, con el tiempo acabó rompiendo la estrategia para difundir también estas piezas en otros de sus canales.

Ante los resultados hallados, nos cuestionamos otro aspecto: si las radiodifusoras no abren canales concretos para las esféricas en movimiento, ¿es posible que sí creen listas de reproducción en sus cuentas de YouTube? Con nuestro planteamiento pretendíamos advertir si los entes trataban de identificar sus productos inmersivos y, por ende, facilitar el acceso a los mismos a los receptores mediante la clasificación de las piezas en listas.

Para ello, procedimos a la revisión de los canales de YouTube de cada medio - oficiales de la radiodifusora, de programas, temáticos, etcétera. Tras esto, los datos resultantes mostraron un panorama dicotómico, puesto que la diferencia entre las cifras de entes que sí crean listas de reproducción frente a los que no resultó ser reducida. Así, un 53,13\% de las televisiones que publica contenidos 360 en YouTube aboga por la creación de una o más listas en su/s canal/es dentro de la plataforma para diferenciar sus vídeos $360^{\circ}$, mientras que el $46,87 \%$ no opta por hacer esta distinción.

Entre las radiodifusoras que no han apostado por la ordenación de contenidos en listas se topan: ORF (Austria), RTP (Portugal), LRT (Lituania), DR (Dinamarca), RTE (Irlanda), YLE (Finlandia); RAI (Italia); $B N N$, VPRO, AVROTROS, Omroep MAX y EO del conglomerado NPO (Países Bajos); y DW, HR y RBB del conglomerado $A R D$ (Alemania).

Por el contrario, aquellos que sí han optado por la creación de listas de reproducción que no solo concentran los contenidos, sino que los identifican y facilitan su acceso y consumo por parte de los receptores, son: RTVE (España), UR (Suecia), RTBF (Bélgica), VRT (Bélgica), MTVA (Hungría), FTV (Francia), BBC (Reino Unido), ZDF (Alemania); TVR (Rumanía); $M D R, B R, N D R, W D R$ y $S W R$ del conglomerado $A R D$ (Alemania); y $V A R A$, KRO-NCRV y NOS del grupo NPO (Países Bajos). 
Si bien la cifra de RTPS que han creado alguna lista de reproducción en una o en varias de sus cuentas de YouTube es en total de 17, el número de listas encontradas asciende a 30. Esta cifra nos lleva a la conclusión de que algunos entes disponen de más de una para diferenciar sus contenidos.

Dentro del 53,13\% de radiodifusoras públicas europeas que recurre a las listas para identificar sus contenidos, el $64,71 \%$ del total solo dispone de una, mientras que el 35,29\% ha creado dos o más.

En ese $64,71 \%$ de entes que identifican sus contenidos $360^{\circ}$ de YouTube por medio de una única lista, se encuentran: RTVE (España), con "Vídeos 360" que se encuentra en su canal RTVE .es; RTBF (Bélgica), con "VR et 360" en el canal RTBF; VRT (Bélgica) con "360/VR" en su canal VRT NWS, dedicado a información de actualidad y noticias; UR (Suecia), cuya lista se titula "Mobbning i 360" -dedicada a un reportaje de acoso escolar- y se encuentra en su canal UR; $B R$, del conglomerado alemán $A R D$, con "360-Grad-Videos", que se encuentra en su canal Bayerischer Rundfunk; NDR, del conglomerado alemán $A R D$, con "Dokus in 360" dentro de su canal NDR Doku, dedicado a documentales; $S W R$, del conglomerado alemán $A R D$, con "360 Grad Views" en SWR; MTVA (Hungría) con “A Dal 2017 - Multicam 360 videók", dedicada al concurso por el cual se elige al ganador que representará al país en Eurovisión", que se encuentra en su canal $A$ Dal 2017; TVR (Rumanía) con "Clipuri filmate cu tehnologie $360^{\circ}$ : Imagini de la Eurovision", dentro del canal TVR; $V A R A$, del grupo neerlandés NPO, con “DWDD Pop Up Museum 2: 360 Tour”, ubicada en el canal $D W D D$, el oficial del programa De Wereld Draait Door; y, finalmente, NOS, del grupo neerlandés NPO, con la lista "Rondkijken in 360 graden" que se halla en el canal de deportes NOS Sport.

El 35,29\% restante y que cuenta con dos o más listas de reproducción está compuesto por:

- $W D R$, del conglomerado alemán $A R D$. Tiene dos listas:

- “360 Grad Videos”, dentro de su canal WDR, de carácter generalista.

- “360-videos", dentro del canal de Sportschau, dedicado a temas deportivos. 
- MDR, del conglomerado alemán ARD. Cuenta con 3 listas:

- "360 Grad-Videos von MDR THÜRINGEN", dentro de su canal oficial como ente: MDR Mitteldeutscher Rundfunkm.

- "MDR Garten", dentro de su canal oficial como ente: MDR Mitteldentscher Rundfunkm. No obstante, se trata de una lista temática, pues todos los vídeos son producciones incluidas dentro del programa de jardinería Garten, de ahí el nombre de la lista.

- “360 VR Denkmaltour", dentro del canal MDR ZEITREISE2go, perteneciente a Zeitrese, un magazine sobre historia. La lista, por tanto, es temática y dispone de contenidos exclusivos del programa.

- ZDF (Alemania). Cuenta con 2 listas:

- Una generalista en el canal oficial del ente ZDF: “360 Grad Videos".

- Y otra temática y oficial del programa Terra X, cuyo canal de YouTube recibe el nombre Terra X Natur \& Geschichte: "VR - Terra $\mathrm{X}$ in 360 ".

- FTV (Francia) dispone de 2 listas:

- Una generalista, "Vidéos 360" en el canal France Télévisions.

- Y "WINGSUIT / BODYBOARD / SNOWBOARD / APNEE en Vidéos $360^{\circ}$ - Le Goût Du Risque”, que es temática y propia del programa de deportes Le Goût du Risque, que le da nombre al canal.

- KRO-NCRV, del grupo neerlandés NPO. Cuenta con tres listas, todas dentro del canal del programa Brandpunt, que recibe el mismo nombre:

- “360 graden video vanuit Irak: indringende beelden van de strijd tegen IS", generalista y engloba todos los vídeos, incluidos los de las dos listas siguientes.

- "Hoe wonen vluchtelingen in Libanon en Eindhoven?", específica.

- "Follow the refugee in $360^{\circ}$ video", específica. 
- $B B C$ (Reino Unido). Cuenta con siete listas repartidas en diferentes canales:

- Una de carácter generalista en su canal de noticias $B B C$ News: "BBC NEWS IN 360 VIDEO".

- Otra también generalista en el canal del laboratorio $B B C$ News Lab "360 \#VR Immersive Journalism".

- Dos dentro del canal oficial del ente, BBC: "360 Videos BBC", que sería de carácter general; y " $360^{\circ}$ Six Nations 2016", dedicada al Torneo de las Seis Naciones celebrado en 2016.

- Dos en el canal de la $B B C$ Earth, que recibe el nombre $B B C$ Earth Unplugged -el término anglosajón “unplugged” hace referencia a que ya no se emite dicho canal de televisión-. Las listas son específicas: "Planet Earth II 360 Films" y "Earth Unplugged 360 Videos".

- Una dentro del programa musical The Voice, cuyo canal se llama BBC The Voice UK. La lista solo contiene vídeos de actuaciones o acontecimientos del programa: " $360^{\circ}$ Virtual Voice | The Voice UK 2016".

Al margen del uso o no de listas de reproducción de YouTube para ordenar e identificar los contenidos inmersivos, también nos interrogamos sobre la existencia o no de una tendencia hacia la concentración de los vídeos $360^{\circ}$ en un solo canal oficial del ente o si por el contrario estos se desperdigaban por diversas cuentas.

Los datos obtenidos resultan muy próximos en cifras. En este sentido, el 56,25\% de las RTPES que difunden o han difundido en algún momento contenidos $360^{\circ}$ en YouTube lo hacen a través de un único canal oficial del ente. Se trata, por ende, de una estrategia de concentración de contenidos que le facilita así al usuario el consumo y acceso a los mismos. Los entes que abogan por la difusión centralizada vía un único canal son: RTVE (España) desde RTVE.es; RTBF (Bélgica) desde RTBF; NDR, del grupo ARD (Alemania), desde NDR Doku; SWR, de $A R D$ (Alemania), desde SWR; $D W$, de $A R D$ (Alemania), $D W$ Deutsch; HR, de ARD (Alemania), hessischerrun dfun; RBB, de $A R D$ 
(Alemania), desde rbb; MTVA (Hungría) desde $A$ Dal; TVR (Rumanía) desde TVR; KRO-NCRV, del grupo NPO (Países Bajos), desde Brandpunt; BNN, de NPO (Países Bajos), Omroep BNN; VPRO, de NPO (Países Bajos), desde Vpronl; AVROTOS, de NPO (Países Bajos), desde AVROTROS; Omroep MAX, de NPO (Países Bajos), Omroep Max; RTP (Portugal) desde RTP; LRT (Lituania) desde Lietuvos nacionalinis radijas ir televizja; RAI (Italia) desde Rai; y, por último, UR (Suecia) desde UR.

Por el contrario, el 43,75\% restante no tiende hacia la concentración o centralización de contenidos en un único canal y aboga por la difusión de sus producciones a través de diferentes canales, habitualmente en estrecha relación con la temática o pertenencia a un determinado programa televisivo. Los entes incluidos en este total son: VRT (Bélgica); BR, del grupo $A R D$ (Alemania); $M D R$, de $A R D$ (Alemania); $W D R$, de $A R D$ (Alemania); ZDF (Alemania); FTV (Francia); DR, del grupo NPO (Países bajos); VARA, de NPO (Países Bajos); NOS, de NPO (Países bajos); EO, de NPO (Países bajos); BBC (Reino Unido); ORF (Austria); YLE (Finlandia); y RTE (Irlanda).

\section{Conclusiones}

Las narrativas inmersivas suponen todo un reto para el panorama audiovisual público, uno que se enmarca precisamente dentro de su apuesta por renovarse, por innovar y por ser, siguiendo la filosofía de servicio público, referentes indispensables para la sociedad. En este sentido, la UER ha jugado un papel crucial al impulsar entre sus miembros la implementación de las técnicas grabación $360^{\circ}$ y de producción de contenidos sintéticos con realidad virtual. Una tarea que ha llevado a cabo desde departamentos como el de Tecnología e Información. A este respecto, hasta marzo de 2017 (inclusive) un total de 33 radiotelevisiones ya incluían en su oferta vídeos $360^{\circ}$ de no ficción.

Con todo, esta investigación se centraba en el uso de dos plataformas digitales: las webs oficiales de cada ente y sus respectivos canales en YouTube. Una vez finalizado el estudio, se confirma que la relevancia de ambas como vías de publicación, difusión y almacenamiento de vídeos esféricos es sustancial. A la cabeza se sitúa YouTube con una abrumadora mayoría que roza el pleno, mientras que las páginas web la siguen muy de cerca. 
En ambas plataformas se percibe como, efectivamente, algunas RTPES intentan aplicar estrategias de ordenación y visibilidad de los contenidos inmersivos. En el caso de las webs, se observan dos tendencias entre los entes: por un lado, aquellos que optan por crear apartados o secciones de contenidos generalistas en formato vídeo esférico y que actúan como videotecas inmersivas; y por otro, aquellos que no aglutinan todos sus vídeos $360^{\circ}$ en un mismo espacio, pero que recurren a otras tácticas como el uso de titulillos para identificarlos y ayudar a destacarlos en informaciones o, incluso, la creación de subsecciones dedicadas a estos contenidos en coberturas especiales multimedia.

No obstante, se aprecia un mayor esfuerzo de planificación en los canales de YouTube de cada radiodifusora. Las RTPES muestran una clara propensión a valerse de sus canales oficiales para publicar sus piezas esféricas. Aunque esto puede conducir a pensar que la dispersión puede reinar en la plataforma, se observa una estrategia de fondo. Justamente el uso de canales ya creados e inicialmente solo con vídeos no esféricos deriva en dos posibilidades: que los entes aprovechan la visibilidad del canal y el conocimiento del púbico de su existencia para difundir un formato de vídeo novedoso; y, ligado a lo anterior, que intentan captar la atención de la audiencia que ya tienen en los mismos y se aseguran así, al menos, un consumo que, aunque podría ser reducido, evitaría cifras de consumo residuales en las piezas esféricas.

Sin embargo, destaca la falta o ausencia de un consenso general a la hora de evitar la descentralización de contenidos. Una tímida mayoría aboga por difundir a través de un único canal en un afán por concentrar todos sus contenidos inmersivos, mas el resto tiende a publicar en diversas cuentas atendiendo al tema o suceso del vídeo, así como a su pertenencia o vinculación con un programa.

Pese a esta situación que, en algunos entes, deriva en un camino de acceso pedregoso, se detecta una interesante tendencia en la propia plataforma. Más de la mitad de los entes ha creado una o varias listas de reproducción dedicadas a vídeos $360^{\circ}$. Esta decisión resulta estratégica por varias razones: sirven para identificar y separar así los vídeos esféricos de los que no lo son; les otorga una mayor visibilidad; y en consecuencia favorece y facilita su acceso y posterior consumo. Además, justo los entes que han optado por crear varios listados en sus 
canales de YouTube evidencian un patrón común: presentan una lista de carácter generalista, que actúa como una suerte de repositorio o videoteca; y otras de diversas temáticas -tema, suceso, programa, etcétera-, dedicadas a contenidos que, por alguna determinada razón desean destacar frente al resto.

Con todo, aunque en YouTube el planteamiento estratégico sea más evidente que en las webs, en ambas se encuentran intentos llevados a cabo por las radiodifusoras para facilitar el acceso, y como consecuencia directa también el consumo, a sus vídeos $360^{\circ}$. Tácticas que plantean ante la corta edad de las narrativas inmersivas en el panorama mediático y el todavía desconocimiento del formato o métodos de consumo de dichos contenidos por buena parte del público.

Finalmente, si bien la UER valora la aplicación de las técnicas, recursos y narrativas inmersivas como una estrategia de potencial para conectar con las audiencias, la incertidumbre de su éxito, gestión y utilidad real -entendida esta como valor añadido que el producto aporta por su contenido y experiencia- se ponen sobre la mesa como hándicaps más urgentes.

\section{Bibliografía}

J Alejandro (2010): Journalism in the age of social media. Oxford: Reuters Institute for the Study of Journalism.

A Baía (2016): "Mundos virtuais e jornalismo imersivo: uma resenha histórica e conceptual". Estudos de jornalismo, 6(1), pp.100-112.

F Biocca \& MR Levy (1995): "Communication applications of virtual reality", en VV AA, Communication in the age of virtual reality (Eds., F Biocca \& MR Levy). Hillsdale: Laurence Erlbaum Associates.

M Bricken (1993): "Mundos virtuales: sin interfase para el diseño", en VV AA, Ciberespacio. Los primeros pasos (Ed., M Benedikt).

México: Consejo Nacional de Ciencia y Tecnología, Equipo Sirius Mexicana.

C Campaláns, D Renó \& V Gosciola (2014): Narrativas Transmedia: entre teorías y prácticas. Barcelona: Oberta UOC Publishing. 
C Costa Sánchez \& M Piñeiro Otero (2010): "Prensa en la cuarta pantalla. Movilidad de la información del papel al bolsillo". El Profesional De La Informacion, 19(6), pp. 632-636.

C Costa (2012): “Ciberperiodismo en el smartphone. Estudio de la multimedialidad, usabilidad, hipertextualidad e interactividad de las aplicaciones de medios nativos digitales para smartphone". Estudios Sobre El Mensaje Periodístico, 18(0).

N De la Peña, P Weil, J Llobera, E Giannopoulos, A Pomés, B Spaniang, D Friedman, M Sánchez-Vives \& M Slater (2010): "Immersive Journalism: immersive virtual reality for the firstperson experience of news". Presence: Teleoperators and virtual enviroments, 19(4), pp. 291-301.

J Díaz Noci (2010): "Medios de comunicación en internet: algunas tendencias". El Profesional De La Información, 19(6), pp. 561-567.

E Domínguez (2013): Periodismo inmersivo: La influencia de la realidad virtual y del videojuego en los contenidos informativos. Barcelona: Editorial UOC.

E Domínguez (2015): "Periodismo inmersivo o cómo la realidad virtual y el videojuego influyen en la interfaz e interactividad del relato de actualidad”. El Profesional De La Información, 24(4), pp.413-423.

E Domínguez (2017): “Going beyond the classic news narrative convention: the background to and challenges of immersion in journalism". Frontiers in digital humanities, 4:10.

P Doyle, M Gelman \& S Gill (2016): "Viewing the future? Virtual reality in journalism", en Knight Foundation: https://goo.gl/ZJX4UG

M Engel \& J De Carvalho (2014): Jornalismo e Convergência. São Paulo: Cultura Académica Editora.

NO Espiritusanto \& P Gonzalo (2011): Periodismo ciudadano. Madrid: Fundación Telefónica.

European Broadcasting Union (2012): Empowering society: a declaration on the core values of public service media. Ginebra: Technology and Innovation.

European Broadcasting Union (2015a): Activity report 2014-2015. Ginebra: Technology and Innovation.

European Broadcasting Union (2015b): Statutes of the European Broadcasting Union. Ginebra: Technology and Innovation. 
European Broadcasting Union (2016a): Activity report 2015-2016. Ginebra: Technology and Innovation.

European Broadcasting Union (2016b). Vision 2020: connection, grow and influence. Ginebra: Technology and Innovation.

European Broadcasting Union (2017a): Opportunities and challenges for public service media in VR, AR and MR. Ginebra: Technology and Innovation.

European Broadcasting Union (2017b): Virtual reality: How are public broadcasters using it?. Ginebra: Technology and Innovation.

D Gillmor (2004): We the media: Grassroots journalism by the people, for the people. Sebastopol: O'Reilly.

GM Hardee (2016): "Immersive Journalism in VR: Four Theoretical Domains for Researching a Narrative Design Framework", en VV AA, Virtual, Augmented and Mixed Reality (Eds., S Lackey \& R Shumaker). VAMR 2016. Lecture Notes in Computer Science, 9740. Springer, Cham.

GM Hardee \& R McMahan (2017): "FIJI: a framework for the immersion-journalism intersection". Frontiers in ICT, 4:21.

H Jenkins (2003): “Transmedia Storytelling. Moving Characters from books to videogames can make them stronger and more compelling". MIT Technology Review: https://goo.gl/GWuNqP

K Kapp (2012): The gamification of learning and instruction: game-based methods and strategies for training and education. San Francisco: Pfeiffer

H Kool (2016): "The etichs of immersive journalism: a rethorical analysis of news storytelling with virtual reality technology". Intersect, vol. 9(3), pp.1-11.

R Longui (2016): "Narrativas imersivas no webjornalismo. Entre interfaces e realidad virtual". XIV Encontro Nacional de Pesquisadores em Jornalismo. Palhoça-Unisul, Brasil.

M Melle \& A Pardo. (2016): Las Narrativas Transmedia en Harry Potter. Trabajo de fin de grado: Universidade de Santiago de Compostela.

JH Murray (1999): Hamlet en la holocubierta: El futuro de la narrativa en el ciberespacio. Barcelona: Paidós.

N Newman \& R Fletcher (2017): Bias, bullshit and lies. Audience perspectives on low trust in media. Oxford: Reuters Institute for the Study of Journalism 
T Owen, F Pitt, R Aronson-Rath \& J Milward (2015): "Virtual reality journalism", en Tow Center for Digital Journalism: https://goo.gl/JpcKUt

S Pérez-Seijo \& X López-García (2017): Xornalismo inmersivo e televisión públicas europeas: plataformas, aplicacións e posibilidades de consumo. Universidade de Santiago de Compostela: Actas I Congreso Internacional AGACOM Alén das fronteiras: redes na diversidade.

C Peters \& T Witschge (2015): "From grand narratives and democracy to small expectations of participation: audiences, citizenship, and interactive tools in digital journalism". Journalism Practice, 9(1), pp.19-34.

C Peters (2016): "Spaces and places of news consumption", en VV AA, The SAGE Handbook of digital journalism (Eds., T Witschge, CW Anderson, D Domingo \& A Hermida). Londres: SAGE Publications.

W Robson \& L Costa (2016): "Jornalismo imersivo: perspectivas para os novos formatos". Leituras do jornalismo, 6, pp.99-116.

Public Service Media (2017): "The best of PSM. Virtual Reality". Public Media Alliance, marzo: https://goo.gl/awK3iS

ML Ryan (2004): La narración como realidad virtual: La inmersión y la interactividad en la literatura y en los medios electrónicos. Barcelona: Paidós.

MIT Open Documentary Lab (2014): "Mapping the intersection of two cultures: interactive documentary and digital journalism". MIT Open DOcuemntary Lab: https://goo.gl/Sjc8G3

R Salaverría (2016): "Los medios de comunicación que vienen", en VV AA, Innovación y desarrollo de los cibermedios en España (Eds., C Sádaba, MD Martínez-Costa \& GA Alberto). Pamplona: EUNSA.

A Toffler (1996): La tercera ola. Barcenola: Plaza \& Janés.

C Toural, X López \& A Silva (2015): “O xornalismo participativo cobra forza en España da man dos dispositivos móbiles" Actas XIV Congreso Internacional IBERCOM 2015, São Paulo, IberCom. 


\section{Reconocimientos de la investigación}

Este estudio está elaborado en el marco del proyecto "Usos y preferencias informativas en el nuevo mapa de medios en España: modelos de periodismo para dispositivos móviles" (Referencia: CSO2015-64662-C4-4R), del Ministerio de Economía y Competitividad de España y cofinanciado por el fondo estructural FEDER. Los resultados del artículo también se corresponden al proyecto de "Indicadores de gobernanza, financiación, rendición de cuentas, innovación, calidad y servicio público de las RTV europeas aplicables a España en el contexto digital" (Referencia: CSO201566543-P) del Programa estatal de Fomento de la Investigación Científica y Técnica de Excelencia, subprograma estatal de Generación de Conocimiento del Ministerio de Economía y Competitividad de España, cofinanciado por el Fondo Europeo de Desarrollo Regional (FEDER) de la Unión Europea. Este trabajo también está elaborado en el marco del programa de actividades de la Red XESCOM (REDES 2016 GI-1641 XESCOM), de la Consellería de Cultura, Educación e Ordenación Universitaria de la Xunta de Galicia (Referencia ED341D R2016/019). Además, la autora Sara Pérez-Seijo es beneficiaria del programa de Formación del Profesorado Universitario (FPU16/06156) financiado por el Ministerio de Educación, Cultura y Deporte de Gobierno de España. 


\section{Los autores y las autoras}

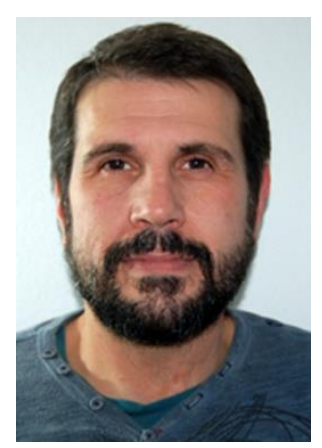

\section{AGUILAR PAREDES, CARLOS}

\section{Universitat de Barcelona}

carlos.aguilar@ub.edu

Profesor asociado en el Grado en Comunicación Audiovisual de la Universidad de Barcelona. Licenciado en Física y Doctor en Comunicación, forma también parte del grupo de investigación DHIGECS de la UB. Sus intereses de investigación se centran en el análisis de la calidad de la información política y en la estructura del sistema audiovisual.

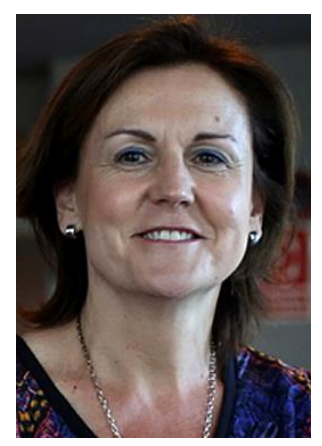

\section{AZURMENDI, ANA}

\section{Universidad de Navarra}

aazur@,unav.edu

Profesora Titular de Derecho de la Comunicación, Facultad de Comunicación, Universidad de Navarra desde 1991. Directora del Center for Internet Studies and Digital Life de la Universidad de Navarra. Directora de la revista académica Communication\&Society 
1997-2013). Profesora del Posgrado en Protección de Datos (AECPD Asociación Española de Consultores de Protección de Datos, 2018).

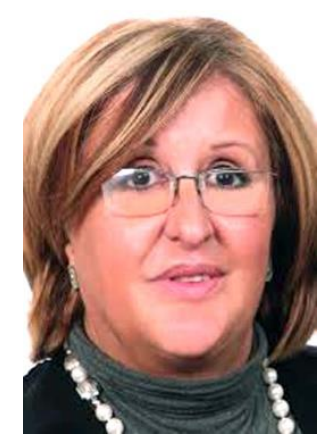

\section{CARIDAD SEBASTIÁN, MERCEDES}

\section{Universidad Carlos III de Madrid}

mercedes@bib.uc3m.es

Doctora en Ciencias de la Información, Universidad Complutense (1979). Catedrática de la Universidad Carlos III de Madrid, Facultad de Humanidades, Comunicación y Documentación, Departamento de Biblioteconomía y ha sido Vicerrectora de Extensión Universitaria de la Universidad Carlos III de Madrid desde 1994 a 2007.

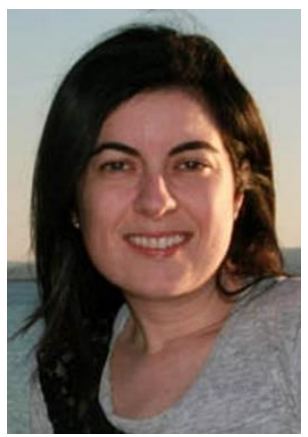

\section{COSTA-SÁNCHEZ, CARMEN}

\section{Universidade da Coruña}

\section{carmen.costa@udc.es}

Profesora de Comunicación Corporativa en el Grado en Comunicación Audiovisual de la Universidade da Coruña. Doctora en Comunicación por la Universidade de Santiago de Compostela. Premio Extraordinario de Doctorado por la Facultad de Ciencias de la Comunicación de la USC. Miembro del Grupo de Investigación en Cultura y Comunicación Interactiva de la Universidade da Coruña. 


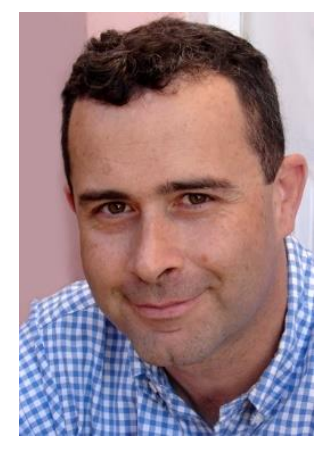

\section{ELÍAS PÉREZ, CARLOS}

\section{Universidad Carlos III de Madrid}

carlos.elias@uc3m.es

Catedrático de Periodismo en la Universidad Carlos III de Madrid (en la actualidad en comisión de servicios en el Departamento de Lógica, Historia y Filosofía de la Ciencia de la UNED). Licenciado en Química y Periodismo, doctorado con Premio Extraordinario en Ciencias Sociales por la Universidad de La Laguna, se especializó en Ciencia, Tecnología y Esfera Pública en la London School of Economics (un año becado como visiting fellow) y en el Departamento de Historia de la Ciencia en la Universidad de Harvard (otro año como visiting scholar).

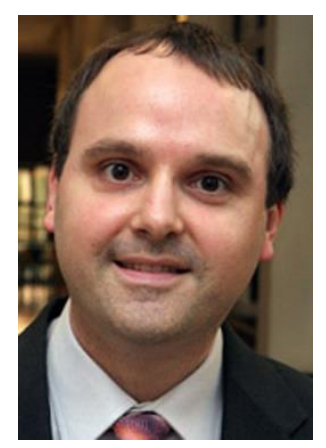

\section{FONDEVILA-GASCÓN, JOAN-FRANCESC}

\section{Universitat Pompeu Fabra}

joanfrancesc.fondevila@,upf.edu

Doctor en Periodismo, en la actualidad es profesor del Departamento de Comunicación de la Universitat Pompeu Fabra y del Departamento de Empresa de la Universitat de Girona. Es investigador principal del Grupo de investigación sobre Periodismo Digital y Banda Ancha. Miembro del grupo de investigación CompolWatch 


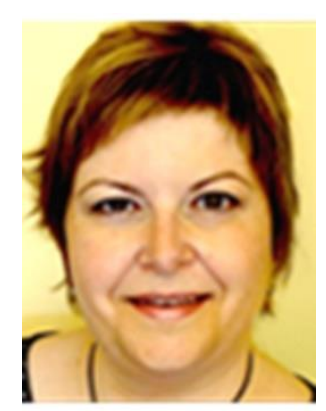

\section{GARCÍA ASENSIO, Ma ÁNGELES}

\section{Universitat de Barcelona}

\section{garciaasensio@ub.edu}

Doctora en Filología Hispánica (Lengua Española) y profesora titular del departamento de Filología Hispánica, Teoría de la Literatura y Comunicación de la Universidad de Barcelona, donde defendió su tesis doctoral: El discurso de los telediarios. Ejerce docencia en cursos de grado (Comunicación Audiovisual) y de postgrado, y es miembro del equipo de coordinación del máster Español Lengua Extranjera en Ámbitos Profesionales

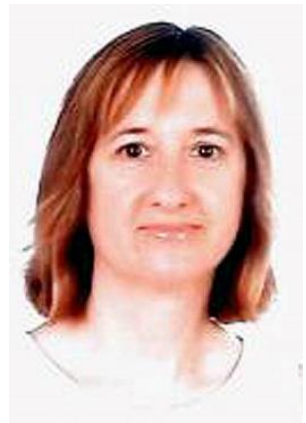

\section{GARCÍA LÓPEZ, FÁTIMA}

\section{Universidad Carlos III de Madrid}

fatimag@bib.uc3m.es

Doctora por la Universidad Carlos III de Madrid y Licenciada en Filología Hispánica por la Universidad Autónoma de Madrid. Desde 1998 viene desarrollando su labor como profesora en el Departamento de Biblioteconomía y Documentación de la Universidad Carlos III de Madrid. Integrante del grupo de investigación ACRÓPOLIS (Análisis de Contenido de Recursos para la Organización y Políticas de Información hacia la Sociedad del Conocimiento). 


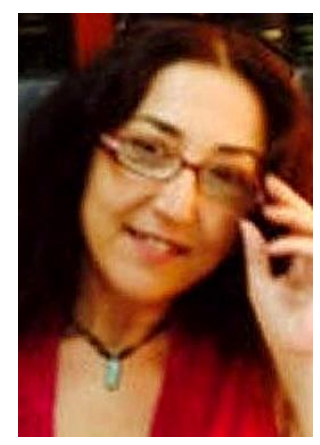

\section{GUARINOS-GALÁN, VIRGINIA}

\section{Universidad de Sevilla}

guarinos@us.es

Virginia Guarinos es doctora en Comunicación Audiovisual y en Ciencias del Espectáculo. Es profesora titular en el Departamento de Comunicación Audiovisual y Publicidad de la Facultad de Comunicación, de la Universidad de Sevilla. Dirige el grupo ADMIRA, de investigación en medios, imágenes y relatos audiovisuales, de la Junta de Andalucía.

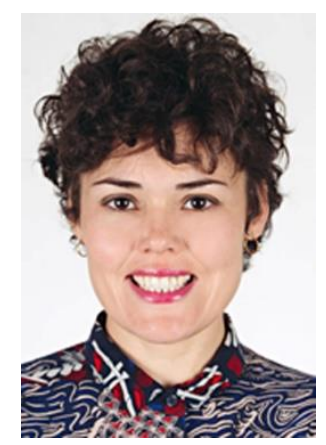

\section{JIMÉNEZ IGLESIAS, LUCÍA}

\section{Universitat de Barcelona}

luciajimenez@ub.edu

Licenciada en Publicidad y Relaciones Públicas (Universidad Pontificia de Salamanca) y en Comunicación Audiovisual (Universidad de Salamanca). Realizó el máster Sociedad de la información y el conocimiento en la UOC (2014) y en 2015 se incorporó al Grupo DHIGECS de la Universitat de Barcelona con una beca predoctoral FI. Actualmente, realiza su tesis dentro del Programa de Doctorado en Información y Comunicación. 


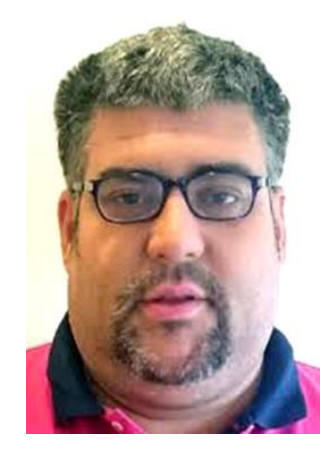

\section{JUANATEY-BOGA, ÓSCAR}

\section{Universidade da Coruña}

\section{oscarjb@udc.es}

Licenciado en Ciencias Económicas y Empresariales (1999) y Doctor en Ciencias Económicas y Empresariales por la Universidad de A Coruña (2006). Master MBA en Dirección y Administración de Empresas, Master en Dirección Comercial y Marketing, y Master en Comunicación Empresarial por la UDC.

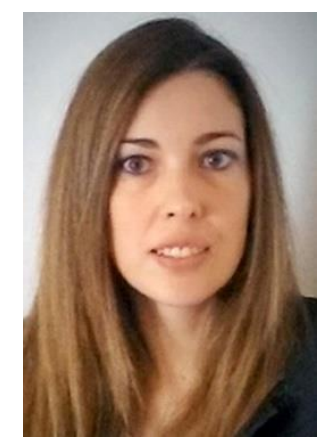

\section{LÓPEZ CEPEDA, ANA MARÍA}

\section{Universidad de Castilla-La Mancha}

ana.lopezcepeda@uclm.es

Licenciada en Periodismo por la Universidad de Santiago de Compostela (USC), Licenciada en Derecho por la Universidad Nacional de Educación a Distancia (UNED) y Doctora en Comunicación y Periodismo por la Universidad de Santiago de Compostela (USC). 


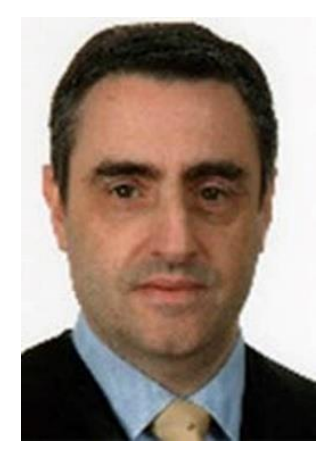

\section{MARQUÉS-PASCUAL, JOAQUÍN}

\section{EAE Business School (Universitat Politécnica de Catalunya)}

joaquin.marques@,campus.eae.es

Doctor en Comunicación (cum laude) por la Universitat Ramon Llull. Abogado y politólogo (UOC). Profesor de EAE Business School (Universidad Politécnica de Cataluña). Imparte docencia en otros centros universitarios españoles (ESRP-UB) y en universidades latinoamericanas (PUCMM y U. de los Hemisferios). Investigador principal del Grupo de investigación sobre comunicación (CommResearch-EAE), Miembro fundador de ACCIEP.

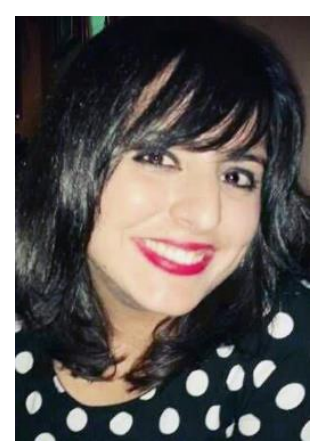

\section{MARTÍNEZ CARDAMA, SARA}

\section{Universidad Carlos III de Madrid}

smartin@,bib.uc3m.es

Doctora con mención internacional y premio extraordinario por la Universidad Carlos III. Máster en Investigación en Documentación por la Universidad Carlos III de Madrid (2009-2011) con premio extraordinario fin de estudios. Diplomada y licenciada en documentación por la Universidad de A Coruña con premio nacional. Ha sido beneficiaria de una beca FPU del Ministerio de educación y actualmente es profesora ayudante doctor del departamento de 
Biblioteconomía y Documentación de la Universidad Carlos III donde ejerce las tareas de secretaria académica.

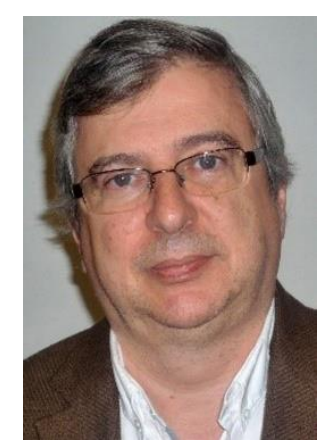

\section{MARTÍNEZ-FERNÁNDEZ, VALENTÍN-ALEJANDRO Universidade da Coruña}

valejand@udc.es

Periodista y profesor Titular del área de Comercialización e Investigación de Mercados de la Universidad de A Coruña. Licenciado en Ciencias de la Información por la Universidad Complutense de Madrid, Master en Dirección y Administración de Empresas (MBA) por la Universidad de A Coruña y Doctor en Ciencias de la Información por la Universidad Complutense de Madrid.

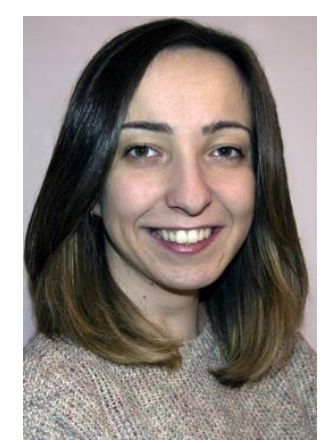

\section{MELLE GOYANES, MARÍA}

\section{Universidade de Santiago de Compostela}

maria.melle@,rai.usc.es

Graduada en Periodismo (2016) por la Universidad de Santiago de Compostela (USC), ha cursado el Máster Universitario en Periodismo y Comunicación: Nuevas Tendencias en Producción, Gestión y Difusión del Conocimiento de la USC (2017) y, en la actualidad, es doctoranda del Programa de Doctoramiento en Comunicación e Información Contemporánea de la USC. 


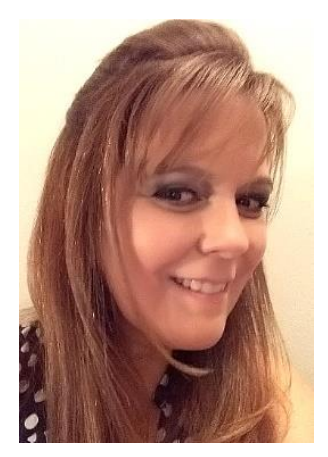

\section{MORALES GARCÍA, ANA MARÍA}

\section{Universidad Carlos III de Madrid}

amorales@,bib.uc3m.es

Doctora en Documentación y Máster en Información (Universidad Carlos III de Madrid). Ha sido Vicedecana del Campus de Colmenarejo, Vicedecana de Estudios Semipresenciales y Estrategia Digital y Subdirectora del Instituto Agustín Millares. Desde 2017 es Vicedecana del Grado en Información y Documentación y Estrategia Digital. Es integrante del grupo de investigación ACRÓPOLIS (Análisis de Contenido de Recursos para la Organización y Políticas de Información hacia la Sociedad del Conocimiento).

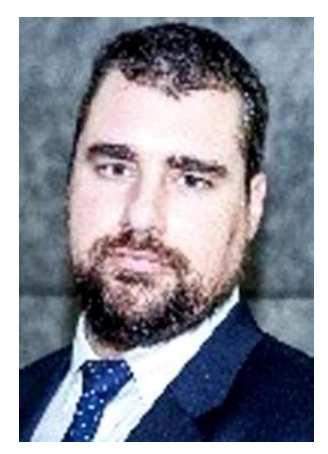

\section{MORILLO BENTUÉ, JUAN}

\section{EAE Business School (Universitat Politécnica de Catalunya)}

imorillo@eae.es

Vicedecano de Postgrado en EAE Business School. Posee un Doctorado y un máster en Economía y Administración de Empresas de la Universidad Rey Juan Carlos I (Madrid). Es ingeniero químico por el Instituto Químico de Sarrià IQS (Barcelona). También cursó el Dirección de Marketing y Ventas de ESADE. 


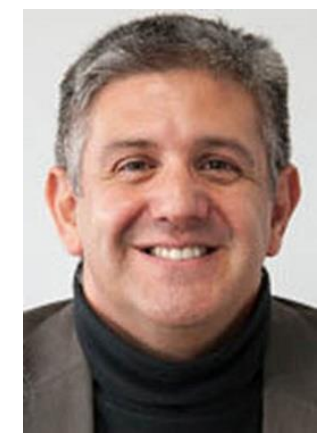

\section{PANIAGUA ROJANO, FRANCISCO JAVIER}

\section{Universidad de Málaga}

fjpaniagua@uma.es

Es licenciado (1996) y doctor (2004) en Periodismo. Desde 2003, es profesor de la Facultad de Ciencias de la Comunicación de la Universidad de Málaga.

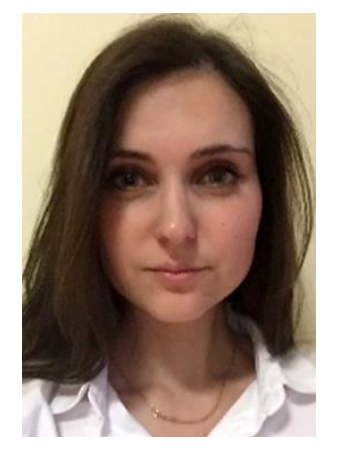

\section{PÉREZ-SEIJO, SARA}

\section{Universidade de Santiago de Compostela}

s.perez.seijo@usc.es

Investigadora del grupo Novos Medios y doctoranda en Comunicación e Información Contemporánea en la Universidade de Santiago de Compostela (USC). Actualmente es beneficiaria del programa de Formación del Profesorado Universitario (FPU16/06156) financiado por el Ministerio de Educación, Cultura y Deporte (Gobierno de España). 


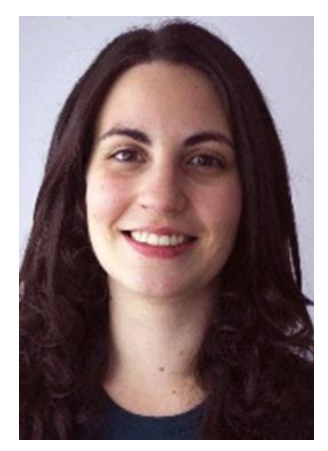

\section{RODRÍGUEZ-CASTRO, MARTA}

Universidade de Santiago de Compostela

m.rodriguez.castro@usc.es

Graduada en Comunicación Audiovisual por la Universidad de Santiago de Compostela (USC) y máster en Investigación aplicada a medios de comunicación por la Universidad Carlos III de Madrid. Actualmente es doctoranda en Comunicación e información contemporánea en la USC, donde es contratada FPU e investigadora del grupo Novos Medios.

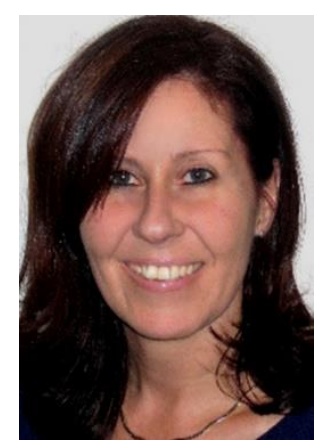

\section{RODRÍGUEZ FERNÁNDEZ, MARÍA MAGDALENA}

\section{Universidad de A Coruña}

mmrodriguez@udc.es

Doctora en Ciencias Económicas y Empresariales por la Universidad de A Coruña. Licenciada en Ciencias Económicas y Empresariales por la Universidad de Santiago de Compostela. Es profesora del Área de Comercialización e Investigación de Mercados en la Universidad de A Coruña. 


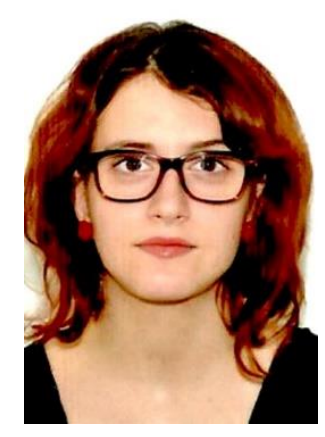

\section{RUIZ MORENO, CRISTINA}

\section{Universitat Ramon Llull}

\section{cristinarm11@,blanquerna.url.edu}

Graduada en Comunicación Audiovisual (Universitat de Barcelona) realizó el trabajo final de grado "Análisis comparativo de la representación de actores políticos y su discurso en el telediario de prime time de TVE y TV3”. Actualmente, estudia el máster en Producción y Comunicación Cultural (Universitat Ramon Llull Blanquerna). Sus intereses incluyen el análisis del discurso en los medios de comunicación y la calidad de la información política.

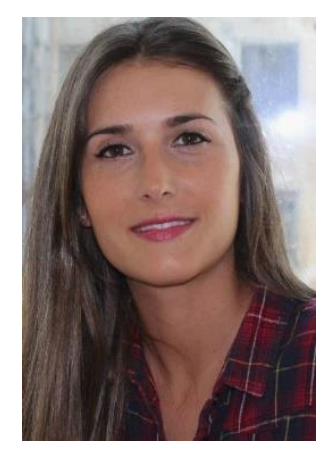

\section{SÁNCHEZ AMBOAGE, EVA}

\section{Universidad de A Coruña}

eva.sanchez.amboage@,udc.es

Doctora en Dirección y Planificación del Turismo por la Universidad de A Coruña. Máster en Profesorado de ESO, BAC, FP y Enseñanza de Idiomas por la Universidad de A Coruña. Máster en Dirección y Planificación del Turismo. Es profesora del Área de Comercialización e Investigación de Mercados en la Universidad de A Coruña. 


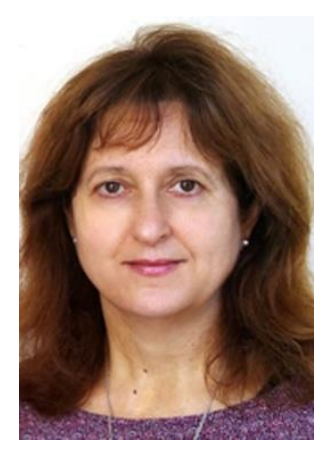

\section{SÁNCHEZ GÓMEZ, LYDIA}

\section{Universitat de Barcelona}

1sanchezg@,ub.edu

Profesora agregada en Comunicación Audiovisual en la Facultad de Biblioteconomía y Documentación de la Universidad de Barcelona. Doctora en filosofía por la Stanford University, centra su investigación en la calidad democrática de los medios de comunicación, la epistemología y la teoría de la comunicación.

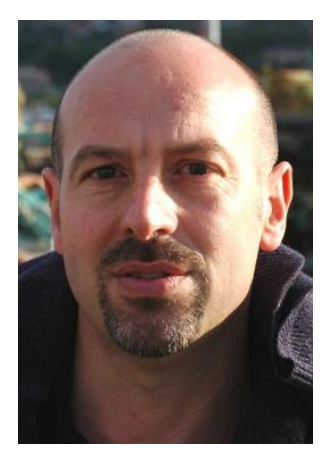

\section{SOENGAS PÉREZ, XOSÉ}

Universidad de Santiago de Compostela

jose.soengas@usc.es

Catedrático de Comunicación Audiovisual en el Departamento de Ciencias de la Comunicación de la Universidad de Santiago de Compostela. Sus investigaciones están centradas en el análisis de los contenidos informativos de radio y de televisión. 


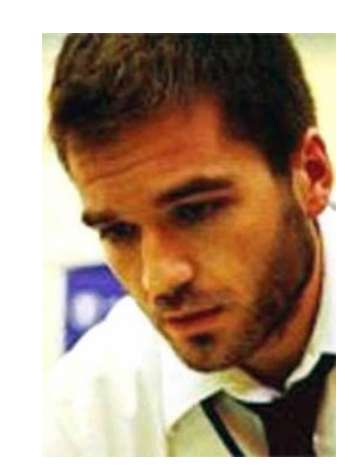

\section{TOURAL-BRAN, CARLOS}

\section{Universidad de Santiago de Compostela}

\section{carlos.toural@usc.es}

Periodista y profesor de Periodismo, pertenece al Departamento de Ciencias de la Comunicación de la Facultad de Ciencias de la Comunicación de la Universidad de Santiago de Compostela de la que es vicedecano. Forma parte del grupo de investigación Novos Medios desde el año 2006. 